\title{
MASS AND CHARGE DISTRIBUTIONS IN CHLORINE-INDUCED NUCLEAR REACTIONS
}
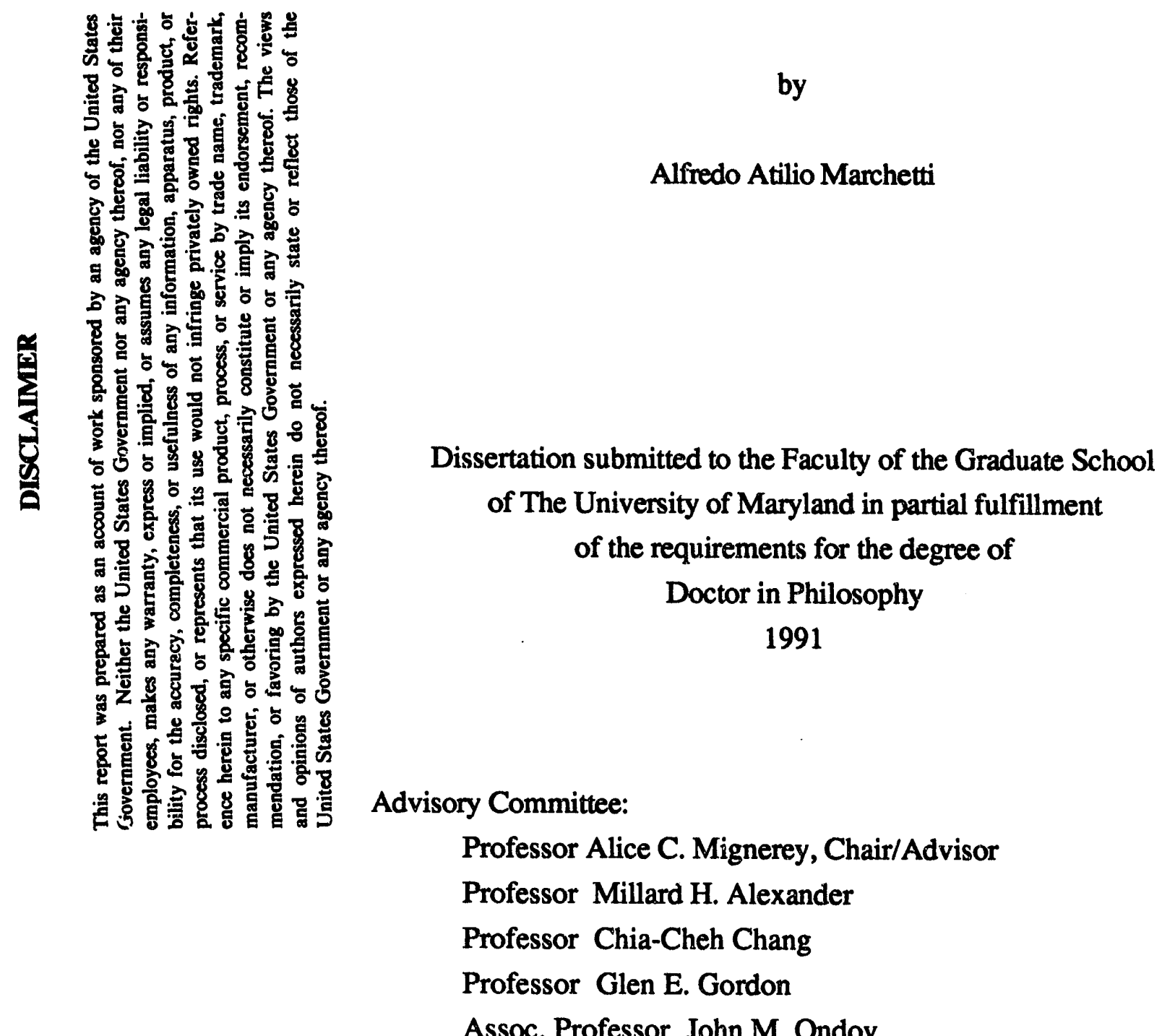

Assoc. Professor John M. Ondov 


\section{ABSTRACT}

Title of the Dissertation: $\quad$ MASS AND CHARGE DISTRIBUTIONS IN CHLORINE-INDUCED NUCLEAR REACTIONS

Alfredo Atilio Marchetti, Doctor of Philosophy, 1991

$\begin{array}{ll}\text { Dissertation directed by: } & \text { Alice C. Mignerey, Professor of Chemistry } \\ \text { Department of Chemistry and Biochemistry }\end{array}$

Projectile-like fragments were detected and characterized in terms of $\mathrm{A}, \mathrm{Z}$, and energy for the reactions ${ }^{37} \mathrm{Cl}$ on ${ }^{40} \mathrm{Ca}$ and ${ }^{209} \mathrm{Bi}$ at $\mathrm{E} / \mathrm{A}=7.3 \mathrm{MeV}$, and ${ }^{35} \mathrm{Cl}$ on ${ }^{209} \mathrm{Bi}$ at $\mathrm{E} / \mathrm{A}=15 \mathrm{MeV}$, at angles close to the grazing angle. Mass and charge distributions were generated in the $\mathrm{N}-\mathrm{Z}$ plane as a function of energy loss, and have been parameterized in terms of their centroids, variances, and coefficients of correlation. There was an attempt to measure light-charged particles in coincidence with projectilelike fragments for the reaction ${ }^{35} \mathrm{Cl}$ on ${ }^{209} \mathrm{Bi}$, but the results were not conclusive. Due to experimental problems, the mass resolution corresponding to the ${ }^{35} \mathrm{Cl}$ on ${ }^{209} \mathrm{Bi}$ reaction was very poor. This prompted the study and application of a deconvolution technique for peak enhancement.

The drifts of the charge and mass centroids for the system ${ }^{37} \mathrm{Cl}$ on ${ }^{40} \mathrm{Ca}$ are consistent with a process of mass and charge equilibration mediated by nucleon exchange between the two partners, followed by evaporation. The asymmetric systems show a strong drift towards larger asymmetry, with the production of neutron-rich nuclei. It was concluded that this is indicative of a net transfer of protons from the light to the heavy partner, and a net flow of neutrons in the opposite direction. The variances for all systems increase with energy loss, as it would be expected from a nucleon exchange mechanism. However, the variances for the reaction ${ }^{37} \mathrm{Cl}$ on ${ }^{40} \mathrm{Ca}$ are higher than those expected from that mechanism. The 
coefficients of correlation indicate that the transfer of nucleons between projectile and target is correlated, as expected from Q-value constraints to the valley of $\beta$-stability.

The results were compared to the predictions of two current models based on a stochastic nucleon exchange mechanism. In general, the comparisons between experimental and predicted variances support this mechanism. However, the need for more realistic driving forces in the model calculations is indicated by the disagreement between predicted and experimental centroids. 


\section{ACKNOWLEDGMENTS}

I thank my advisor, Dr. Alice C. Mignerey, for her full support throughout my time as a graduate student. I wish to thank the people that participated in the Oak Ridge experiment, in particular Kevin Morley, as well as the Oak Ridge personnel. Dr. Herbert Breuer's help with the data analysis process is also gratefully acknowledged.

Finally, I am very grateful for the support received from my family and friends.

This work was supported by the Director, Office of Energy Research, Division of Nuclear Physics of the Office of High Energy and Nuclear Physics, of the U.S. Department of Energy under Contract DOE/ER/40321. 
coefficients of correlation indicate that the transfer of nucleons between projectile and target is correlated, as expected from Q-value constraints to tire valley of $\beta$-stability.

The results were compared to the predictions of two current models based on a stochastic nucleon exchange mechanism. In general, the comparisons between experimental and predicted variances support this mechanism. However, the need for more realistic driving forces in the model calculations is indicated by the disagreement between predicted and experimental centroids. 


\section{TABLE OF CONTENTS}

ACKNOWLEDGEMENTS ...........................................

TABLE OF CONTENTS ................................................ ii

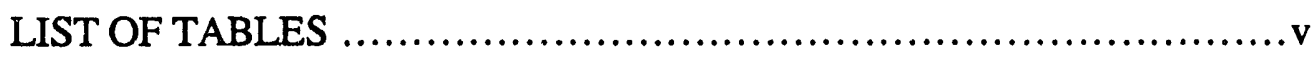

LIST OF FIGURES .............................................. vii

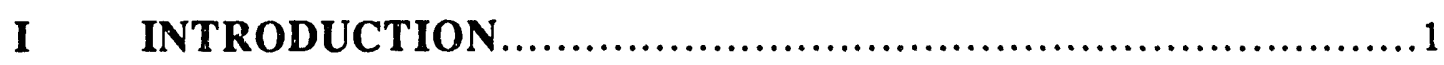

I.A Deep-Inelastic Collisions ..........................................5

I.A.1 Mass and Charge Distributions....................................6

I.B Research Goals .................................................

II EXPERIMENTAL PROCEDURES AND DATA REDUCTION....9

II.A Argonne Experimental Set-Up................................... 10

II.A.1 Calibrations............................................. 13

II.B Oak Ridge Experimental Set-Up ................................ 20

II.B.1 Calibrations ............................................. 33

II.C Light-Charged Particle Detector .................................... 45

II.C.1 Prototype Test ......................................... 46

II.C.2 Detector and Results................................ 52

II.D Kinetic Energy Loss Calculation .................................... 55

III DECONVOLUTION........................................... 74

III.A Background ...................................................... 74

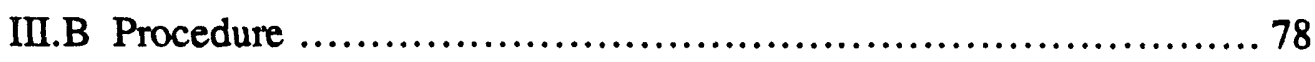

III.C Results....................................................... 83

III.D Application to Other Mass Spectra .............................. 95

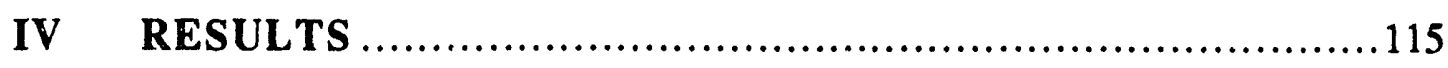

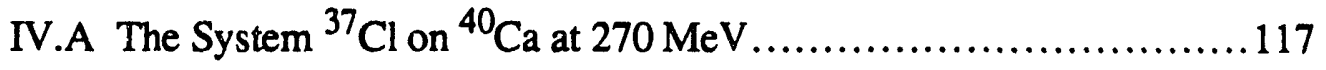




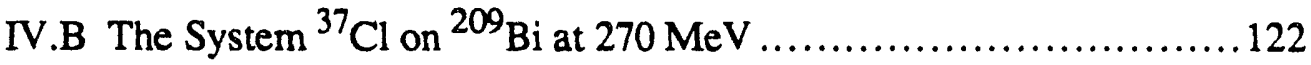

IV.C The System ${ }^{35} \mathrm{Cl}$ on ${ }^{209} \mathrm{Bi}$ at $528 \mathrm{MeV}$........................133

IV.D Comparison between Moment Analysis and Gaussian Fit ........... 144

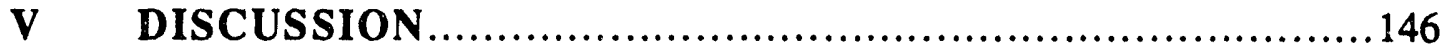

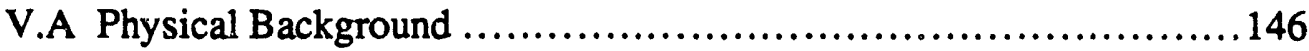

V.A.1 Stochastic Nucleon Exchange Model of Randrup............ 150

V.A.2 Stochastic Nucleon Exchange Model of Tassan-Got .......152

V.B Evaporation Correction of Model Predictions........................... 155

V.C Comparison of Model Predictions to the Experimental Results........ 158

V.C.1 The System ${ }^{37} \mathrm{Cl}$ on ${ }^{40} \mathrm{Ca}$ at $270 \mathrm{MeV}$...................... 158

V.C. 2 The System ${ }^{37} \mathrm{Cl}$ on ${ }^{209} \mathrm{Bi}$ at $270 \mathrm{MeV}$...................... 168

V.C.3 The System ${ }^{35} \mathrm{Cl}$ on ${ }^{209} \mathrm{Bi}$ at $528 \mathrm{MeV}$......................176

V.D Systematics........................................................ 188

V.D.1 Mass and Charge Equilibration..............................188

V.D.2 Variances and Correlation Coefficients........................ 199

VI CONCLUSIONS ..............................................203

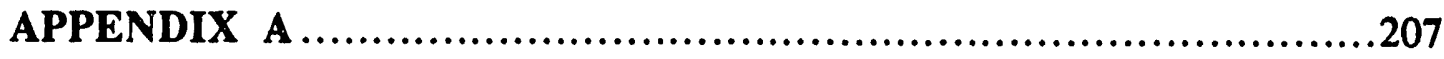

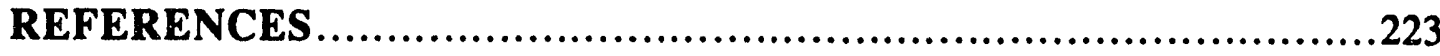




\section{LIST OF TABLES}

Table II. 1 10

Reaction Parameters.

Table III.1

Comparison of Peak Centroids and Areas between the Original and Deconvolved Spectra.

Table III.2

Comparison of Peak Centroids and Areas between the Original and Deconvolved Spectra of Figure III.8.

Table A.1 207

Parameters obtained using a moment analysis for the system ${ }^{37} \mathrm{Cl}+{ }^{40} \mathrm{Ca}$ at $270 \mathrm{MeV}$. The energy loss values have been corrected assuming equal division of the excitation energy.

Table A. 2 209

Parameters obtained using a Gaussian fit for the system ${ }^{37} \mathrm{Cl}+{ }^{40} \mathrm{Ca}$ at 270 $\mathrm{MeV}$. The energy loss values have been corrected assuming equal division of the excitation energy.

Table A.3 211

Parameters obtained using a moment analysis for the system ${ }^{37} \mathrm{Cl}+{ }^{209} \mathrm{Bi}$ at $270 \mathrm{MeV}$. The energy loss values have been corrected assuming equal division of the excitation energy.

Table A.4

Parameters obtained using a Gaussian fit for the system ${ }^{37} \mathrm{Cl}+{ }^{209} \mathrm{Bi}$ at 270

$\mathrm{MeV}$. The energy loss values have been corrected assuming equal division of the excitation energy.

Table A.5 .215

Parameters obtained using a moment analysis for the system ${ }^{37} \mathrm{Cl}+{ }^{209} \mathrm{Bi}$ at $270 \mathrm{MeV}$. The energy loss values have been corrected assuming thermal division of the excitation energy.

Table A.6

Parameters obtained using a Gaussian fit for the system ${ }^{37} \mathrm{C} !+{ }^{209} \mathrm{Bi}$ at 270 $\mathrm{MeV}$. The energy loss values have been corrected assuming thermal division of the excitation energy. 


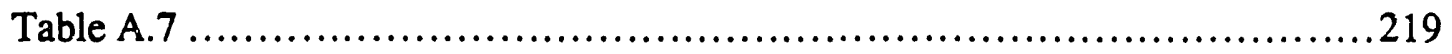

Parameters obtained using a moment analysis for the system ${ }^{35} \mathrm{Cl}+{ }^{209} \mathrm{Bi}$ at $528 \mathrm{MeV}$. The energy loss values have been corrected assuming equal division of the excitation energy.

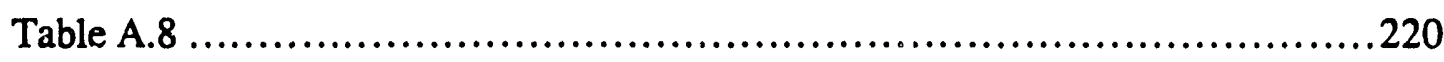

Parameters obtained using a Gaussian fit for the system ${ }^{35} \mathrm{Cl}+{ }^{209} \mathrm{Bi}$ at 528 $\mathrm{MeV}$. The energy loss values have been corrected assuming equal division of the excitation eriergy.

Table A.9 221 Parameters obtained using a moment analysis for the system ${ }^{35} \mathrm{Cl}+{ }^{209} \mathrm{Bi}$ at $528 \mathrm{MeV}$. The energy loss values have been corrected assuming thermal division of the excitation energy.

Table A.10

Parameters obtained using a Gaussian fit for the system ${ }^{35} \mathrm{Cl}+{ }^{209} \mathrm{Bi}$ at 528 $\mathrm{MeV}$. The energy loss values have been corrected assuming thermal division of the excitation energy. 


\section{LIST OF FIGURES}

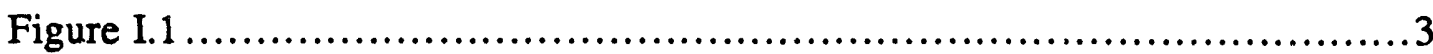

Schematic representation of heavy-ion reaction mechanisms.

Figure II.1

Flow chart for the data analysis program LISA.

Figure II.2 16

Contour plot of the raw $\mathrm{dE}$ as a function of $\mathrm{E}$ channels for the system ${ }^{37} \mathrm{Cl}$ on ${ }^{40} \mathrm{Ca}$ at $270 \mathrm{MeV}$.

Figure II.3 19

Contour plot of the linearized atomic number as a function of laboratory energy for the system ${ }^{37} \mathrm{Cl}$ on ${ }^{40} \mathrm{Ca}$ at $270 \mathrm{MeV}$.

Figure II.4

Contour plot of the mass as a function of laboratory energy for the system ${ }^{37} \mathrm{Cl}$ on ${ }^{40} \mathrm{Ca}$ at $270 \mathrm{MeV}$.

Figure II.5

Contour plot of the atomic number as a function of mass for the system ${ }^{37} \mathrm{Cl}$ on ${ }^{40} \mathrm{Ca}$ at $270 \mathrm{MeV}$ before correcting $\mathrm{A}$ and $\mathrm{Z}$ for their mutual dependence.

Figure II.6 26

Contour plot of the atomic number as a function of mass for the system ${ }^{37} \mathrm{Cl}$ on ${ }^{40} \mathrm{Ca}$ at $270 \mathrm{MeV}$ after correcting $\mathrm{A}$ and $\mathrm{Z}$ for their mutual dependence.

Figure II.7 28

Representative (a) mass and (b) charge distributions for the system ${ }^{37} \mathrm{Cl}$ on ${ }^{40} \mathrm{Ca}$ at $270 \mathrm{MeV}$.

Figure II.8

Side view of the Time-of-Flight facility at HHIRF.

Figure II.9 35

Simplified representation of the electronic setup for the Oak Ridge experiment.

Figure II.10

Contour plot of the atomic number as a function of the laboratory energy for the system ${ }^{35} \mathrm{Cl}$ on ${ }^{209} \mathrm{Bi}$ at $528 \mathrm{MeV}$. 
Figure II.11

Contour plot of the mass as a function of laboratory energy for the system ${ }^{35} \mathrm{Cl}$ on ${ }^{209} \mathrm{Bi}$ at $528 \mathrm{MeV}$.

Figure II.12

Representative (a) mass and (b) charge distribution for the system ${ }^{35} \mathrm{Cl}$ on ${ }^{209} \mathrm{Bi}$ at $528 \mathrm{MeV}$.

Figure II.13

(a) Sketch of the prototype light-charged-particle detector. (b) Sketch of the $\mathrm{dE}$ signal of as seen on an oscilloscope. (c) Same as in (b) for the E signal.

Figure II.14 51

Contour plots of the $\mathrm{dE}$ signal as a function of the $\mathrm{E}$ signal of the prototype detector for two different targets (polypropylene and carbon).

Figure II.15

(a) Sketch of one of the dE-E telescopes of the light-charged-particle detector.

(b) Top view of the layout of the light-charged-particle detector inside the scattering chamber.

Figure II.16 57

Contour plots of the $\mathrm{dE}$ signal as a function of the $\mathrm{E}$ signal for a polypropylene target. The signals of the PMTs 1,6 , and 7 of the lightcharged-particle detector are shown.

Figure II.17

Contour plots of the $\mathrm{dE}$ signal as a function of the $\mathrm{E}$ signal for $\mathrm{Bi}$ target. The signals of the PMTs 6, and 7 of the light-charged-particle detector are shown.

Figure II.18 63

Mass evaporated as a function of the excitation energy for several possible target-like fragments assuming two different spin values.

Figure II.19

(a)Mass evaporated for possible nuclei formed in the reaction ${ }^{35} \mathrm{Cl}+{ }^{209} \mathrm{Bi}$ as a function of excitation energy. (b) Ground state $Q$-value as a function of the atomic number of the projectile-like fragment in the reaction ${ }^{35} \mathrm{Cl}+{ }^{209} \mathrm{Bi}$.

Figure II.20 69

Representative contour plots of the atomic number as a function of the neutron number for the reaction ${ }^{37} \mathrm{Cl}+{ }^{40} \mathrm{Ca}$ at $270 \mathrm{MeV}$. 
Figure II.21

Representative contour plots of the atomic number as a function of the neutron number for the reaction ${ }^{37} \mathrm{Cl}+{ }^{209} \mathrm{Bi}$ at $270 \mathrm{MeV}$.

Figure 11.22 73

Representative contour plots of the atomic number as a function of the neutron number for the reaction ${ }^{35} \mathrm{Cl}+{ }^{209} \mathrm{Bi}$ at $528 \mathrm{MeV}$.

Figure III. 1 82

(a) Original spectrum. (b) Spectrum shown in (a) after being distorted with a random Gaussian. (c) The result of deconvolving the spectrum shown in (b).

Figure III.2 85

Chi-squared as a function of the filter length.

Figure III.3 87

Deconvolved spectra after smoothing 3 times with filter lengths of: (a) 23, (b) 21 , (c) 19 , and (d) 15 points.

Figure III.4

Chi-squared as a function of the weight factor $w$.

Figure III.5 92

(a) Square of the FWHM of the deconvolved spectra as a function of the square of the FWHM of the spread function. (b) Chi-squared as a function of the FWHM of the spread function.

Figure III.6 94

Deconvolved spectra as a function of the FWHM of the spread function: (a) 1.00 , (b) 0.80 , (c) 0.60 , and (d) 0.40 mass units.

Figure III.7 98

Mass spectra energy gated at $460 \mathrm{MeV}$ of laboratory energy with a $2 \mathrm{MeV}$ energy bin: (a) original, (b) distorted, and (c) deconvolved.

Figure III.8 100

Mass spectra energy gated at $440 \mathrm{MeV}$ of laboratory energy with a $2 \mathrm{MeV}$ energy bin: (a) original, (b) distorted, and (c) deconvolved.

Figure III.9 102

Mass spectra energy gated at $420 \mathrm{MeV}$ of laboratory energy with a $2 \mathrm{MeV}$ energy bin: (a) original, (b) distorted, and (c) deconvolved.

Figure III.10 106

(a) Mass spectra for $Z=18$, (b) same as (a) after deconvolution. 
Figure III.11

(a) Mass spectra for $Z=16$, (b) same as (a) after deconvolution.

Figure III.12

(a) Mass spectra for $Z=15$, (b) same as (a) after deconvolution.

Figure III.13

(a) Mass spectra for $Z=14$, (b) same as (a) after deconvolution.

Figure III.14

(a) Mass spectra for $Z=13$, (b) same as (a) after deconvolution.

Figure IV.1

The values of $\langle\mathrm{Z}\rangle,\langle\mathrm{N}\rangle$, and $\langle\mathrm{Z}\rangle \mid\langle\mathrm{N}\rangle$ as a function of energy loss for the reaction ${ }^{37} \mathrm{Cl}+{ }^{40} \mathrm{Ca}$ at $270 \mathrm{MeV}$. The energy loss scale was corrected assuming equal division of the excitation energy.

Figure IV.2

The values of $\sigma z^{2}, \sigma_{N}{ }^{2}$, and $\rho$ as a function of energy loss for the reaction ${ }^{37} \mathrm{Cl}+{ }^{40} \mathrm{Ca}$ at $270 \mathrm{MeV}$. The energy loss scale was corrected assuming equal division of the excitation energy.

Figure IV.3

The values of $\langle\mathrm{Z}\rangle,\langle\mathrm{N}\rangle$, and $\langle\mathrm{Z}\rangle \mid\langle\mathrm{N}\rangle$ as a function of energy loss for the reaction ${ }^{37} \mathrm{Cl}+{ }^{209} \mathrm{Bi}$ at $270 \mathrm{MeV}$. The energy loss scale was corrected assuming equal division of the excitation energy.

Figure IV.4

The values of $\langle\mathrm{Z}\rangle,\langle\mathrm{N}\rangle$, and $\langle\mathrm{Z}\rangle \mid\langle\mathrm{N}\rangle$ as a function of energy loss for the reaction ${ }^{37} \mathrm{Cl}+{ }^{209} \mathrm{Bi}$ at $270 \mathrm{MeV}$. The energy loss scale was correrted assuming thermal division of the excitation energy.

Figure IV.5

The values of $\sigma_{\mathrm{Z}}{ }^{2}, \sigma_{\mathrm{N}}{ }^{2}$, and $\rho$ as a function of energy loss for the reaction ${ }^{37} \mathrm{Cl}+{ }^{209} \mathrm{Bi}$ at $270 \mathrm{MeV}$. The energy loss scale was corrected assuming equal division of the excitation energy.

Figure IV.6

The values of $\sigma_{\mathrm{Z}}{ }^{2}, \sigma_{\mathrm{N}}{ }^{2}$, and $\rho$ as a function of energy loss for the reaction ${ }^{37} \mathrm{Cl}+{ }^{209} \mathrm{Bi}$ at $270 \mathrm{MeV}$. The energy loss scale was corrected assuming thermal division of the excitation energy. 
Figure IV.7

The values of $\langle\mathrm{Z}\rangle,\langle\mathrm{N}\rangle$, and $\langle\mathrm{N}\rangle \mid\langle\mathrm{Z}\rangle$ as a function of energy loss for the reaction ${ }^{37} \mathrm{Cl}+{ }^{209} \mathrm{Bi}$ at $270 \mathrm{MeV}$. The circles and squares represent corrections of the energy loss scale assuming equal and thermal division of the excitation energy, respectively.

Figure IV.8 135

The values of $\langle\mathrm{Z}\rangle,\langle\mathrm{N}\rangle$, and $\langle\mathrm{Z}\rangle \mid\langle\mathrm{N}\rangle$ as a function of energy loss for the reaction ${ }^{35} \mathrm{Cl}+{ }^{209} \mathrm{Bi}$ at $528 \mathrm{MeV}$. The energy loss scale was corrected assuming equal division of the excitation energy.

Figure IV.9

The values of $\langle\mathrm{Z}\rangle,\langle\mathrm{N}\rangle$, and $\langle\mathrm{Z}\rangle \mid\langle\mathrm{N}\rangle$ as a function of energy loss for the reaction ${ }^{35} \mathrm{Cl}+{ }^{209} \mathrm{Bi}$ at $528 \mathrm{MeV}$. The energy loss scale was corrected assuming thermal division of the excitation energy.

Figure IV.10

The values of $\sigma \mathrm{Z}^{2}, \sigma_{\mathrm{N}}{ }^{2}$, and $\rho$ as a function of energy loss for the reaction ${ }^{35} \mathrm{Cl}+{ }^{209} \mathrm{Bi}$ at $528.8 \mathrm{MeV}$. The energy loss scale was corrected assuming equal division of the excitation energy.

Figure IV.11

The values of $\sigma \mathrm{z}^{2}, \sigma_{\mathrm{N}}{ }^{2}$, and $\rho$ as a function of energy loss for the reaction ${ }^{35} \mathrm{Cl}+{ }^{209} \mathrm{Bi}$ at $528.8 \mathrm{MeV}$. The energy loss scale was corrected assuming thermal division of the excitation energy.

Figure IV.12

The values of $\langle\mathrm{Z}\rangle,\langle\mathrm{N}\rangle$, and $\langle\mathrm{N}\rangle \mid\langle\mathrm{Z}\rangle$ as a function of energy loss for the reaction ${ }^{35} \mathrm{Cl}+{ }^{209} \mathrm{Bi}$ at $528 \mathrm{MeV}$. The circles and squares represent corrections of the energy loss scale assuming equal and thermal division of the excitation energy, respectively.

Figure V.1 .160

Model predictions for $\langle\mathrm{Z}\rangle,\langle\mathrm{N}\rangle$, and $\langle\mathrm{N}\rangle \mid\langle\mathrm{Z}\rangle$ corresponding to the primary distributions of the reaction ${ }^{37} \mathrm{Cl}$ on ${ }^{40} \mathrm{Ca}$ at $270 \mathrm{MeV}$ as a function of energy loss.

Figure V.2

Model predictions for $\sigma^{2} \mathrm{Z}, \sigma_{\mathrm{N}}^{2}$, and $\rho_{\mathrm{NZ}}$ corresponding to the primary distributions of the reaction ${ }^{37} \mathrm{Cl}$ on ${ }^{40} \mathrm{Ca}$ at $270 \mathrm{MeV}$ as a function of energy loss. 
Figure V.3

Experimental results and model predictions for $\langle\mathrm{Z}\rangle,\langle\mathrm{N}\rangle$, and $\langle\mathrm{N}\rangle \mid\langle\mathrm{Z}\rangle$ corresponding to the secondary distributions of the reaction ${ }^{37} \mathrm{Cl}$ on ${ }^{40} \mathrm{Ca}$ at $270 \mathrm{MeV}$ as a function of energy loss.

Figure V.4 167

Experimental results and model predictions for $\sigma^{2} \mathrm{Z}, \sigma_{\mathrm{N}}^{2}$, and $\rho_{\mathrm{NZ}}$ corresponding to the secondary distributions of the reaction ${ }^{37} \mathrm{Cl}$ on ${ }^{40} \mathrm{Ca}$ at $270 \mathrm{MeV}$ as a function of energy loss.

Figure V.5

Model predictions for $\langle\mathrm{Z}\rangle,\langle\mathrm{N}\rangle$, and $\langle\mathrm{N}\rangle \mid\langle\mathrm{Z}\rangle$ corresponding to the primary distributions of the reaction ${ }^{37} \mathrm{Cl}$ on ${ }^{209} \mathrm{Bi}$ at $270 \mathrm{MeV}$ as a function of energy loss.

Figure V.6 173

Model predictions for $\sigma^{2} \mathrm{Z}, \sigma_{\mathrm{N}}^{2}$, and $\rho_{\mathrm{NZ}}$ corresponding to the primary distributions of the reaction ${ }^{37} \mathrm{Cl}$ on ${ }^{209} \mathrm{Bi}$ at $270 \mathrm{MeV}$ as a function of energy loss.

Figure V.7 175

Experimental results and model predictions for $\langle\mathrm{Z}$, $\langle\mathrm{N}\rangle$, and $\langle\mathrm{N}\rangle|\langle\mathrm{Z}\rangle$ corresponding to the secondary distributions of the reaction ${ }^{37} \mathrm{Cl}$ on ${ }^{209} \mathrm{Bi}$ at $270 \mathrm{MeV}$ as a function of energy loss.

Figure V.8 178

Experimental results and model predictions for $\sigma^{2} \mathrm{Z}, \sigma_{\mathrm{N}}^{2}$, and $\rho_{\mathrm{NZ}}$ corresponding to the secondary distributions of the reaction ${ }^{37} \mathrm{Cl}$ on ${ }^{209} \mathrm{Bi}$ at $270 \mathrm{MeV}$ as a function of energy loss.

Figure V.9 180

Model predictions for $\langle\mathrm{Z}\rangle,\langle\mathrm{N}\rangle$, and $\langle\mathrm{N}\rangle \mid\langle\mathrm{Z}\rangle$ corresponding to the primary distributions of the reaction ${ }^{35} \mathrm{Cl}$ on ${ }^{209} \mathrm{Bi}$ at $528 \mathrm{MeV}$ as a function of energy loss.

Figure V.10

Model predictions for $\sigma^{2} \mathrm{Z}, \sigma_{\mathrm{N}}^{2}$, and $\rho_{\mathrm{NZ}}$ corresponding to the primary distributions of the reaction ${ }^{35} \mathrm{Cl}$ on ${ }^{209} \mathrm{Bi}$ at $528 \mathrm{MeV}$ as a function of energy loss. 
Figure V.11

Experimental results and model predictions for $\langle\mathrm{Z}\rangle,\langle\mathrm{N}\rangle$, and $\langle\mathrm{N}\rangle \mid\langle\mathrm{Z}\rangle$ corresponding to the secondary distributions of the reaction ${ }^{35} \mathrm{Cl}$ on ${ }^{209} \mathrm{Bi}$ at $528 \mathrm{MeV}$ as a function of energy loss.

Figure V.12

Experimental results and model predictions for $\sigma_{\mathrm{Z}}^{2} \sigma_{\mathrm{N}}^{2}$, and $\rho_{\mathrm{NZ}}$

corresponding to the secondary distributions of the reaction ${ }^{35} \mathrm{Cl}$ on ${ }^{209} \mathrm{Bi}$ at $528 \mathrm{MeV}$ as a function of energy loss.

Figure V.13

Evolution of $\langle\mathrm{N}\rangle$ and $\left\langle\mathrm{Z}>\right.$ in the $\mathrm{N}-\mathrm{Z}$ plane for the reaction ${ }^{37} \mathrm{Cl}$ on ${ }^{209} \mathrm{Bi}$ at $270 \mathrm{MeV}$.

Figure V.14 192

Evolution of $\langle\mathrm{N}\rangle$ and $\langle\mathrm{Z}\rangle$ in the $\mathrm{N}-\mathrm{Z}$ plane for the reaction ${ }^{35} \mathrm{Cl}$ on ${ }^{209} \mathrm{Bi}$ at $528 \mathrm{MeV}$.

Figure V.15

Average nucleon drift for the reactions ${ }^{40,48} \mathrm{Ca}$, and ${ }^{58,64} \mathrm{Ni}$ on ${ }^{238} \mathrm{U}$ at $\mathrm{E} / \mathrm{A}=$ 8.5 MeV as a function of energy loss.

Figure V.16 .198

Evolution of $\langle\mathrm{N}\rangle$ and $\langle\mathrm{Z}\rangle$ in the $\mathrm{N}-\mathrm{Z}$ plane for the reaction ${ }^{74} \mathrm{Ge}$ on ${ }^{165} \mathrm{Ho}$ at $\mathrm{E} / \mathrm{A}=8.5 \mathrm{MeV}$.

Figure V.17

Comparison to model predictions of the $\langle\mathrm{Z}\rangle,\langle\mathrm{N}\rangle$, and $\langle\mathrm{N}\rangle \mid\langle\mathrm{Z}\rangle$ values for the reaction ${ }^{58} \mathrm{Ni}$ on ${ }^{165} \mathrm{Ho}$ at $\mathrm{E} / \mathrm{A}=16 \mathrm{MeV}$. 


\section{CHAPTER I INTRODUCTION}

The study of the products formed during the collisions between complex nuclei provide a formidable tool to investigate the properties of nuclear matter. These products are a signature of the mechanisms of interaction between the nuclei during the collision. The mechanisms of heavy-ion reactions have a strong dependence on the kinetic energy of the incoming projectile and the distance between the centers of the projectile and target, known as the impact parameter. By their nature, these reactions can involve large transfers of energy, mass, and angular momentum. Depending on the amount of relative kinetic energy available, different excitations and densities of nuclear matter can be achieved. The observation of phase transitions in nuclear matter may be realized in the laboratory. Furthermore, the production of new states of matter (quark-gluon plasma) is expected at ultrarelativistic energies. Overall, the study of nuclear matter under extreme conditions and the possibility of new collective phenomena are very unique features of heavy-ion reactions. A simple schematic representation of the different possible mechanisms as a function of bombarding energy and impact parameter is shown in Figure I.1.

Considering the nucleus as a totally degenerate Fermi gas, the energy corresponding to the maximum nucleon momentum is approximately $37 \mathrm{MeV}$. At energies around the Coulomb barrier and depending on the impact parameter, only one or two heavy nuclei are observed in the exit channels. Since the relative kinetic energy per nucleon is much smaller than $37 \mathrm{MeV}$ on impact, the nuclei remain practically degenerate and collisions between nucleons are forbidden by the Pauli exclusion principle. Therefore, the mechanism in this energy regime can be described by single particle interactions with a mean field, and is referred as one-body 
Figure I.1

Schematic representation of heavy-ion reaction mechanisms as a function of bombarding energy and impact parameter. 


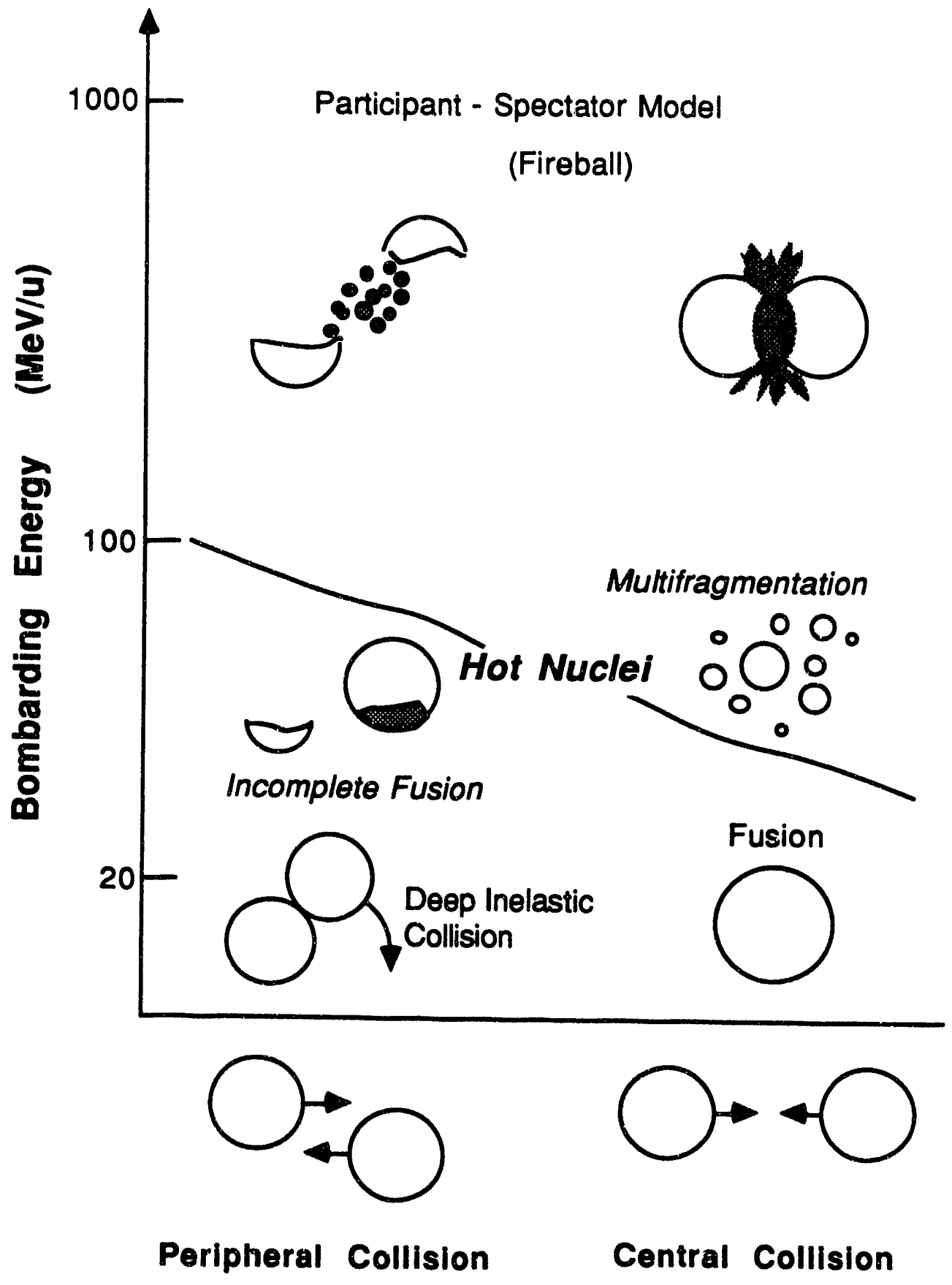


dissipation. The products are mostly a reflection of the forces generated by the combined potential of the two nuclei at different impact parameters.

As the energy increases, heavy-ion reactions occur with the production of three or more heavy fragments. Because of the larger amounts of energy available, the reaction becomes more violent and less sensitive to the details of the combined potential. Interactions between nucleons became important as the number of available states increases and the degeneracy decreases (two-body dissipation). Basically, the projectile cuts through the target generating a "hot fragment" and one or two more or less "cold fragments". Finally, as the energy increases even more, relativistic effects become important. The nuclear potential has practically no effect at such large kinetic energies, and the interaction during the collision becomes mainly nucleon-nucleon in nature.

The reactions studied here belong to the low energy regime, which roughly corresponds to bombarding energies of $\sim 5$ to $20 \mathrm{MeV}$ per nucleon. At energies near the Coulomb barrier, two extreme mechanisms were recognized: direct reactions and compound nucleus formation. Direct reactions refer to the one step transfer of one or a few nucleons and occur at impact parameters corresponding to grazing trajectories. At the other extreme, compound nucleus formation occurs at low impact parameters (more central collisions). It represents the fusion of the projectile and target to form one nucleus whose subsequent decay has no memory of the entrance channel. In this case, all the center-of-mass kinetic energy is transformed into reaction Q-value and excitation energy. Except for the pioneering work by Kaufmann and Wolfgang around 1960 [KAU 61], it was not until the early seventies that a different type of mechanism was realized for these reactions. There are several names for this process: deep-inelastic collisions, damped collisions, dissipative collisions, etc. Most of them 
are associated with the idea of large transfers of kinetic energy into internal excitation of the reaction products.

\section{I.A DEEP-INELASTIC COLLISIONS}

The characteristics of deep inelastic collisions have been reviewed extensively in the literature [FRE 84, GOB 80, LEF 78, SCH 77, SCH 84]. These reactions are binary processes which can be associated with impact parameters between those corresponding to compound nucleus formation and direct reactions. Among their main characteristics are mass and charge distributions of the products centered close to the values of the projectile and target, angular distributions peaked at forward angles or around the grazing angle for heavier systems, and the dissipation of considerable amounts of kinetic energy and angular momentum. These characteristics are consistent with the following scenario. The reaction starts with the formation of a rotating dinuclear system. As the system rotates, nucleons are exchanged between the reaction partners and relative kinetic energy and angular momentum are dissipated. The dissipated relative kinetic energy increases with increasing interaction time (decreasing impact parameter), and is of the order of tens to hundreds of $\mathrm{MeV}$. Before the dinuclear system completes a rotation, a separation occurs producing two

excited nuclei: the projectile-like fragment and the target-like fragment. The excitation energy of the fragments is released via light particle evaporation and/or gamma-ray emission. If the fragment is heavy enough, fission can also occur.

Nucleon transfers between projectile and target are responsible for the mass and charge drifts observed in the products of these reactions. These transfers are also assumed to be largely responsible for the energy and angular momentum dissipation. This is seen in the strong correlation between the evolution of the mass and charge 
distributions and energy loss. The energy loss is defined as the difference in the center-of-mass kinetic energy between the entrance and exit channels. Deep-inelastic processes should be expected to occur at energy losses between 0 (elastic event) and $E_{\mathrm{cm}}-V_{C}$, where $E_{c m}$ represents the kinetic energy in center-of-mass of the entrance channel and $\mathrm{V}_{\mathrm{C}}$ the Coulomb barrier. The transfer of nucleons between the target and projectile is accepted as a vehicle for energy damping. However, it should be pointed out that other forms of energy dissipation based on the excitation of collective modes have also been suggested [BRO 74, 76].

\section{I.A.1 Mass and Charge Distributions}

Mass and charge distributions are represented by the yields of product nuclei in the $\mathrm{A}-\mathrm{Z}$ or $\mathrm{N}-\mathrm{Z}$ plane as a function of energy loss. The distributions resemble twodimensional Gaussians with centroids close to the mass and charge of the projectile and the target, and variances which increase with increasing energy loss. These stochastic features are reminiscent of the statistical behavior of processes like diffusion, and prompted the study of these reactions in terms of transport equations. In deep-inelastic collisions, the projectile and target are often viewed as two nuclei joined by a "neck" which is considered itself a degree of freedom. Once the "neck" is formed, transfer of nucleons can occur between the two nuclei. The direction of these transfers will depend on the potential gradients of the system. Therefore, the drift in the average values of mass and charge observed in the reaction products can be associated with the driving forces acting on the dinucleus. On the other hand, the variances can be associated with nucleon currents between both nuclei.

It is impossible to measure directly primary distributions, because evaporation

occurs a very short time $\left(\sim 10^{-20} \mathrm{~s}\right)$ after the primary fragments are formed. In 
addition, in many experimental situations, the only quantities measured are the $A, Z$, and energy of the secondary projectile-like fragment at a certain angle. Therefore, the reconstruction of the primary event $\mathrm{A}, \mathrm{Z}$, and energy requires several assumptions referring to the division of excitation energy between projectile- and target-like fragments, and the number and type of particles evaporated.

\section{I.B RESEARCH GOALS}

The study of the evolution of the mass and charge distributions is important for the elucidation of the interaction mechanism during deep-inelastic collisions. It is the purpose of this study to determine the mass and charge distributions of the projectile-like fragments for the systems ${ }^{37} \mathrm{Cl}$ on ${ }^{40} \mathrm{Ca}$ and ${ }^{209} \mathrm{Bi}$ at $\mathrm{E} / \mathrm{A}=7.3 \mathrm{MeV}$, and ${ }^{35} \mathrm{Cl}$ on ${ }^{209} \mathrm{Bi}$ at $\mathrm{E} / \mathrm{A}=15 \mathrm{MeV}$. In the experiment corresponding to the last system, a light-charged particle detector was included in an attempt to measure evaporated charge in coincidence with projectile-like fragments. The systems chosen have different mass asymmetry and ratio $N / Z$ to study the effect of these parameters on the distributions of products.

The experimental setup and data reduction procedures are described in Chapter II. Due to experimental problems, the mass resolution of the ${ }^{35} \mathrm{Cl}$ on ${ }^{209} \mathrm{Bi}$ system was very poor. It was necessary to resort to techniques of peak enhancement to rescue the mass information. The procedure, known in general as deconvolution, is fully described in Chapter III. Once the mass and charge distributions were determined as a function of energy loss, they were characterized by their centroids, variances and correlation coefficients. These results are presented in Chapter IV.

Two models used to treat deep-inelastic collisions are described in Chapter V. The two models, developed by Randrup [RAN 78, 79, 82] and Tassan-Got [TAS 88, 
89], respectively, are based on the stochastic nucleon exchange mechanism. This mechanism assumes that the energy and angular momentum dissipation in deepinelastic collisions is mainly due to nucleon exchanges between the projectile and target. Though many of the basic assumptions are the same for both models, there are significant differences in their predictions. In the same chapter, the experimental results are compared to the predictions of both models. Results from other systems are also discussed in reference is the systems studied here and model predictions. Finally, Chapter VI contains the conclusions of this study. 


\section{CHAPTL? II EXPERIMENTAL PROCEDURES AND DATA REDUCTION}

Two separate experiments are considered here. The first was intended to investigate the system ${ }^{35} \mathrm{Cl}+{ }^{209} \mathrm{Bi}$ at $15 \mathrm{MeV} / \mathrm{A}$ and took place at Oak Ridge National Laboratory during January 1988 . The original project proposed the study of this system only. However, the availability of data from a previous experiment with similar information at lower energy prompted its inclusion in this study. This second experiment investigated the systems ${ }^{37} \mathrm{Cl}+{ }^{209} \mathrm{Bi}$ and ${ }^{37} \mathrm{Cl}+{ }^{40} \mathrm{Ca}$ at a bombarding energy of 7.3 MeV/A and took place at Argonne National Laboratory in December of 1980. The author did not participate in the data collection process of the Argonne experiment, but performed the full off-line data analysis. Reaction parameters for all three systems studied are displayed in Table II.1. The parameters were obtained from the tables of W. W. Wilcke et al. [WIL 80], or were calculated using the formulas described in that paper.

While the experimental set-up was different for each experiment, conceptually they were very similar. The time-of-flight technique was used to identify the mass number of projectile-like fragments. The atomic number of such fragments was deduced using the $\mathrm{dE}$ vs. E technique. The Oak Ridge experiment also attempted to detect light charged particles in coincidence with projectile-like fragments.

The off-line data analysis was done using the program LISA which was originally developed in Germany [BRE 89]. This software package is resident in the VAX cluster of the Experimental Nuclear Physics Group at the University of Maryland where both experiments were analyzed. The program LISA is interactive and allows display and manipulation of data. It reads the data in an event-by-event mode, storing the spectra that have been defined by the user. The user's algorithms 
Table II.1 Reaction Parameters.

\begin{tabular}{cccc}
\hline Parameter & ${ }^{37} \mathrm{Cl}+{ }^{40} \mathrm{Ca}$ & ${ }^{37} \mathrm{Cl}+{ }^{209} \mathrm{Bi}$ & ${ }^{35} \mathrm{Cl}+{ }^{209} \mathrm{Bi}$ \\
\hline$E_{\text {lab }}$ & $270.0 \mathrm{MeV}$ & $270.0 \mathrm{MeV}$ & $528.8 \mathrm{MeV}$ \\
\hline $\mathrm{E}_{\mathrm{cm}}$ & $140.2 \mathrm{MeV}$ & $229.4 \mathrm{MeV}$ & $452.9 \mathrm{MeV}$ \\
\hline$\phi_{1 / 4}(\mathrm{lab})$ & $12.0^{\circ}$ & $52.7^{\circ}$ & $20.5^{\circ}$ \\
\hline$\phi_{1 / 4}(\mathrm{~cm})$ & $23.1^{\circ}$ & $60.8^{\circ}$ & $23.8^{\circ}$ \\
\hline $\mathrm{L}_{\text {qrazine }}$ & $97 \mathrm{hbar}$ & $140 \mathrm{hbar}$ & $269 \mathrm{hbar}$ \\
\hline$L_{\text {critic }}$ & $64 \mathrm{hbar}$ & $109 \mathrm{hbar}$ & $101 \mathrm{hbar}$ \\
\hline$R_{\text {int }}$ & $10.44 \mathrm{fm}$ & $13.17 \mathrm{fm}$ & $10.33 \mathrm{fm}$ \\
\hline$V_{\text {coul }}$ (Rint) & $46.8 \mathrm{MeV}$ & $154.2 \mathrm{MeV}$ & $154.8 \mathrm{MeV}$ \\
\hline
\end{tabular}

$E_{\text {lab }}$ is the laboratory energy, $E_{c m}$ is the center-of-mass energy, $\phi_{1 / 4}$ is the quarterpoint angle, $\mathrm{L}$ is the angular momentum with "critic" representing the fusion value, $R_{\text {int }}$ is the interaction radius, and Vcoul is the Coulomb potential.

are incorporated in the subroutines INSONE and INSERT. A flow chart for this code is shown in Figure II.1.

\section{II.A ARGONNE EXPERIMENTAL SET-UP}

The beam provided by Argonne's Superconducting LINAC (presently ATLAS) was ${ }^{37} \mathrm{Cl}$ at $270.0 \mathrm{MeV}$. The beam current was between 13 and $50 \mathrm{nA}$ during the experiment. The targets were self supporting ${ }^{209} \mathrm{Bi}$ and ${ }^{40} \mathrm{Ca}$ and had thicknesses of 700 and $300 \mu \mathrm{g} / \mathrm{cm}^{2}$, respectively. A silicon telescope was positioned on each side of the beam. Each telescope consisted of a transmission silicon detector with an active area of $50 \mathrm{~mm}^{2}$ and a thickness of $17.1 \mu \mathrm{m}$, and a stop silicon detector with an active area of $300 \mathrm{~mm}^{2}$. The distance between the transmission and stop detectors was about $62 \mathrm{~cm}$, and the distance between the target and the 


\section{Figure II.1}

Flow chart for the data aralys is program LISA. 


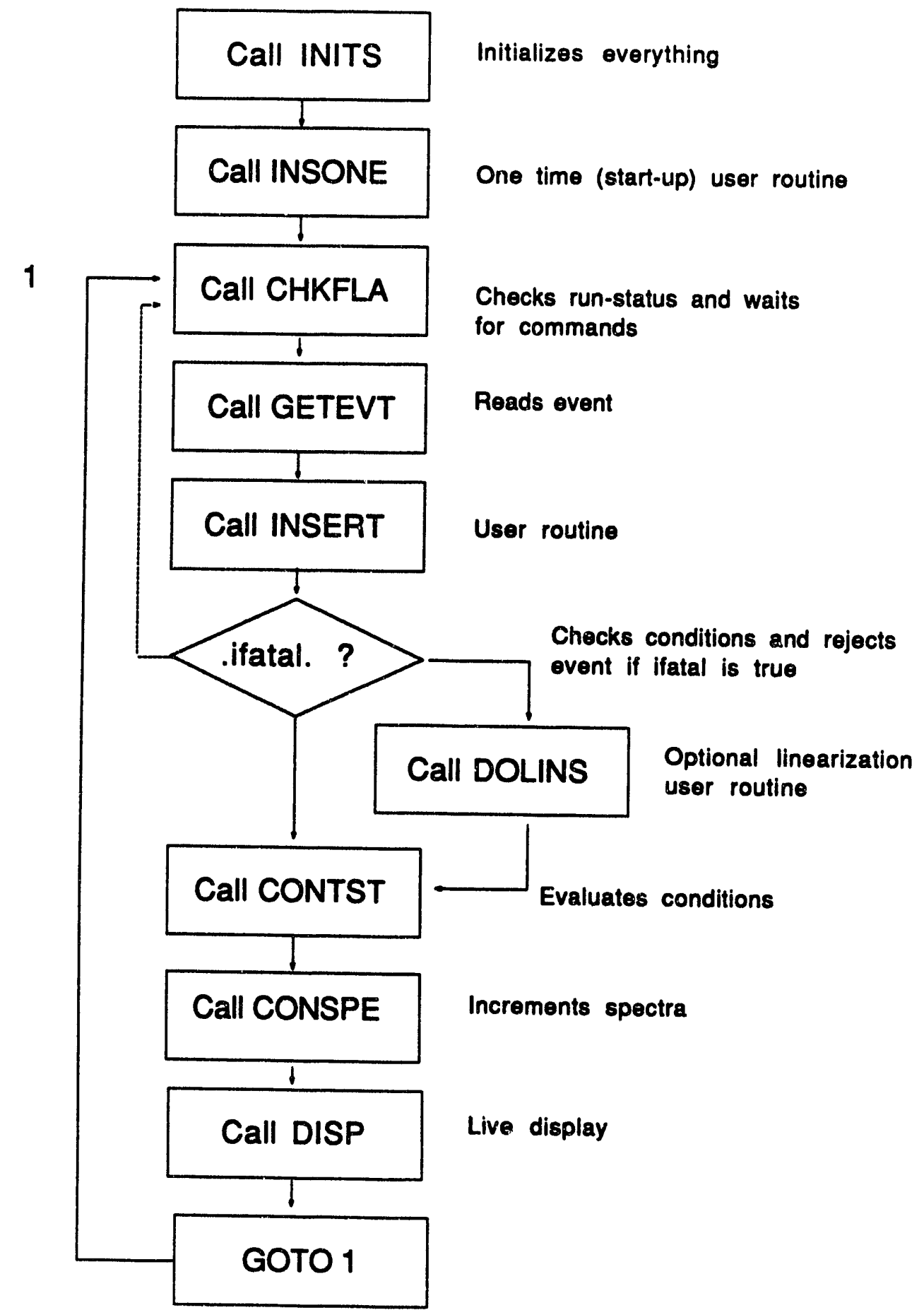


transmission detector was about $14 \mathrm{~cm}$. Each telescope was mounted on a table that could be rotated to allow changes in the angular setting. Data were collected near the grazing angle: at $13.0^{\circ}$ for the $\mathrm{Ca}$ target and at $44.0^{\circ}$ for the $\mathrm{Bi}$ target. The timing resolution required for the mass determination ( $<100 \mathrm{ps)}$ was achieved using Spieler design fast pickoffs. The on-line data were written to tape in an event-by-event mode. The event trigger was a coincidence between the $\mathrm{dE}$ and $\mathrm{E}$ detectors of either telescope.

During the experiment, the telescopes were always at symmetric positions with respect to the beam, thus carrying basically the same information. Only the data from one of the telescopes were fully analyzed here. The other was used occasionally as a check.

\section{II.A.1 Calibrations}

Non-linearities in the response of the electronics were checked using a precision calibration pulser and the energy signals were corrected with a second degree polynomial. The gain of each detector was established by calibrating with a ${ }^{252} \mathrm{Cf}$ fission source. The energy signals were then normalized and added to give the total detected energy. Pulse-height-defect corrections were made to the total detected energy [MOU 78]. A final calibration of the energy scale was achieved by multiplying by a factor that reproduced correctly the energy of the elastic peak minus the energy lost in half of the target thickness. The discrepancy between this last calibration and the ${ }^{252} \mathrm{Cf}$ fission source calibration was found to be less than $1.0 \%$. The energies of the elastic peaks were obtained by classical kinematics calculations using the program KINEQ, which is part of the Oak Ridge software [OAK 87]. 
These energies were $244.4 \mathrm{MeV}$ for the $\mathrm{Bi}$ target at $44.0^{\circ}$ and $257.4 \mathrm{MeV}$ for the $\mathrm{Ca}$ target at $13.0^{\circ}$, based on a beam energy of $270.0 \mathrm{MeV}$.

Corrections due to energy loss in half of the target thickness as a function of the atomic number and energy of the projectile-like fragment were also included. The energy loss for different atomic numbers and energies was calculated using the program STOPX [OAK 87], and the results were stored in a file. For each event, the energy loss was calculated by taking the charge and energy of the particle and interpolating the energy loss value from the file. The energy loss calculated was then added to the particle total energy to obtain its corrected energy. The energy resolution (FWHM) was $1.7 \mathrm{MeV}$ for the elastic peak of the Ca target at $8.0^{\circ}(265.2 \mathrm{MeV})$.

The charge and mass calibrations were done using the data corresponding to the Ca target at $13.0^{\circ}$, because this provided a wider range of charges and masses in the products than did the Bi target. According to Bethe's formula [FRI 81], the energy loss $(\mathrm{dE} / \mathrm{dx})$ of a nonrelativistic charged particle in matter can be roughly described by:

$$
\frac{\mathrm{dE}}{\mathrm{dx}} \alpha \frac{\mathrm{m} \mathrm{z^{2 }}}{\mathrm{E}}
$$

where $\mathrm{m}, \mathrm{Z}$, and $\mathrm{E}$ are the mass, charge, and energy of the particle. A plot of the raw channels $\mathrm{dE}$ vs. E, found in Figure II.2, shows a series of lines (Z-lines), each one corresponding to a different atomic number. Since it is important in the charge and mass distribution analysis to have mass and charge parameters independent of the fragment energy, the functional energy dependence of the Z-lines had to be corrected. The theoretical description for this dependence given in equation II. 1 is not complete enough to give an acceptable correction. The correction is deemed acceptable when the centroids as a function of energy do not change by more than 0.1 charge units. 
Figure II.2

Contour plot of the raw $\mathrm{dE}$ as a function of $\mathrm{E}$ channels for the system ${ }^{37} \mathrm{Cl}$ on ${ }^{40} \mathrm{Ca}$ at $270 \mathrm{MeV}$. 


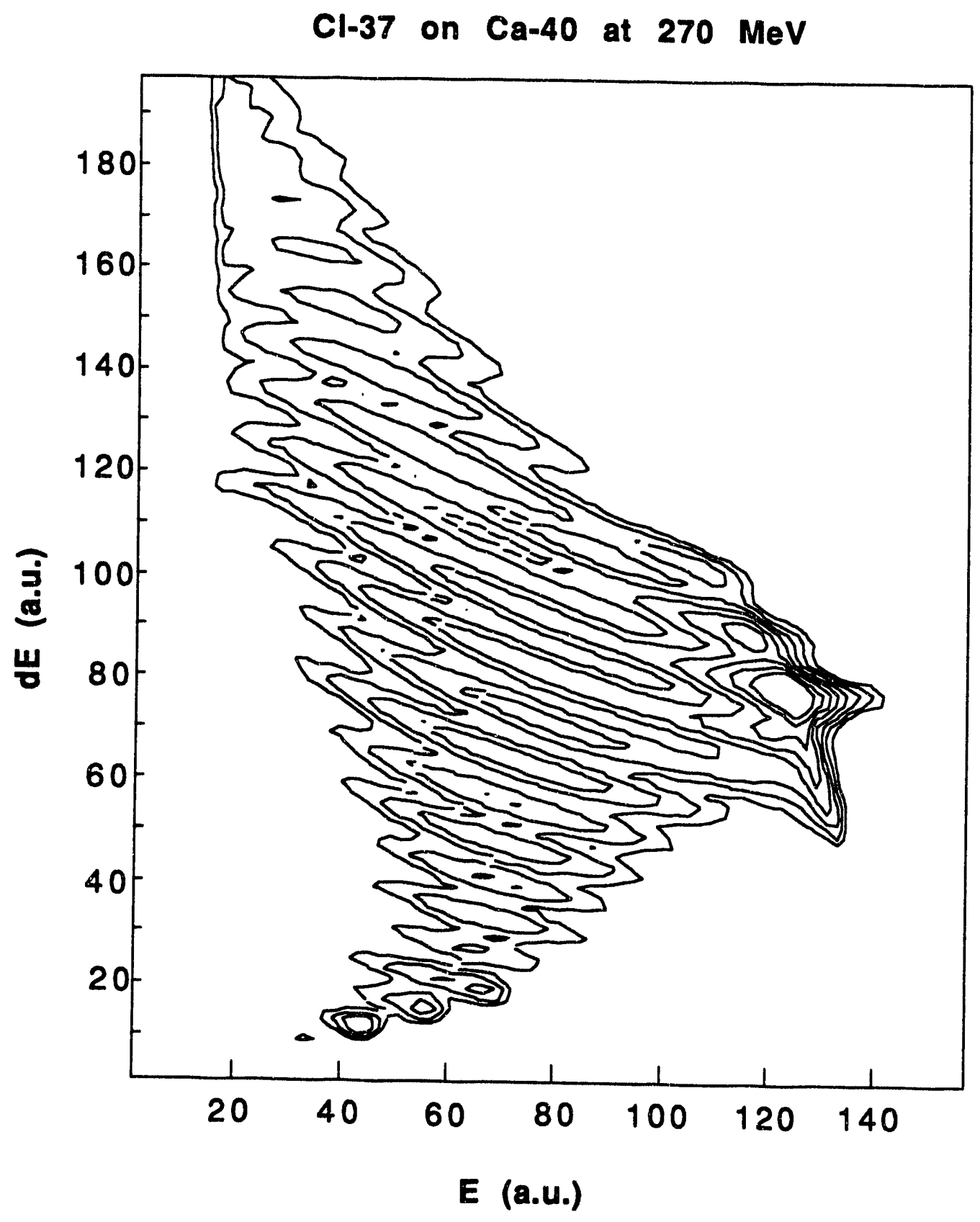


The first step in correcting the Z-lines was the application of a formula based on empirical fits to stopping-power data [FRI 81]:

$$
Z=\text { constant }\left[\left(d E^{\alpha}+E\right)^{\beta}-E^{\gamma}\right]^{1 / 2}
$$

where $\alpha, \beta$, and $\gamma$ are constants with values $1.16,1.725$, and 1.73 , respectively. After this formula had been applied, successive corrections were made using polynomial fits in cifferent regions in the $Z$-E plane. Once the $Z$ parameter was independent of energy, a polynomial fit was employed to adjust the position (gain) of the $\mathrm{Z}$ centroids to correspond to atomic numbers. A contour plot of the corrected $\mathrm{Z}$ as a function of the laboratory energy is shown in Figure II.3.

The time-of-flight technique relies on the mass being proportional to the product $\mathrm{Et}^{2}$, where $\mathrm{t}$ is the time of transit for a fixed distance and $\mathrm{E}$ the energy of the particle in question. The time-of-flight between the $\mathrm{dE}$ and $\mathrm{E}$ detectors was measured using a time-to-analog converter (TAC) connected to an $8 \mathrm{~K}$ analog-to-digital converter (ADC). If the TAC response is linear, as expected, the time corresponding to a measurement $T$ is proportional to $\left(T-T_{0}\right)$, where $T_{0}$ is an offset. The TAC calibration showed good linearity with a gain of about $27.8 \mathrm{ps} / \mathrm{channel}$. Once the offset is established, the mass should be given by:

$$
\mathrm{m}=\text { constant } \mathrm{E}\left(\mathrm{T}-\mathrm{T}_{0}\right)^{2} \text {. }
$$

Since the time was measured between the $\mathrm{dE}$ and $\mathrm{E}$ detectors, $\mathrm{E}$ is the energy of the particle as measured in the $\mathrm{E}$ detector. In principle, the mass parameter obtained using equation II. 3 should be independent of the energy. That was not the case in practice and empirical corrections were required to make the mass centroids 
Figure II.3

Contour plot of the linearized atomic number as a function of laboratory energy for the system ${ }^{37} \mathrm{Cl}$ on ${ }^{40} \mathrm{Ca}$ at $270 \mathrm{MeV}$. 


\section{Cl-37 on Ca-40 at $270 \mathrm{MeV}$}

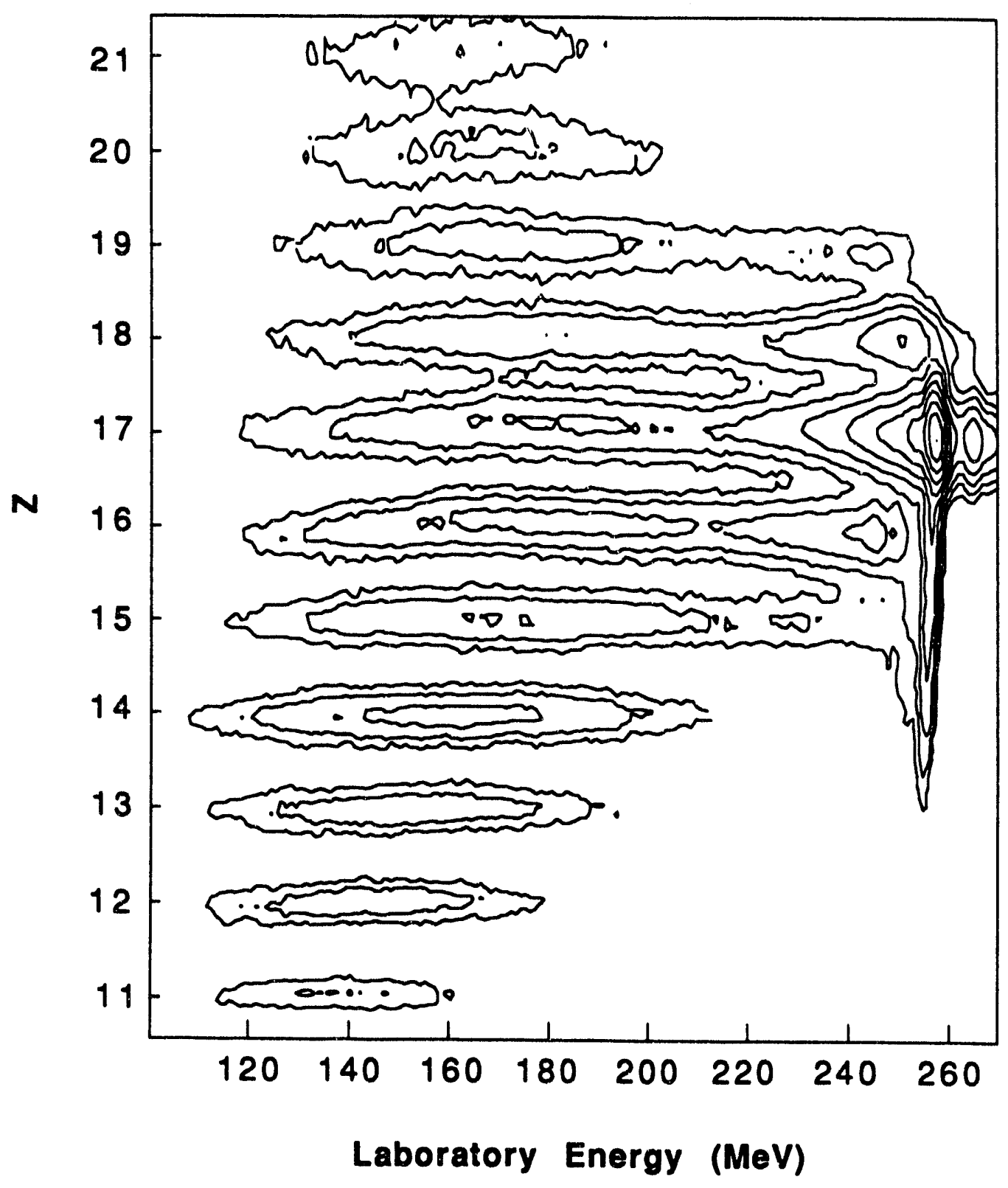


independent of the energy (within 0.1 mass units). These corrections included the use of different offset values for each of three energy regions. Final adjustments were done using polynomial fits, as in the case of the Z-lines. A contour plot of the corrected mass as a function of the laboratory energy is displayed in Figure II.4.

A plot of the atomic number as a function of mass is shown in Figure II.5, where an energy gate was set to eliminate the elastic component. It can be seen that for the same mass there is a shift of the centroid with the atomic number and vice versa. A linear correction on both the atomic number and the mass was made to eliminate this shift, and the result can be seen in Figure II.6. The resolutions (FWHM) were 0.5 mass unit for $A=37$ and 0.4 charge unit for $Z=17$. Representative charge and mass distributions are shown in Figure II.7.

\section{II.B OAK RIDGE EXPERIMENTAL SET-UP}

The experiment took place at the Oak Ridge National Laboratory Holifield Heavy Ion Research Facility (HHIRF). The Laboratory has a 25-MV vertical tandem accelerator that can be operated alone or coupled to an isochronous cyclotron, to serve as an energy booster. The particle beam can be delivered to different target stations that are equipped with different nuclear instruments. This experiment utilized the time-of-flight spectrometer. The spectrometer lay-out can be found in Figure II.8. It consists of a $30.5-\mathrm{cm}$ diameter scattering chamber connected to a time-of-flight arm. The time-of-flight arm is equipped with two timing detectors, and with a large foursegments ion chamber $\mathrm{dE}-\mathrm{E}$ detector at its end. The arm can be rotated to allow changes in the angular setting. As in the Argonne experiment, the combination of time and $\mathrm{dE}-\mathrm{E}$ information allows the characterization by energy, charge, and mass of the particles entering the spectrometer. 
Figure II.4

Contour plot of the mass as a function of laboratory energy for the system ${ }^{37} \mathrm{Cl}$ on ${ }^{40} \mathrm{Ca}$ at $270 \mathrm{MeV}$. 


\section{Cl-37 on $\mathrm{Ca}-40$ at $270 \mathrm{MeV}$}

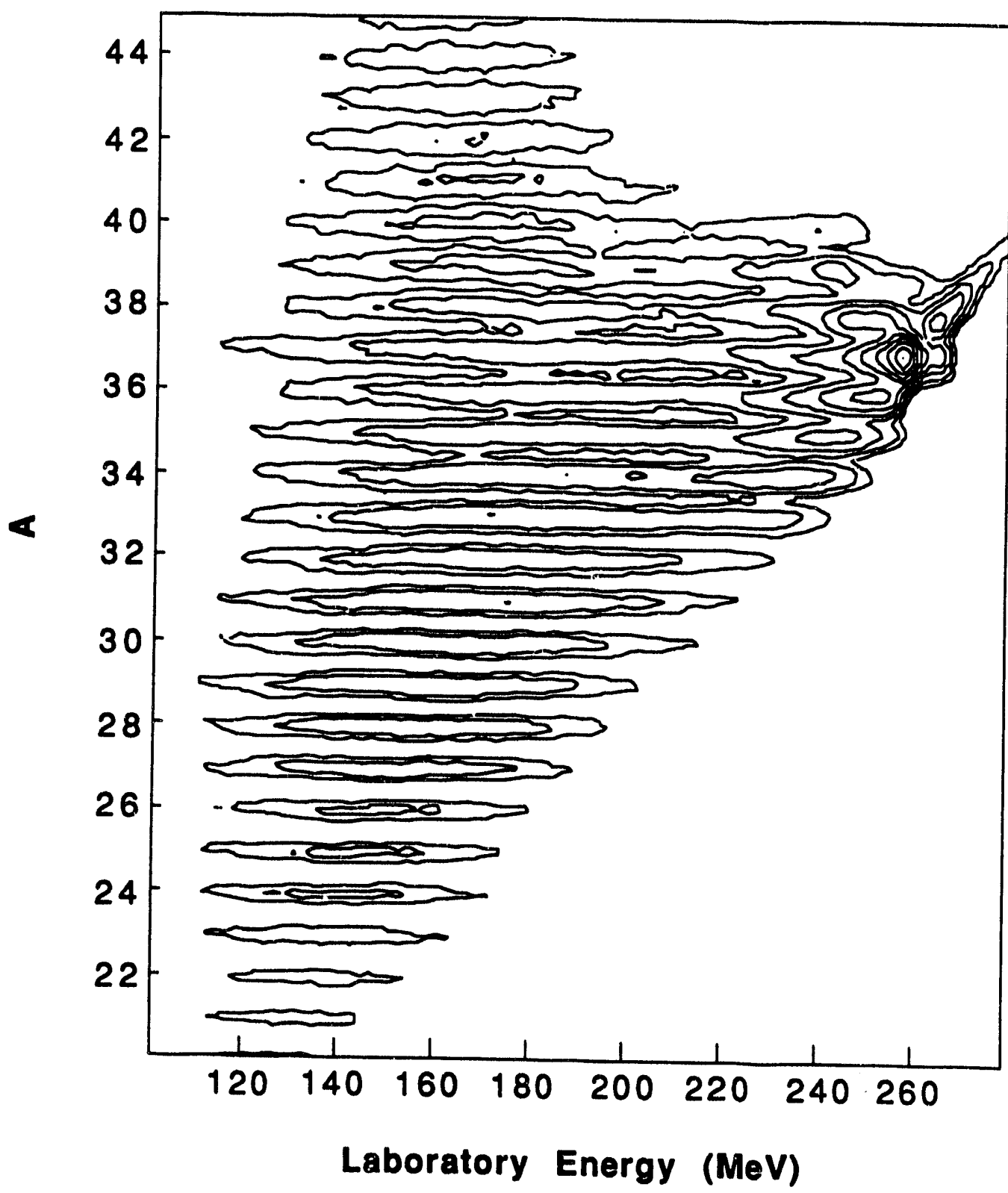


Figure 11.5

Contour plot of the atomic number as a function of mass for the system ${ }^{37} \mathrm{Cl}$ on ${ }^{40} \mathrm{Ca}$ at $270 \mathrm{MeV}$ before correcting $\mathrm{A}$ and $\mathrm{Z}$ for their mutual dependence. An energy gate was set to eliminate elastic events. 


\section{Cl-37 on $\mathrm{Ca}-40$ at $270 \mathrm{MeV}$}

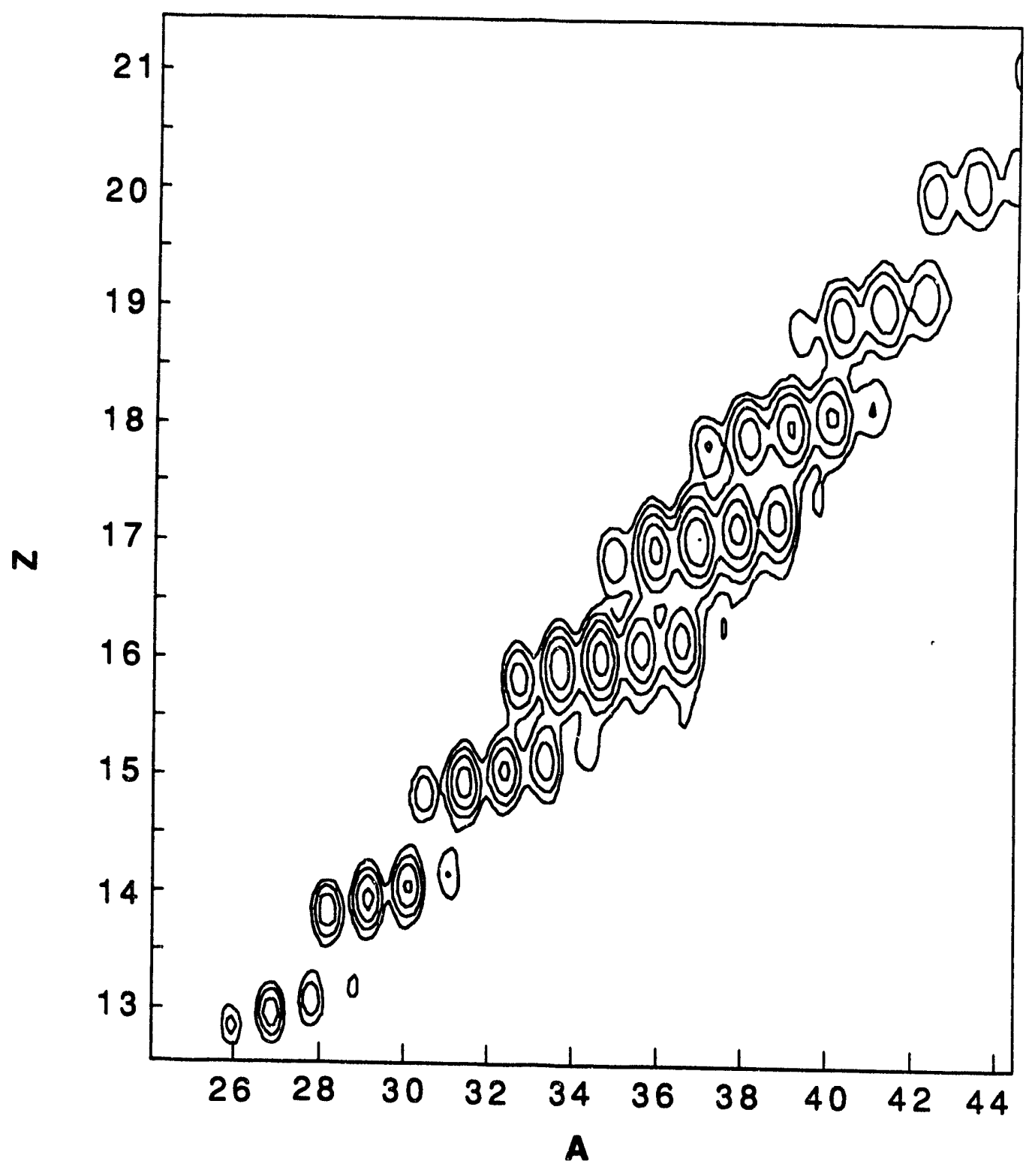


Figure II.6

Contour plot of the atomic number as a function of mass for the system ${ }^{37} \mathrm{Cl}$ on ${ }^{40} \mathrm{Ca}$ at $270 \mathrm{MeV}$ after correcting $\mathrm{A}$ and $\mathrm{Z}$. for their mutual dependence. An energy gate was set to eliminate elastic events. 


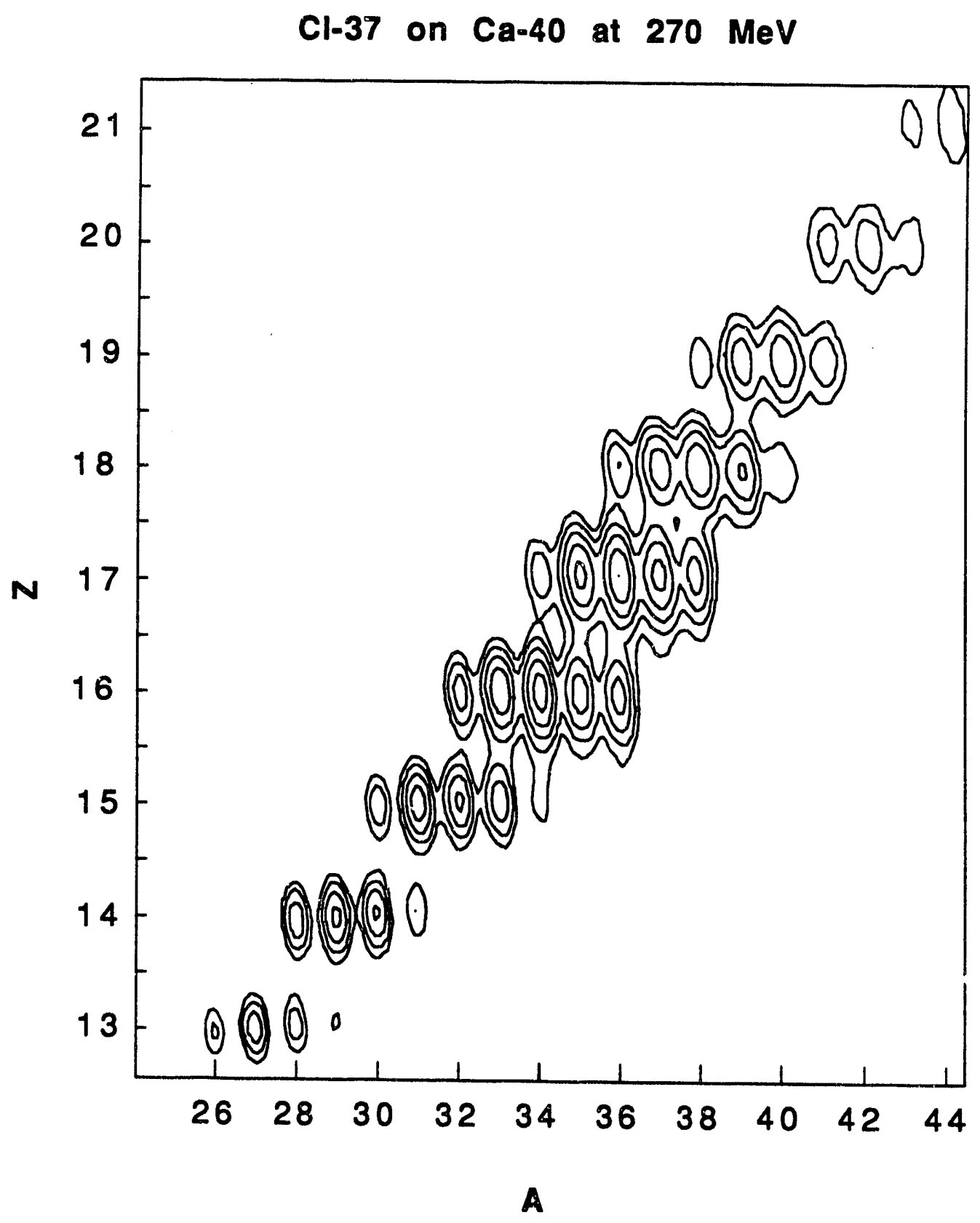


Figure II.7

Representative (a) mass and (b) charge distributions for the system ${ }^{37} \mathrm{Cl}$ on ${ }^{40} \mathrm{Ca}$ at $270 \mathrm{MeV}$. An energy gate was set to eliminate elastic events. 

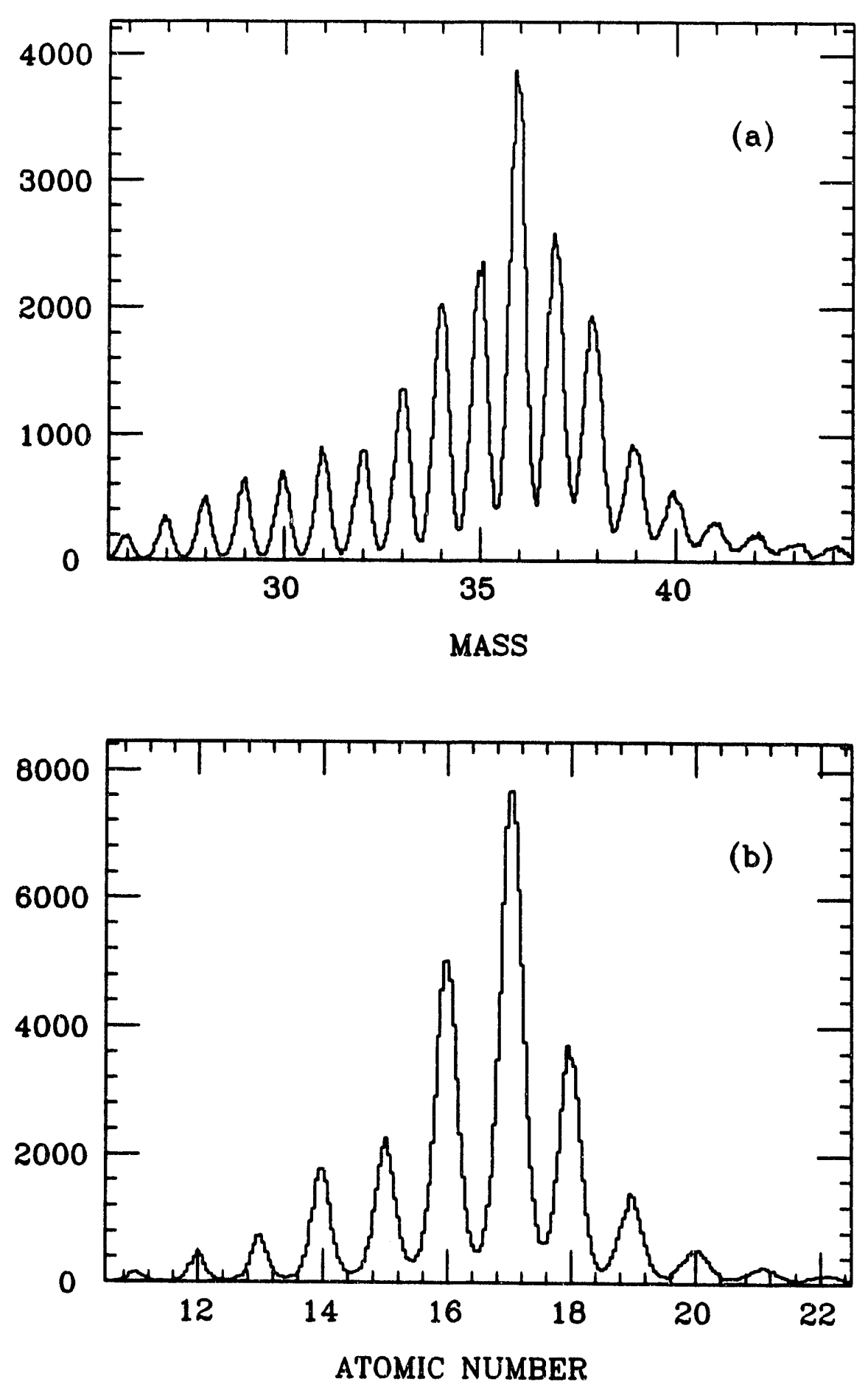
Figure II. 8

Side view of the Time-of-Flight facility at HHIRF. Dimensions are in mm. 


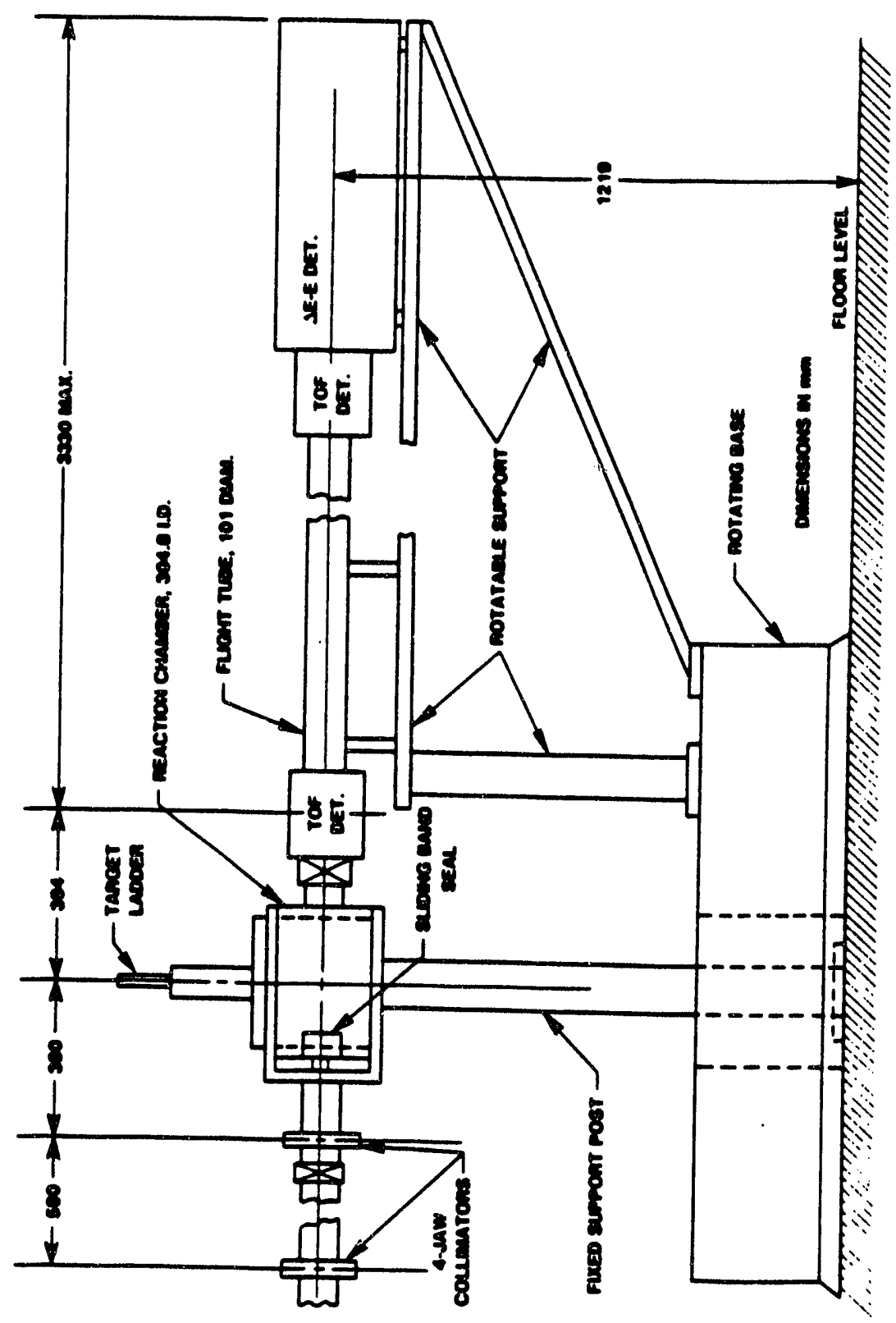


A 528.8-MeV beam of ${ }^{35} \mathrm{Cl}$, provided by the coupled operation of the tandem and cyclotron, was delivered to the time-of-flight station. The beam current was kept between 15 and $20 \mathrm{nA}$ throughout the experiment. The charge state of ${ }^{35} \mathrm{Cl}$ was $14^{+}$; the time structure of the beam was determined by the cyclotron frequency $(10.71$ $\mathrm{MHz}$.). The target was self supporting ${ }^{209} \mathrm{Bi}\left(1000 \mu \mathrm{g} / \mathrm{cm}^{2}\right)$. A potential of $1500 \mathrm{~V}$ was applied to the target to suppress secondary electrons. The time-of-flight arm was positioned at $18.0^{\circ}$ for data collection. A collimator consisting of a stainless steel plug with an oval orifice of about $3 \mathrm{~mm}$ by $6 \mathrm{~mm}$ was placed at the entrance of the arm.

Two large area $\mathrm{dE}-\mathrm{E}$ plastic scintillator detectors were mounted inside the scattering chamber, one on each side of the beam. The purpose of this detector was to identify light charged particles in coincidence with projectile-like fragments. The design, construction, and performance of these detectors is discussed in Section II.C.

The start and stop detectors used in the time-of-flight measurement were transmission-type parallel plate avalanche counters (PPACs). They were mounted on the time-of-flight arm separated by a distance of $253 \mathrm{~cm}$. The start and stop PPAC had areas of $2 \times 2 \mathrm{~cm}^{2}$, and $8 \times 10 \mathrm{~cm}^{2}$, respectively. Each PPAC had four windows made of $60 \mu \mathrm{g} / \mathrm{cm}^{2}$ polypropylene. The two internal widows were aluminized and served as the cathode; the anode was a plane of parallel wires between the two cathode planes. For both detectors, the filling gas was isobutane at a pressure of about 6 torr. The potentials of the anodes were set to $400 \mathrm{~V}$ and $420 \mathrm{~V}$ for the start and stop PPAC, respectively. The anode signals were used for the time measurement. Each cathode plane of the stop PPAC had been aluminized forming parallel strips of metal. The strips of each plane were connected in series through delay chips to an output on each side of the plane. Position information in the direction perpendicular to the strips was obtained by measuring the time difference 
between the output on each side of the plane. The two planes were arranged so that the strips of one plane were perpendicular to the strips of the other plane, thus providing $\mathbf{x}$ - and $\mathbf{y}$-position information.

The ionization chamber had four consecutive anodes of $10,10,20$, and $40 \mathrm{~cm}$ in length respectively. The entrance to the chamber was a $300 \mu \mathrm{g} / \mathrm{cm}^{2}$ mylar window. A mixture of $90 \% \mathrm{Ar}$ and $10 \%$ methane $(\mathrm{P}-10)$ was used as the filling gas at a pressure of about 410 torr. The optimum choice for filling gas was carbon tetrafluoromethane $\left(\mathrm{CF}_{4}\right)$, but the HHIRF was not able to provide it at the time. Attempts to use isobutane failed because the purity of the available gas was not adequate. Therefore, P-10 was chosen by elimination. The potentials applied to the ionization chamber were $2000 \mathrm{~V}$ to the anode, $500 \mathrm{~V}$ to the Frisch grid, and $-1000 \mathrm{~V}$ to the cathode.

The time-of-fight was measured using a TAC and an 8K ADC. The position signals were recorded using two TACs, one for the up-down direction and the other for the left-right direction of the stop PPAC. Each individual position output (up, down, left, and right) was also timed against the anode signal of the PPAC using a time-to-digital converter (TDC). The energy signals of the four anodes of the ionization chamber and the corresponding drift times were recorded. The drift times were taken between the anode signal of the stop PPAC and each of the four anode signals of the ionization chamber using a TDC. The drift times provided $x$-position information. Signals recorded for the plastic detector are described in Section II.C.2. As seen, some signals are recorded redundantly. It is customary to do so, when possible, to prevent the loss of information if malfunctions occur during signal processing.

The data acquisition system used is described in the HHIRF computer handbook [OAK 87]. All data input to the system was done through CAMAC 
modules. A programmable microprocessor (Event-Handler) developed at the HHIRF was used; this microprocessor was mounted in a CAMAC crate. The main tasks of the Event-Handler were to detect the occurrence of an event, to read the digitized data from the CAMAC modules, and to store it in a buffer to be read by the host computer. The event trigger was a coincidence between the start and stop PPACs. The event trigger made the Event-Handler read a logic input register and determine if it was a valid event by checking which detectors had fired. In the case of a valid event, the Event-Handler sent to "the external world" a busy signal to inhibit further input while the ADCs and TDCs were converting. After the event was processed, the Event-Handler cleared all the electronics and waited for the next event. The events were written to tape in an event-by-event mode by the host computer.

A simplified schematic of the electronic set-up is shown in Figure II.9. Delays cables were used when necessary. The start and stop PPACs were connected forward to the time-of-flight TAC; that means that the start signal was not delayed to come after the stop signal, as used in some other set-ups.

\section{II.B.1 Calibrations}

A precision calibration pulser was used to check the electronics for nonlinearities in each of the four energy signals of the ionization chamber. A polynomial correction to linearize and normalize the energy signals was performed on each element separately.

When working with large area detectors, it is often found that the signals are position dependent. In general, for best results, position corrections are applied. The stop PPAC and the ionization chamber qualified as large area detectors. Corrections were to be performed using the position information of the stop PPAC. 


\section{Figure II.9}

Simplified representation of the electronic set-up for the Oak Ridge experiment. Only one $\mathrm{dE}$ channel is shown for the ion chamber and one position channel for the stop PPAC. Schematic legend:

ADC = analog-to-digital converter
CFD = constant fraction discriminator
DELAY AMP = delay amplifier
FIFO = fan-in fan-out
PMT = photomultiplier tube
TDC = time-to-digital converter

AMP = amplifier

COINC. UNIT = coincidence unit FAST AMP = fast amplifier

PA = preamplifier

TAC = time-to-analog converter

QDC = charge integrating ADC. 
IONIZATION CHAMBER:

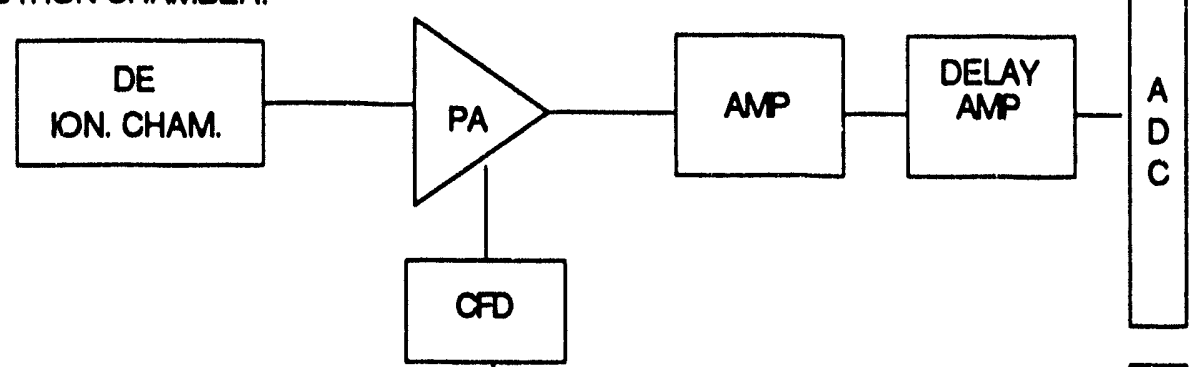

TIME-OF-FLIGHT:

Stop

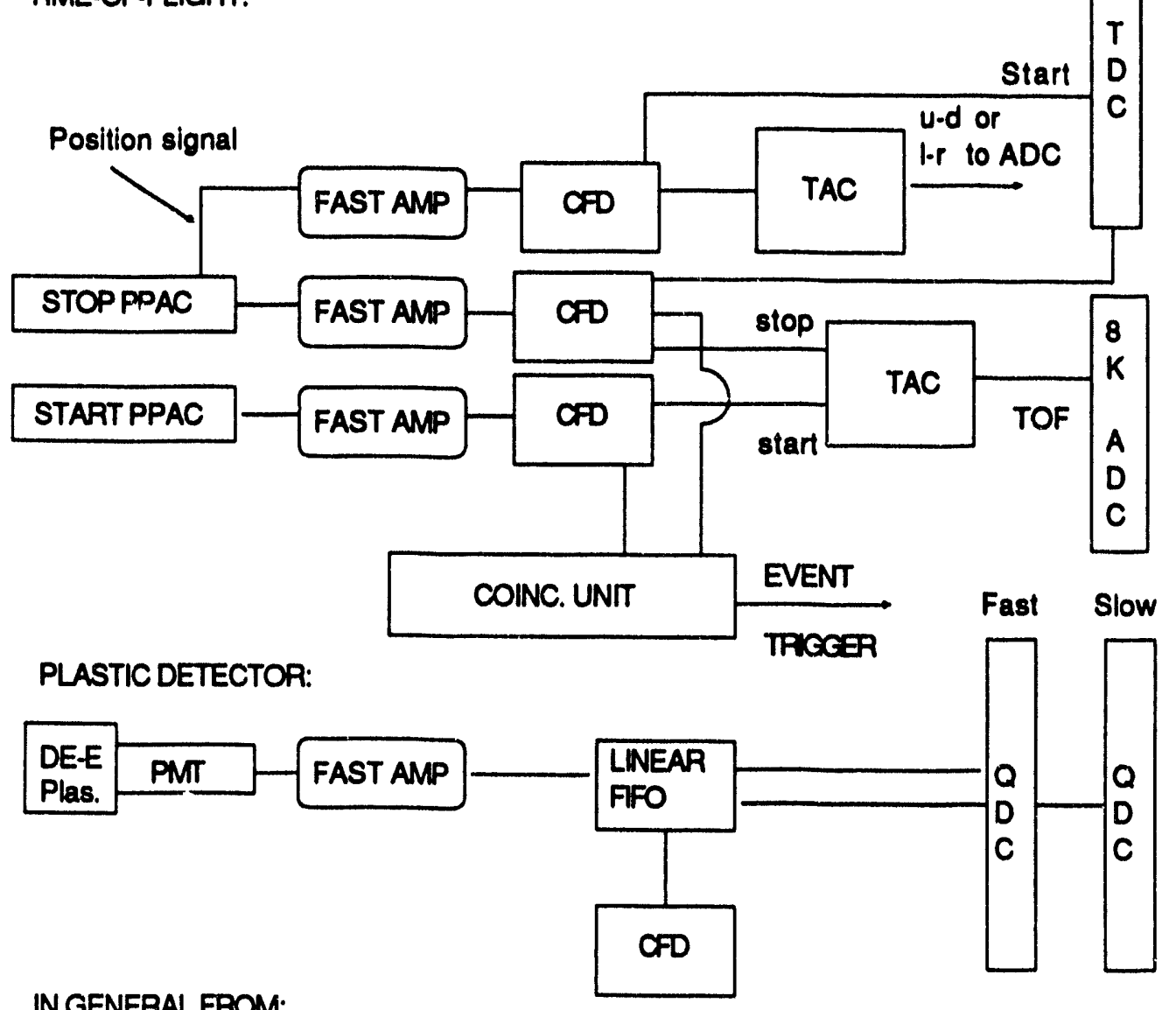

IN GENERAL FROM:

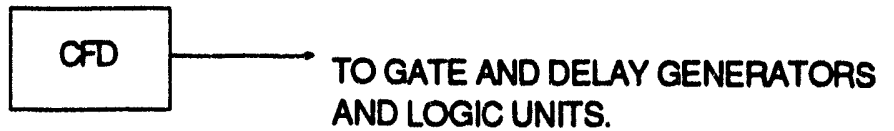


Unfortunately, the position signals had an efficiency of less than $10 \%$, which was statistically unacceptable for practical corrections. One source of low efficiency may have been electronic noise comparable in voltage to the actual signals of the position channels. This required that the threshold of the discriminator be raised to values close to the actual position signals, inadvertently rejecting valid signals as well.

A partial correction was applied using the $x$-position information provided by the measurement of the electron-drift time in the ionization chamber. The elastic centroids of the time-of-flight and the energy signals were plotted as a function of the drift time of the third anode. The $x$-position dependence of the signals was corrected using polynomials. A drift-time gate was also established to reject events either without drift time or near the extremes of the drift time spectrum.

The parameter that showed the strongest $x$-dependence was the energy of the first element of the ionization chamber (dE1). The elastic centroid shifted as much as $\pm 8 \%$ from the average value. Even after the position correction, the elastic peak of dE1 was very broad, probably due to a strong y-dependence. The energy signals of the other elements (dE2, dE3, and dE4) and the time-of-flight showed much less dependence on the $x$-position. The maximum shifts from the average centroids were not larger than $\pm 1.5 \%$.

After position correction, the four $\mathrm{dE}$ signals were added together to generate a new parameter proportional to the total energy deposited in the ion chamber. The addition of the four signals was multiplied by a factor to normalize the total energy to that of the elastic peak minus the energy loss in half of the target thickness and the windows of the detectors. Normally this would have been done with data collected at angles lower than the grazing angle, to have a well defined elastic peak from which the resolution could have also been estimated. However, the elastic particles were barely stopped in the chamber at $18.0^{\circ}$, at lower angles the elastically scattered 
particles did not stop in the gas. Attempts to increase the gas pressure were ruled out for fear that the large window at the entrance of the ion chamber would not hold the pressure. Hence, the elastic centroid at $18.0^{\circ}$ had to be used to calibrate the energy scale. Corrections for energy loss in half of the target thickness and the windows of the detectors as a function of atomic number and energy, were performed in the way described for the Argonne experiment. For the elastic peak at $18.0^{\circ}$, the energy was $520.2 \mathrm{MeV}$ with a FWHM of about $10 \mathrm{MeV}$. It should be stressed that this width does not actually represent the energy resolution, because the elastic peak was measured close to the grazing angle, where other processes contribute significantly to the total width.

The atomic number determination was done following the $\mathrm{dE}-\mathrm{E}$ technique described in Section II.A.1. It was decided not to use the first element of the ionization chamber for the atomic number determination due to its poor resolution. The Z-lines were obtained using $\mathrm{dE} 2$ as the $\mathrm{dE}$ parameter and the addition of $\mathrm{dE} 3$ and $\mathrm{dE4}$ as the E parameter. As a consequence, events that deposited all their energy in the first two elements did not have $\mathrm{Z}$ identification and were not considered. A contour plot of the corrected $\mathrm{Z}$ as a function of the laboratory energy is shown in Figure II.10. A FWHM of about 0.3 charge units was measured for $Z=17$. The determination of the mass presented a very difficult problem. From previous experiments, it is known that the energy resolution can be less than $1 \%$ after position corrections. For the time resolution, a conservative value is $400 \mathrm{ps,}$, also after position corrections. The relative error for the mass as a function of energy and time is given by:

$$
\frac{\delta m}{m}=\frac{\delta E}{E}+\frac{2 \delta t}{t}
$$


Figure II.10

Contour plot of the atomic number as a function of the laboratory energy for the system ${ }^{35} \mathrm{Cl}$ on ${ }^{209} \mathrm{Bi}$ at $528 \mathrm{MeV}$. 
Cl-35 on Bi-209 at $528 \mathrm{MeV}$

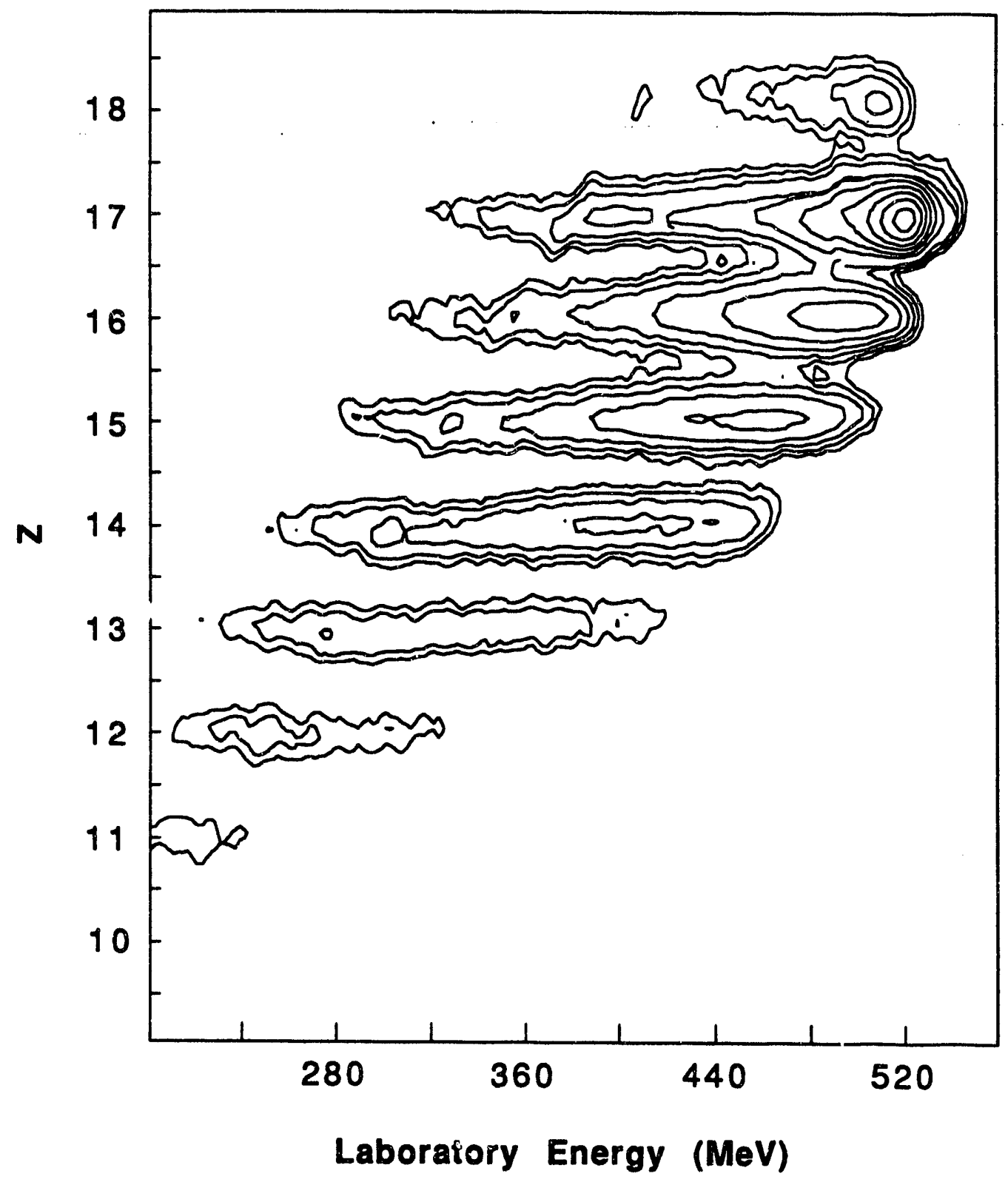


For a 253-cm flight path, the time for an elastic event is about $47.1 \mathrm{~ns}$. Assuming an energy resolution of $0.8 \%$, the mass resolution (FWHM) should be about 0.9 mass units. This resolution is acceptable but borderline for mass determination. It was clear that, with the problems encountered in this experiment, such resolution would be practically impossible to achieve.

A time-of-flight gain of about $8 \mathrm{ps} / \mathrm{channel}$ with very good linearity was determined by calibration with a time calibrator. After establishing a gate around $\mathrm{Z}=$ 17, the width (FWHM) of the "elastic" peak measured at $18.0^{\circ}$ was about 900 ps. Considering the energy resolution to be around $1 \%$ (a value consistent with previous experiments), the resulting mass resolution would have an upper limit of about 1.7 mass units.

Without defined peaks, mass cannot be unambiguously corrected for energy dependence, because the positions of the centroids cannot be established with certainty. Much time was spent trying to rescue the mass information. Narrow gates were established for $Z$ and $x$-position to try to elucidate mass centroids to no avail. Finally, a new approach was tried: the use of deconvolution techniques to enhance spectral resolution. A brief discussion on deconvolution and its application are presented in Chapter III. With the aid of this technique to identify mass centroids, corrections for energy dependence were done as described for the Argonne experiment. A contour plot of the corrected mass as a function of the laboratory energy is shown in Figure II.11. A satellite of about $10 \%$ the intensity of the actual mass peak was found. No physical explanation has been established for its presence. However, it should not significantly affect the mass distribution because of its low intensity. Representative charge and mass distributions are shown in Figure II.12. 
Figure II.11

Contour plot of the mass as a function of laboratory energy for the system ${ }^{35} \mathrm{Cl}$ on ${ }^{209} \mathrm{Bi}$ at $528 \mathrm{MeV}$. 
Cl-35 on Bi-209 at $528 \mathrm{MeV}$

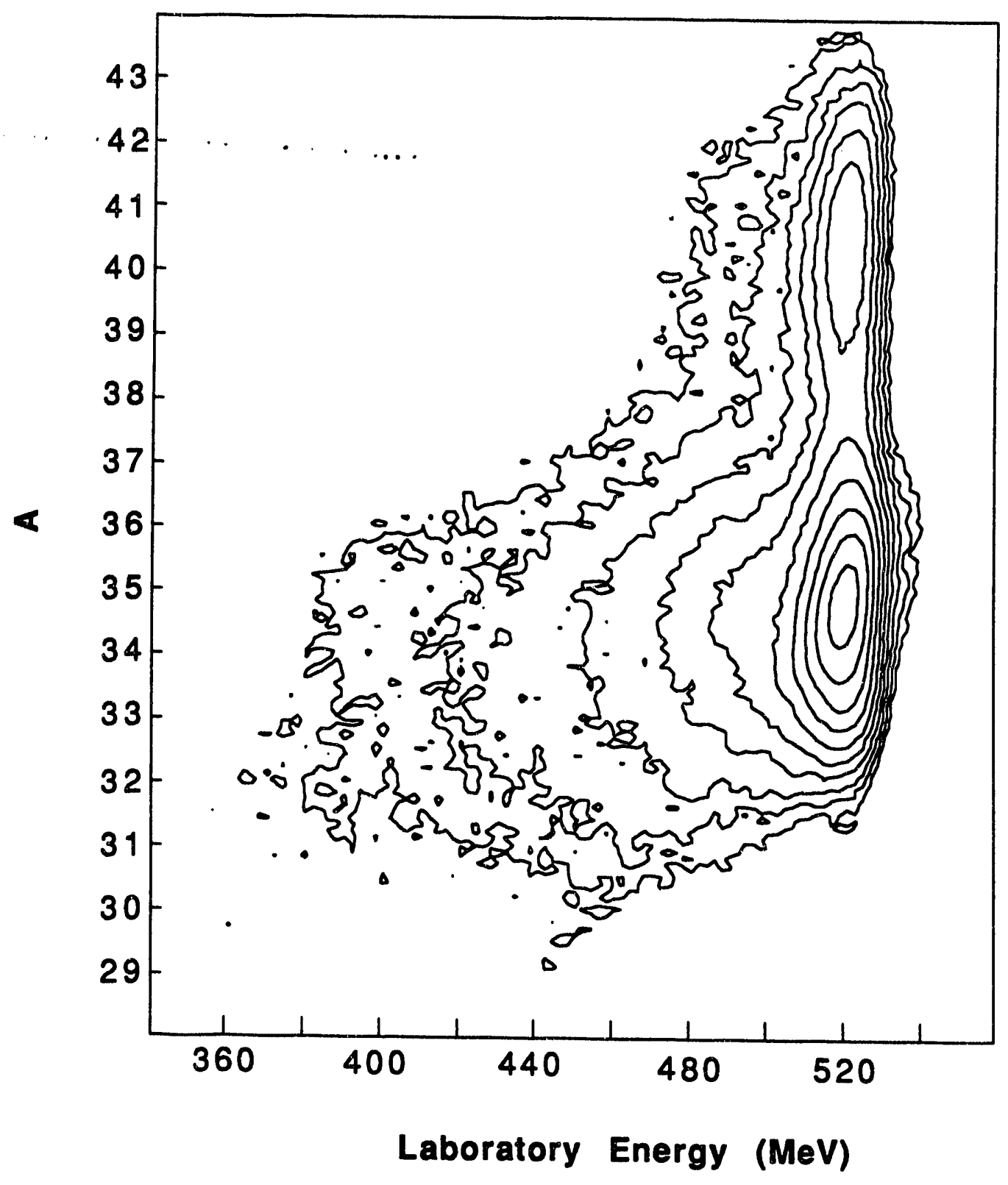


Figure II.12

Representative (a) mass and (b) charge distribution for the system ${ }^{35} \mathrm{Cl}$ on ${ }^{209} \mathrm{Bi}$ at $528 \mathrm{MeV}$. A gate was established to eliminate elastic events. There are two curves for the mass: one represents the data as is (single wide peak), and the other the effect of the deconvolution procedure on the data. 

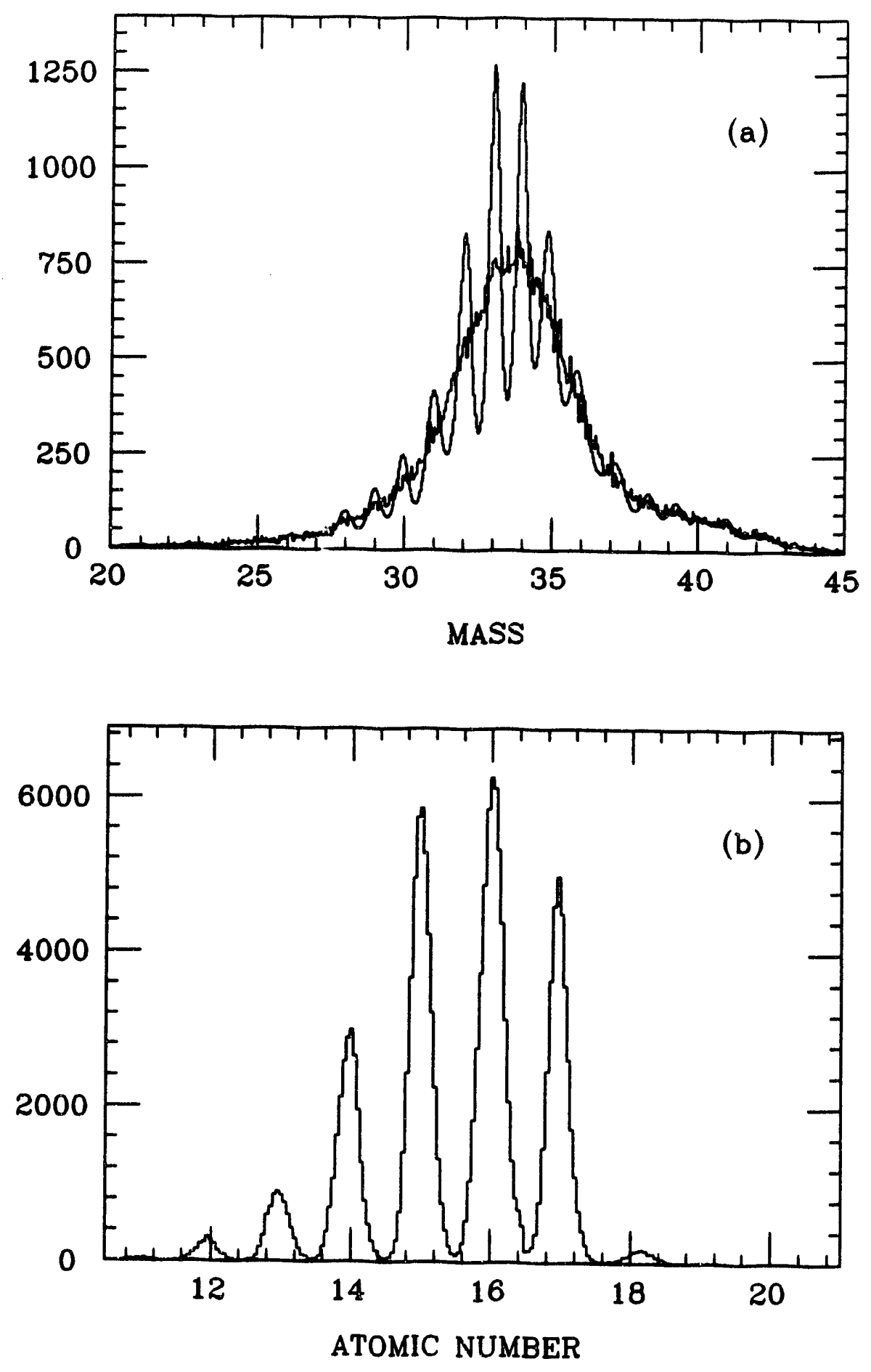


\section{II.C LIGHT-CHARGED-PARTICLE DETECTOR}

The design and construction of a light-charged-particle detector was part of the Oak Ridge experiment. The main purpose of this detector was to identify protons and alpha particles emitted by evaporation of excited projectile-like fragments. To have good efficiency, the detector had to cover as much solid angle as possible. The type of detector chosen wäs a dE-E plastic scintillator of the phoswich design [KNO 79, LEO 87].

A plastic scintillator consists of a fluorescent organic compound forming a solid solution in a plastic matrix. Plastics are available in a variety of sizes and shapes that cannot be matched by other detectors. They are also relatively inexpensive. Their main disadvantage is the poor linearity of the signal with both energy and charge, when compared to other types of detectors. However, for the purpose of particle identification of low $\mathrm{Z}$ products, this disadvantage is normally well outweighed by the advantages.

When a particle loses energy in the plastic, part of that energy is converted into electronic excitation of the molecules of organic scintillator, which subsequently deexcite. One of the main processes of deexcitation is light emission, with the amount of light produced proportional to the energy deposited. The process is characterized by a time constant $\tau$ called the fluorescent or decay constant. If at time zero the light intensity is $I_{0}$, the intensity $I$ at a time $t$ will approximately be given by:

$$
I=I_{0} e^{-t / \tau}
$$

The phoswich technique [WIL 52] uses two scintillators with different decay constants to build a dE-E telescope. Both scintillators are optically coupled to the 
same photomultiplier tube (PMT). If the decay constants are different enough, the current signal from the PMT can be decomposed into the two contributions ( $\mathrm{dE}$ and E). The scintillator with the smaller decay constant is called the fast scintillator, and the other one is called the slow scintillator.

The plastic scintillators needed to build the detector were purchased from the Bicron Corporation. The commercial denomination for the fast and slow scintillators are $\mathrm{BC}-400$ and $\mathrm{BC}-444$, respectively. The $\ddot{\mathrm{BC}}-400$ has a decay constant of $2.4 \mathrm{~ns}$ and the BC-444 has a decay constant of about $300 \mathrm{~ns}$ [TEH 87]. The rise time of the signal in both plastics is on the order of $1 \mathrm{~ns}$ or less. The principal constraint in the design of the detector was the small space available in the $30.5-\mathrm{cm}$ diameter scattering chamber. The use of regular PMTs in this small chamber would have required an awkward set-up. For that reason, very small PMTs that had recently become available from the Hamamatsu Corporation were used.

\section{II.C.1 Prototype Test}

A prototype detector was built and tested at the HHIRF in August 1987. A beam of ${ }^{58} \mathrm{Ni}$ at $197.97 \mathrm{MeV}$ impinging on several targets was used. The test took place at the 1.6-m diameter scattering chamber of beam line $\mathrm{C} 16$.

The detector consisted of a $0.1 \times 2.0 \times 12 \mathrm{~cm}^{3}$ sheet of BC-400 mounted on a $3.0 \times 2.0 \times 12.0 \mathrm{~cm}^{3}$ block of BC-444. Both elements were coupled to the same PMT at $90^{\circ}$ through an optical guide. The PMT used was the model R647-01 of the Hamamatsu Corporation. This is a 7-cm long and $1.3-\mathrm{cm}$ diameter head-on PMT. The sides of the detector were painted with reflecting white paint to improve the efficiency of light collection. The front part of the detector was covered with a thin aluminized mylar foil and the rest of the detector was wrapped with electrical tape. A 
sketch of the detector is shown in Figure II.13 (a). Once mounted in the scattering chamber, the detector covered from about $5^{\circ}$ to $90^{\circ}$ in-plane, and $\pm 5^{\circ}$ out-of-plane.

Two separate pieces of BC- 400 and BC-444 were also placed inside of the scattering chamber. Each piece was optically coupled to a different PMT, and placed close to the beam. The purpose of this arrangement was to allow looking at the signals from each plastic individually. This was very helpful in setting the gates for signal processing.

The anode signal from the detector PMT was split and sent to two individually gated charge integrating analog-to-digital converters (QDCs). The first QDC had a gate of $30 \mathrm{~ns}$, therefore integrating mainly the fast decaying $\mathrm{dE}$ component. The second QDC had a gate of $750 \mathrm{~ns}$ delayed $30 \mathrm{~ns}$ with respect to the $\mathrm{dE}$ signal. This one integrated mainly the $\mathrm{E}$ component. Sketches of the individual fast and slow signals, and gates are shown in Figure II.13 (b)-(c), as seen on an oscilloscope.

Contour plots of the dE signal as a function of the $E$ signal are shown in Figure II.14 for polypropylene $\left(\mathrm{CH}_{2}\right)$, and $\mathrm{C}$ targets. It is evident from Figure II.14 that the difference between both targets is the presence of a well defined peak in the dE-E plane in the $\mathrm{CH}_{2}$ case, which is not present in the $\mathrm{C}$ case. This peak was assigned to $\mathrm{H}$ recoils. The peak appears on the ridge where particles deposit most of their energy in the $\mathrm{dE}$ element, indicating that most of the protons were stopped in the first element. This is consistent with the recoil energies ( 0 to $4 \mathrm{MeV})$, and range of the protons in the plastic ( 0.2 to $0.3 \mathrm{~mm}$ for a $4-\mathrm{MeV}$ proton). The contour line appearing in both the $\mathrm{C}$ and $\mathrm{CH}_{2}$ targets is also observed with a Ni target. This line can be assigned to neutrons, gamma rays, and electrons, which would not lose much energy in the dE element. It is important to mention that QDCs need to be corrected by subtracting a pedestal integration before assigning an absolute energy value to their reading. This correction was not performed, and therefore each energy scale 


\section{Figure II.13}

(a) Sketch of the prototype light-charged-particle detector. (b) Sketch of the dE signal of as seen on an oscilloscope. (c) Same as in (b) for the E signal. 


\section{Prototype Detector}

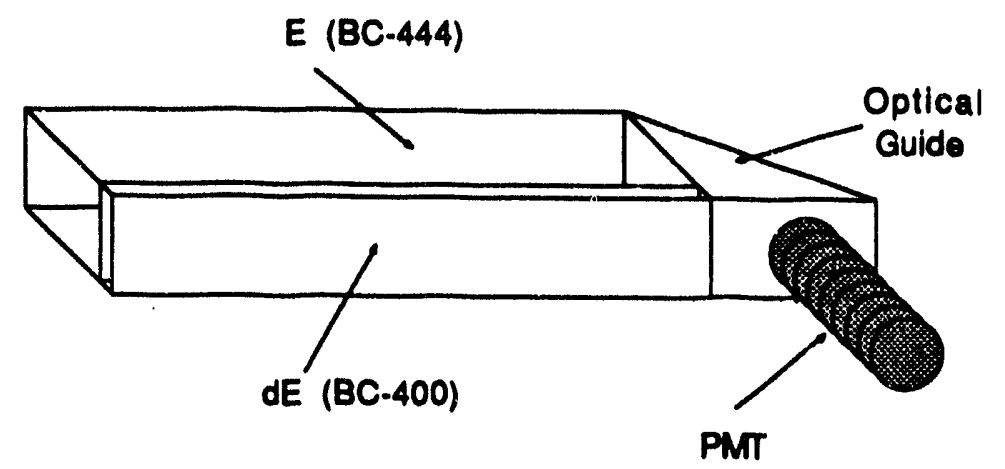

(a)

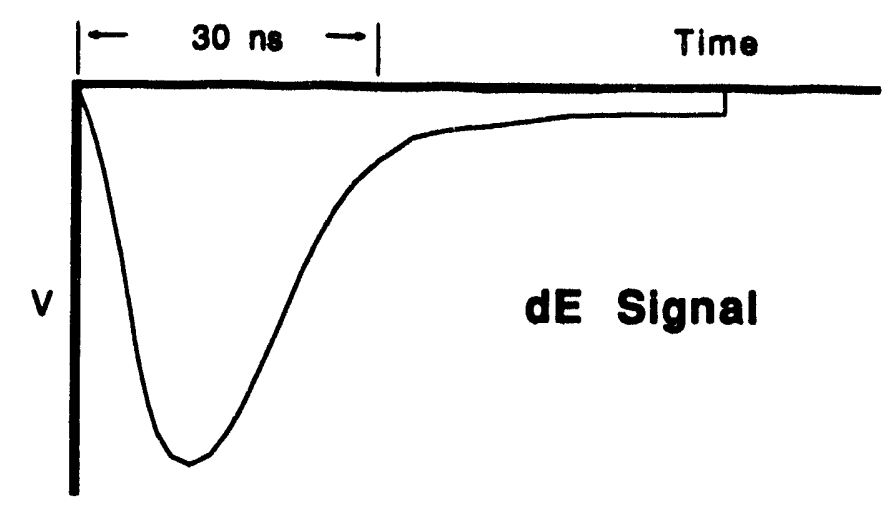

(b)

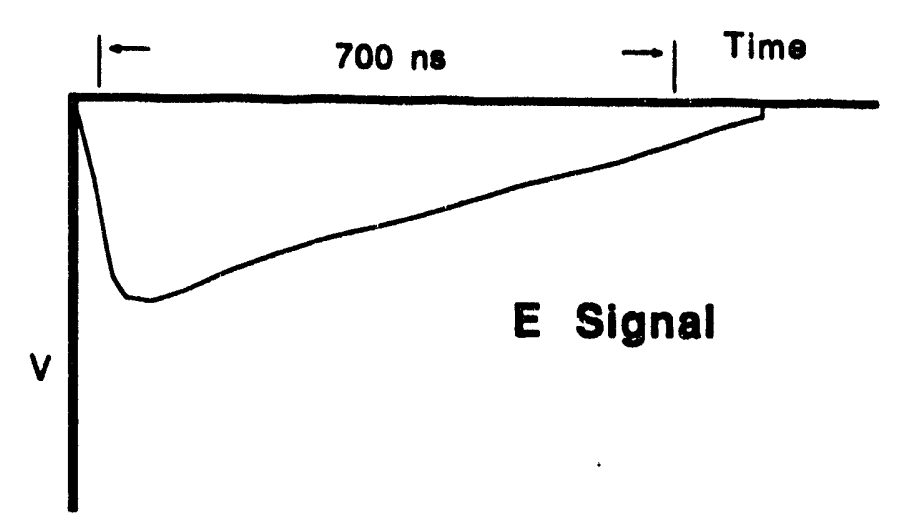

(c) 
Figure II.14

Contour plots of the $\mathrm{dE}$ signal as a function of the $\mathrm{E}$ signal of the prototype detector for two different targets (polypropylene and carbon). 


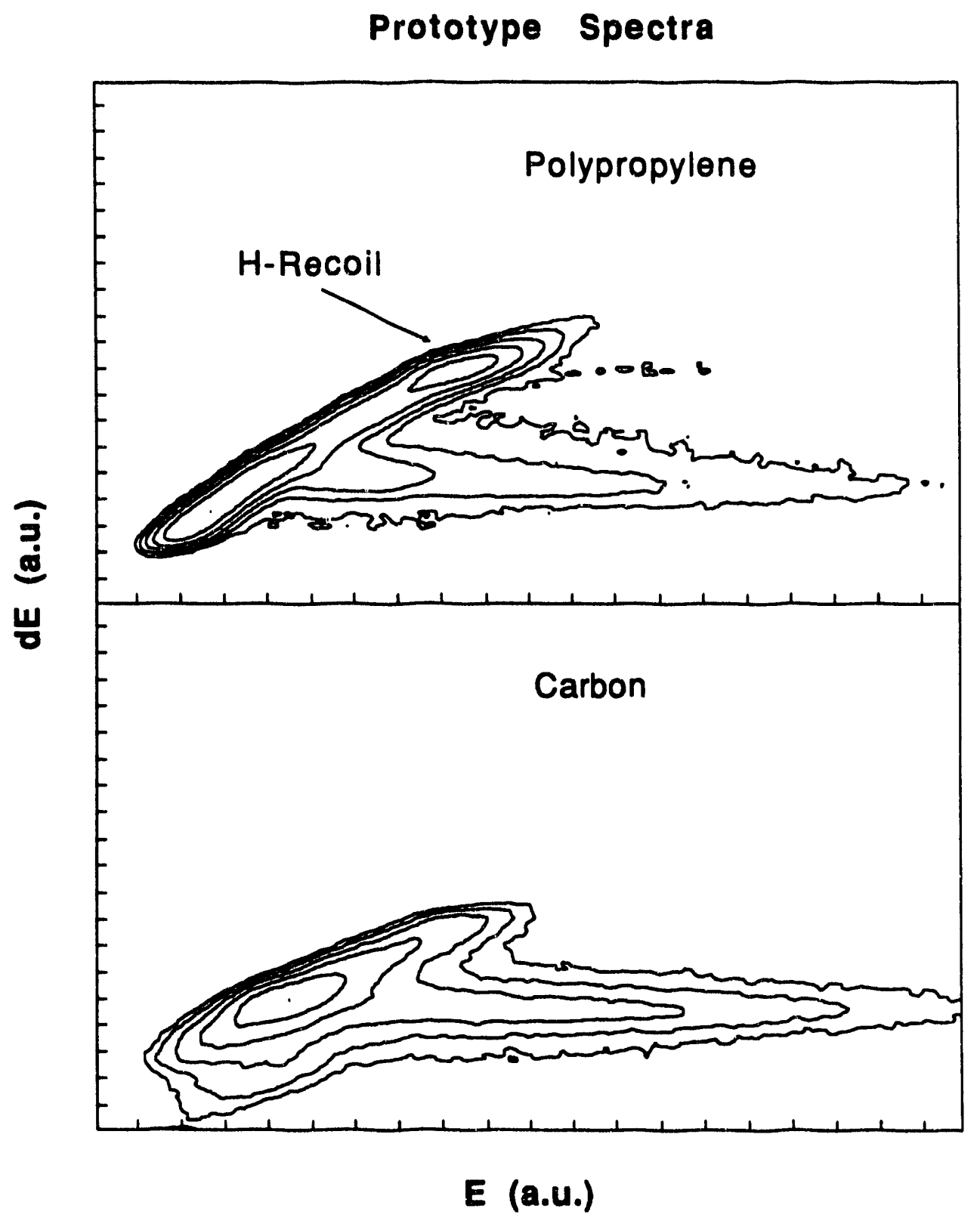


( $\mathrm{dE}$ and $\mathrm{E}$ ) should be considered shifted by a constant undetermined amount.

There were concerns about the efficiency of light collection and light output of the thin $\mathrm{dE}$ element. Since the $\mathrm{dE}$ and $\mathrm{E}$ elements were not optically coupled to each other, the light was collected only on a $0.01 \times 2.0 \mathrm{~cm}^{2}$ strip in the $\mathrm{dE}$ element. The dE signal was, however, very strong. As a consequence of this, it was decided to use half the thickness of the $\mathrm{dE}$ element in the construction of the actual detector to lower the energy threshold for both protons and alpha particles entering the $E$ element.

\section{II.C.2 Detector and Results}

Eight dE-E plastic-scintillator telescopes were used to construct two lightcharged-particle detectors for the Oak Ridge Experiment. Each telescope consisted of a $0.05 \times 3 \times 10 \mathrm{~cm}^{3}$ sheet of BC-400 mounted on a $3 \times 3 \times 10 \mathrm{~cm}^{3}$ block of BC- 444 , optically coupled at $45^{\circ}$ to a PMT through a light guide, as shown in Figure II.15 (a). The telescopes were mounted in groups of four in two aluminum holders to form the detectors. The sides of the telescopes were painted with reflecting white paint to avoid crosstalk and improve light collection. The front part of the detector was covered with very thin aluminized mylar. The rest of the detector was protected rom external light by the aluminum holder with the exception of the light guides and PMTs, which were covered with black electrical tape.

The PMTs used were the model R1666 of the Hamamatsu Corporation. This PMT is only 5-cm long and 1.8-cm diameter. The PMT selected was different from the one used in the test for two reasons: it was shorter, and a very compact base had been designed for it. The small bases were developed at Washington University for the "Dwarf Ball" detector. Eight electronic boards, along with the wiring diagram, 
Figure II.15

(a) Sketch of one of the dE-E telescopes of the light-charged-particle detector.

(b) Top view of the layout of the light-charged-particle detector inside the scattering chamber. 


\section{Detector Telescope}
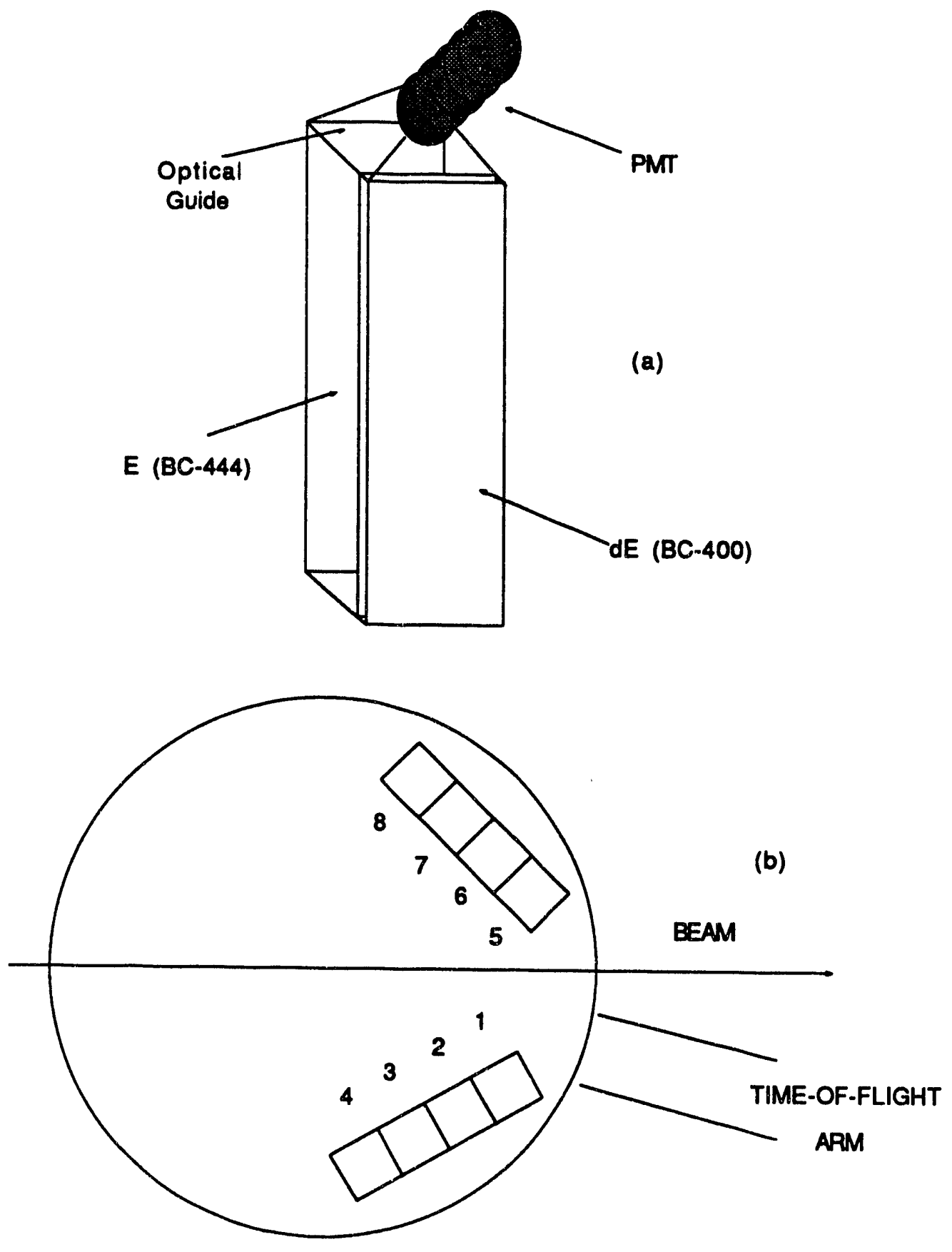
were provided by Washington University. The electronics shop of the Physics Department of the University of Maryland did the wiring of the bases.

Each detector was placed on a rotating arm inside the scattering chamber, as shown in Figure II.15 (b). The left detector covered from $-10^{\circ}$ to $-75^{\circ}$ in-plane and \pm $28^{\circ}$ out-of-plane. The right detector, which was next to the time-of-flight arm entrance, covered from $25^{\circ}$ to $105^{\circ}$ in-plane and $\pm 35^{\circ}$ out-of-plane. The telescopes were numbered from 1 to 4 on the right, and from 5 to 8 on the left, as indicated in Figure II.15 (b).

The anode signals of each PMT were treated as described in Section II.C.1 to obtain the $\mathrm{dE}$ and $\mathrm{E}$ components. The gates were set to $25 \mathrm{~ns}$ for the QDC integrating the fast component and $400 \mathrm{~ns}$ for the one integrating the slow component. All the PMTs had a common QDC gate with the exception of PMT 5, whose electronics were separated because of its proximity to the beam.

$A \mathrm{CH}_{2}$ target was used to calibrate for $\mathrm{Z}$. Contour plots of the raw signals $\mathrm{dE}$ as a function of $E$ show a clear $Z=1$ line. Examples are shown in Figure II. 16 for PMTs 1, 6, and 7. While they do not appear in these contour plots, indications of an alpha line were seen in color density plots. The contour plots shown in Figure II.17 correspond to the Bi target, where there is no clear indication of a $Z=1$ line. Unfortunately, this prevented further studies with these detector.

\section{II.D KINETIC ENERGY LOSS CALCULATION}

The total kinetic energy loss $\left(\mathrm{E}_{\text {loss}}\right)$ is defined as the difference between the initial and the final kinetic energy in the center of mass of the system. In two-body kinematics, the expression for the energy loss, in the laboratory system is 
Figure II.16

Contour plots of the $\mathrm{dE}$ signal as a function of the $\mathrm{E}$ signal for a polypropylene target. The signals of the PMTs 1,6 , and 7 of the lightcharged-particle detector are shown. 


\section{Polypropylene Spectra}

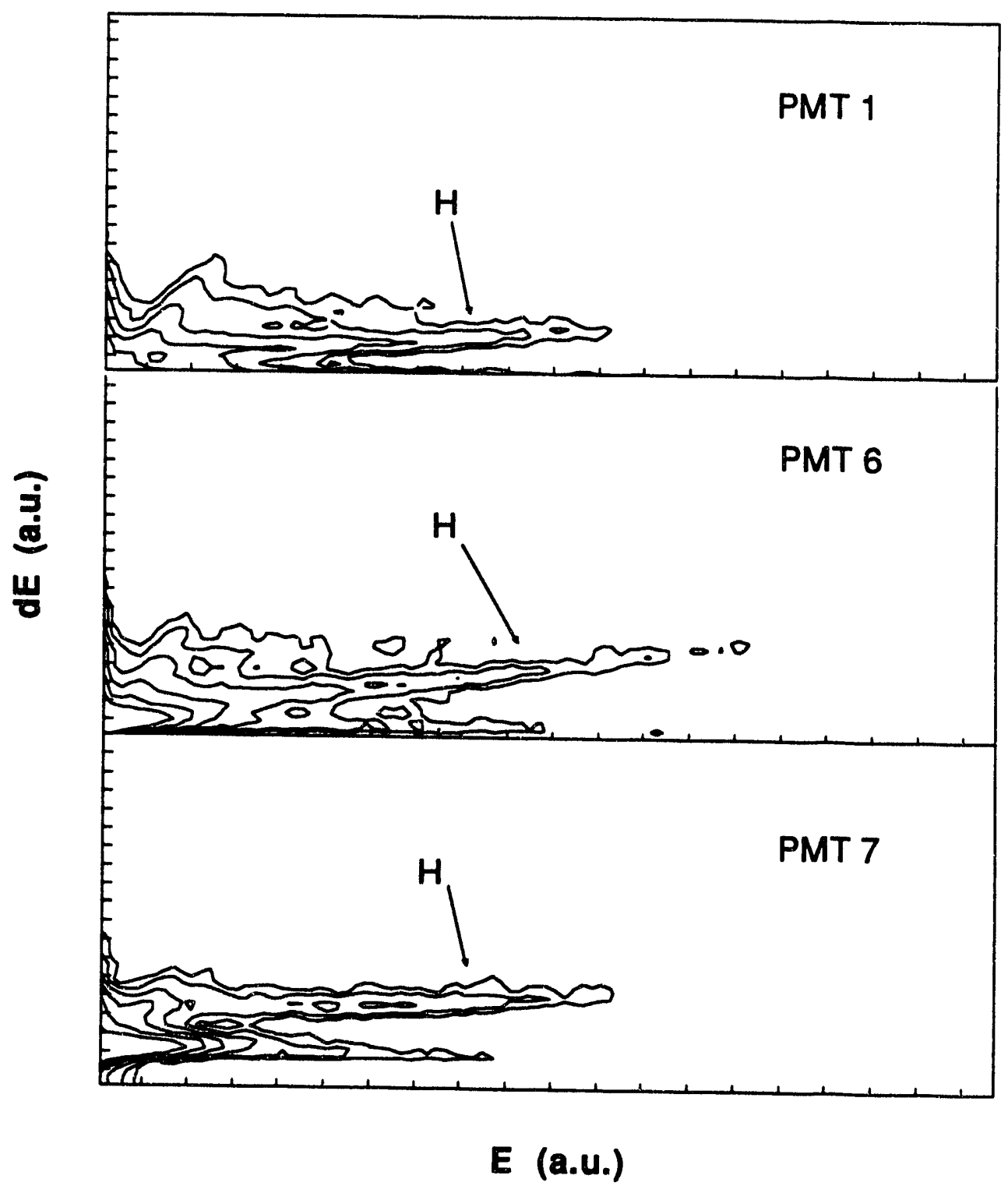




\section{Figure II.17}

Contour plots of the $\mathrm{dE}$ signal as a function of the $\mathrm{E}$ signal for $\mathrm{Bi}$ target. The signals of the PMTs 6, and 7 of the light-charged-particle detector are shown. 


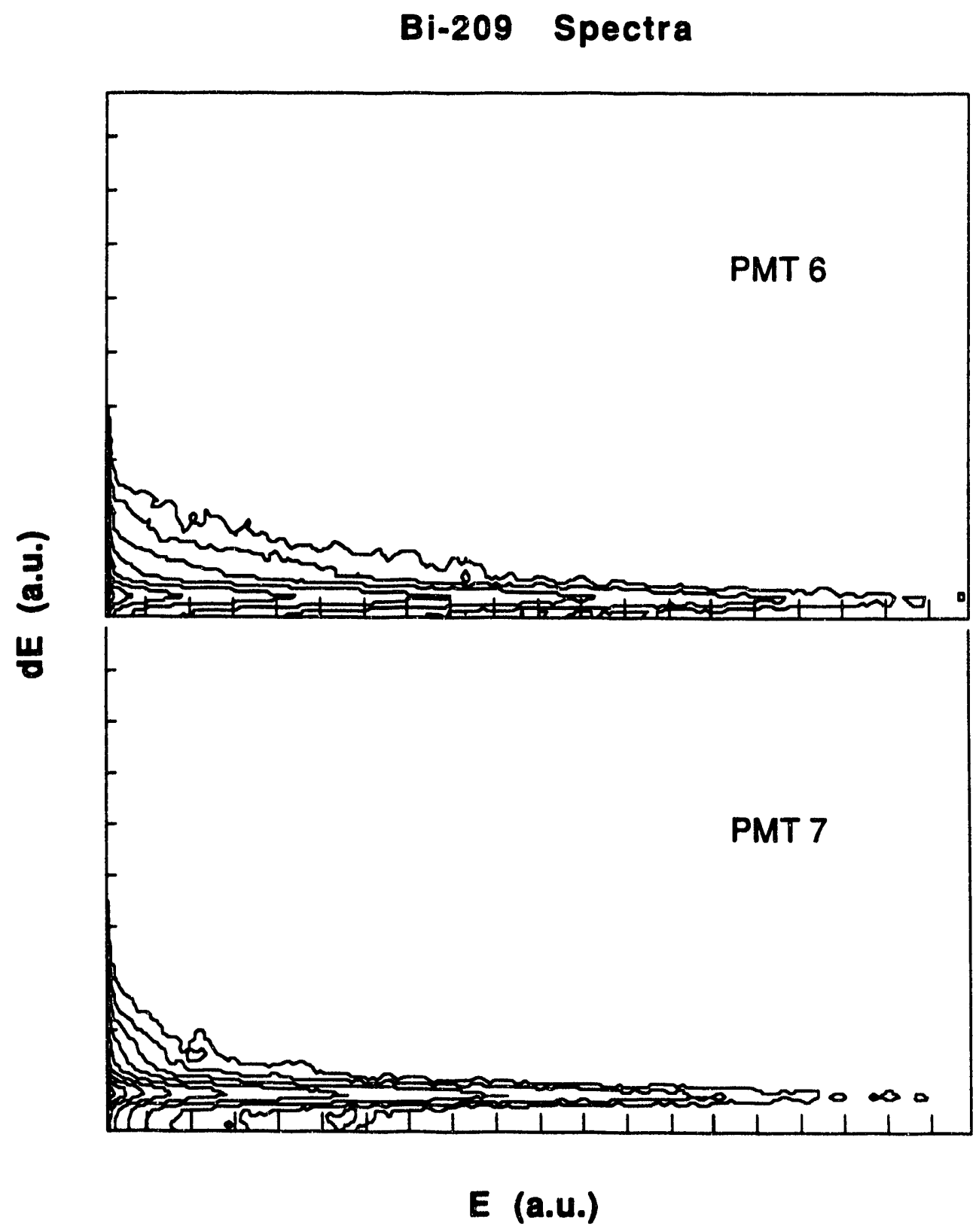




$$
\mathrm{E}_{\text {loss }}=\mathrm{E} 1\left(1-\frac{\mathrm{M} 1}{\mathrm{M} 4}\right)-\mathrm{E} 3\left(1+\frac{\mathrm{M} 3}{\mathrm{M} 4}\right)+2 \cos (\theta) \sqrt{\frac{\mathrm{E} 1 \mathrm{E} 3 \mathrm{M} 1 \mathrm{M} 3}{\mathrm{M} 4^{2}}}
$$

where $\mathrm{E}$ stands for laboratory kinetic energy, $\mathrm{M}$ for mass, and $\theta$ for the projectile-like fragment laboratory angle. The numbers 1 to 4 represent the projectile, target, projectile-like fragment, and target-like fragment, respectively.

In an experiment, the energy, charge, and mass of the fragments are measured after evaporation has occurred. Since equation II.6 is strictly valid for two-body processes, the $\mathrm{E}_{\text {loss }}$ calculated using directly the experimental parameters is incorrect. It was necessary to introduce corrections for evaporation to the mass and erergy of the projectile-like fragment to make a better estimation of $E_{\text {loss. }}$ Assumptions in this correction are that the velocity of the projectile-like fragment does not change, on the average, because of evaporation, that the evaporated mass can be expressed as a smooth function of the excitation energy of the projectile-like fragment, and that the ground state Q-value can be expressed as a smooth function of the projectile-like fragment Z. Since only total kinetic energy loss is measured, the correction also needs to assume a form of excitation energy division between projectile-like and target-like fragments.

The total evaporated mass was determined for a series of possible reaction products of the systems under study, as a function of excitation energy. Linear fits were performed to obtain an expression for the average mass evaporated as a function of the excitation energy. The evaporation calculations were done using the PACE code [GAV 80]. The spin of the particle, which is one of the inputs to this code, was calculated assuming the sticking limit [BEN 85]. Calculations at fixed spin values (1 and 15 hbar) showed that the average evaporated mass did not have a strong 
dependence on the spin. However, the evaporated mass shows greater dispersion for the higher spin. This effect is shown in Figure II.18. The calculated evaporated mass as a function of excitation energy is shown in Figure II.19 (a) assuming the sticking limit for ${ }^{35} \mathrm{Cl}$ on ${ }^{209} \mathrm{Bi}$. Because of the small spin dependence of the evaporated mass, calculations on the other two systems showed very similar plots. Ground state Q-values were plotted as a function of the atomic number for each of the systems and fit with a quadratic polynomial. The ground state $\mathrm{Q}$-value as a function of the atomic number is shown in Figure II.18 (b) for the case of ${ }^{35} \mathrm{Cl}$ on ${ }^{209} \mathrm{Bi}$.

The correction method was iterative. For each event, the step-by-step procedure can be summarized as follows:

1. Calculate a first estimate of $E_{\text {loss }}$ using the experimental $M 3$ and E3, assuming $M 4=M 1+M 2-M 3$.

2. Calculate the ground state $Q$-value $\left(\mathrm{Q}_{\mathrm{gg}}\right)$ from the projectile-like fragment Z.

3. Determine the total excitation energy as $E_{\text {loss }}-\mathbf{Q}_{\mathbf{g g}}$.

4. Assume a form of excitation energy division and calculate the excitation energy of the projectile-like fragment.

5. Calculate the mass evaporated ( $\mathrm{dM})$ using the excitation energy obtained in step 4, add it to M3 and recalculate M4.

6. Calculate the energy of the projectile-like fragment by multiplying the original energy by the ratio $(M 3+d M) / M 3$.

7. Recalculate $E_{\text {loss }}$ and find the difference from the last value obtained. Repeat steps 3 to 7 until the difference becomes smaller than $0.1 \mathrm{MeV}$ or the number of iterations becomes reaches 100 (abort event).

Distributions of atomic number as a function of neutron number were then determined for all the systems at different energy losses. The neutron number was 
Figure II.18

Mass evaporated as a function of the excitation energy for several possible projectile-like fragments of the reaction ${ }^{35} \mathrm{Cl}+{ }^{209} \mathrm{Bi}$ assuming two different spin values: (a) $1 \mathrm{hbar}$ and (b) $15 \mathrm{hbar}$. The equations for the straight lines shown in the plots are:
(a) $y=0.0818 x+0.0574$
(b) $y=0.0963 x-0.3502$ 


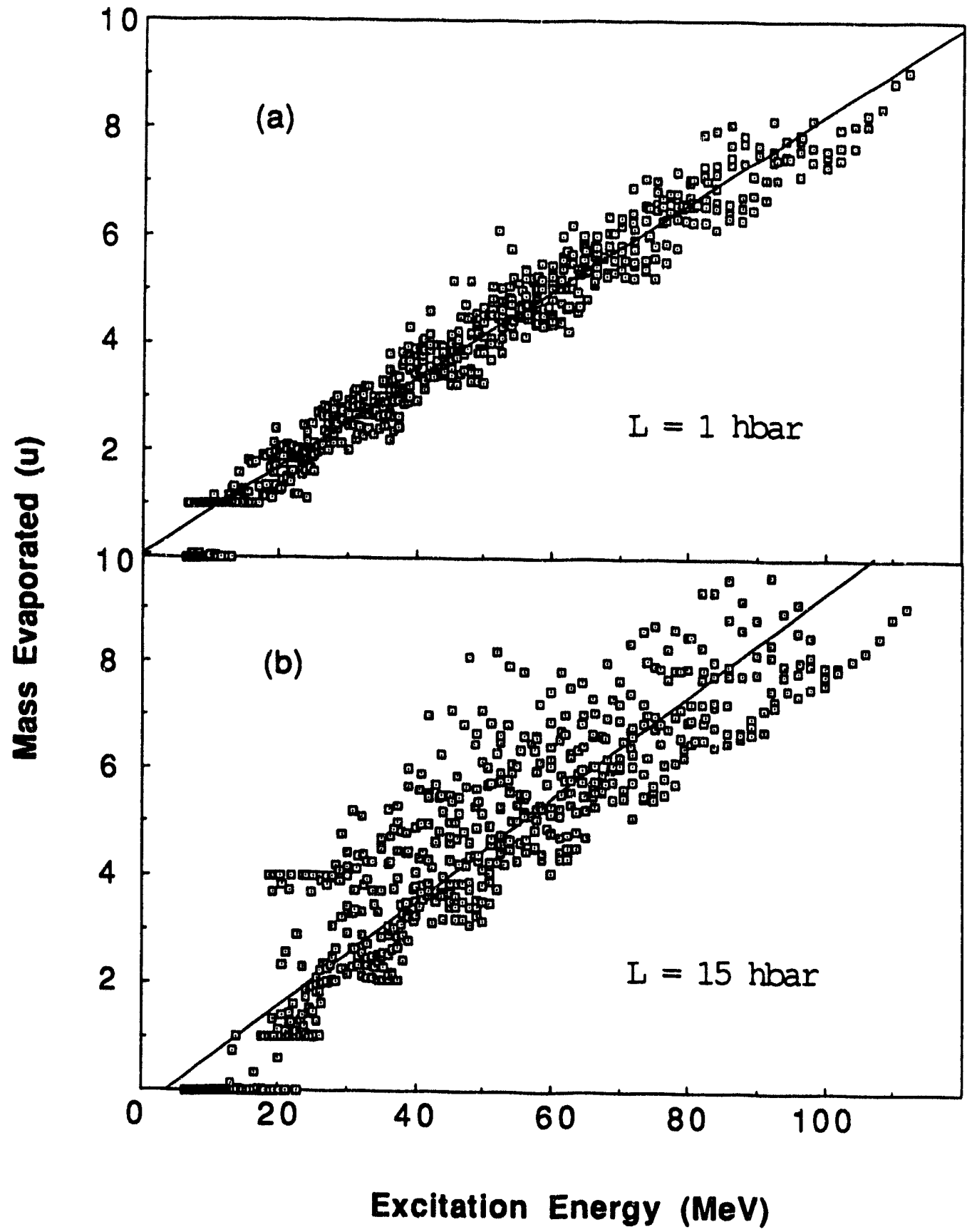


Figure II.19

(a) Mass evaporated for possible nuclei formed in the reaction ${ }^{35} \mathrm{Cl}+{ }^{209} \mathrm{Bi}$ as a function of excitation energy, calculating the spin using the sticking limit. (b) Ground state Q-value as a function of the atomic number of the projectilelike fragment in the reaction ${ }^{35} \mathrm{Cl}+{ }^{209} \mathrm{Bi}$. 

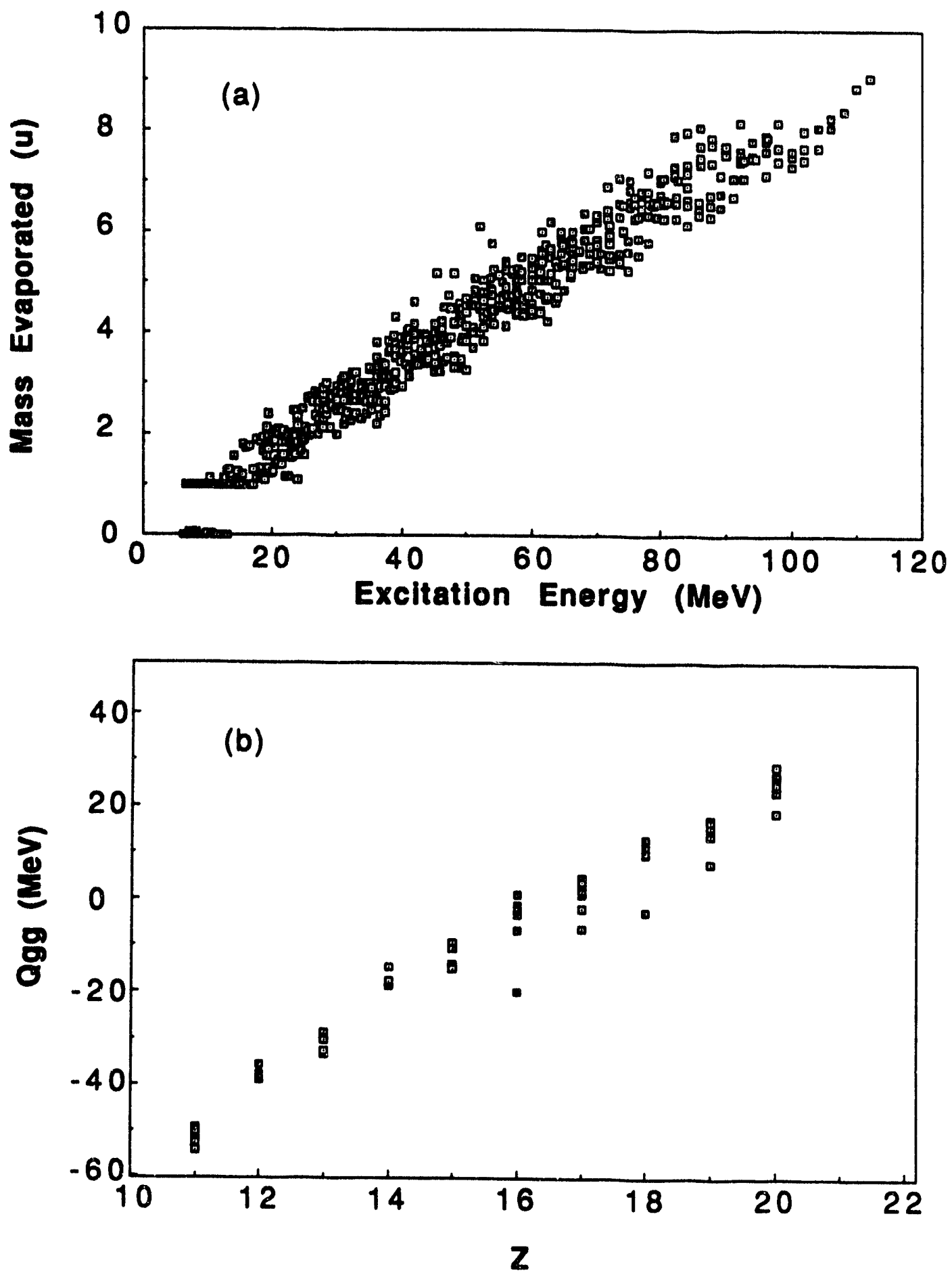
obtained directly by subtracting the charge from the mass; its resolution, can be roughly estimated as the square root of the addition of the squares of the mass and charge resolutions. Two cases were considered for the correction of the energy loss scale in the case of the $\mathrm{Bi}$ reactions: equal division of excitation energy between the reaction partners and division according to the mass of the products (thermal division). Only equal division was considered for the $\mathrm{Ca}$ target, since both projectile and target are practically identical in mass. Typical distributions of atomic number as a function of neutron number are shown in Figures II.20-22.

The $\mathrm{N}-\mathrm{Z}$ distributions resemble two-dimensional Gaussian functions that can be expressed by:

$$
P_{(N, Z)}=h \exp -\frac{1}{2\left(1-\rho^{2}\right)}\left[\frac{(N-<N>)^{2}}{\sigma_{N}^{2}}+\frac{(Z-<Z>)^{2}}{\sigma_{Z}^{2}}-\frac{2 \rho(N-<N>)(Z-<Z>)}{\sigma_{Z} \sigma_{N}}\right],
$$

where $\mathrm{P}$ represents the probability, $\mathrm{h}$ is a normalization factor, $<>$ represents the centroid, $\sigma^{2}$ the variance, and $\rho$ the correlation coefficient. For a Gaussian population, the first and second moments are good estimates of the centroid and variance, respectively [CRA 46]. The charge first and second moments are given by:

$$
\begin{aligned}
& \left\langle Z>=\frac{1}{n} \sum_{i=1}^{n} Z_{i}\right. \text {, and } \\
& \sigma_{Z^{2}}=\frac{1}{n-1} \sum_{i=1}^{n}\left(Z_{i^{-}-<Z}\right)^{2}
\end{aligned}
$$


respectively. The corresponding equations for mass or neutron number moments follow directly. The correlation coefficient is given by:

$$
\begin{aligned}
& r=\frac{\sigma_{N Z}}{\sigma_{Z} \sigma_{N}}, \text { where } \\
& \sigma_{N Z}=\frac{1}{n-1} \sum_{i=1}^{n}\left(Z_{i}-<Z>\right)\left(N_{i}-<N>\right) .
\end{aligned}
$$

All relative yieids were transformed to the center-of-mass system, and mass and charge distributicns characterized by their centroids, variances, and correlation coefficier.ts. Two approaches were taken to determine these parameters. One was a direct moment analysis of the data; the other was the application of a fitting algorithm that presupposed a Gaussian distribution [BRE 83a]. The results obtained using these two methods are discussed in Chapter $T \mathrm{~V}$. 
Figure II.20

Representative contour plots of the atomic number as a function of the neutron number for the reaction ${ }^{37} \mathrm{Cl}+{ }^{40} \mathrm{Ca}$ at $270 \mathrm{MeV}$, for $\mathrm{E}_{\text {loss }}=20,60,40$, and $80 \mathrm{MeV}$. 
Cl-37 on $\mathrm{Ca}-40$ at $270 \mathrm{MeV}$

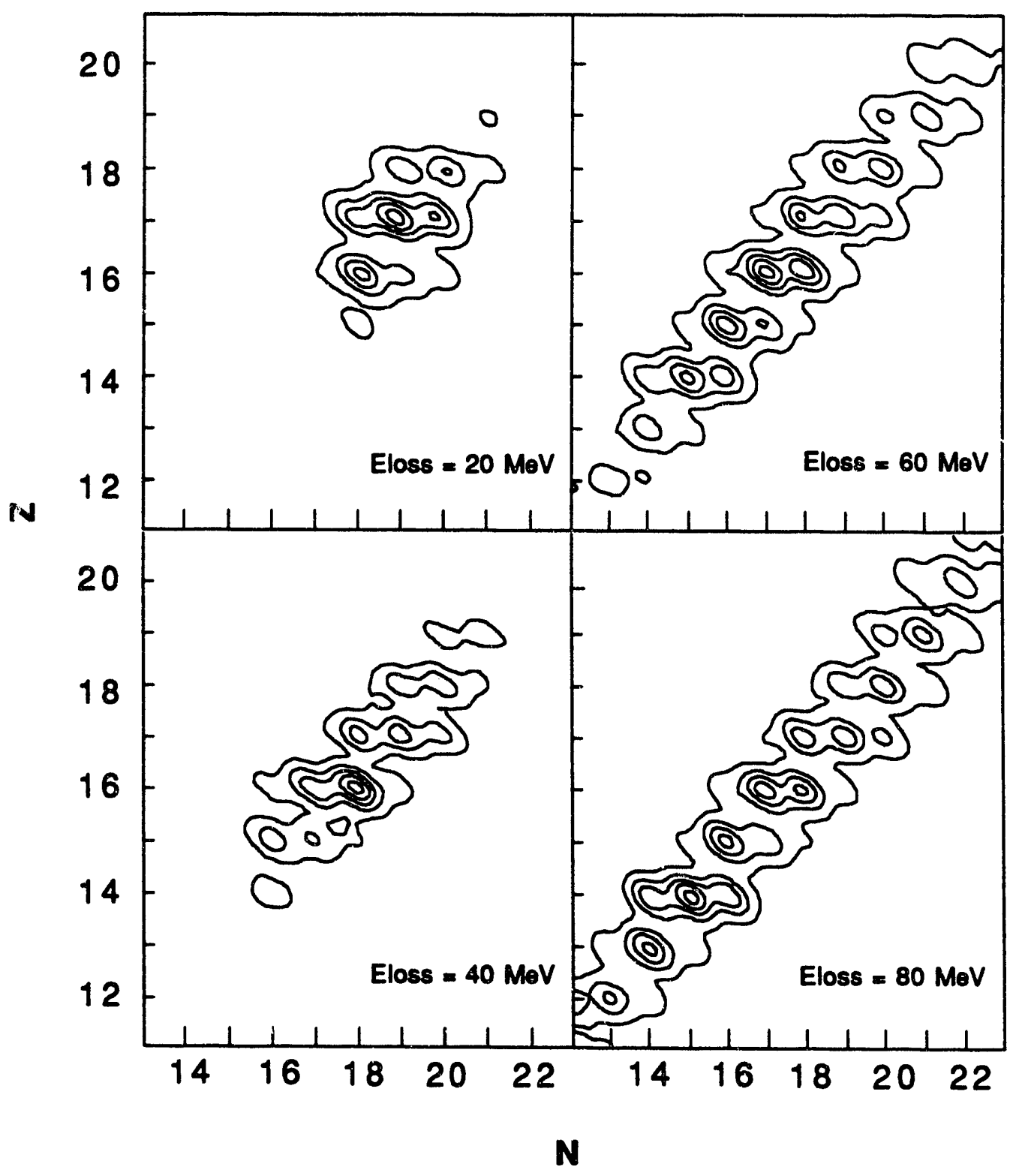


Figure II.21

Representative contour plots of the atomic number as a function of the neutron number for the reaction ${ }^{37} \mathrm{Cl}+{ }^{209} \mathrm{Bi}$ at $270 \mathrm{MeV}$, for $\mathrm{E}_{\text {loss }}=20,40,60$, and $80 \mathrm{MeV}$. 


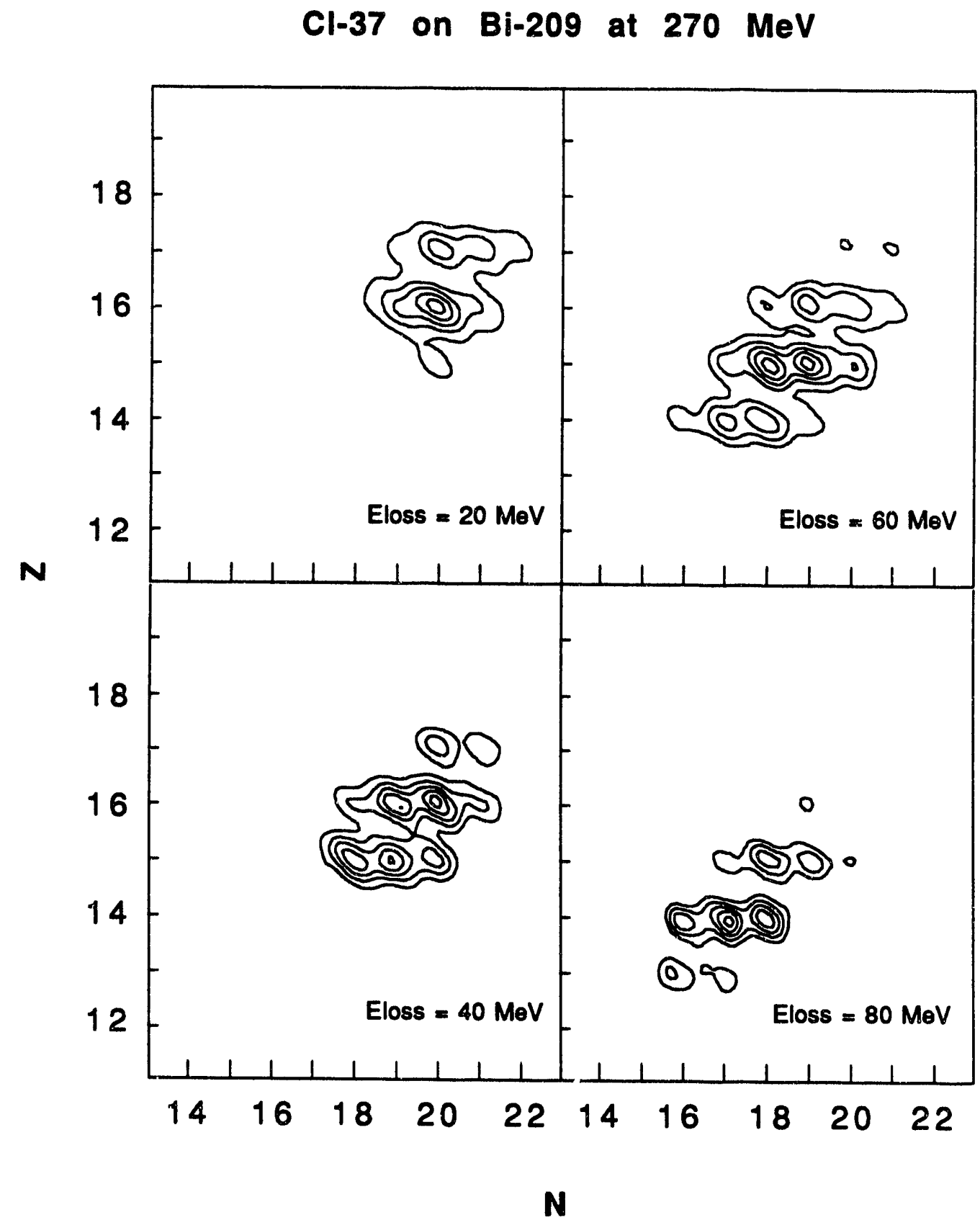


Figure II.22

Representative contour plots of the atomic number as a function of the neutron number for the reaction ${ }^{35} \mathrm{Cl}+{ }^{209} \mathrm{Bi}$ at $528 \mathrm{MeV}$, for $\mathrm{E}_{\mathrm{loss}}=20,60,110$, and $190 \mathrm{MeV}$. 
$\mathrm{Cl}-35$ on $\mathrm{Bi}-209$ at $528 \mathrm{MeV}$

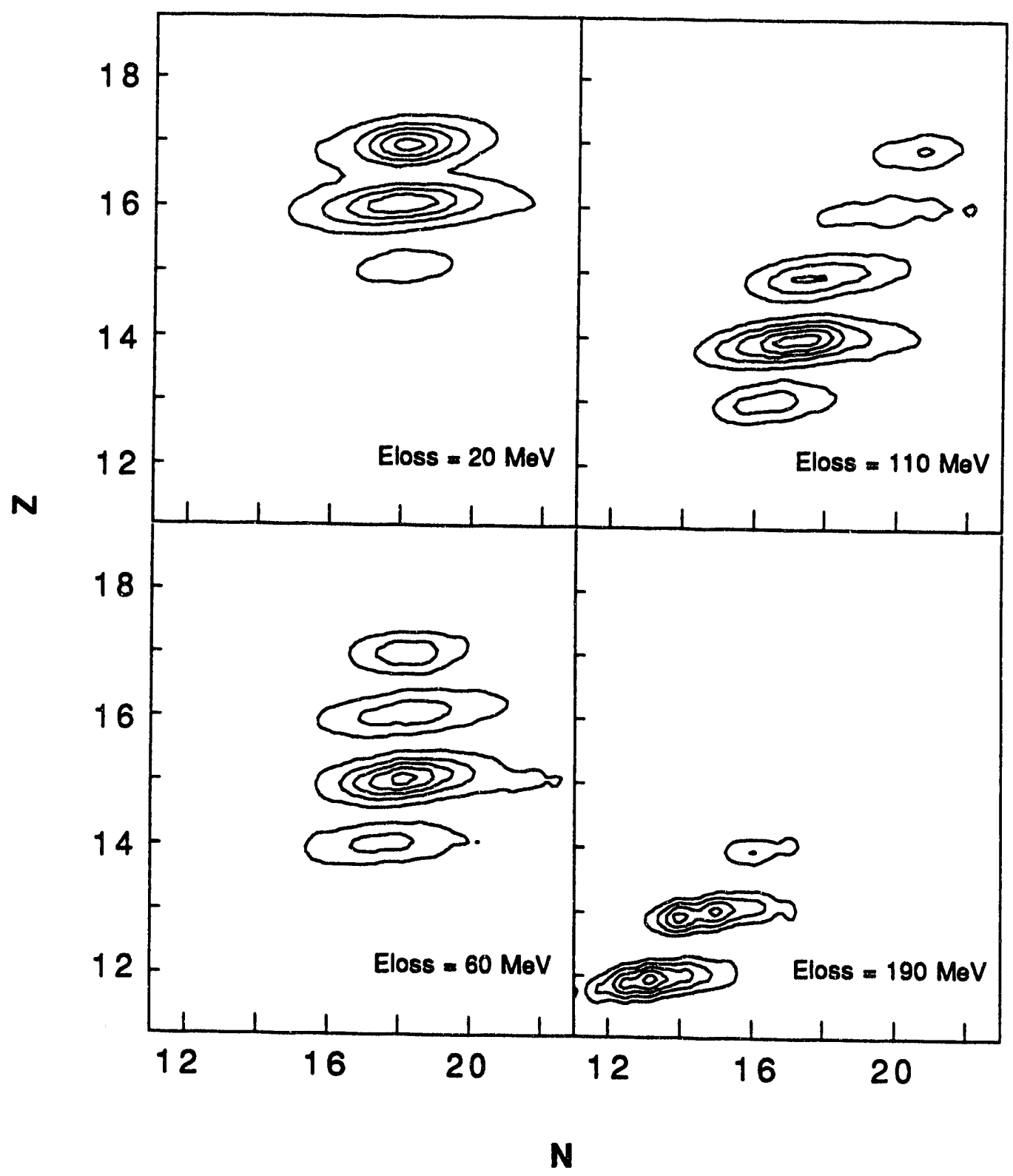




\section{CHAPTER III DECONVOLUTION}

The mass data from the Oak Ridge experiment has a resolution (FWHM)

greater than one mass unit, due to the lack of position information. In consequence, individual mass lines cannot be distinguished in the mass vs. energy plots and corrections for energy dependence of the mass parameterization become very difficult. Attempts were made to find mass centroids for different energy and charge gates by using Gaussian fits. Unfortunately, the position and number of centroids were very dependent on the initial guess chosen for the fitting algorithm. It was concluded that the only way to retrieve the mass information was by using some method of peak enhancement that would reveal the peaks present in the spectra.

Deconvolution methods are commonly applied in image restoration and optical spectroscopy, but their principles can easily be extended to other types of experimental data. A study was conducted to evaluate the feasibility of improving the resolution of mass spectra. The primary reference used in the development of this chapter is Peter A. Jansson's book on deconvolution [JAN 84].

\section{III.A BACKGROUND}

When an observable is measured as a function of one or more variables, the resulting spectrum comprises both the physical event and the distortions introduced by the measuring instrument. For example, the finite resolution of a monochromator will cause a measurement at a certain wavelength to have contributions from neighboring ones. These distortions can be described as a mathematical convolution if they add up linearly. For a continuous variable $\mathrm{x}$ the result of measuring an observable at a certain point $b$ 
can be described by the convolution integral

$$
I(b)=\int_{-\infty}^{\infty} S(b-x) O(x) d x
$$

where $I$ is the result of the measurement, also known as the image, $S$ is the spread function of the instrument, and $O$ is the object being measured. The spread function of an ideal instrument is Dirac's $\delta$ function, in which case the image and the object will be identical. It is the purpose of the deconvolution process to restore the object given the image and the spread function.

To manipulate digitized data, it is convenient to express the convolution process in a matrix formulation:

$$
\mathbf{I}=\mathbf{S} \mathbf{O} \text {. }
$$

The image $I$ and the object $\mathbf{O}$ are now represented by column vectors, and the spread function $\mathbf{S}$ is represented by a matrix. It would seem that the deconvolution problem is reduced to finding the inverse of the spread matrix:

$$
\mathbf{O}=\mathbf{S}^{-1} \mathbf{I}
$$

Unfortunately, this deterministic approach presents some practical problems. Each consecutive row of $\mathbf{S}$ acts on a neighboring point of the spectrum, and therefore the matrix elements between rows are very similar. This similarity does not provide a strong set of independent equations and the matrix could be singular, that is without an inverse. Even if the inverse matrix can be found, it may be ill-conditioned, which 
means that small perturbations in the image can produce large spurious peaks in the calculated object [AND 77].

The presence of noise in the data is another important aspect to consider in any deconvolution procedure. The effect of the addition of noise is to eliminate any unique association between object and image [AND 77]. Therefore, there will not be a unique solution and some criteria has to be developed to select an adequate one. Most deconvolution techniques will yield good results when tested on computer generated noise-free data. However, with actual experimental data, high frequency components due to noise can be greatly enhanced. It becomes necessary to improve the signal to noise ratio of the data for the deconvolution to be successful. For example, this can be accomplished by smoothing the data.

Single or multiple polynomial filters are commonly used to smooth digitized spectra. Smoothing or filtering refers to a process of convolution of the spectrum with a weighting function. The spectrum can be convolved one or more times with a particular weighting function, and the process is called single or multiple smoothing, respectively. Convolution with a filter will enhance the signal to noise ratio to the expense of worsening the resolution. This effect can be accounted for by considering the filter as part of the spread function. Therefore, the final spread function is the convolution of the spread function of the measuring system and the filter used to smooth the data. It should be noted that information beyond the cutoff frequency of the filter is lost. A discussion on the effects of smoothing and recommended procedures can be found in a review paper by $P$. Willson and T. Edwards [WIL 76].

Iterative methods of deconvolution have the advantage of allowing more control of the solution as it :volves. A traditional linear method developed by Van Cittert [VAN 31] can be represented in its discrete form by 


$$
\mathbf{O}^{\mathbf{k}+1}=\mathbf{O}^{\mathbf{k}}+\left[\mathbf{I}-\mathbf{S} \mathbf{O}^{\mathbf{k}}\right]
$$

where the superscript $\mathbf{k}$ indicates the iteration cycle. The image is generally taken as the first estimate of the object and the iteration progresses from there. This method is classified as linear because each element of the object can be expressed as a linear combination of the elements of the image. A parameter that multiplies the correction term can be introduced to ensure proper convergence. It should be stressed that convergence alone does not guarantee a physically correct solution. Traditional linear deconvolution methods have been used with moderate success in the past and are the basis of some modern constrained nonlinear methods [JAN 84]. The deconvolution method studied here belongs to the second category and is based on Jansson's algorithm [JAN 70].

Jansson found that the introduction of physical constraints greatly improved the results of the deconvolution process. His algorithm is characterized by the introduction of a relaxation function $R$ that depends on the object estimate:

$$
\mathbf{O}^{k+1}(i)=\mathbf{O}^{k}(i)+R\left(O^{k}(i)\right)\left[I-S O^{k}\right](i),
$$

where $\mathrm{i}$ indicates the vector component index. The relaxation function allows control of the correction term of the iteration to mold the solution to the physical bounds. The simplest form of such a function is a constant value in the physical region and zero elsewhere. Clipping of the nonphysical solution as described normally produces results inferior to those obtained using a relaxation function that allows the correction to evolve gradually as the iteration proceeds.

Finally, there is no strict recipe as to how to deconvolve a particular spectrum. As mentioned before, the ill-conditioned nature of the problem and the presence of 
noise do not guarantee a unique solution. Some optimization criteria, in conjunction with judgement based on previous knowledge of the object, should be used to determine the best estimate. Any method should be tested using known spectra before drawing conclusions on unknown ones.

\section{III.B PROCEDURE}

The application of Jansson's algorithm is straightforward and does not require complex computer programming. Once equation III. 5 is established for $k=0$, the iteration proceeds until some convergence criteria are met. However, the method requires addressing the problem of noise, selection of a proper relaxation function, and knowledge of the spread function.

To evaluate the method, a known object is needed. A two-dimensional mass vs. energy spectrum from a previous experiment which shows well resolved mass lines with a FWHM of 0.55 mass units was chosen for testing [PLA 88]. This spectrum had been corrected for energy dependence and an overall projection on the mass axis can be found in Figure III.1 (a). The sizes of the energy and mass bins are $2 \mathrm{MeV}$ and 0.05 mass units, respectively. The next step was to introduce a distortion in the original spectrum that would degrade the mass resolution randomly to simulate an experimental spread function. This was accomplished by convolving the mass on each energy bin with a randomized Gaussian function with a FWHM of 0.707 mass units. The resulting distorted spectrum has a FWHM of 0.90 mass units. The projection of the distorted spectrum on the mass axis, shown in Figure III.1 (b), was used to test the deconvolution method. The display and manipulation of spectra were done using the same software (LISA) described in Chapter II. 
As mentioned earlier, it is important to smooth the data prior to deconvolution. Willson et al. [WIL 76] suggest the use of multiple quartic filters. Multismoothing with one or a combination of filters is also the procedure followed in several of the examples quoted in Jansson's book. The filter replaces a point in the spectrum by a linear combination of the point in question and the points around it. The number of points considered determines the filter length. The coefficients for the linear combination are a function of the filter length and the degree of the polynomial fit. The procedure chosen here was multismoothing with a quartic filter using the filter length as the test parameter. The coefficients for the filter weighting function were obtained from Savitzky and Golay's tables after being corrected by Steinier et al. [SAV 64, STE 72].

The relaxation function has to modulate the correction term in accordance with the physical limits. In principle, any function that satisfies the boundary conditions of the problem could be used. The only physical constraint utilized in this case is that the mass had to be positive. After some preliminary trials, the function that seemed to yield the best results was

$$
R\left(O^{k}(i)\right)=w_{r} O^{k}(i),
$$

where $w$ and $r$ are constant factors. The constant $r$ is equal to the inverse of the highest intensity in the spectrum and the spread function amplitude, 'while $w$ is a variable weight factor that affects the speed of convergence and the final solution.

The spread function for the distorted spectrum is a normalized Gaussian with a FWHM of 0.707 mass units. In this case the spread function is known because it was purposely generated. However, in an experimental situation, the spread function has to be found. In some cases, it can be determined experimentally; in others, an 
educated guess is the only approach. It seems reasonable to assume a Gaussian function for the spread introduced by a measuring instrument, but there could be other contributions to the line width and they may not be necessarily Gaussian. A total restoration of a spectral line would require knowledge of all the different contributions to the line width. In the case of the Oak Ridge data, some partial restoration was expected by using a Gaussian function that would make evident the mass centroids. For this reason, the effect of changing the FWHM of the spread function on the deconvolved spectra was investigated.

After some trials, the initial conditions for testing were established. The smoothing was done by convolving the distorted spectrum three times with a 25-point quartic polynomial. The weight factor $w$ was set to 0.05 , and the FWHM of the spread function was set to 0.707 mass units. The number of iterations was arbitrarily fixed at 400 . The deconvolved spectrum obtained with these parameters is shown in Figure III.1 (c).

The use of a chi-squared test [BEV 69] served as a guide to optimize the different parameters. The chi-squared was calculated from the smoothed image and the deconvolved final spectrum. The smoothed image $\mathbf{Z}$ refers to the spectrum to be deconvolved after being filtered with the 25-point quartic polynomial. The deconvolved spectrum is then reconvolved with the spread function to produce a spectrum $\mathbf{R}$ which should be identical to the smoothed image. The chi-squared is computed by adding the squares of the differences between spectrum $\mathbf{R}$ and the smoothed image $\mathbf{Z}$ for each mass bin $i$, according to:

$$
X^{2}=\sum_{i=1}^{n} \frac{(R(i)-Z(i))^{2}}{Z(i)} \quad \text { for } Z(i) \neq 0
$$




\section{Figure III.1}

(a) Original spectrum. (b) Spectrum shown in (a) after being distorted with a random Gaussian with FWHM of 0.707 mass units. (c) The result of deconvolving the spectrum shown in (b) with $w=0.05$, number of iterations $=400$, smoothed 3 times with a 25-point quartic filter, and FWHM of the spread function $=0.707$ mass units. 
Test Spectra

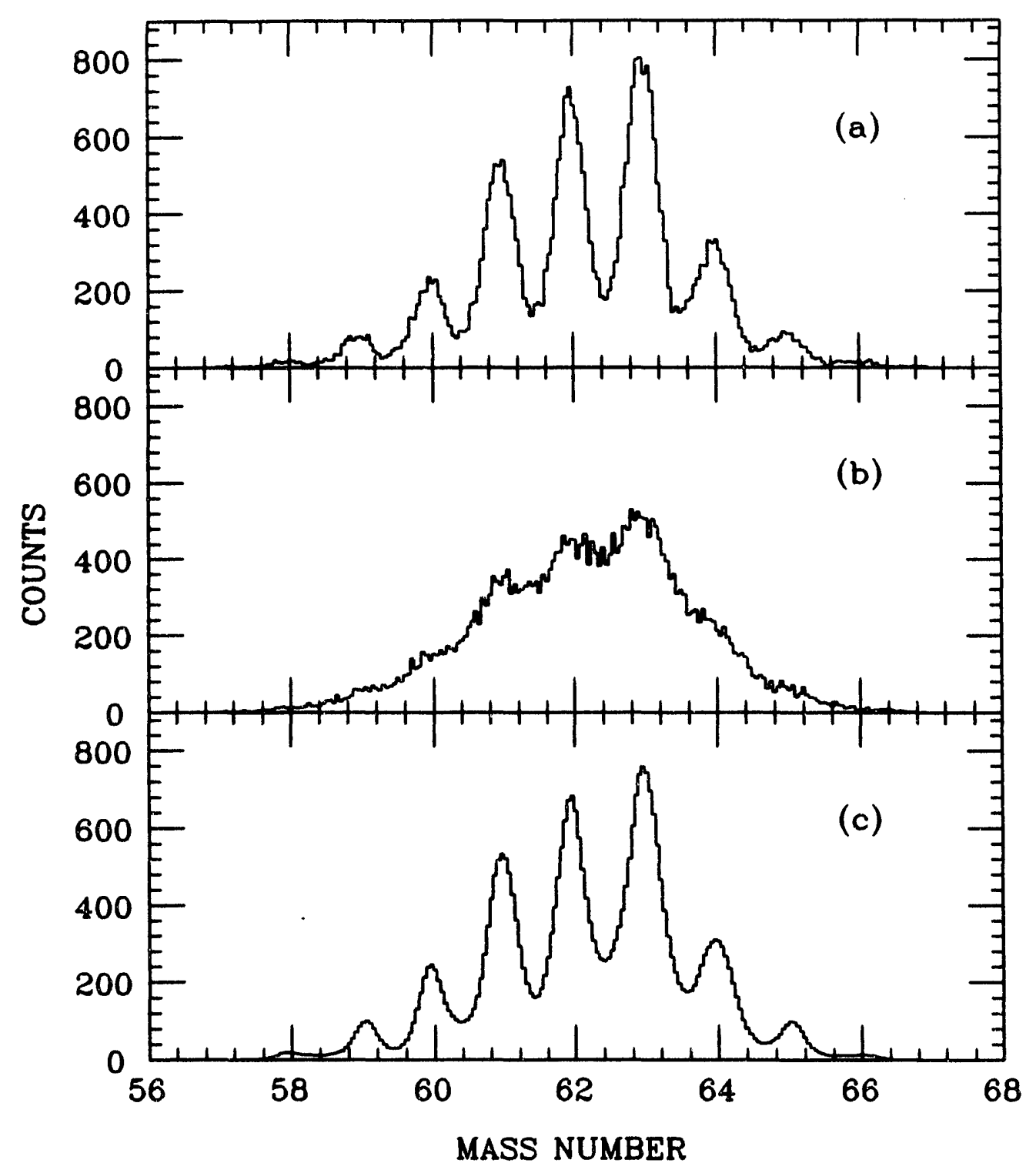


The minimum chi-squared should indicate the best parameter choice, but because of the nature of the problem the best solution is not necessarily the physically correct one. The previous knowledge of the system and the physical constraints become important in selecting the correct solution. Convergence of the iteration process was checked by monitoring the absolute value of the difference between the last two consecutive spectra after each iteration.

\section{III.C RESULTS}

The results that follow correspond to the initial conditions stated in Section III.B as applied to the distorted spectrum shown in Figure III.1 (b) (these conditions are summarized in Table III.1).

The variable that most affected the deconvolution results was the smoothing. The filter length was changed from 11 to $15,19,21,23$, and 25 points. The number of convolutions with the data was kept at three in all cases. The chi-squared was recorded and plotted in Figure III.2 as a function of the filter length. Up to the 19point filter, the deconvolved spectra show splitting of the mass peaks into two components; from the 21-point filter on, the number of peaks and shape of the spectra reproduce the object very well, as shown in Figure III.3. Observations of the deconvolved spectra indicate that the 25-point filter gives the best results, in agreement with the chi-squared values.

The chi-squared seems to decrease as the weight factor increases, as can be seen in Figure III.4. However, for weight factors greater than 0.3, the iteration diverges and chi-squared increases sharply. There do not seem to be significant changes in the deconvolved spectra for weight factors between 0.005 and 0.1 , and they all reproduce the object very well. After a value of 0.1 , the shape of the 


\section{Figure III.2}

Chi-squared as a function of the filter length. 


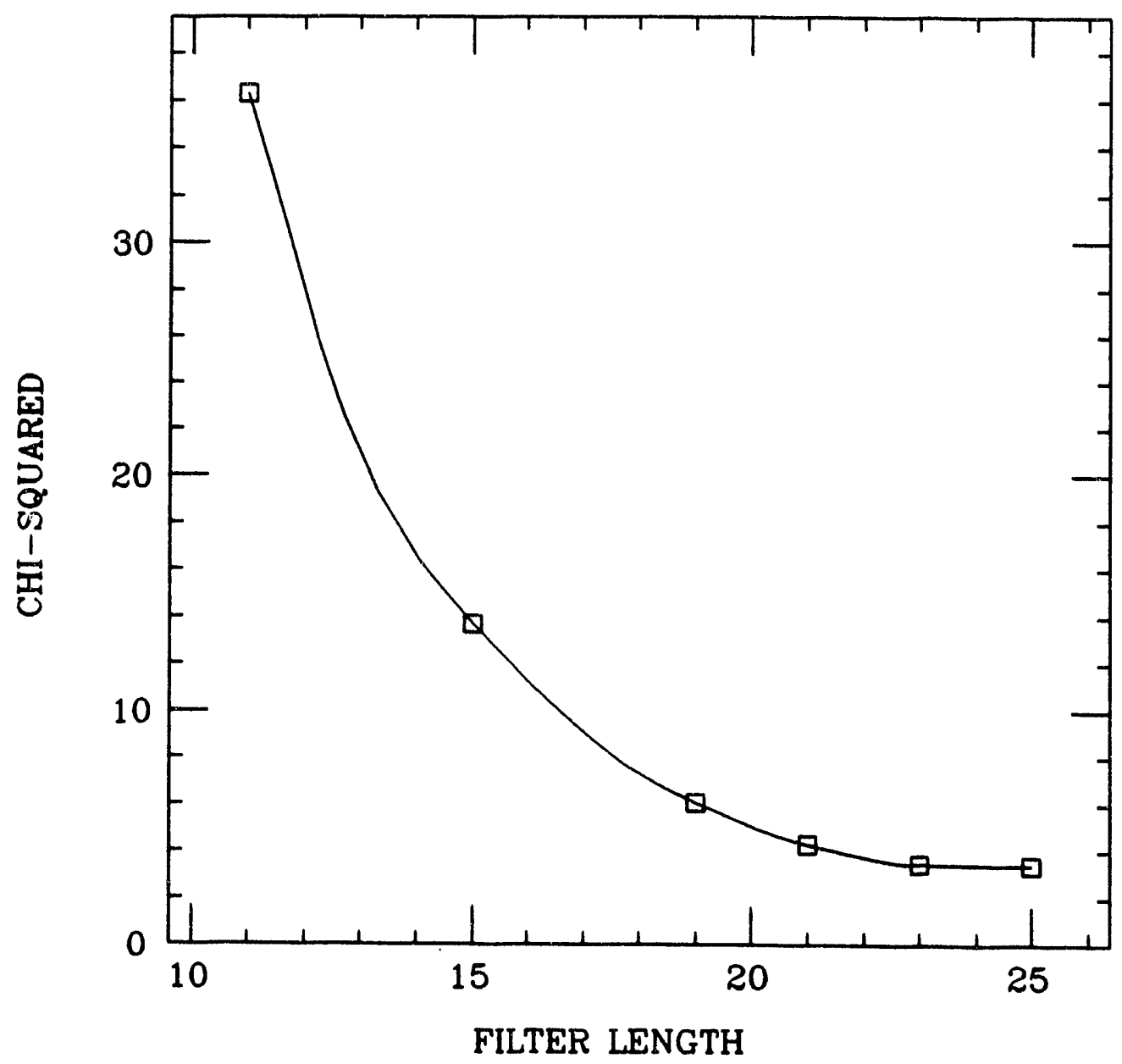


Figure III.3

Deconvolved spectra after smoothing 3 times with filter lengths of: (a) 23, (b) 21 , (c) 19, and (d) 15 points. 
Smoothing

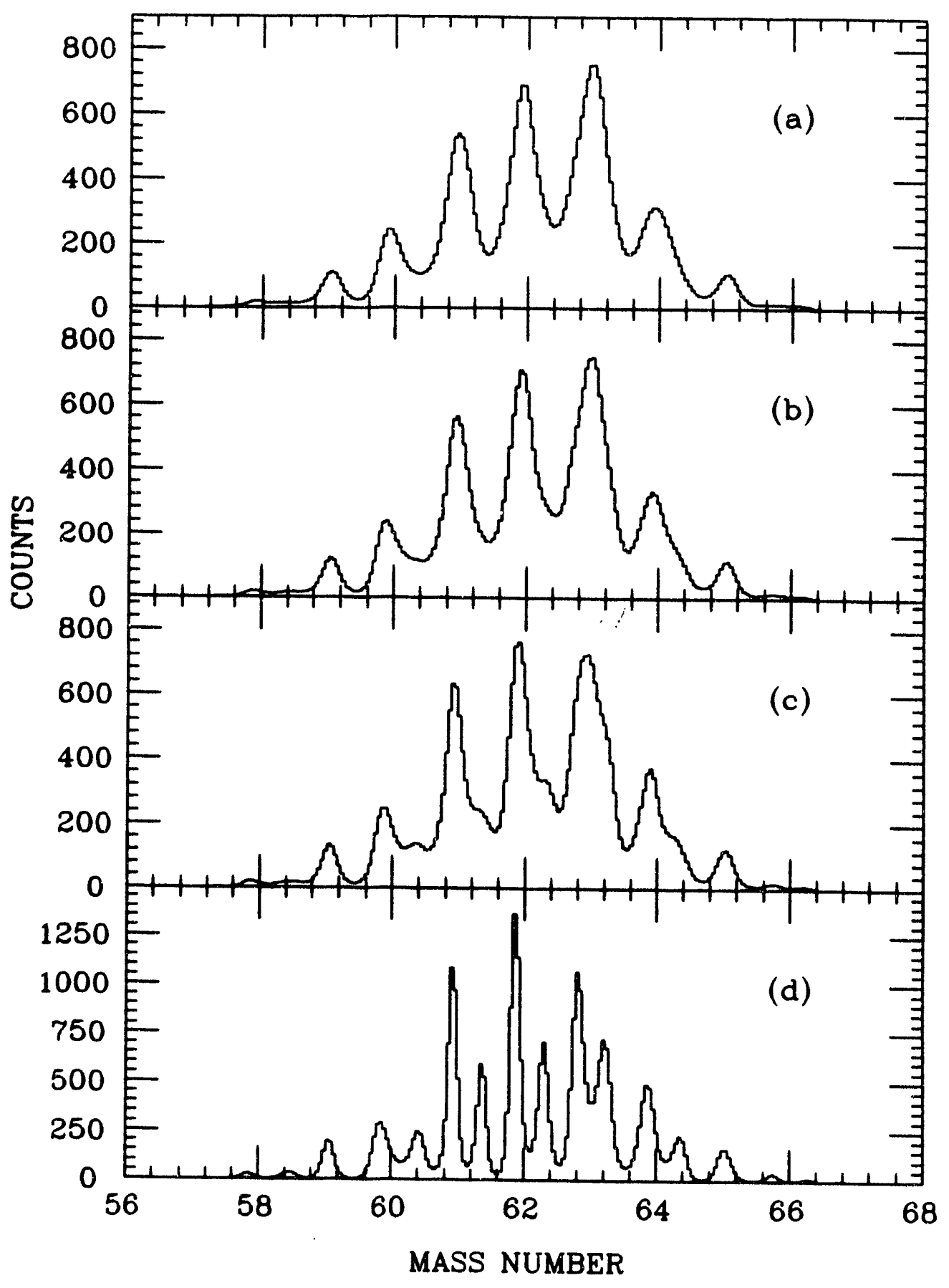


Figure III.4

Chi-squared as a function of the weight factor w.

88. 


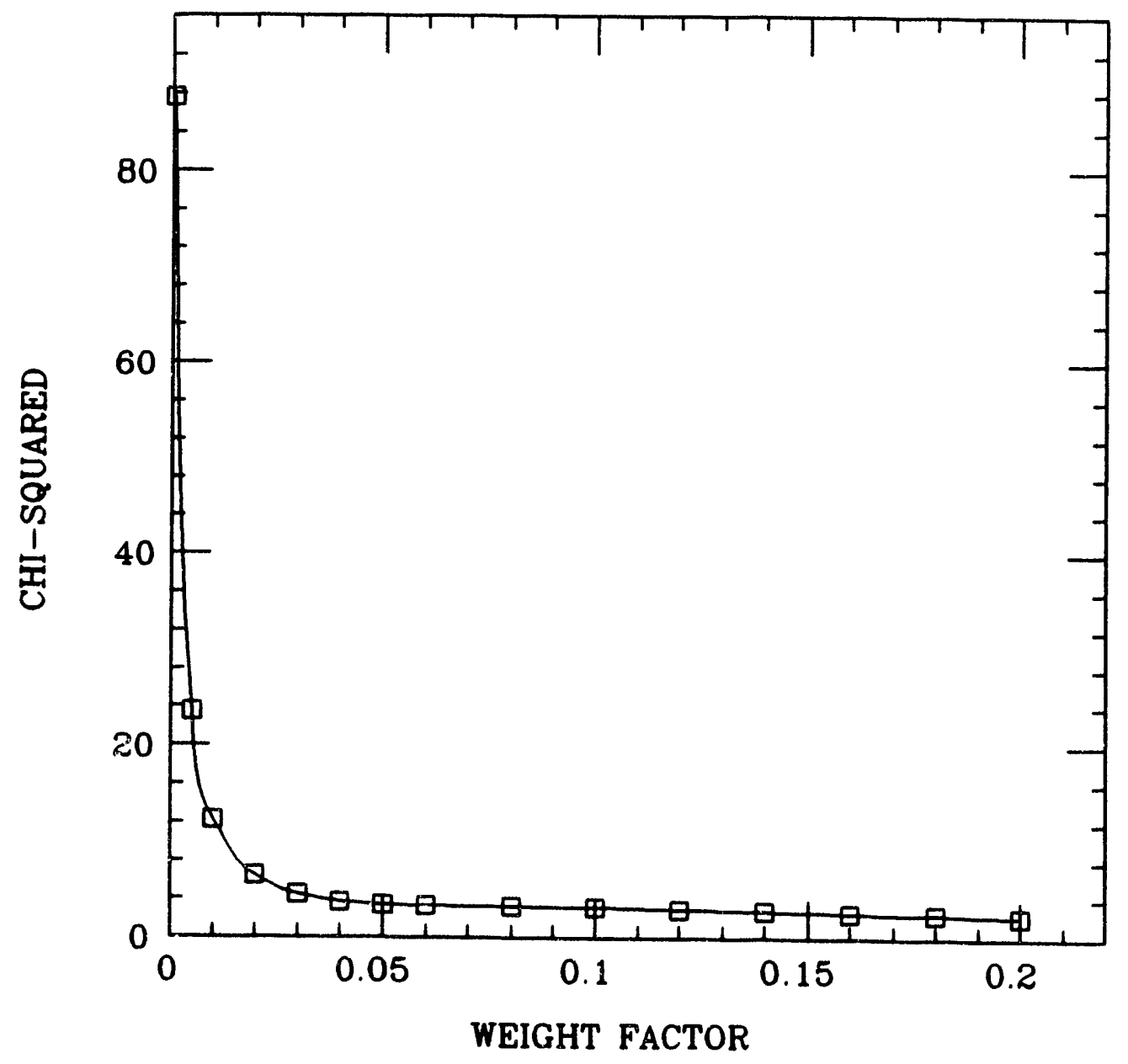


spectrum becomes irregular, although the chi-squared keeps decreasing slightly, which could be due to convergence to an unphysical solution.

The effect of changing the FWHM of the Gaussian spread function was studied because the mass resolution for the Oak Ridge data is not known. When two Gaussian functions are convolved, the result is a Gaussian with variance equal to the sum of the variances of the individual functions. A plot of the square of the FWHM of the deconvolved spectra versus the square of the FWHM of the spread function used is shown in Figure III.5 (a). There is a clear linear dependence until the FWHM of the spread function exceeds that of the spectrum that is being deconvolved. The chi-squared increases slowly with the FWHM of the spread function until this value exceeds that of the distorted spectrum and then a sharp increase occurs, as shown in Figure III.5 (b). Fortunately, modifying the FWHM of the spread function shows practically no effect on the position of the mass centroids, as seen in Figure III.6.

The number of iterations was set to a large number (400). However, less than 100 iterations were actually necessary to ensure proper convergence. It was also observed that the area of the peaks is quite well conserved, except when extreme parameter values were used. For the purpose of this study, the most important result was the relative insensitivity of the position of the mass centroids to changes in the algorithm parameters.

A comparison of the mass centroids and peak areas between the original and deconvolved spectra is given in Table III.1. These values were obtained using Gaussian fits to the original and resultant deconvolved spectra. 
Figure III.5

(a) Square of the FWHM of the deconvolved spectra as a function of the square of the FWHM of the spread function. (b) Chi-squared as a function of the FWHM of the spread function. 

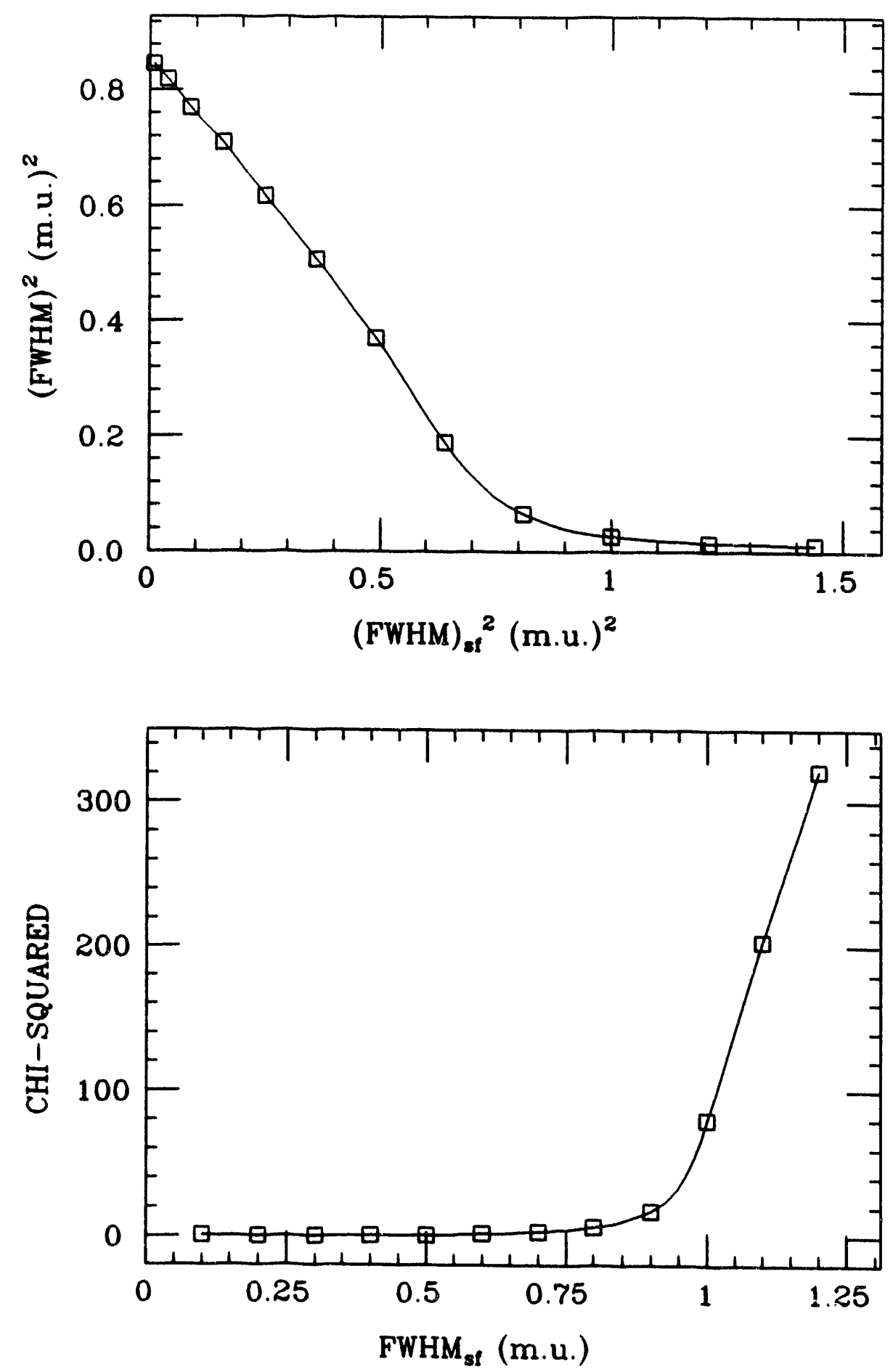
Figure III.6

Deconvolved spectra as a function of the FWHM of the spread function: (a) 1.00 , (b) 0.80 , (c) 0.60 , and (d) 0.40 mass units. 
FWHM of Spread Function

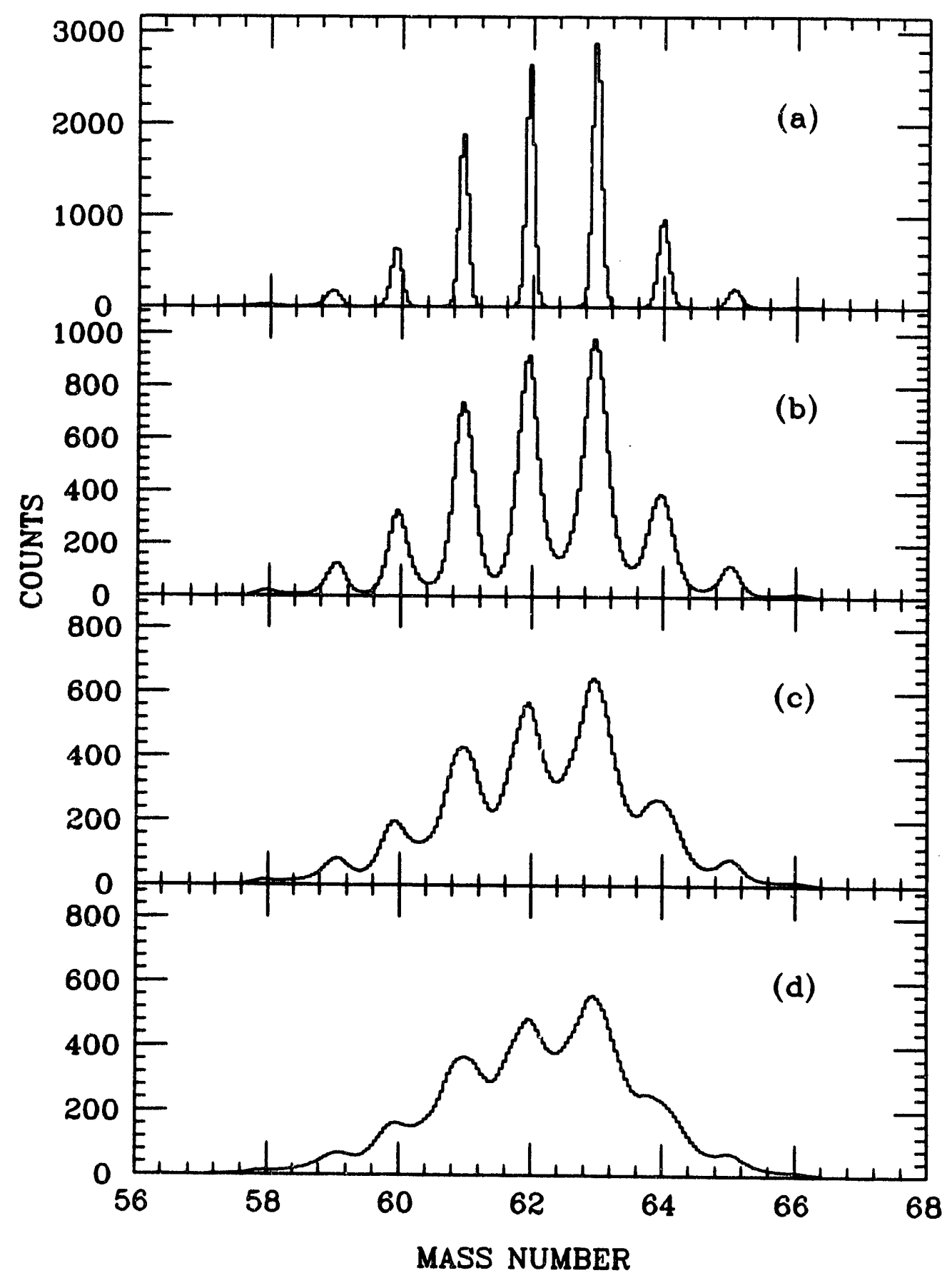


Table III.1 Comparison of Peak Centroids and Areas between the Original and Deconvolved Spectra*.

\begin{tabular}{ccccc}
\hline Mass Number & $\begin{array}{c}\text { Original } \\
\text { Centroid }\end{array}$ & $\begin{array}{c}\text { Deconvolved } \\
\text { Centroid }\end{array}$ & Original Area & $\begin{array}{c}\text { Deconvolved } \\
\text { Area }\end{array}$ \\
\hline 59 & 58.989 & 59.034 & 981 & 1105 \\
& \pm 0.058 & \pm 0.079 & \pm 140 & \pm 186 \\
\hline 60 & 59.997 & 59.981 & 2628 & 2804 \\
& \pm 0.013 & \pm 0.019 & \pm 85 & \pm 116 \\
\hline 61 & 60.985 & 60.979 & 6335 & 6460 \\
& \pm 0.003 & \pm 0.005 & \pm 59 & \pm 81 \\
\hline 62 & 61.989 & 61.968 & 8253 & 8234 \\
& \pm 0.002 & \pm 0.003 & \pm 55 & \pm 75 \\
\hline 63 & 62.989 & 62.978 & 9660 & 9560 \\
& \pm 0.002 & \pm 0.003 & \pm 55 & \pm 74 \\
\hline 64 & 63.981 & 63.961 & 3959 & 4067 \\
& \pm 0.007 & \pm 0.009 & \pm 70 & \pm 97 \\
\hline 65 & 64.978 & 65.009 & 1075 & 1170 \\
& \pm 0.048 & \pm 0.068 & \pm 134 & \pm 180 \\
\hline
\end{tabular}

$*$ Deconvolved with the following parameters: $\mathrm{w}=0.05, \mathrm{FWHM}=0.707$ mass units, 25 -point quartic polynomial filter ( 3 times), and 400 iterations.

\section{III.D APPLICATION TO OTHER MASS SPECTRA}

The purpose of this study is to correct the Oak Ridge mass data for energy dependence. This requires gating the mass spectra in energy intervals, finding the mass centroids (deconvolution), and obtaining the functional correction. As a consequence of the energy gates, the statistics can get very poor. Deconvolution is very sensitive to the signal to noise ratio of the data, which gets worse when making energy gates. To evaluate the effect of low statistics, the deconvolution procedure 
was tested on different energy gates of the sample mass spectrum used in Section III.C.

Attempts made using the set of parameters derived in Section III.C resulted in very poor restorations. In principle, it should not be expected of those parameters to be adequate for other spectra. It was apparent that the immediate problem was how to improve the signal to noise ratio. Instead of using a longer quartic polynomial, it was decided to convolve the spectra more times using the 25-point filter. The number of convolutions started at 3 and increased by one until the chi-squared (eq. III.7) did not change by more than $1 \%$. After this parameter was set, the weight factor was treated in a similar manner: starting at 0.05 and increasing it by multiplying by 1.25 until the chi-squared did not change by more than $5 \%$. The number of iterations was set to 150. This algorithm was applied to three different energy gates. The original, distorted, and deconvolved spectra for each one of the three gates are shown in Figures III.7, III.8, and III.9. A visual inspection indicates that the restorations are in good agreement with the original.

The effect of the FWHM of the spread function was tested by changing it from 0.707 to 0.5 and 0.9 mass units; the centroids of the spectra corresponding to each energy gate were not affected, as concluded in Section III.C. Gaussian fits were performed on the original and deconvolved spectra of Figure III.8 to make a quantitative comparison. The results are summarized in Table III.2.

The next step was to use the algorithm on the Oak Ridge data. Deconvolving the Oak Ridge data was not as straightforward as in the test case. First, the resolution was greater than 1.0 mass units, which combined with the energy smear of the elastic peak discussed in Chapter II, did away with any clear indication of a peak centroid, even for the high yield peaks. Second, the energy detector was made up of four independent elements, which could cause the mass to have discontinuities when 
Figure III.7

Mass spectra energy gated at $460 \mathrm{MeV}$ of laboratory energy with a $2 \mathrm{MeV}$ energy bin: (a) original, (b) distorted, and (c) deconvolved. 


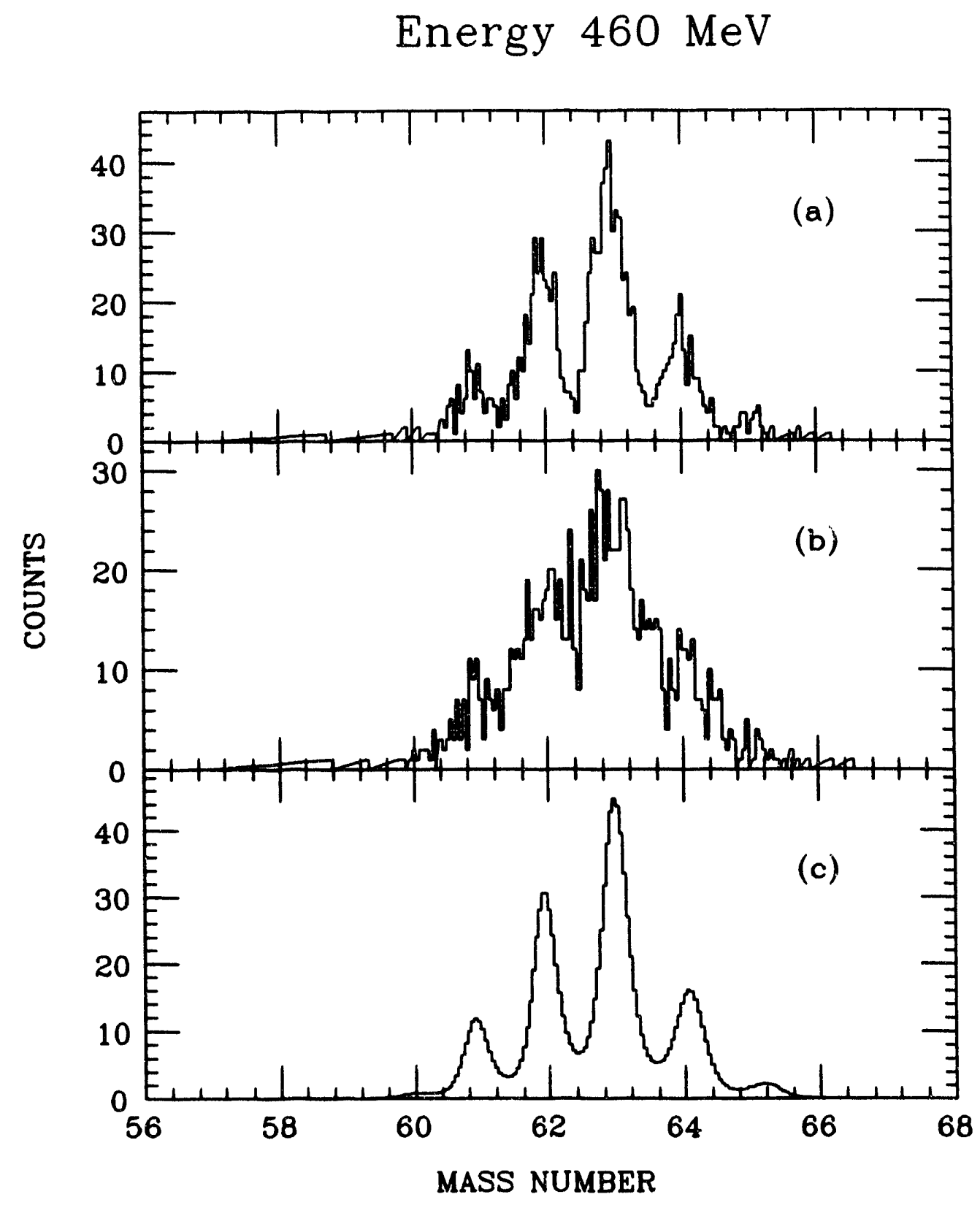




\section{Figure III.8}

Mass spectra energy gated at $440 \mathrm{MeV}$ of laboratory energy with a $2 \mathrm{MeV}$ energy bin: (a) original, (b) distorted, and (c) deconvolved. 


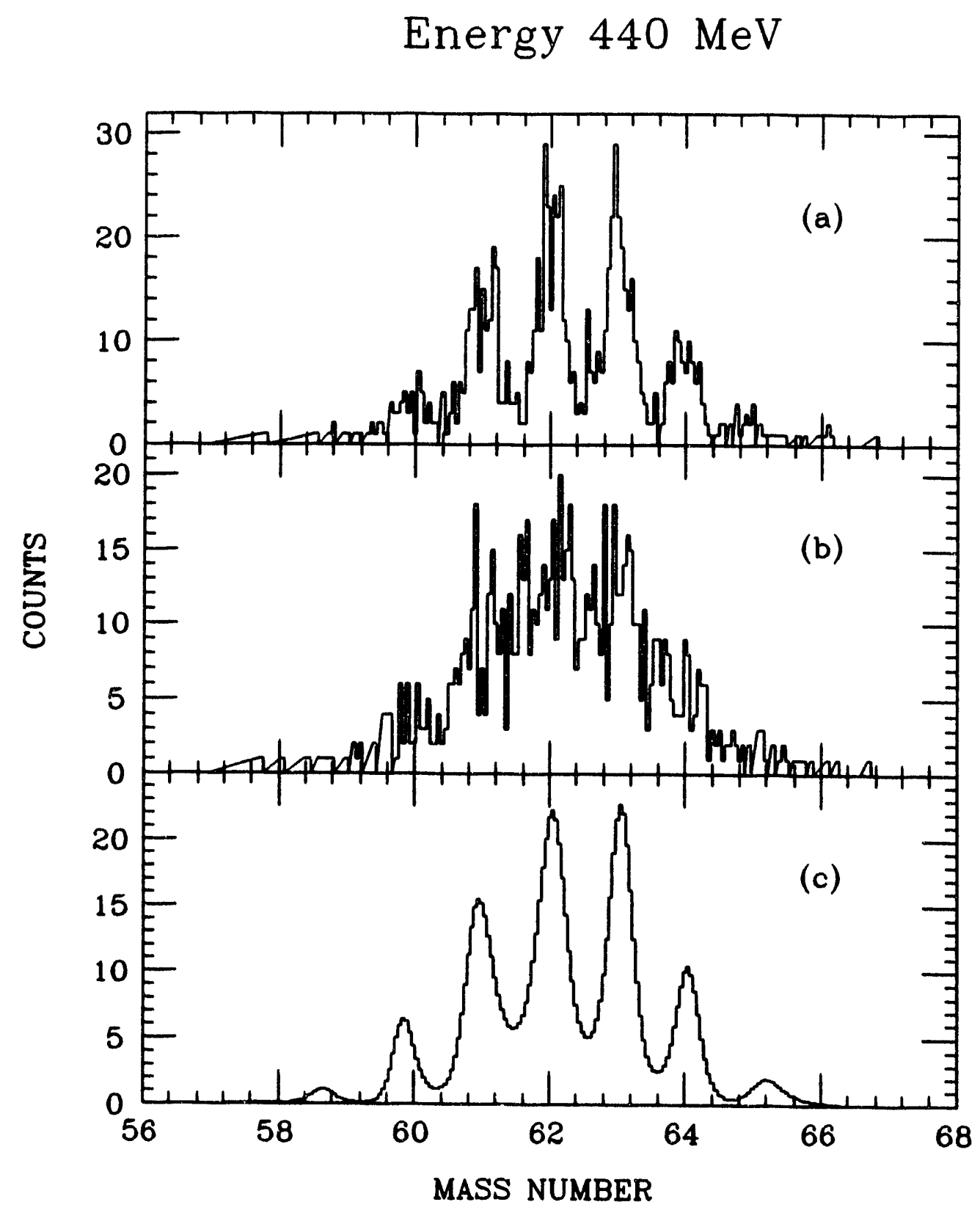


Figure III.9

Mass spectra energy gated at $420 \mathrm{MeV}$ of laboratory energy with a $2 \mathrm{MeV}$ energy bin: (a) original, (b) distorted, and (c) deconvolved. 


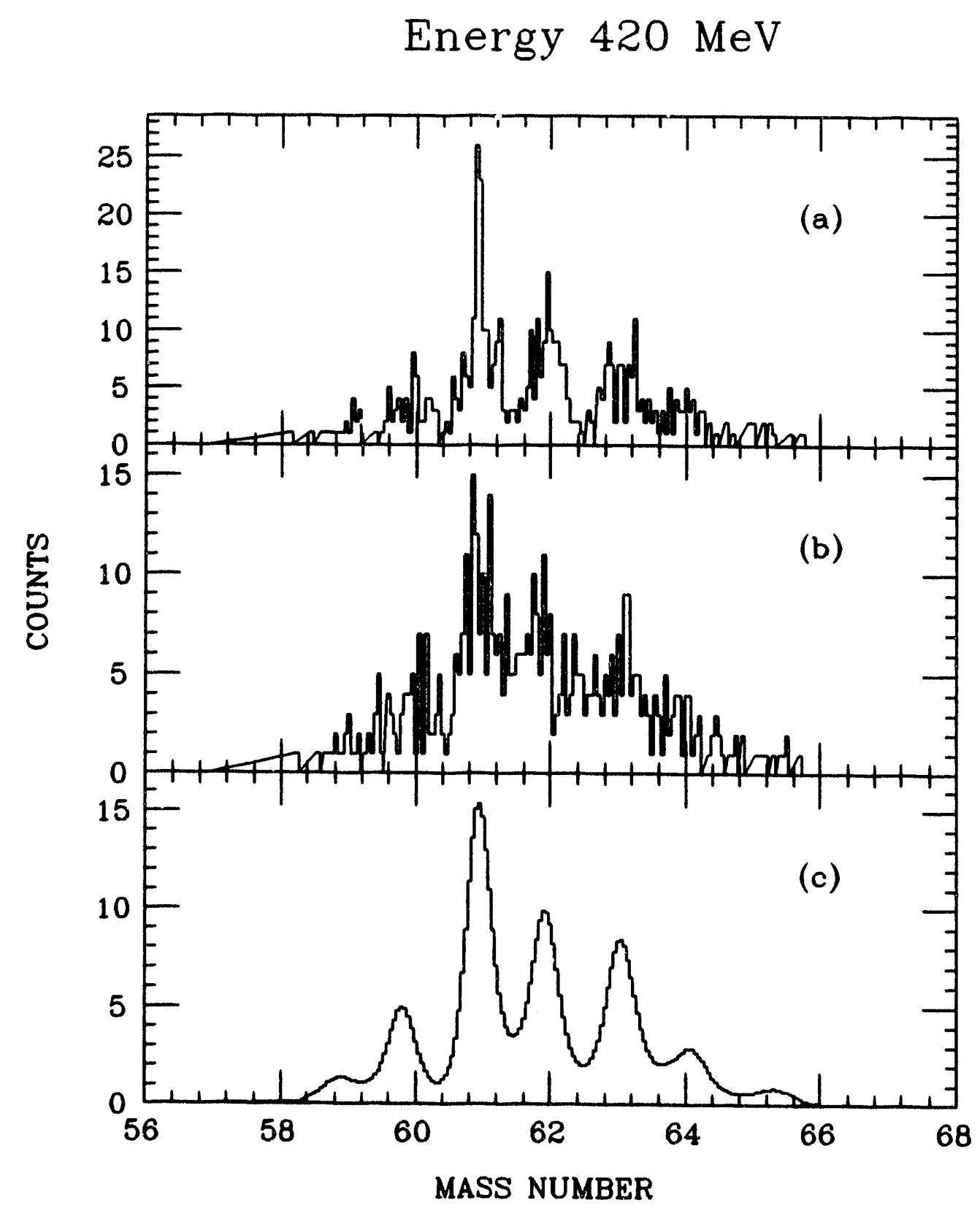


Table III.2 Comparison of Peak Centroids and Areas between the Original and Deconvolved Spectra of Figure III.8*.

\begin{tabular}{|c|c|c|c|c|}
\hline Mass Number & $\begin{array}{l}\text { Original } \\
\text { Centroid }\end{array}$ & $\begin{array}{c}\text { Deconvolved } \\
\text { Centroid }\end{array}$ & Original Area & $\begin{array}{c}\text { Deconvolved } \\
\text { Area }\end{array}$ \\
\hline \multirow[t]{2}{*}{60} & 60.081 & 59.880 & 63 & 63 \\
\hline & \pm 0.123 & \pm 0.037 & \pm 19 & \pm 5 \\
\hline \multirow[t]{2}{*}{61} & 61.047 & 61.011 & 190 & 177 \\
\hline & \pm 0.019 & \pm 0.007 & \pm 11 & \pm 3 \\
\hline \multirow[t]{2}{*}{62} & 62.024 & 62.066 & 274 & 256 \\
\hline & \pm 0.012 & \pm 0.004 & \pm 10 & \pm 3 \\
\hline \multirow[t]{2}{*}{63} & 62.997 & 63.078 & 253 & 246 \\
\hline & \pm 0.014 & \pm 0.005 & \pm 10 & \pm 3 \\
\hline \multirow[t]{2}{*}{64} & 63.972 & 64.072 & 113 & 106 \\
\hline & \pm 0.044 & \pm 0.001 & \pm 13 & \pm 4 \\
\hline
\end{tabular}

* Deconvolved with the following parameters: $w=9.53, F W H M=0.707$ mass units, 25-point quartic polynomial filter (19 times), and 150 iterations.

plotted versus the total energy. The latter would cause functional corrections to be more difficult and hinder the deconvolution results, raising questions such as "Has the peak really shifted or is this an unphysical solution?". Finally, the presence of spurious peaks in the spectra could affect the deconvolution even though their yield was low. However, the deconvolution procedure has been proven to be reliable in a variety of extreme conditions. The chi-squared criteria could not be used in some cases and the number of convolutions with the filter were determined by qualitative observation. As mentioned, the FWHM of the spread function was unknown and it was set to 1.0 mass units. This value was chosen because it is smaller than the estimated maximum value (1.7 mass units), and experience showed that the deconvolution procedure gives better results when the FWHM of the spread function has an intermediate value with respect to the overall resolution. 
Mass vs. energy plots were obtained for different atomic numbers. Mass spectra were generated at $10-\mathrm{MeV}$ energy intervals, and the centroids were determined after deconvolution. The mass vs. energy dependence was determined for the atomic numbers 17, 16, and 15. Linear functions were used to correct the energy dependence for $Z=16$, and 17; a quadratic function was used for $Z=15$. The same functional dependance of $\mathrm{Z}=17$ was assumed for all the atomic numbers above it. Similarly, any atomic number below 15 is considered to have the same energy dependence as for $Z=15$. After this correction was made, the deconvolution was performed on the mass spectra corresponding to different atomic numbers to determine the mass gain with $\mathrm{Z}$. The mass dependence on $\mathrm{Z}$ was adjusted using linear functions for $Z=18,16,15,14$, and 13 . Any mass corresponding to $Z$ below 13 is assumed to have the same gain as for $Z=13$. Likewise, for any mass corresponding to $Z$ above 18 , the same gain of $Z=18$ is assumed.

Finally, a total mass spectrum (excluding only $Z=17$ ) was generated and deconvolved. The peak centroids were found at the expected values of the mass coordinate. Mass spectra were also generated and deconvolved for individual atomic numbers after all the corrections were made, and the centroids were found consistent with the mass coordinate. Figures III.10 to III.13 show the corrected mass spectra for individual atomic numbers and the result of applying the deconvolution procedure to them. It could be roughly evaluated from this experience that the mass assignments should be correct within at least 1 mass unit in most cases. 


\section{Figure III.10}

(a) Mass spectra for $Z=18$.

(b) Same as (a) after deconvolution. 


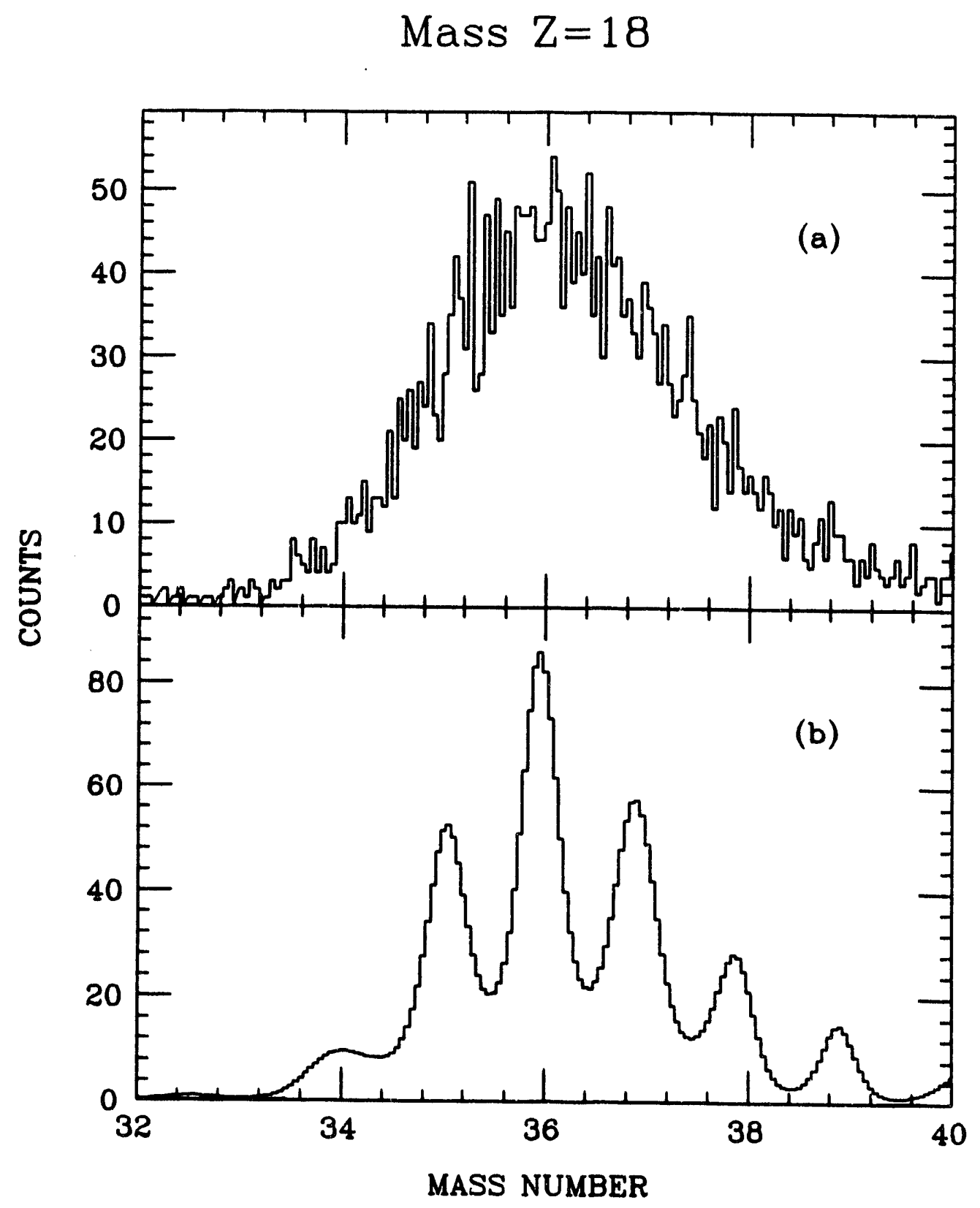


Figure III.11

(a) Mass spectra for $Z=16$.

(b) Same as (a) after deconvolution. 


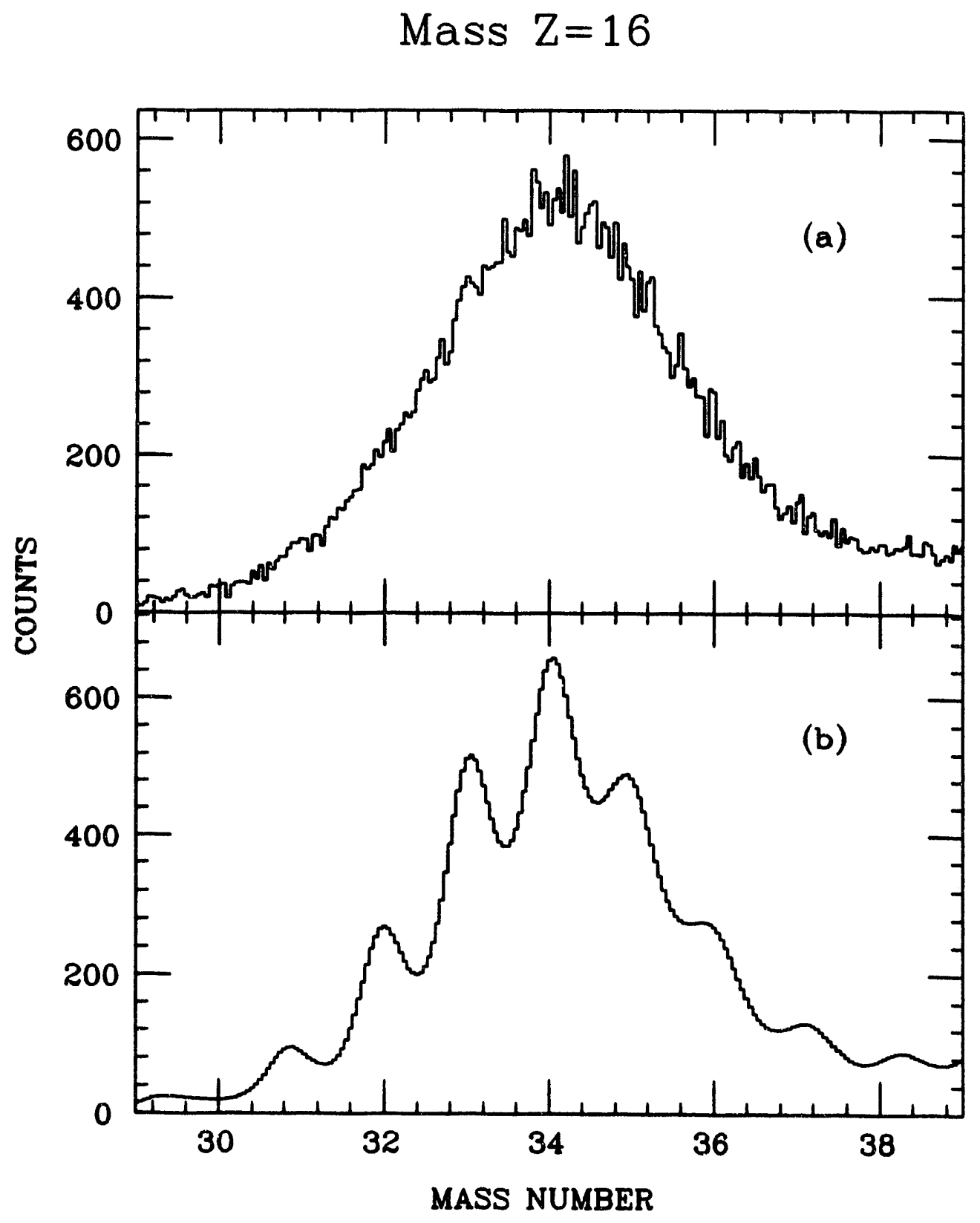


Figure III.12

(a) Mass spectra for $Z=15$.

(b) Same as (a) after deconvolution. 


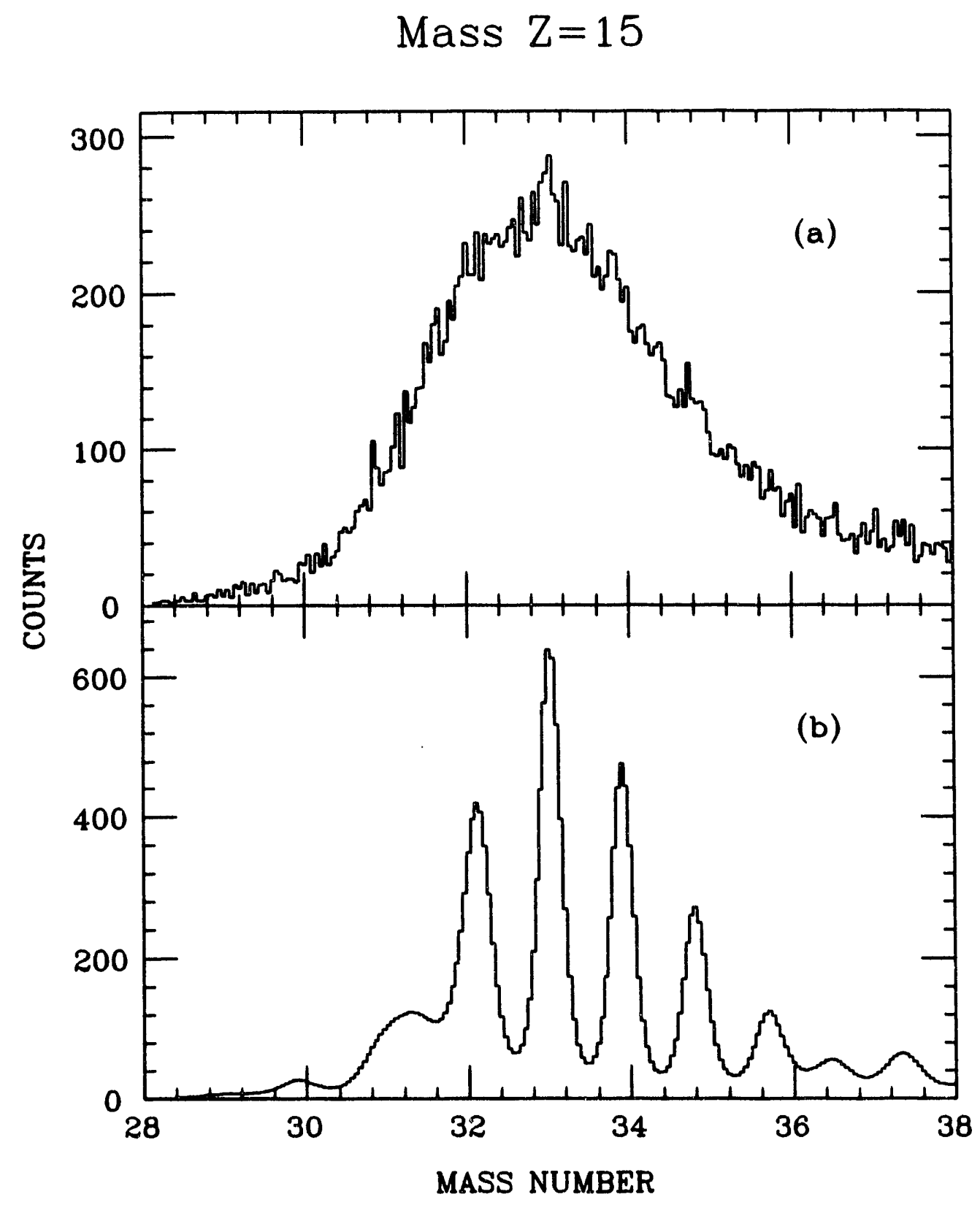


Figure III.13

(a) Mass spectra for $Z=14$.

(b) Same as (a) after deconvolution. 


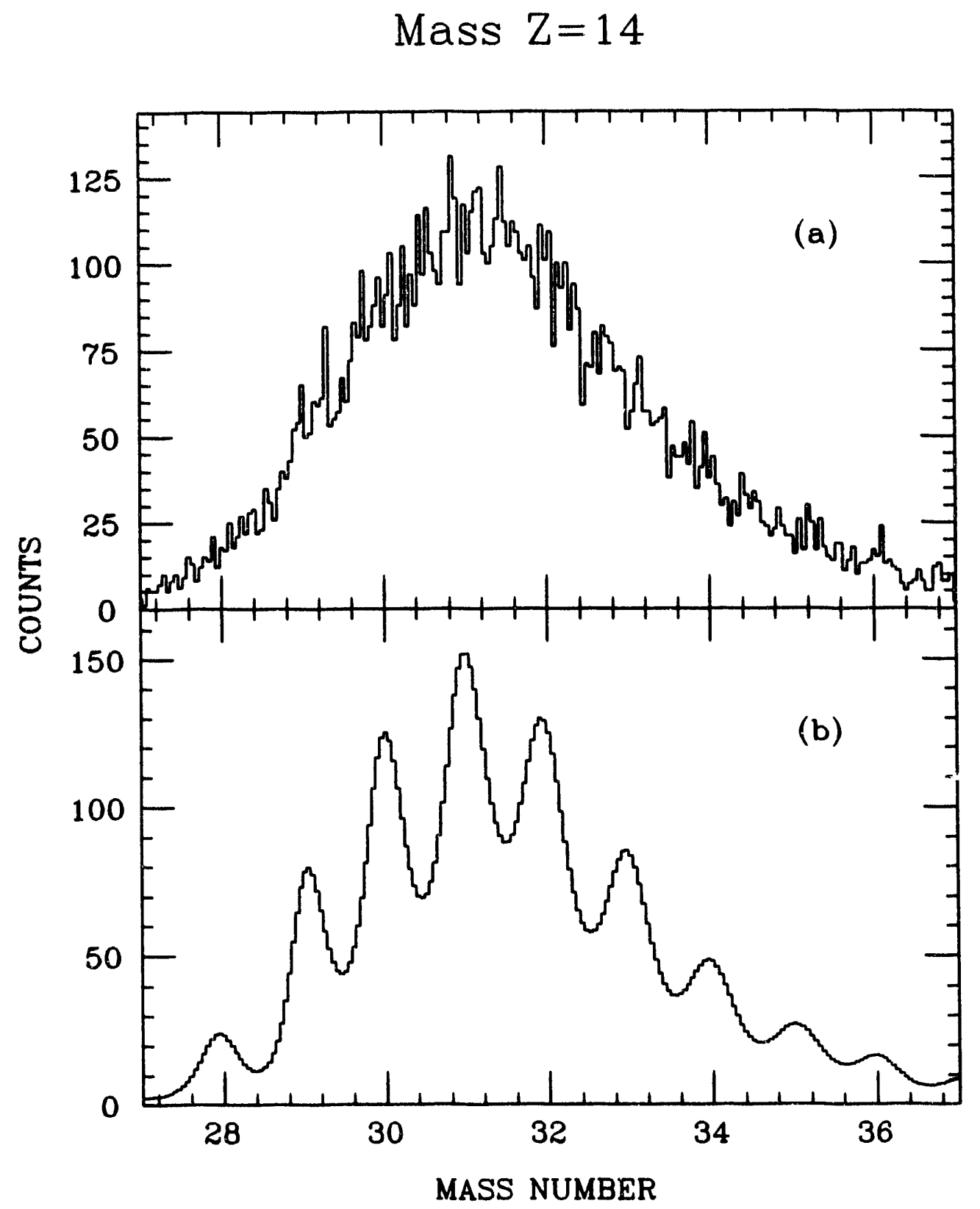


Figure III.14

(a) Mass spectra for $Z=13$.

(b) Same as (a) after deconvolution. 


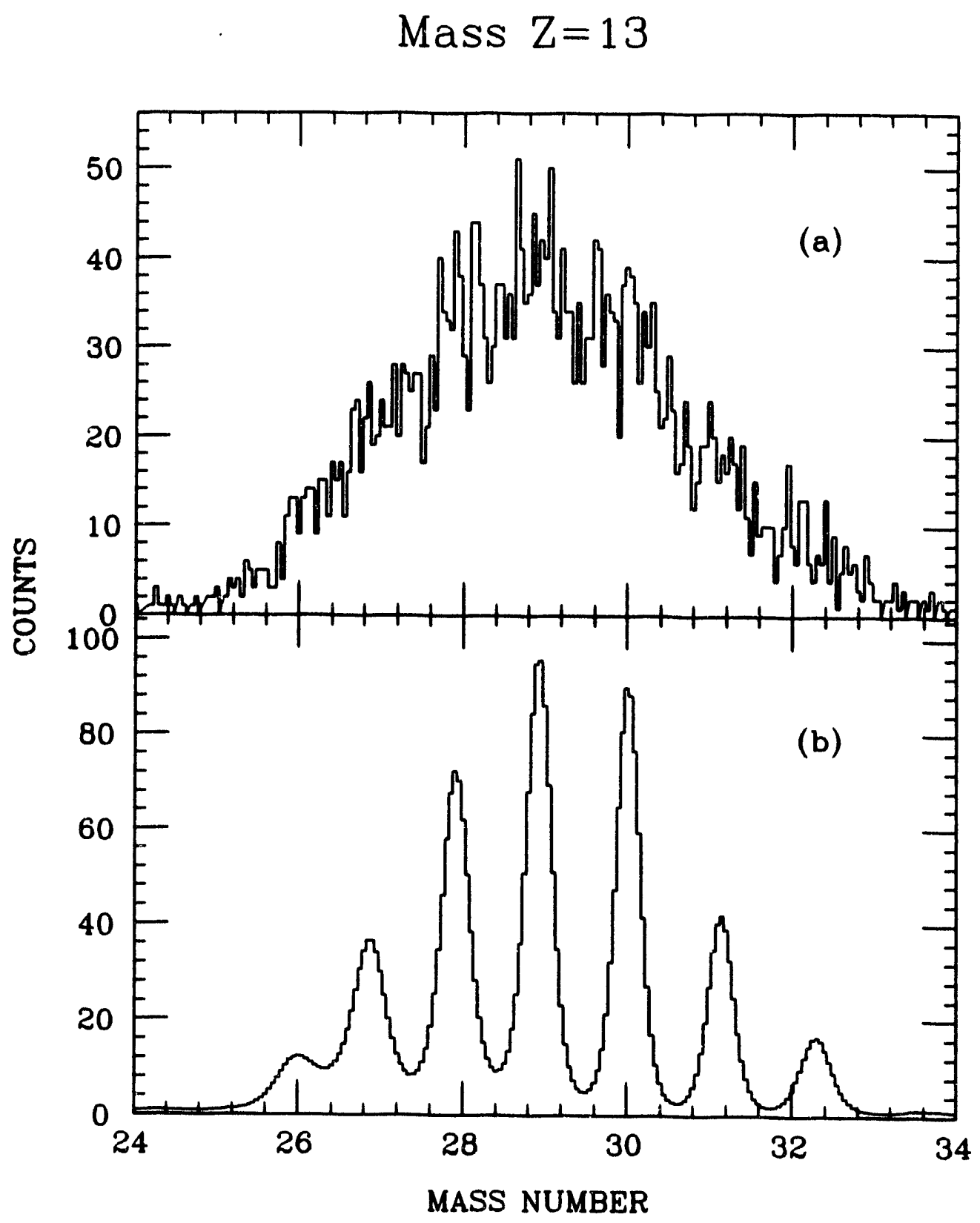




\section{CHAPTER IV RESULTS}

After the calibrations described in Chapter II, the projectile-like fragments are completely characterized by their atomic and mass numbers, relative yield, and energy. Hence, it is possible to produce distributions of products and study their evolution with energy loss. In this chapter, the results of this study are presented. The distributions were transformed to the center-of-mass system and described in terms of statistical parameters, as presented in Chapter II.

The experimental distributions of mass and charge were generated as a function of the energy loss in the $\mathrm{N}-\mathrm{Z}$ plane. The bin size of the $\mathrm{N}$ and $\mathrm{Z}$ coordinates was 0.25 units of mass and charge, respectively. The distributions were gated in consecutive intervals of the energy loss coordinate. The value assigned as the energy loss for a particular distribution corresponds to the center of its gate interval. For the

reactions ${ }^{37} \mathrm{Cl}+{ }^{40} \mathrm{Ca}$ and ${ }^{37} \mathrm{Cl}+{ }^{209} \mathrm{Bi}$, the gates were $4 \mathrm{MeV}$ wide throughout all the range of energy loss. For the reaction ${ }^{35} \mathrm{Cl}+{ }^{209} \mathrm{Bi}$, the gates were $10-\mathrm{MeV}$ wide for the first $100 \mathrm{MeV}$ of energy loss, and $20 \mathrm{MeV}$ wide from there on.

Since the experimental distributions roughly resemble two-dimensional Gaussians, the following independent parameters were chosen to characterize these distributions: average neutron number $(\langle N\rangle)$, average atomic number $(\langle Z\rangle)$, variance in the neutron number $\left(\sigma_{N}{ }^{2}\right)$, variance in the atomic number $\left(\sigma_{Z}{ }^{2}\right)$, and correlation coefficient $(\rho)$. This choice of parameters is sufficient to completely characterize the distributions if they are purely two-dimensional Gaussians. However, it should be stressed that the neutron and atomic number are discrete variables, and, in some cases, the experimental distributions show clear departures from Gaussian behavior. 
Because of the non-Gaussian behavior of some of the distributions, two approaches were taken to determine the characteristic parameters: two-dimensional Gaussian fit and moment analysis. For a Gaussian distribution, the first and second moments are equal to the centroid and variance, respectively. The Gaussian fits were performed using the algorithm developed by $\mathrm{H}$. Breuer et al. [BRE 83a]. The computer algorithms required for moment analysis were developed by the author. The second moment was corrected for grouping due to the finite bin size [CRA 46], and for the experimental resolution. The errors in the parameters generated by the moment analysis were calculated by propagating the statistical counting errors in the moment formulas. It should be noted that the Oak Ridge N-Z distributions were not deconvolved to determine the characteristic parameters either by moment analysis or Gaussian fit. The deconvolution technique was used only to establish the mass calibration (neutron number). In Chapter II, the mass resolution (FWHM) was estimated to be, roughly, 1.7 mass units for the Oak Ridge data. Since the charge resolution is much smaller than the mass resolution, the neutron number resolution should also be around 1.7 units.

As mentioned in Chapter II, the energy loss scale was corrected for evaporation effects. An assumption of how the excitation energy is divided between projectile- and target-like fragments is needed for this correction. Presently, it is accepted that for short interaction times (low energy loss) the excitation energy is divided more or less equally among the partners [AWE 84, VAN 84, SOH 85, BEN 88, WIL 89a, WIL 89b]. As the iteraction time increases (energy loss increases), the excitation energy tends to equilibrate between the two partners (thermalization), which means a division proportional to the mass of each fragment. Obviously, only asymmetric systems will be sensitive to the difference between equal and thermal division of the excitation energy. In those cases, the evolution of system between the 
two extremes seems to be a smooth function. Using the same rationale, the difference between equal and thermal division of excitation energy is expected to have an important effect on the energy loss correction when the entrance channel is asymmetric. For the ${ }^{37} \mathrm{Cl}$ on ${ }^{40} \mathrm{Ca}$ reaction, only equal division of excitation energy was considered because the system is nearly symmetric. For ${ }^{35} \mathrm{Cl}$ on ${ }^{209} \mathrm{Bi}$ and ${ }^{37} \mathrm{Cl}$ on ${ }^{209} \mathrm{Bi}$ systems, two corrections were made: one assuming equal division and the other assuming thermal division of the excitation energy. Reaction parameters for all three systems studied are displayed in Chapter II (Table II.1).

IV.A THE SYSTEM ${ }^{37} \mathrm{Cl}+{ }^{40} \mathrm{Ca}$ AT $270 \mathrm{MeV}$

The values of $<\mathrm{Z}>$ and $<\mathrm{N}>$ as a function of energy loss obtained using both Gaussian fit and moment analysis are shown in Figure IV.1, along with the ratio $\langle N>|<Z>$. The $\langle\mathrm{Z}>$ and $\langle\mathrm{N}\rangle$ decrease with increasing energy loss. The results obtained by both methods agree up to about $80 \mathrm{MeV}$ of energy loss. Differences as large as 0.5 in atomic number and 1 in neutron number are observed at energy losses greater than $80 \mathrm{MeV}$. The ratio $\langle\mathrm{N}>|<\mathrm{Z}>$ initially decreases, but after about $40 \mathrm{MeV}$ of energy loss remains more or less constant within the error.

In Figure IV.2 the values of $\sigma \mathrm{z}^{2}, \sigma_{\mathrm{N}}{ }^{2}$, and $\rho$ are displayed as a function of energy loss for both Gaussian fit and moment analysis. The variances obtained by both methods agree very well up to about $70 \mathrm{MeV}$ of energy loss; at higher energy losses the variances obtained by the Gaussian method are much greater. The correlation coefficient increases sharply with energy loss and between 40 and $60 \mathrm{MeV}$ reaches a more or less constant value very close to 1.0. Moment analysis gives significantly lower values for $\rho$ than the Gaussian fit at energy losses of less than about $40 \mathrm{MeV}$. 


\section{Figure IV.1}

The values of $\langle\mathrm{Z}\rangle,\langle\mathrm{N}\rangle$, and $\langle\mathrm{Z}\rangle \mid\langle\mathrm{N}\rangle$ as a function of energy loss for the reaction ${ }^{37} \mathrm{Cl}+{ }^{40} \mathrm{Ca}$ at $270 \mathrm{MeV}$. The circles represent the results from the Gaussian fit method and the diamonds represent the results from a moment analysis. The energy loss scale was corrected assuming equal division of the excitation energy. 


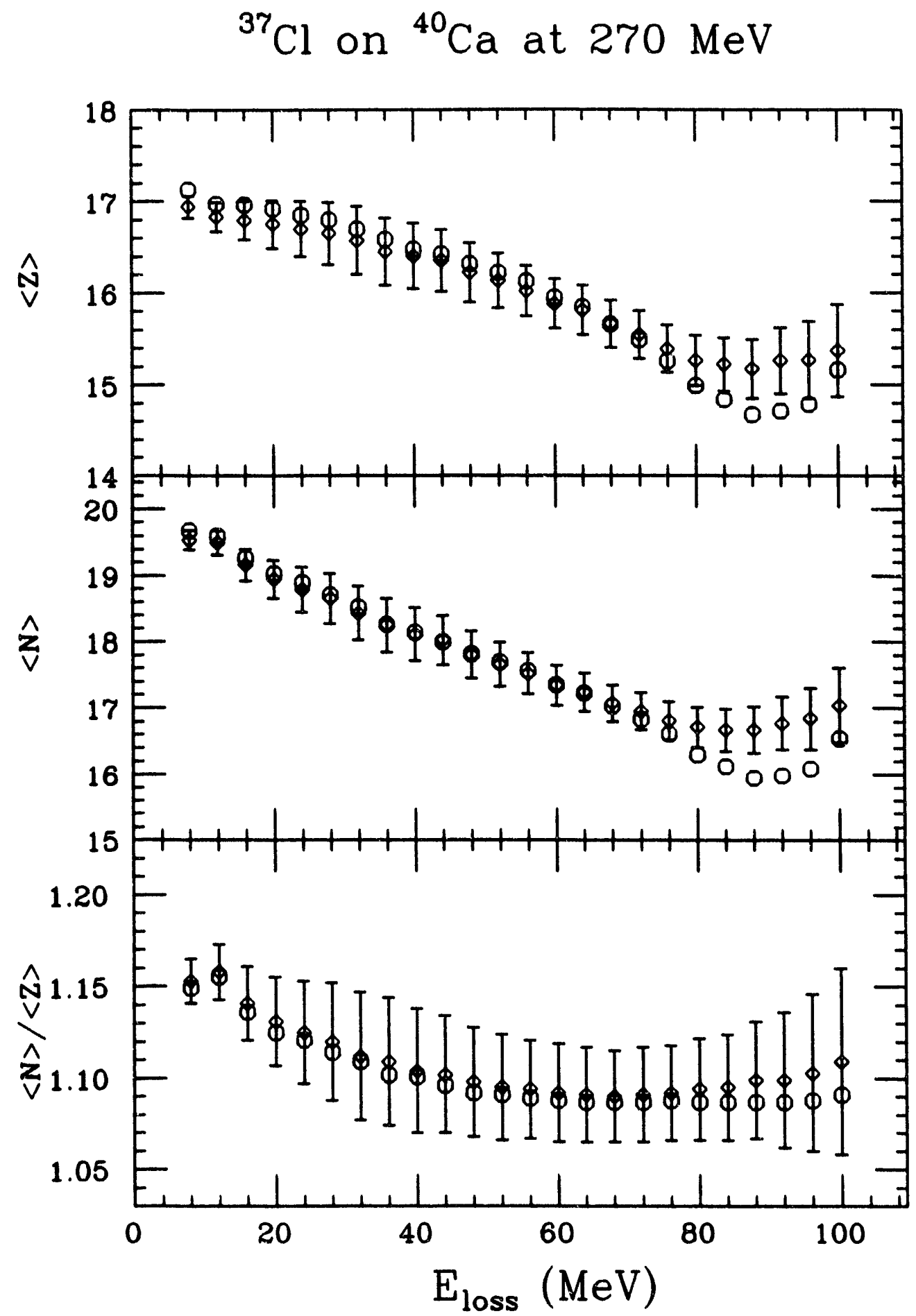




\section{Figure IV.2}

The values of $\sigma \mathrm{Z}^{2}, \sigma_{\mathrm{N}}{ }^{2}$, and $\rho$ as a function of energy loss for the reaction ${ }^{37} \mathrm{Cl}+{ }^{40} \mathrm{Ca}$ at $270 \mathrm{MeV}$. The circles represent the results from the Gaussian fit method and the diamonds represent the results from a moment analysis. The energy loss scale was corrected assuming equal division of the excitation energy. 


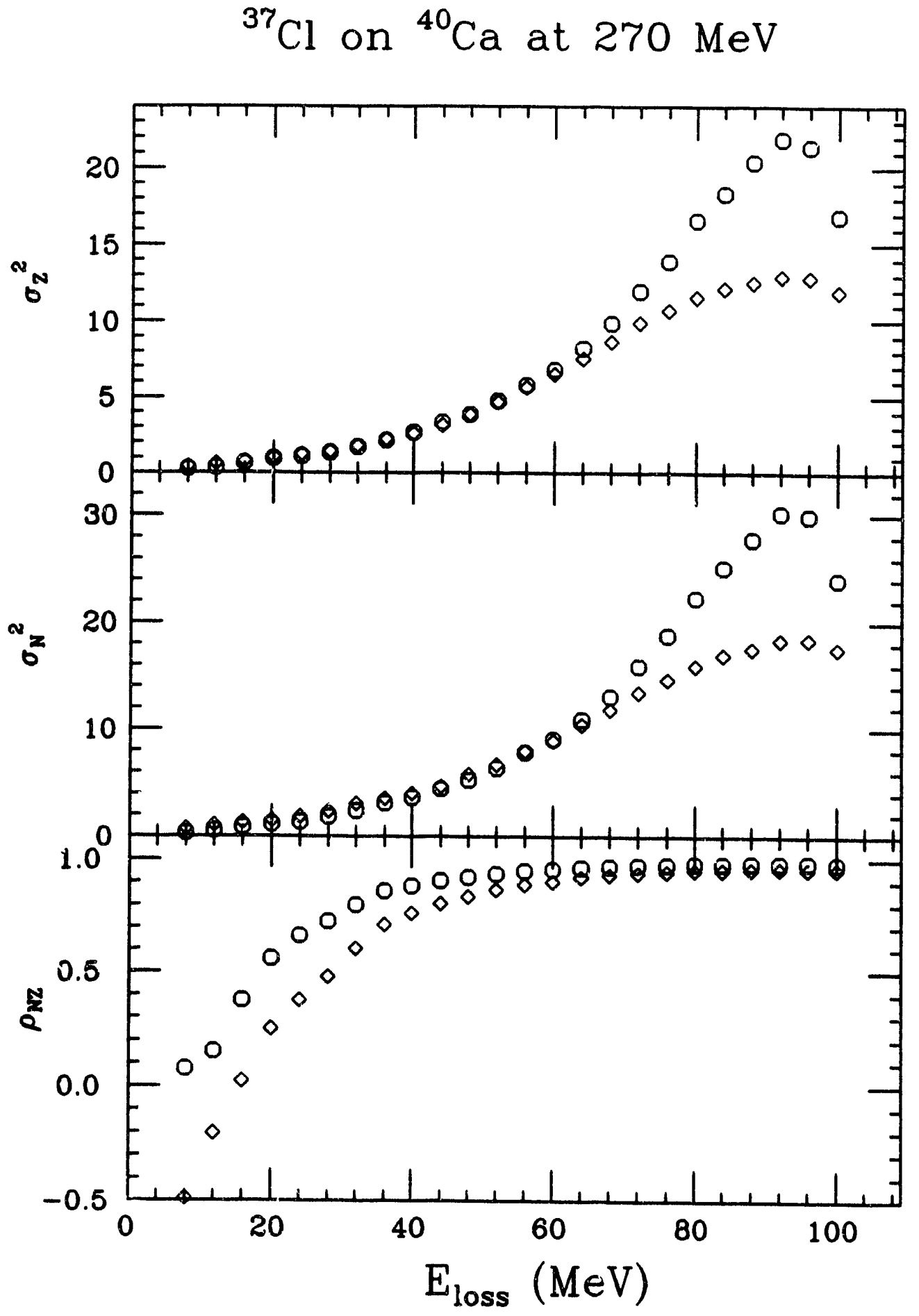


IV.B THE SYSTEM ${ }^{37} \mathrm{Cl}+{ }^{209} \mathrm{Bi}$ AT $270 \mathrm{MeV}$

The results of $\langle\mathrm{Z}\rangle,\langle\mathrm{N}\rangle$, and $\langle\mathrm{N}\rangle|<\mathrm{Z}\rangle$ shown in Figures IV.3 and 4 correspond to corrections of the energy loss scale assuming equal and thermal division of the excitation energy, respectively. There is very good agreement between moment analysis and the Gaussian fit for the values of $\langle\mathrm{Z}\rangle,\langle\mathrm{N}\rangle$, and $\langle\mathrm{N}\rangle \mid\langle\mathrm{Z}\rangle$ as a function of energy loss. The $\langle\mathrm{Z}\rangle$ and $\langle\mathrm{N}\rangle$ decrease with increasing energy loss. The ratio $\langle\mathrm{N}\rangle \mid\langle\mathrm{Z}\rangle$ raises slightly, and reaches a constant value immediately after about $20 \mathrm{MeV}$ of energy loss.

Plots of $\sigma_{\mathrm{Z}}{ }^{2}, \sigma_{\mathrm{N}}{ }^{2}$, and $\rho$ as a function of energy loss are shown in Figures IV.5 and 6, which correspond to energy loss corrections assuming equal and thermal division of the excitation energy, respectively. The variances obtained using the moment analysis are slightly higher than those obtained using the Gaussian fit method. The correlation coefficient raises sharply up to about $20 \mathrm{MeV}$ of energy loss, and then continues increasing at a much slower rate with increasing energy loss. At low energy loss the values of $\rho$ obtained from the moment analysis are smaller than the ones obtained using the Gaussian fit.

The values of $\langle\mathrm{Z}\rangle,\langle\mathrm{N}\rangle$, and $\langle\mathrm{N}\rangle \mid\langle\mathrm{Z}\rangle$ corresponding to both corrections of the energy loss scale are compared in Figure IV.7. For clarity, only the resuits corresponding to the Gaussian fit are displayed. The differences are not very significant in most of the energy loss range. However, after the first $20 \mathrm{MeV}$ of energy loss, the $\langle\mathrm{Z}>$ and $<\mathrm{N}>$ corresponding to equal division of the excitation energy are increasingly smaller than those corresponding to thermal division. This result is expected, because evaporation increases with excitation energy, and, at a given energy loss, the equal division of excitation energy will deposit more excitation the lighter partner than thermal division does. 


\section{Figure IV.3}

The values of $\langle\mathrm{Z}\rangle,\langle\mathrm{N}\rangle$, and $\langle\mathrm{Z}>|\langle N\rangle$ as a function of energy loss for the reaction ${ }^{37} \mathrm{Cl}+{ }^{209} \mathrm{Bi}$ at $270 \mathrm{MeV}$. The circles represent the results from the Gaussian fit method and the diamonds represent the results from a moment analysis. The energy loss scale was corrected assuming equal division of the excitation energy. 


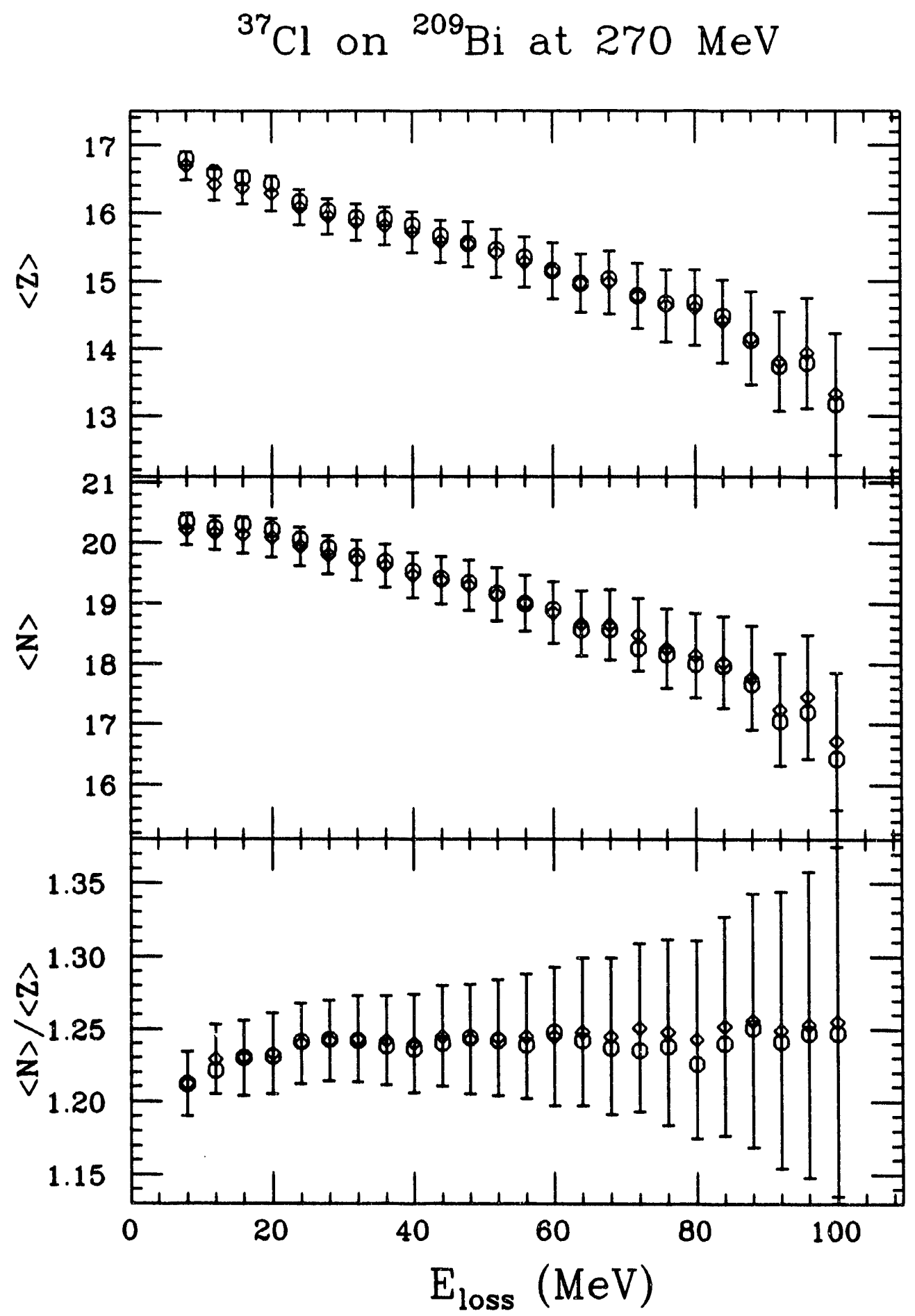




\section{Figure IV.4}

The values of $\langle Z\rangle,\langle N\rangle$, and $\langle Z\rangle \mid\langle N\rangle$ as a function of energy loss for the reaction ${ }^{37} \mathrm{Cl}+{ }^{209} \mathrm{Bi}$ at $270 \mathrm{MeV}$. The squares represent the results from the Gaussian fit method and the diamonds represent the results from a moment analysis. The energy loss scale was corrected assuming thermal division of the excitation energy. 


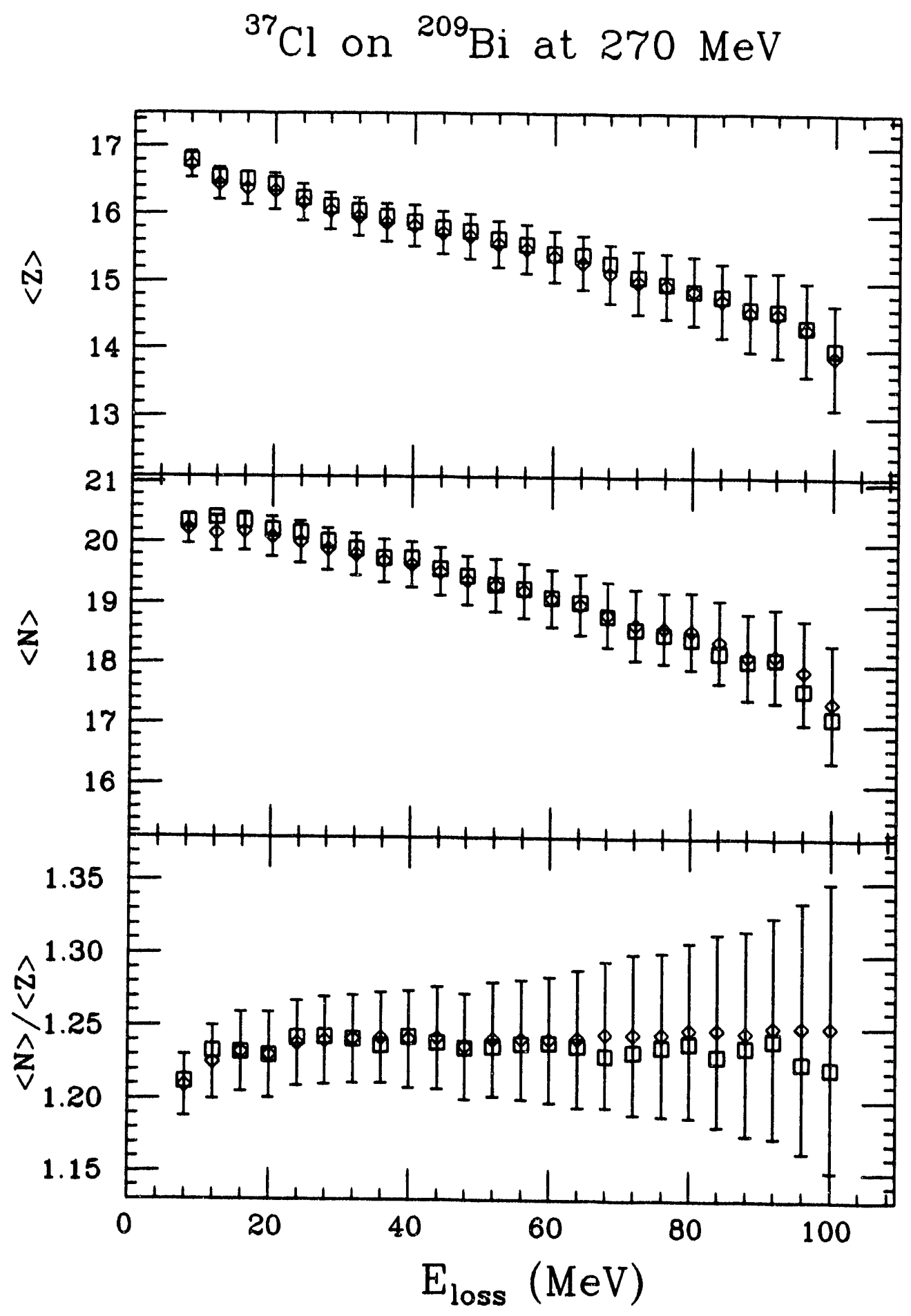




\section{Figure IV.5}

The values of $\sigma \mathrm{Z}^{2}, \sigma_{\mathrm{N}}{ }^{2}$, and $\rho$ as a function of energy loss for the reaction ${ }^{37} \mathrm{Cl}+{ }^{209} \mathrm{Bi}$ at $270 \mathrm{MeV}$. The circles represent the results from the Gaussian fit method and the diamonds represent the results from a moment analysis. The energy loss scale was corrected assuming equal division of the excitation energy. 


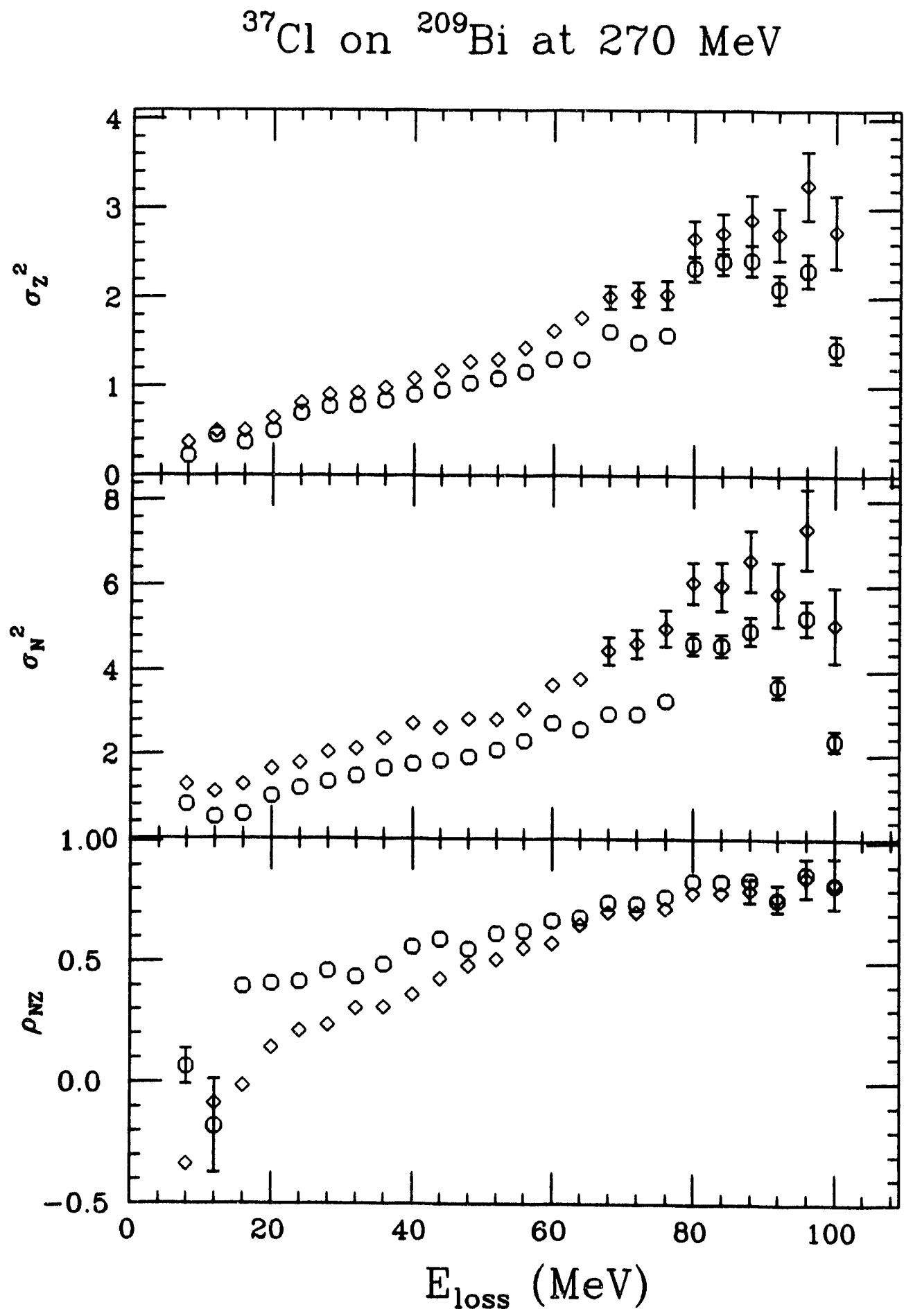




\section{Figure IV.6}

The values of $\sigma_{\mathrm{Z}}{ }^{2}, \sigma_{\mathrm{N}}{ }^{2}$, and $\rho$ as a function of energy loss for the reaction ${ }^{37} \mathrm{Cl}+{ }^{209} \mathrm{Bi}$ at $270 \mathrm{MeV}$. The squares represent the results from the Gaussian fit method and the diamonds represent the results from a moment analysis. The energy loss scale was corrected assuming thermal division of the excitation energy. 


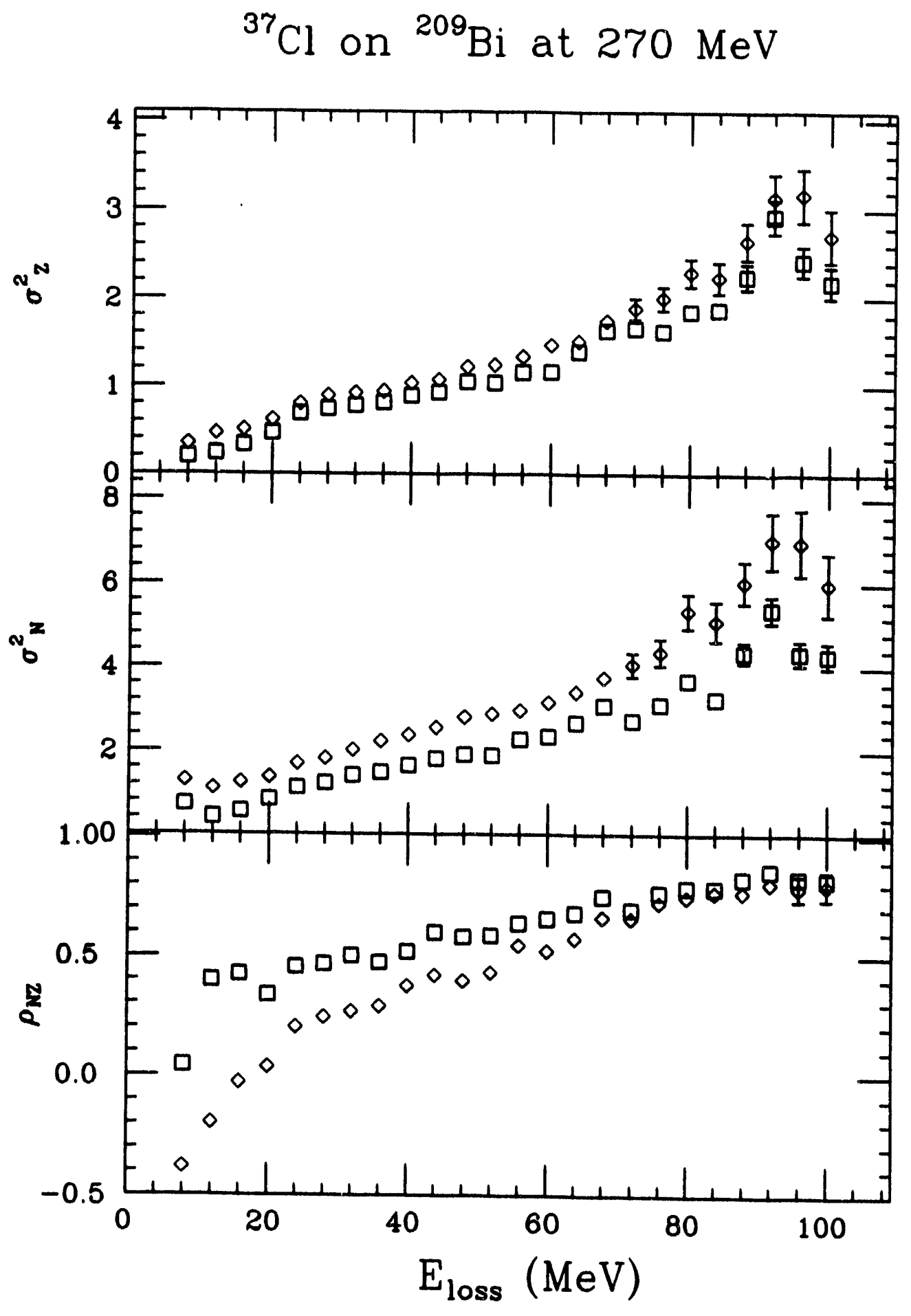




\section{Figure IV.7}

The values of $\langle\mathrm{Z}\rangle,\langle\mathrm{N}\rangle$, and $\langle\mathrm{N}\rangle \mid\langle\mathrm{Z}\rangle$ as a function of energy loss for the reaction ${ }^{37} \mathrm{Cl}+{ }^{209} \mathrm{Bi}$ at $270 \mathrm{MeV}$. The circles and squares represent corrections of the energy loss scale assuming equal and thermal division of the excitation energy, respectively. 


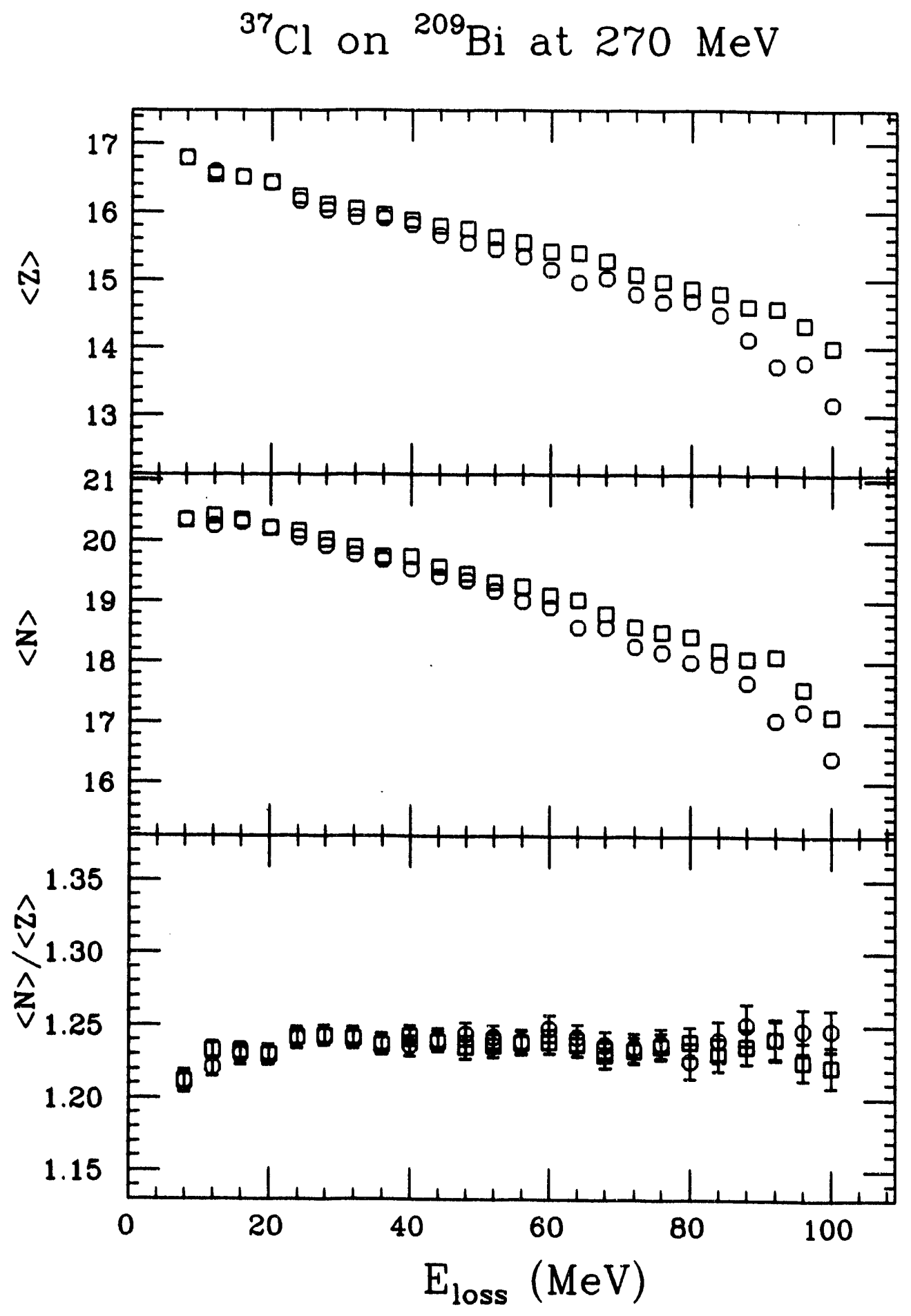


IV.C THE SYSTEM ${ }^{35} \mathrm{Cl}+{ }^{209} \mathrm{Bi}$ AT $528 \mathrm{MeV}$

Plots of $\langle\mathrm{Z}\rangle,\langle\mathrm{N}\rangle$, and $\langle\mathrm{Z}\rangle \mid\langle\mathrm{N}\rangle$ are shown in Figures IV. 8 and 9 for corrections of the energy loss scale corresponding to equal and thermal division of the excitation energy, respectively. No significant differences are found between the results obtained using moment analysis or Gaussian fit. The value of $\langle Z\rangle$ decreases more or less steadily with increasing energy loss. The value of $\langle\mathrm{N}\rangle$ remains approximately constant up to about $100 \mathrm{MeV}$ of energy loss, then it starts decreasing. This behavior is also reflected in the ratio $\langle\mathrm{N}\rangle|<\mathrm{Z}\rangle$ which increases as a function of energy loss up to about $100 \mathrm{MeV}$ and then starts decreasing. There could be a systematic error for the neutron numbers corresponding to $Z<15$, since the energy dependence of the mass centroids was established only up to $Z=15$, as described in Chapter III. However, the direction of this error is not known and the drift seems too large to be due only to this.

The results of $\sigma \mathrm{z}^{2}, \sigma_{\mathrm{N}}{ }^{2}$, and $\rho$ are plotted in Figures IV.10 and IV.11 for the corrections of the energy loss scale corresponding to equal and thermal division of the excitation energy, respectively. As in the case of the averages and ratios, there are no significant differences between the results of the moment analysis and Gaussian fit. The $\sigma \mathrm{z}^{2}$ increases up to $100 \mathrm{MeV}$ of energy loss, and from there on, starts decreasing. The $\sigma_{\mathrm{N}}^{2}$ seems to follow more or less the same behavior. The correlation coefficient shows a sudden increase at about $100 \mathrm{MeV}$ of energy loss (going from negative to positive) and then remains approximately constant.

As in the previous system, the values of $\langle\mathrm{Z}\rangle,\langle\mathrm{N}\rangle$, and $\langle\mathrm{N}\rangle \mid\langle\mathrm{Z}\rangle$ corresponding to both corrections of the energy loss scale are shown in Figure IV.12. No significant differences are observed for the first $100 \mathrm{MeV}$ of energy loss. After that, the differences in $<Z>$ start increasing with energy loss, reaching up to 2 charge 
Figure IV.8

The values of $\langle\mathrm{Z}\rangle,\langle\mathrm{N}\rangle$, and $\langle\mathrm{Z}\rangle \mid\langle\mathrm{N}\rangle$ as a function of energy loss for the reaction ${ }^{35} \mathrm{Cl}+{ }^{209} \mathrm{Bi}$ at $528 \mathrm{MeV}$. The circles represent the results from the Gaussian fit method and the diamonds represent the results from a moment analysis. The energy loss scale was corrected assuming equal division of the excitation energy. 


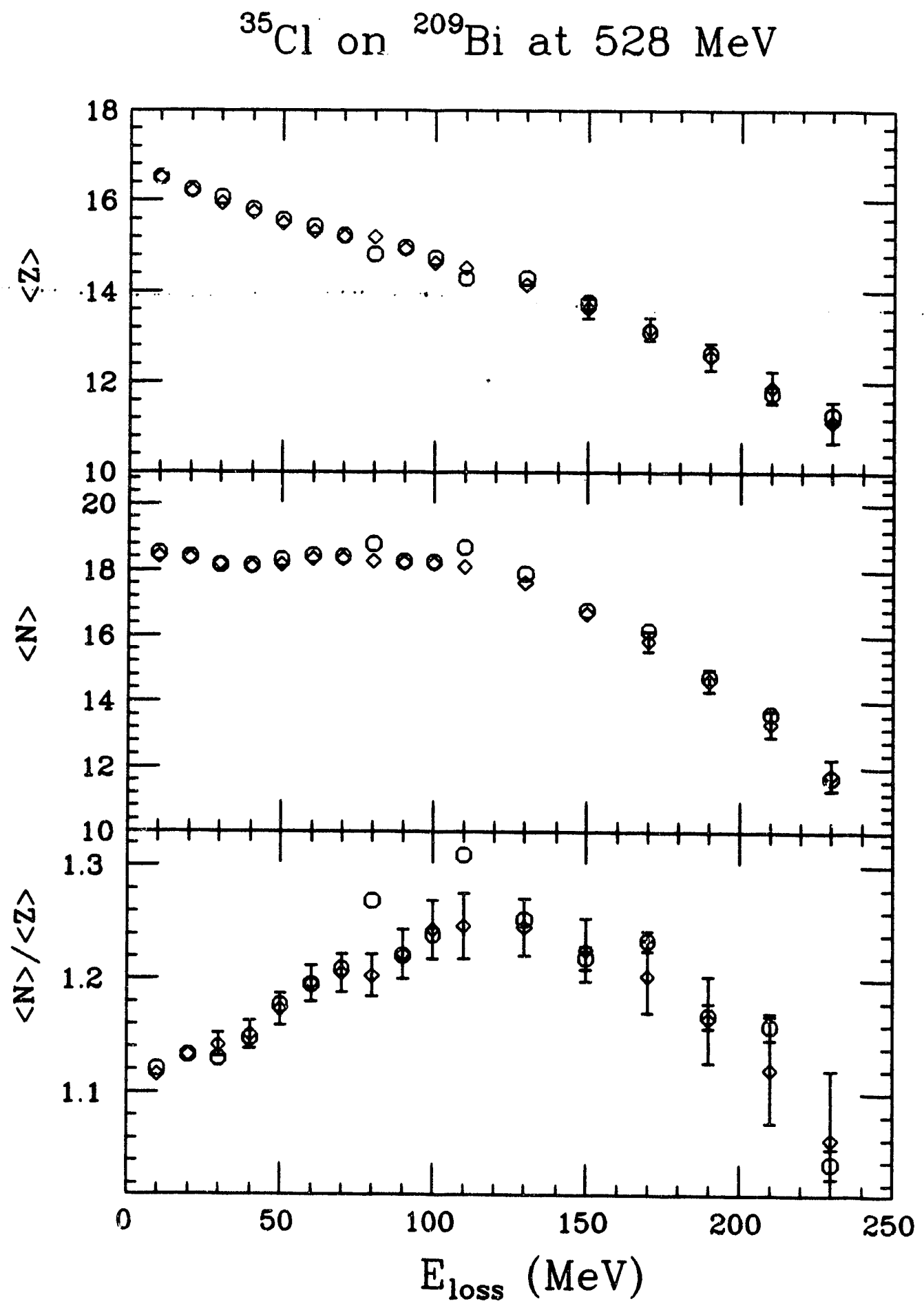




\section{Figure IV.9}

The values of $\langle\mathrm{Z}\rangle,\langle\mathrm{N}\rangle$, and $\langle\mathrm{Z}\rangle|<\mathrm{N}\rangle$ as a function of energy loss for the reaction ${ }^{35} \mathrm{Cl}+{ }^{209} \mathrm{Bi}$ at $528 \mathrm{MeV}$. The squares represent the results from the Gaussian fit method and the diamonds represent the results from a moment analysis. The energy loss scale was corrected assuming thermal division of the excitation energy. 


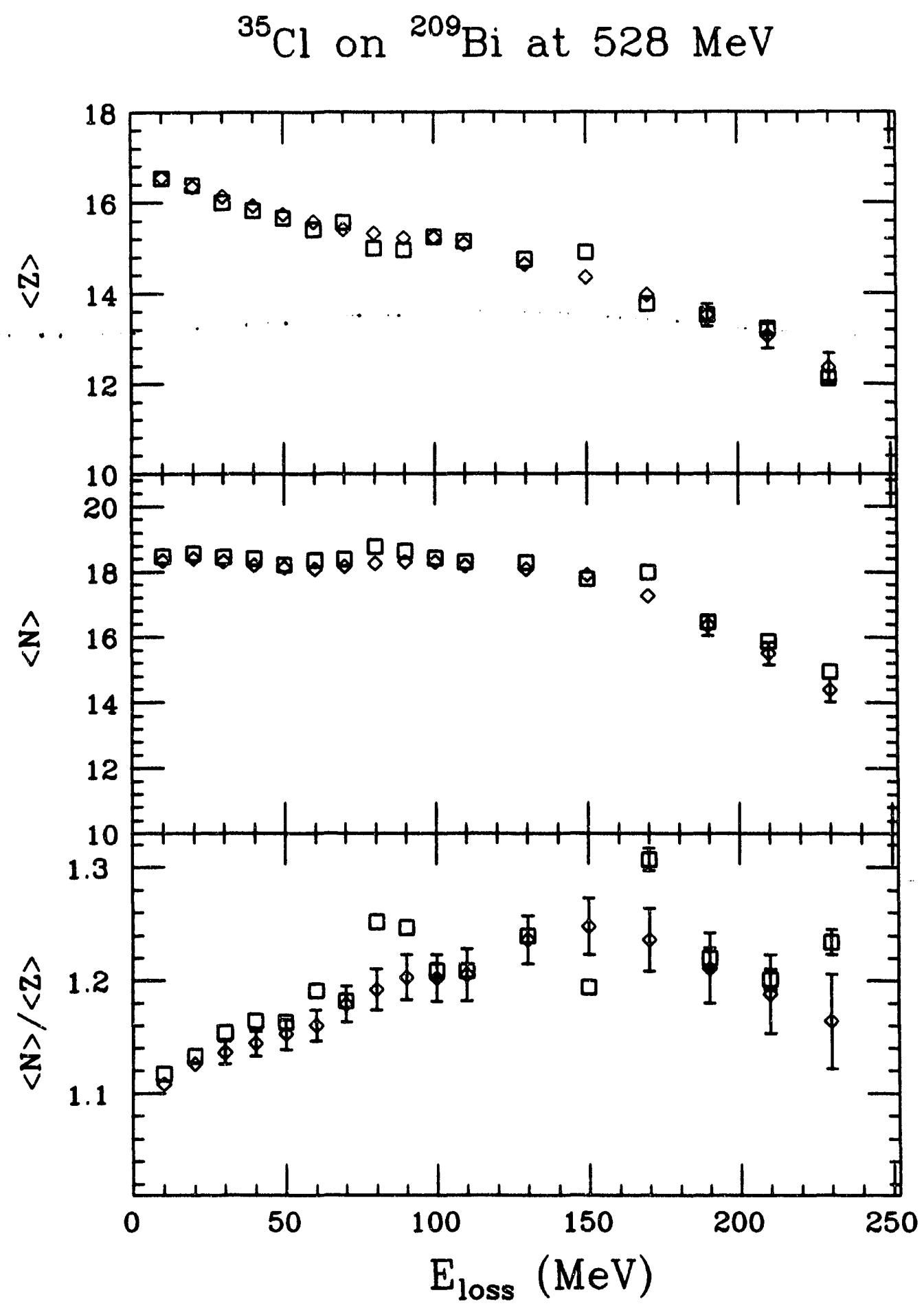


Figure IV.10

The values of $\sigma \mathrm{Z}^{2}, \sigma_{\mathrm{N}}{ }^{2}$, and $\rho$ as a function of energy loss for the reaction ${ }^{35} \mathrm{Cl}+{ }^{209} \mathrm{Bi}$ at $528.8 \mathrm{MeV}$. The circles represent the results from the Gaussian fit method and the diamonds represent the results from a moment analysis. The energy loss scale was corrected assuming equal division of the excitation energy. 


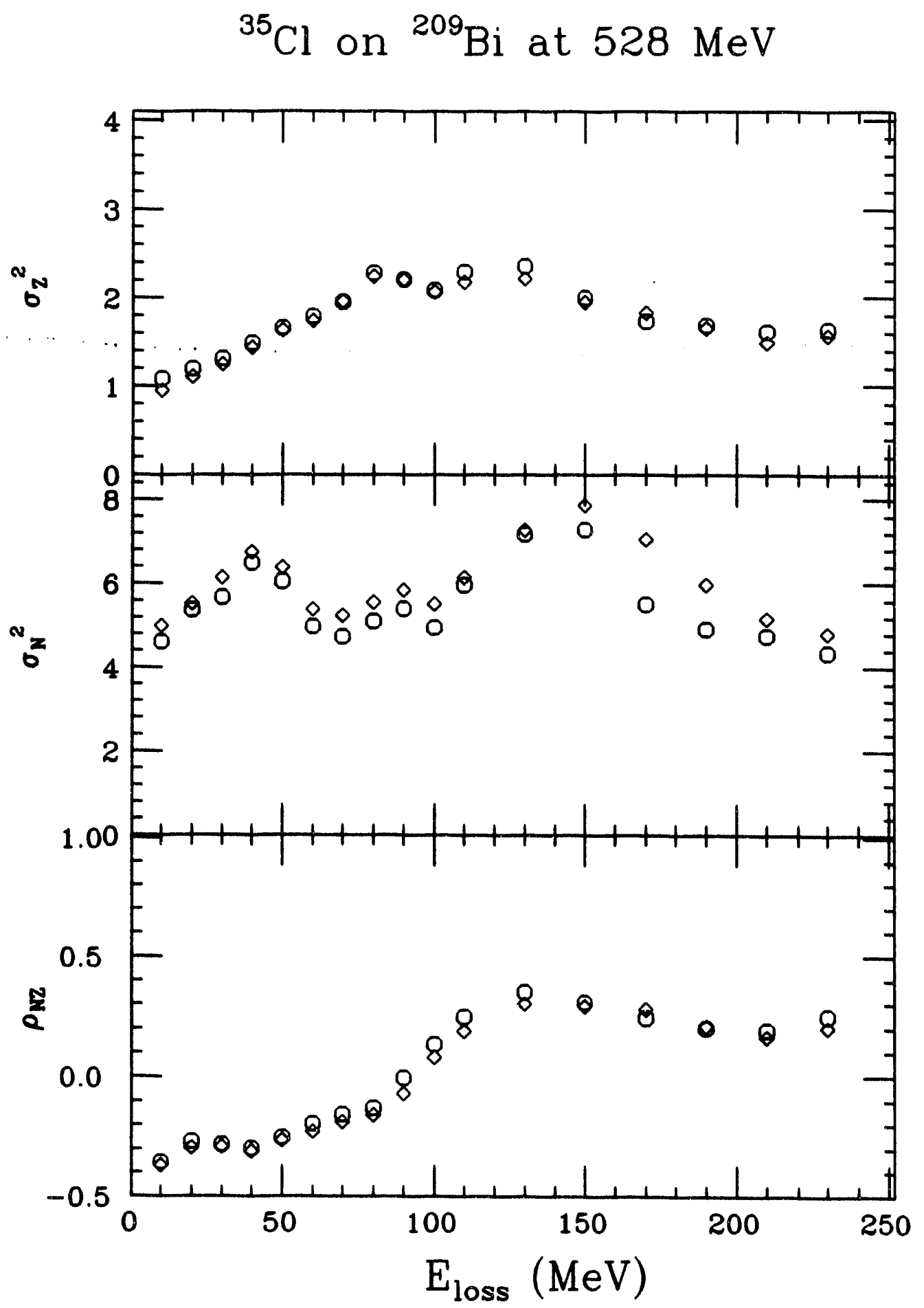


Figure IV.11

The values of $\sigma \mathrm{z}^{2}, \sigma \mathrm{N}^{2}$, and $\rho$ as a function of energy loss for the reaction ${ }^{35} \mathrm{Cl}+{ }^{209} \mathrm{Bi}$ at $528.8 \mathrm{MeV}$. The squares represent the results from the Gaussian fit method and the diamonds represent the results from a moment analysis. The energy loss scale was corrected assuming thermal division of the excitation energy. 


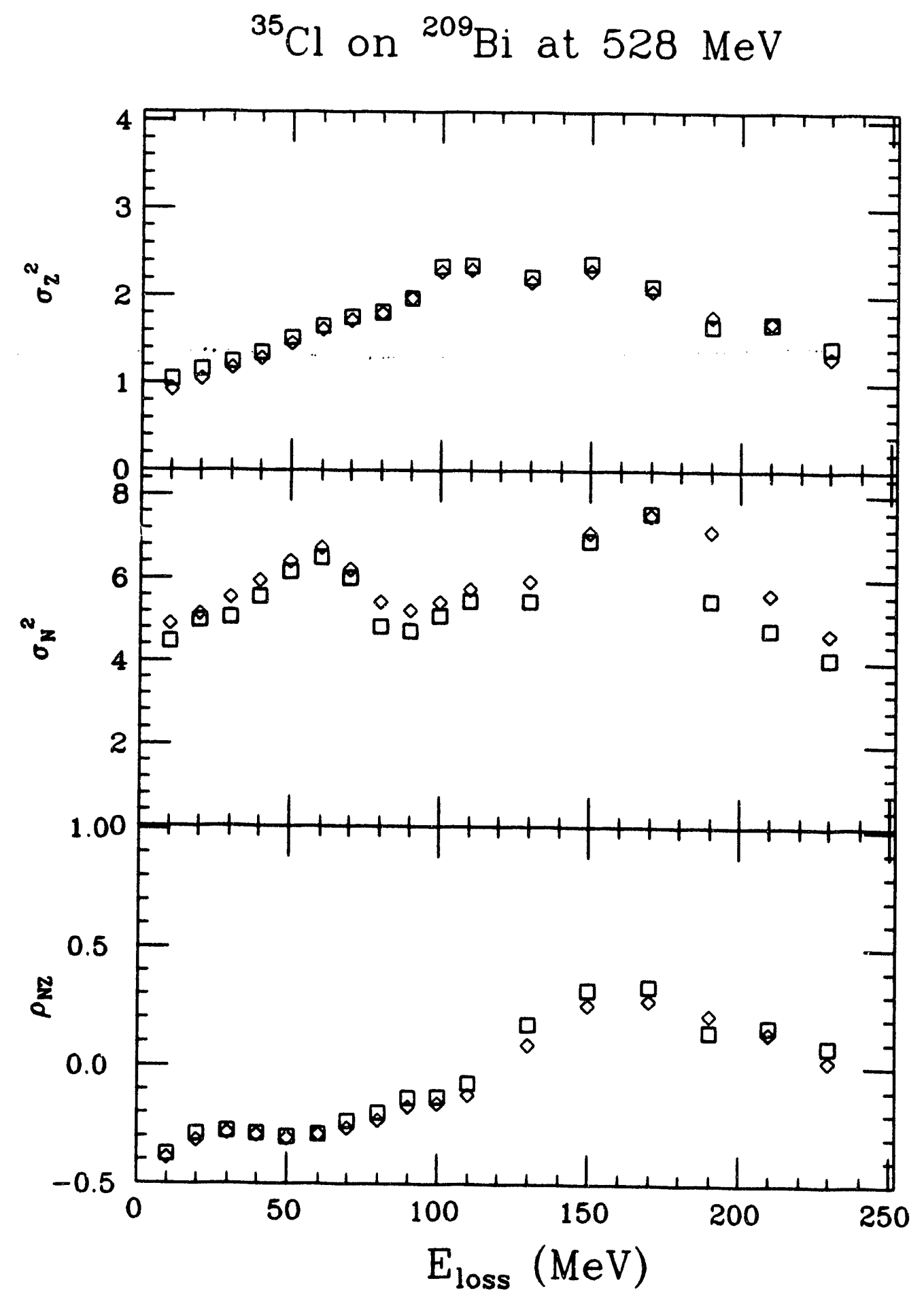


Figure IV.12

The values of $\langle\mathrm{Z}\rangle,\langle\mathrm{N}\rangle$, and $\langle\mathrm{N}\rangle \mid\langle\mathrm{Z}\rangle$ as a function of energy loss for the reaction ${ }^{35} \mathrm{Cl}+{ }^{209} \mathrm{Bi}$ at $528 \mathrm{MeV}$. The circles and squares represent corrections of the energy loss scale assuming equal and thermal division of the excitation energy, respectively. 


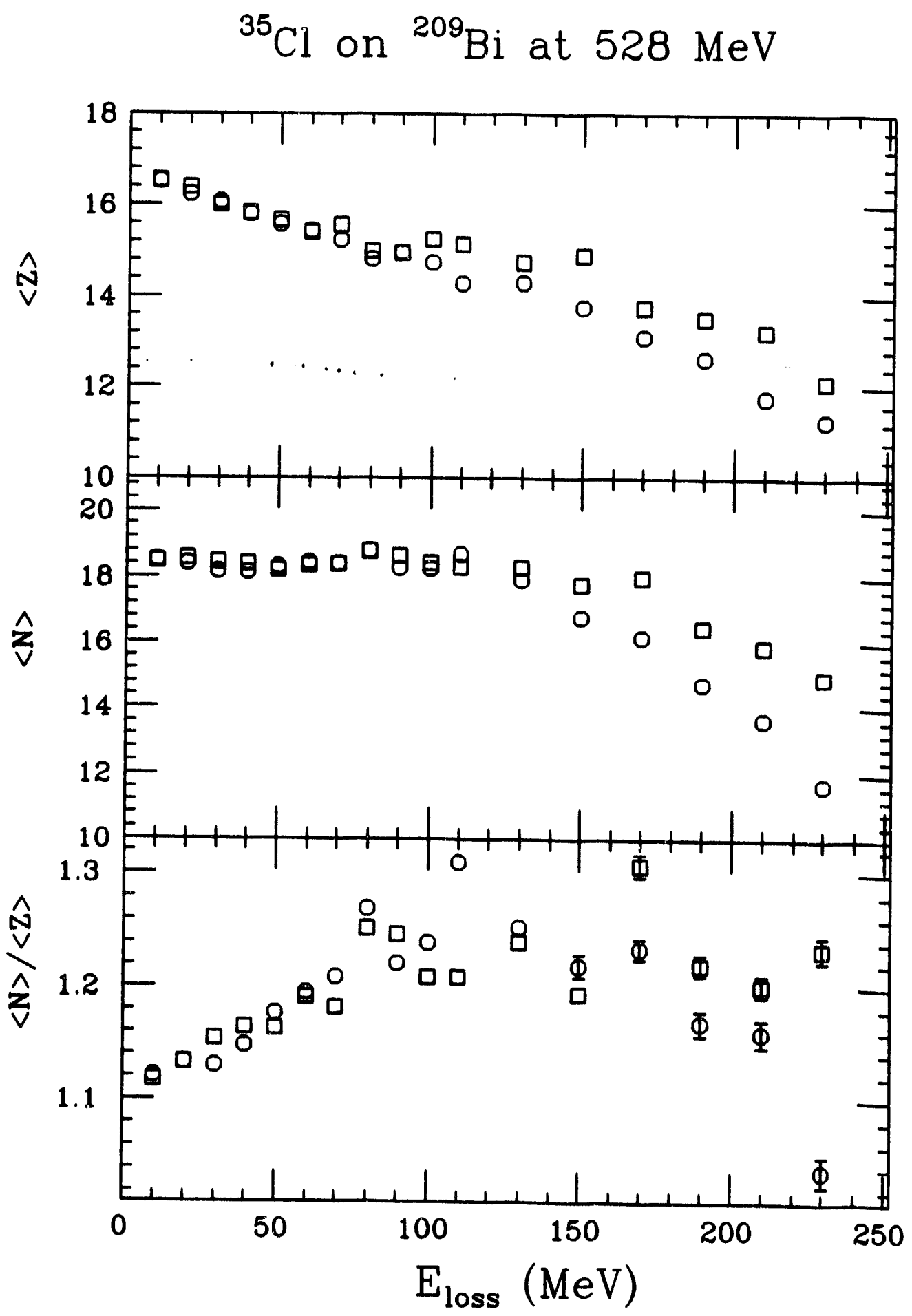


units. The differences in $\langle\mathrm{N}\rangle$ evolve similarly, giving differences of up to 4 mass units. As expected, the $\langle\mathrm{Z}\rangle$ and $\langle\mathrm{N}\rangle$ corresponding to equal division of the excitation energy are smaller than those corresponding to thermal division.

\section{IV.D COMPARISON BETWEEN MOMENT ANALYSIS AND GAUSSIAN FIT}

There are practically no differences between the Gaussian fit and moment analysis in the determination of the average values and their ratio in the three systems

studied. This is expected since the averages are not very sensitive to the details of the distribution. On the other hand, the variances and correlation coefficient are very sensitive to the details of the distribution. For the two very asymmetric systems, both methods of evaluation do not produce great differences in the variances. However in the case of ${ }^{37} \mathrm{Cl}$ on ${ }^{40} \mathrm{Ca}$, important differences are observed at high energy loss. The reason for this discrepancy is that the distribution has to be truncated in the $\mathrm{N}-\mathrm{Z}$ plane due to oxygen contamination. This truncation should not have an important effect on a Gaussian fit, but it will affect very much the variances calculated using moment analysis.

The correlation coefficients of the systems ${ }^{37} \mathrm{Cl}$ on ${ }^{209} \mathrm{Bi}$ and ${ }^{40} \mathrm{Ca}$ show significant differences at low energy loss depending on the method used. The correlation coefficient provides a measure of the mutual dependence between $\mathrm{N}$ and Z. In a two-dimensional Gaussian, it is related to the angle of orientation of the distribution in the $\mathrm{N}-\mathrm{Z}$ plane. However, at low energy loss, the distributions are composed of only a small number of nuclides and their Gaussian characteristic is barely evident. This may make the orientation of the Gaussian a parameter very sensitive to small variations in the distribution. The low resolution in the $\mathrm{N}$ value of 
the Oak Ridge data may result in a poor definition of the angle in the $\mathrm{N}-\mathrm{Z}$ plane, especially at low energy loss.

Finally, it seems that there are no valid criteria to choose one method over the other. For the most part, both methods are more or less in good agreement and when they are not the meaning of the parameters of the distribution is already questionable. The numerical values obtained for the distribution parameters for the three systems in question using the Gaussian fit and moment analysis can be found in Appendix A. 


\section{CHAPTER V DISCUSSION}

The evolution of the parameters of the mass and charge distributions is a consequence of the deep-inelastic mechanism. It is interesting to compare model predictions to the experimental data to test the validity of the physical ideas behind the model. In this chapter the experimental data are compared to calculations from two current models for deep-inelastic reactions and to published results from different systems. The two models are based on stochastic transport theories, and a basic background of the physical foundations is given. It is not a purpose of this chapter to review the various theoretical models that describe deep-inelastic collisions; a general review can be found in articles by W.U. Schröder and J.R. Huizenga [SCH 84], and by H. Freiesleben and J.V. Kraft [FRE 84]. A review on transport theories applied to heavy-ion reactions has been published by H.A. Weindenmüller [WEI 80].

\section{V.A PHYSICAL BACKGROUND}

The interaction between two nuclei during a nuclear reaction is a complex multibody problem. One approach taken to treat the Hamiltonian $(H)$ of such systems is to divide the degrees of freedom into collective (macroscopic) and intrinsic (microscopic):

$$
H=H_{c}+H_{i}+H_{c i}
$$

where $H_{C}$ and $H_{i}$ represent the Hamiltonian of the collective and intrinsic variables respectively, and $H_{C i}$ is the Hamiltonian of the coupling between both variables types. In general, the collective degrees of freedom are the variables of experimental 
interest. They represent, for example, the total kinetic energy, mass, and angular momentum of the system. Normally, the intrinsic variables are not of practical interest, but they affect the evolution of the collective ones. The importance of this effect depends on the coupling Hamiltonian. In cases where the coupling is weak, first order perturbation theory can readily be applied. However, from the features of deep-inelastic collisions described in Chapter I, it is evident that the coupling between collective and instrinsic variables is very strong. The coupling Hamiltonian accounts for the transfer of energy from the collective to the intrinsic variables. It is responsible, for example, for the significant damping of the total kinetic energy that produces very excited nuclei in the exit channels.

Simple phenomenological models consider the coupling by introducing frictional forces in the equations of motion. This approach does not account for the fluctuations observed experimentally in the collective variables. There is a stochastic aspect to deep-inelastic collisions similar to the the type of phenomena described in statistical mechanics (Brownian motion, thermal noise, etc.). This prompted the application of theories developed in non-equilibrium statistical mechanics to formulate models for heavy-ion reactions. The most interesting models are the ones that use basic principles for their predictions and do not depend on fitted parameters; they provide the best physical understanding of the reaction mechanism.

The Liouvillean formulation of quantum mechanics can be used to describe the problem theoretically [BAL 84]. The evolution of the system in time is given by the von Neumann equation (quantum analogue of Liouville's equation):

$$
\text { i hbar } \frac{\mathrm{d} \rho}{\mathrm{d} t}=[H, \rho]
$$


where $\rho$ is the density operator, $H$ is the Hamiltonian, and the square bracket represents the commutator (the Poisson bracket in classical mechanics). This formulation is more general than the standard one in Hilbert space. An essential feature is that the density operator can be reduced by using the method of Nakajima and Zwanzig [NAK 58, ZWA 60]. The density operator is decomposed into the sum of two operators, one of them describing the evolution of the relevant variables. Formally, this procedure corresponds to a projection of the total density operator on the plane parameterized by the relevant variables. After some manipulations and averaging over the intrinsic variables, an exact generalized master equation can be obtained:

$$
\mathrm{i} h \mathrm{hbar} \frac{\mathrm{d} d}{\mathrm{~d} t}=L_{\text {eff }} d-\mathrm{i} \int_{0}^{\mathrm{t}-\mathrm{t}_{0}} \mathrm{~K}(\mathrm{~s}) d(\mathrm{t}-\mathrm{s}) \mathrm{ds}+\mathrm{I}(\mathrm{t})
$$

where $d$ is the reduced density operator, $L_{e f f}$ is an effective Liouvillian operator acting only on the relevant variables, $\mathrm{K}$ is a memory kernel which descries the evolution of the intrinsic variables, and $\mathrm{I}$ is an inhomogeneity term. The equation V.3 is very complicated and it becomes necessary to resort to approximations for practical applications.

Transport models differ in the assumptions used to simplify the problem (treatment of the intrinsic variables, choice of macroscopic variables, etc.). It is generally assumed that the macroscopic variables are much slower in their evolution in time than the microscopic variables. Therefore, the intrinsic variables can be considered at equilibrium within the time scale of the collective ones. This type of approximation is called Markovian. Hofmann and Siemens derived equations of motion for the macroscopic variables based on these assumptions [HOF 76,77]. 
They considered the intrinsic variables as a thermal bath for the collective ones. They further assumed that the coupling between collective and intrinsic variables could be treated using the methods of linear response theory. Since the collective variables for heavy-ion reactions at low energies exhibit classical behavior, a transport equation is obtained similar to the Fokker-Planck equation. The distribution function $f$ in collective phase space is then described by:

$$
\frac{\mathrm{d} f}{\mathrm{dt}}=\left[H_{C}, f\right] \cdot \sum_{\mathrm{i}} \frac{\delta}{\delta C_{i}} \mathrm{v}_{\mathrm{i}} f+\sum_{\mathrm{j} j} \frac{\delta}{\delta C_{i}} \frac{\delta}{\delta C_{j}} \mathrm{D}_{\mathrm{ij}} f
$$

where $C_{i}$ represents a collective variable, $V_{i}$ is the drift coefficient, $D_{i j}$ is the diffusion coefficient, and the first term of the equation is a Poisson bracket. The Poisson bracket contains terms only for those variables whose conjugate is present in the Hamiltonian (e.g.: momentum and position). As the system evolves in time, the drift coefficient reflects the speed of change in the average value of the variable distribution, while the diffusion coefficient accounts for the stochastic aspects of the process (dispersion).

Nörenberg [NOR 75] developed a non-perturbative approach based on the random matrix model. He defined averages over the intrinsic states by dividing the channel space into subsets (coarse graining) in which the macroscopic variables have about the same value. He then assumed that the coupling matrix elements are random numbers with Gaussian distributions. After other simplifications, the author deduced a Pauli-type master equation:

$$
\frac{d P_{v}(t)}{d t}=\sum_{\mu} \omega_{v \mu}(t)\left[d_{v} P_{\mu}(t)-d_{\mu} P_{v}(t)\right]
$$


where $P_{v}$ is the probability of the system to be in a coarse cell $v, \omega_{v \mu}$ is the transition probability between the cells $v$ and $\mu$, and $d$ represents the number of states present in the cell. The equation V.4 was further simplified to a Fokker-Planck type of equation. For this common approximation, the variables $\mathrm{d}$ and $\mathrm{P}$ are expanded in a Taylor series up to the second order terms, and $\omega$ is assumed to be sharply peaked, symmetric and slowly varying.

\section{V.A.1 Stochastic Nucleon Exchange Model of Randrup}

The application of Transport Theory to deep-inelastic collisions is the basis of Randrup's model [RAN 78,79,82]. Randrup adopted the dynamical frame developed by Hofmann and Siemens. The time evolution of the distribution function $f$ is governed by equation V.3. The distribution function depends on the collective variables besides the time and solving it can be cumbersome. The problem was simplified by using an approximation known as the mean-trajectory method, which is fully described in reference [RAN 82].

In Randrup's model it is assumed that nucleon exchange is the only important mechanism of dissipation. Therefore, the damping of the kinetic energy, the transport of angular momentum, and the evolution of the system in the $\mathrm{N}-\mathrm{Z}$ plane are explained in terms of the exchange of nucleons between the reaction partners. The system is represented by two Fermi-Dirac gases that exchange particles. The Fermi energy corresponding to a nucleus at zero temperature (totally degenerate) is about 37 $\mathrm{MeV}$. At typical temperatures reached in deep inelastic processes (kT 0.5 - 2.0 $\mathrm{MeV}$ ), the nucleus can be considered to remain totally degenerate and, because of the Pauli exclusion principle, collisions between nucleons are highly improbable. 
Therefore, a nucleon interacts mainly via collisions with the mean field generated by the other nucleons (the "walls" of the container). Since the two nuclei are in motion with respect to each other, a nucleon transferring from one nucleus to the other carries relative momentum. The transferred nucleon equilibrates in the new mean field, and in this way the relative kinetic energy is transformed into reaction Q-value. This type of mechanism is known as one-body dissipation.

The dinuclear system is idealized as two spherical nuclei ( $A$ and $B$ ) joined by a small cylindrical neck. The collective or relevant variables are: the distance between the two sphere centers and the corresponding conjugate momentum, the angle of the dinuclear axis with the reaction plane, the mean spin projections of the projectile-like and target-like fragments, the atomic number and the neutron number of the projectile-like fragment, and the radius of the neck. In addition, some redundant variables are defined for convenience.

The drift and diffusion coefficients are calculated according to

$$
\begin{aligned}
& \mathrm{V}_{i}=\int d \varepsilon N^{\prime}(\varepsilon)<\left(f^{B}-f^{A}\right) C_{i}>\text {, and } \\
& \mathrm{D}_{i j}=\int d \varepsilon N^{\prime}(\varepsilon)<\left[f^{B}\left(1-f^{A}\right)+f^{A}\left(1-f^{B}\right)\right] C_{i} C_{j}>,
\end{aligned}
$$

respectively. The quantity $N^{\prime}$ represents a one way nucleon current including a form factor; $f$ represents the single particle occupation probability of nucleus $\mathrm{A}$ or $\mathrm{B}$, the symbol $<>$ indicates a flux average, and the Pauli blocking factor is $1-f$.

The change in intrinsic excitation energy associated with a nucleon transfer from $B$ to $A$ is defined as

$$
\mathbf{w}=\mathbf{F}_{\mathbf{A}}-\mathbf{U} \mathbf{p}
$$


where $\mathrm{F}_{\mathrm{A}}$ is the ground state change of energy produced by the nucleon transfer, $\mathrm{U}$ is the relative velocity of the nuclei, and $p$ the momentum of the transferred nucleon. For nearly degenerated gases, equations V.5 and V.6 can be simplified to

$$
\begin{aligned}
& \mathrm{V}_{i} \approx N^{\prime}\left(\varepsilon_{F}\right)<C_{i} \mathrm{w}>F \\
& \mathrm{D}_{i j} \approx N^{\prime}\left(\varepsilon_{F}\right)<0.5 \mathrm{w} C_{i} C_{j} \operatorname{coth} \frac{\mathrm{w}}{2 \tau}>F
\end{aligned}
$$

where $\tau$ is the nuclear temperature and the subscript $F$ indicates that only particles in the Fermi surface should be considered in the flux average.

The dynamical equations for the mean trajectory are derived using the Lagrange-Rayleigh formulation of the equations of motion. The conservative driving forces are derived from the Lagrangian of the macroscopic system. The dissipative forces are obtained from the Rayleigh dissipation function. The dissipation function is composed of four terms. The first term is the window friction, the strength of which is proportional to the current of exchanged nucleons. The second term is referred as to wall dissipation and originates in the change of the neck radius. The third and four terms are associated with the energy dissipated with the change of the partition of neutrons and protons between the two nuclei.

\section{V.A.2 Stochastic Nucleon Exchange Model of Tassan-Got}

Assuming the same basic scenario that Randrup used, Tassan-Got developed another model to describe deep-inelastic reactions [TAS 88,89]. He utilizes the following working hypotheses: 
1. The system is described as two potential wells, each containing a fixed number of nucleons.

2. Each ensemble of nucleons is at statistical equilibrium in its corresponding well (Markovian hypothesis).

3. The nucleons are treated in the classical limit.

4. The exchange of nucleons is the only dissipative mechanism.

These assumptions are identical to the ones used in Randrup's model.

This model has been implemented using a Monte Carlo method. The observables are calculated on an event-by-event basis. An event starts with two nuclei approaching in an analytically described Coulomb trajectory. When the two nuclei are within range of the nuclear field a window opens and stochastic transfers can occur. At that stage, the relative motion and potential are solved numerically in steps. At each step the neutron and proton transfer probabilities are calculated. The possibility of occurrence of a transfer and the type of transfer is determined by random number generation for each step of the trajectory. If a transfer happens, the characteristics of the nuclei are changed in accordance (mass, atomic number, angular momentum, excitation energy, etc.). The motion is conservative between transfers and only the transfers generate dissipation. As the two nuclei separate, the nuclear field weakens. Finally, they return to a pure Coulomb trajectory. The resulting event is stored and a new event follows.

For a given nucleon transfer from nucleus 1 to nucleus 2, Tassan-Got determines the effect on the relative kinetic energy by invoking energy conservation:

$$
\Delta \delta_{1}+\Delta \delta_{2}+\Delta E_{1}+\Delta E_{2}+\Delta K+\Delta U=0
$$


where $\Delta \delta$ represents the change in ground state energy, $\mathrm{K}$ is the relative kinetic energy, and $U$ is the potential energy of the composite system. The quantity $\Delta E$ represents the difference between the Fermi energy $\left(\varepsilon_{F}\right)$ and the energy of the nucleon in question $(\varepsilon)$ :

$$
\Delta \mathrm{E}_{1}=\varepsilon_{\mathrm{F} 1}-\varepsilon_{1}
$$

$$
\Delta E_{2}=\varepsilon_{2}-\varepsilon_{F 2}
$$

where the prime indicates the quantity after nucleon transfer. The combination of equations V.10, 11, and 12 gives:

$$
\Delta \mathrm{K}=-\Delta \mathrm{U}-\left(\varepsilon_{2}-\varepsilon_{1}\right)
$$

In a similar way, if $S_{1}$ and $S_{2}$ represent the nuclear spin, and $L$ the relative angular momentum, the change in relative angular momentum $(\Delta \mathrm{L})$ will be given by:

$$
\begin{aligned}
& \Delta S_{1 \text { or } 2}=m_{1} \text { or } 2 \\
& \Delta L=-\left(m_{2}-m_{1}\right) .
\end{aligned}
$$

The transfer process is described by five parameters $[\sigma=(\varepsilon, \lambda, \mu, \rho, \theta)]$. The first three characterize the velocity of the nucleon being transferred; the last two describe the window position. The transfer probability $(\mathrm{P})$ of a nucleon from a nucleus 1 to nucleus 2 is then given by 


$$
P=\int d^{5} \sigma \phi T n_{1}\left(1-n_{2}\right)
$$

where $\phi$ is the one way local flux, T is a barrier penetrability depending on the particle potential at the window, and $\mathrm{n}$ represents the occupation probability of nucleus 1 or 2.

The probabilities for the four possible nucleon transfers are calculated using equation V.16 and the fate of the system is determined by random drawing. If a transfer happens, its characteristics are also determined by random drawing using the partial probability integrand of equation V.16. A physical restriction used in this model is that only nucleons moving towards the window can be transferred; this restriction is not present in Randrup's model.

\section{V.B EVAPORATION CORRECTION OF MODEL PREDICTIONS}

Model calculations for the three experimental systems were performed using the computer codes created by Randrup and Tassan-Got. Both codes predict primary distributions which are given as a function of energy loss. To compare with experimental data, corrections for evaporation had to be included. For the correction, the nuclei of the primary distributions are submitted as input to an evaporation code. The yields of the nuclei resulting from the evaporation simulation properly normalized to the primary distribution constitute the secondary distributions. Moment analysis was performed on these distributions to obtain their characteristic parameters as a function of energy loss. The evaporation code used was PACE [GAV 80]. The relevant inputs to this code are the nucleus $A$ and $Z$, the excitation energy, and the spin. The PACE code simulates the decay of a given excited nucleus using a Monte 
Carlo method. The number of events per input nucleus was arbitrarily set to 100 . It is important to remember that only projectile-like fragments were detected experimentally, therefore these distributions are the only ones considered for comparison.

For the case of Randrup's code, the primary distribution is given in terms of the parameters of a two-dimensional Gaussian distribution in the $\mathrm{N}-\mathrm{Z}$ plane as a function of the energy loss. Every nucleus in the $\mathrm{N}-\mathrm{Z}$ plane with an associated probability of over 5\% was used as a PACE input for the evaporation correction. Randrup's code also generates an output consisting of average values for parameters like temperature, spin, rotational energy, etc. Some assumptions had to be made regarding the parameters required by the evaporation code for each indi vidual nucleus. For the different reaction products, the rotational energy $\left(\mathrm{E}_{\mathrm{rot}}\right)$ is calculated by scaling the average value $(<>)$. The scaling is done assuming the same l-value for the angular momentum of every nucleus, and multiplying the average rotational energy by the ratio of moments of inertia; the latter can be expressed as a ratio of masses only:

$$
\mathrm{E}_{\mathrm{rot}}=\left\langle\mathrm{E}_{\mathrm{rot}}>\left(\frac{\langle\mathrm{M}\rangle}{\mathrm{M}}\right)^{5 / 3}\right. \text {. }
$$

To calculate the total excitation energy $\left(E^{*}\right)$ for a particular reaction channel, the ground state $Q$-value $\left(\mathrm{Q}_{\mathrm{gg}}\right)$ was added to the energy loss $\left(\mathrm{E}_{\mathrm{loss}}\right)$ and the total rotational energy subtracted:

$$
E^{*}=E_{\text {loss }}+Q_{g g}-E_{\text {rot-total }}
$$


The total rotational energy is the addition of the rotational energy of the target-like and projectile-like fragments.

It was assumed that the temperatures of the projectile-like and target-like fragments were identical to the average values given by the model, likewise for the spin values. To calculate the excitation energy of the projectile-like fragment, the excitation energy obtained in equation V.18 was multiplied by an excitation energy division factor. This factor was calculated using the relation:

$$
\frac{E_{\text {PLF }}^{*}}{E^{*}{ }_{\text {TLF }}}=\frac{\text { aPLF } T^{2} \text { PLF }}{\text { a TLF }^{2} \text { TLF }} \sim \frac{A_{\text {PLF }} T^{2} \text { PLE }}{A_{\text {TLF }} T^{2} \text { TLF }}
$$

where $\mathrm{A}$ is the mass, $\mathrm{a}$ is the level density parameter (roughly $\mathrm{A} / 8$ ), $\mathrm{T}$ is the temperature, and the subscripts TLF and PLF mean target-like and projectile-like fragment, respectively. The yield of the different nuclei obtained after evaporation was multiplied by a factor proportional to the probability corresponding to the parent nucleus in the primary distribution, and the resulting secondary yield was stored, along with the corresponding $A, Z$, and energy loss, for subsequent moment analysis.

On the other hand, Tassan-Got's code operates on an event-by-event mode. A number of events is generated for each value of incoming angular momentum (L). For the cases under study, the number of events was chosen to be proportional to $2 \mathrm{~L}$ +1 to maintain a direct relation with the physical cross section. The end result was a detailed discrete primary distribution. In each event, the code characterizes completely the projectile- and target-like fragments of the primary distribution in terms of excitation energy, spin, energy loss, etc.. Therefore, the output corresponding to the projectile-like fragments was directly stored in a file to be 
submitted to PACE. The results of the evaporation calculations were also stored for subsequent moment analysis to obtain $\langle\mathrm{Z}\rangle,\langle\mathrm{N}\rangle,\langle\mathrm{N}\rangle \mid\langle\mathrm{Z}\rangle, \sigma^{2} \mathrm{Z}, \sigma^{2} \mathrm{~N}$, and $\rho_{\mathrm{NZ}}$.

\section{V.C COMPARISON OF MODEL PREDICTIONS TO THE EXPERIMENTAL RESULTS}

In this section experimental distributions are compared to the evaporation corrected model distributions. As in Chapter IV, the results are expressed as a function of energy loss in terms of $\langle N\rangle$ and $\langle Z\rangle$, the ratio $\langle N\rangle \mid\langle Z\rangle$, the variances $\sigma Z^{2}$ and $\sigma N^{2}$, and correlation coefficient $\rho \mathrm{NZ}$. A comparison between the primary distributions predicted by each model is also shown. For simplicity, only the experimental data corresponding to the Gaussian fits are shown for comparison. It was shown in Chapter IV that, for the most part, there is no difference between the results obtained using moment analysis and Gaussian fit.

V.C.1 The system ${ }^{37} \mathrm{Cl}$ on ${ }^{40} \mathrm{Ca}$ at $270 \mathrm{MeV}$

The values of $\langle\mathrm{Z}\rangle,\langle\mathrm{N}\rangle$, and the ratio $\langle\mathrm{N}\rangle \mid\langle\mathrm{Z}\rangle$ as a function of energy loss are shown in Figure V.1 for the primary distribution of projectile-like fragments as predicted by the models. Both models show the same results: a slight increase in the average atomic number and a slight decrease in the average neutron number with increasing energy loss. The tendency is to equilibrate the $\langle\mathrm{N}\rangle \mid\langle\mathrm{Z}\rangle$ ratio of the system. In Figure V.2 the variances $\sigma_{\mathrm{Z}}{ }^{2}$ and $\sigma_{\mathrm{N}}{ }^{2}$ are shown along with the correlation coefficient in the $\mathrm{N}-\mathrm{Z}$ plane $\left(\rho_{\mathrm{NZ}}\right)$; both models reveal the same trend. The variances increase with energy loss for $\mathrm{Z}$ and $\mathrm{N}$, while the correlation coefficient tends to one. 
Figure V.1

Model predictions for $\langle\mathrm{Z}\rangle,\langle\mathrm{N}\rangle$, and $\langle\mathrm{N}\rangle \mid\langle\mathrm{Z}\rangle$ corresponding to the primary distributions of the reaction ${ }^{37} \mathrm{Cl}$ on ${ }^{40} \mathrm{Ca}$ at $270 \mathrm{MeV}$ as a function of energy loss. The solid line represents the results from Randrup's model and the dashed line represents the results from Tassan-Got's. The horizontal dotted lines represent the ratio $N / Z$ of the projectile (top) and compound system (bottom), respectively. 


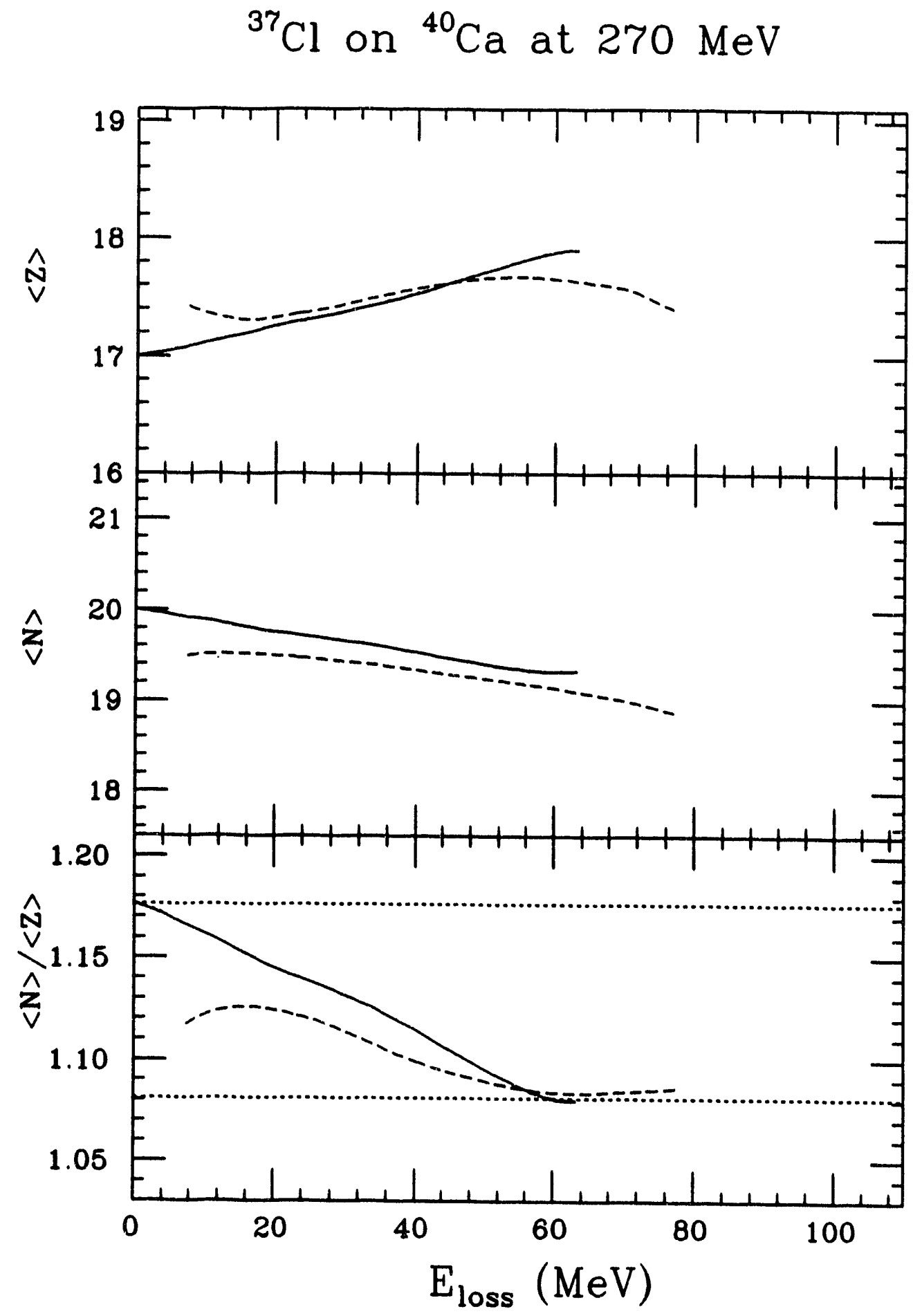


Figure V.2

Model predictions for $\sigma^{2} \mathrm{Z}, \sigma^{2} \mathrm{~N}$, and $\rho_{\mathrm{NZ}}$ corresponding to the primary distributions of the reaction ${ }^{37} \mathrm{Cl}$ on ${ }^{40} \mathrm{Ca}$ at $270 \mathrm{MeV}$ as a function of energy loss. The solid line represents the results from Randrup's model and the dashed line represents the results from Tassan-Got's. 


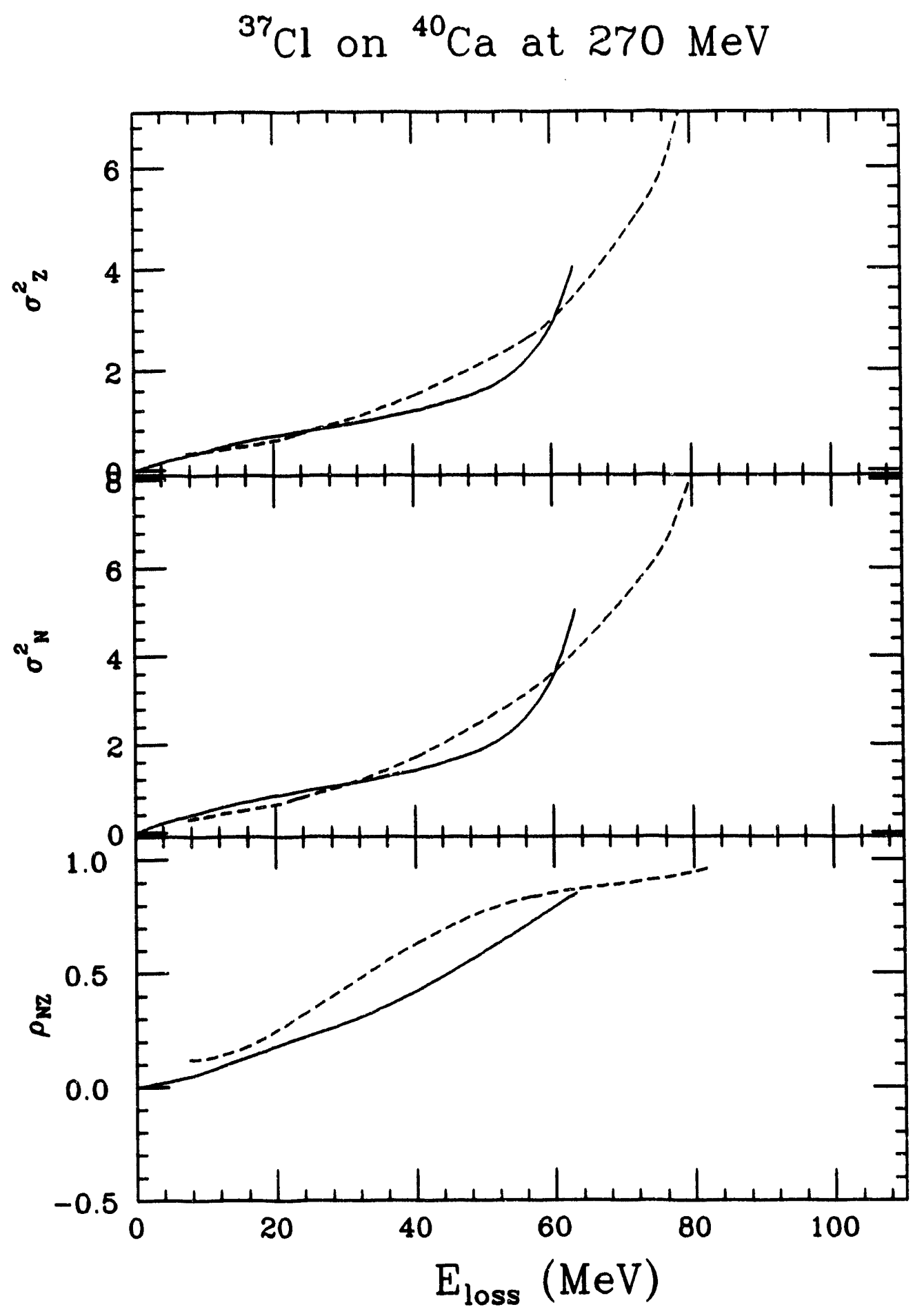


In Figures V.3 and 4 the models, after evaporation corrections, are compared to the experimental distributions. As seen in Figure V.3, there is a good agreement between model predictions and the data for the case of $\langle\mathrm{Z}\rangle,\langle\mathrm{N}\rangle$, and their ratio. However, Figure V.4 shows that, as the energy loss increases, the experimental variances become substantially larger than the ones predicted by both models. This discrepancy occurs well before the Coulomb barrier $\left(E_{\text {loss }} \sim 93 \mathrm{MeV}\right)$. The experimental correlation coefficient raises and tends to 1.0 faster than the model predictions .

The primary distribution of a symmetric system should not drift in the averages of $Z$ and $N$, because, physically, there is not a preferential direction of the flow of nucleons between nuclei. In consequence, the values predicted for $\langle\mathrm{Z}\rangle$ and $<\mathrm{N}>$ by different models have to be rather insensitive to the model being used. Therefore, a comparison between the predicted and experimental $\langle\mathrm{Z}\rangle$ and $\langle\mathrm{N}\rangle$ will serve mainly as a test for the evaporation correction. On the other hand, the variances in the $\mathrm{Z}$ and $\mathrm{N}$ distributions are not greatly affected by evaporation; they should be more a reflection of the reaction mechanism, and hence serve as a test for the model in question.

The system presented in this section is almost symmetric and it can be expected to behave as a symmetric one for practical purposes. The good agreement observed between the experimental and predicted $\langle\mathrm{Z}\rangle$ and $\langle\mathrm{N}\rangle$ indicates tirat the method of evaporation correction is appropriate. The variances are, however, underestimated by both models, as is the correlation coefficient. This could be indicative of either an inadequate model description of the mechanism or another type of process taking place which contributes to the width of the distribution.

D. K. Lock et al. [LOC 85] compared the predictions from Randrup's model to the results of Breuer et al. [BRE 83b] on the systems ${ }^{36} \mathrm{Fe}$ on ${ }^{56} \mathrm{Fe}$ and ${ }^{238} \mathrm{U}$. The 
Figure V.3

Experimental results (circles) and model predictions for $\langle\mathrm{Z}\rangle,\langle\mathrm{N}\rangle$, and $\langle\mathrm{N}>|<\mathrm{Z}>$ corresponding to the secondary distributions of the reaction ${ }^{37} \mathrm{Cl}$ on ${ }^{40} \mathrm{Ca}$ at $270 \mathrm{MeV}$ as a function of energy loss. The solid line represents the results from Randrup's model and the dashed line represents the results from Tassan-Got's. The horizontal dotted lines represent the ratio $N / Z$ of the projectile (top) and compound system (bottom), respectively. 


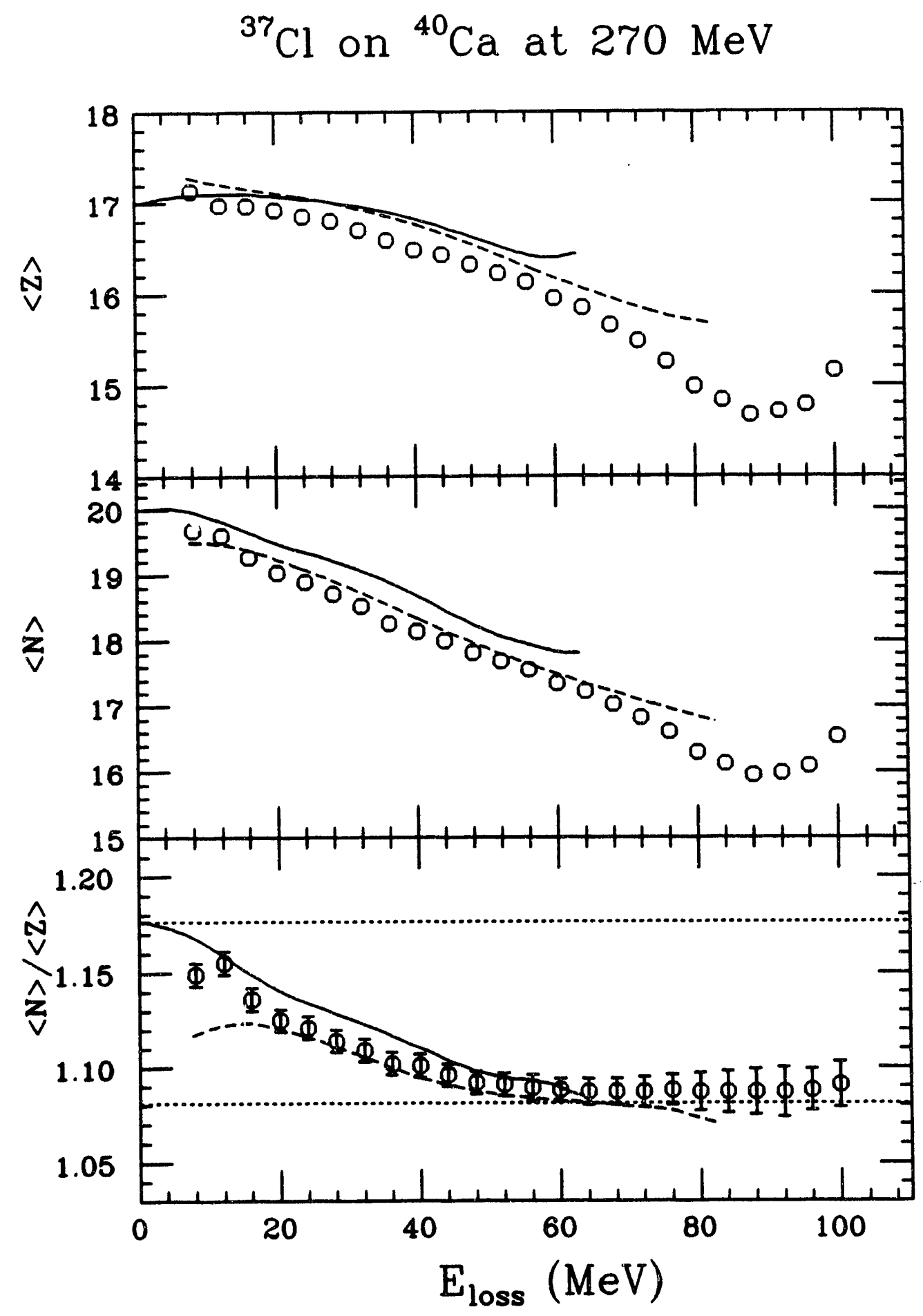


Figure V.4

Experimental results (circles) and model predictions for $\sigma^{2}, \sigma_{N}^{2}$, and $\rho_{N Z}$ corresponding to the secondary distributions of the reaction ${ }^{37} \mathrm{Cl}$ on ${ }^{40} \mathrm{Ca}$ at $270 \mathrm{MeV}$ as a function of energy loss. The solid line represents the results from Randrup's model and the dashed line represents the results from TassanGot's. 


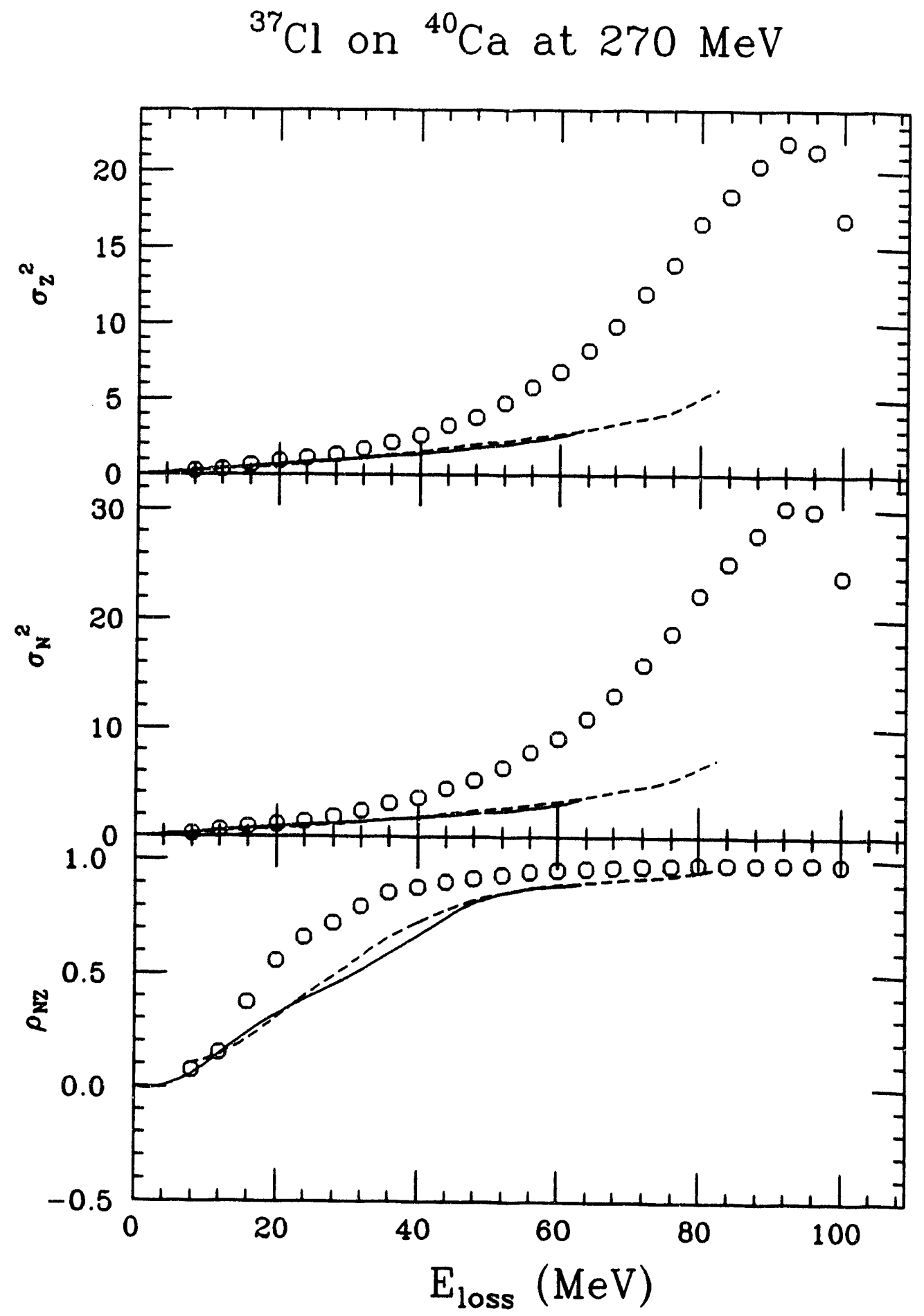


authors' observations on the symmetric system are qualitatively the same as the ones presented here for ${ }^{37} \mathrm{Cl}$ on ${ }^{40} \mathrm{Ca}$, with the exception of the correlation coefficient which, in their case, is in good agreement with the data after being corrected for evaporation effects. Since the correlation coefficient in the $\mathrm{N}-\mathrm{Z}$ plane is an indicator of how neutron and proton transfers between nuclei have a mutual dependence, the difference in the $N / Z$ ratio between nuclei should be a strong factor in determining these transfers. There is no such difference in a totally symmetric system like ${ }^{56} \mathrm{Fe}$ on ${ }^{56} \mathrm{Fe}$. However, the system ${ }^{37} \mathrm{Cl}$ on ${ }^{40} \mathrm{Ca}$ presents a significant difference in the $N / Z$ ratio between target and projectile that could help explain the discrepancy observed. The symmetric systems can generate fusion-fission products with masses close to that of the projectile and kinetic energies close to the Coulomb barrier; thus, the opening of fusion-fission channels can explain the large variances observed in $\mathbf{N}$ and $\mathrm{Z}$.

V.C.2 The system ${ }^{37} \mathrm{Cl}$ on ${ }^{209} \mathrm{Bi}$ at $270 \mathrm{MeV}$

The predictions of the models for the projectile-like primary distributions of the asymmetric system ${ }^{37} \mathrm{Cl}$ on ${ }^{209} \mathrm{Bi}$ arfer mainly in the $\langle\mathrm{Z}\rangle$ and $\langle\mathrm{N}\rangle$ values. As shown in Figure V.5, Tassan-Got predicts a lower $<Z>$ than Randrup, and the difference increases with energy loss. The $<\mathrm{N}\rangle$ value is also lower for Tassan-Got's prediction and so is the ratio $\langle\mathrm{N}>\mid<\mathrm{Z}\rangle$. However, the latter appears to have the same functional dependence in both models: a steady increase with energy loss towards the ratio N/Z of the compound system. It is interesting to note that, while Randrup's model indicates a more or less constant $\langle\mathrm{Z}\rangle$ and increasing $\langle\mathrm{N}\rangle$ with increasing energy loss, Tassan-Got's model shows a more or less constant $\langle\mathrm{N}\rangle$ and a 
Figure V.5

Model predictions for $\langle\mathrm{Z}\rangle,\langle\mathrm{N}\rangle$, and $\langle\mathrm{N}\rangle \mid\langle\mathrm{Z}\rangle$ corresponding to the primary distributions of the reaction ${ }^{37} \mathrm{Cl}$ on ${ }^{209} \mathrm{Bi}$ at $270 \mathrm{MeV}$ as a function of energy loss. The solid line represents the results from Randrup's model and the dashed line represents the results from Tassan-Got's.. The horizontal dotted lines represent the ratio $N / Z$ The horizontal dotted lines represent the ratio $N / Z$ of the projectile (bottom) and compound system (top). 


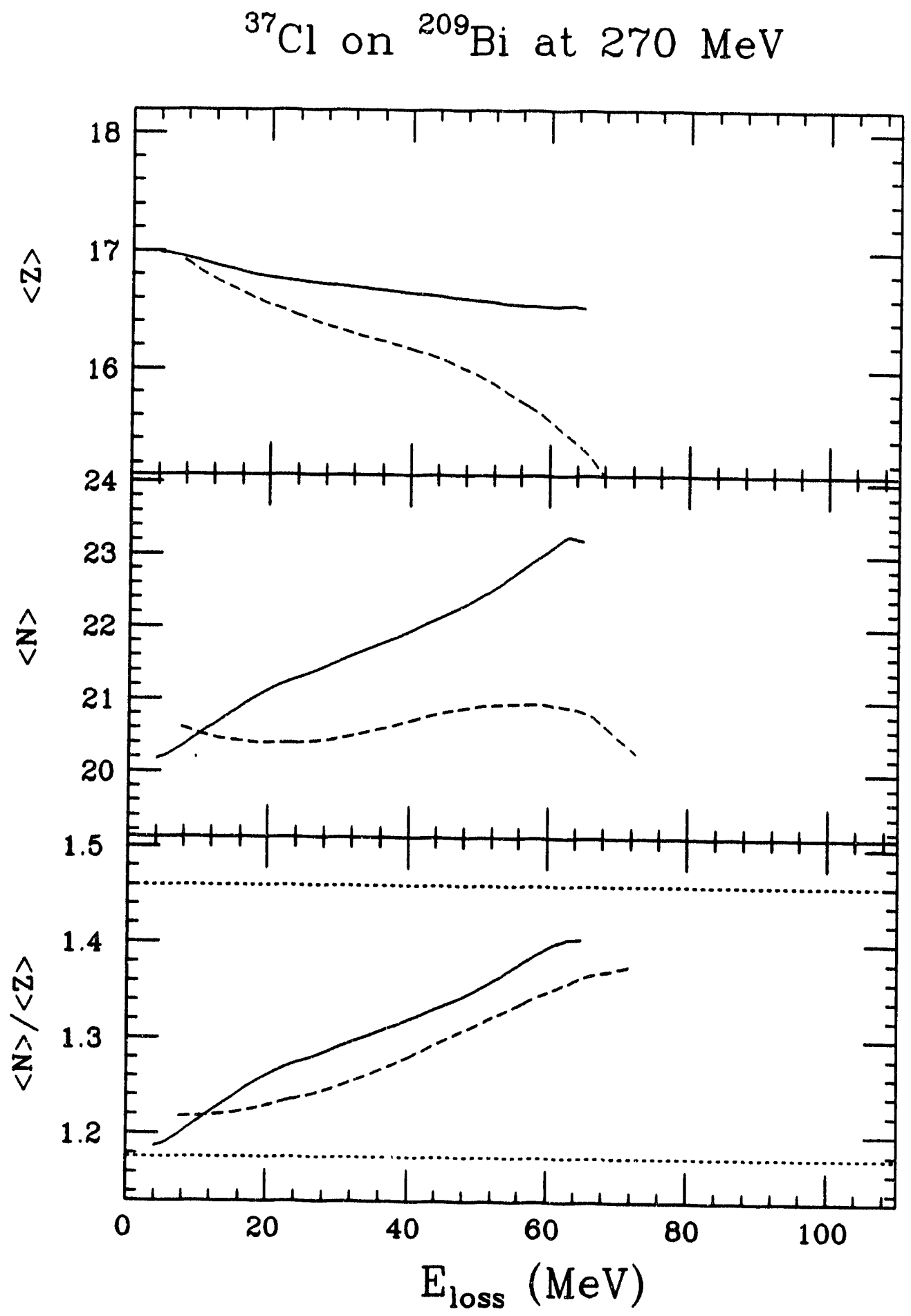


decreasing $\langle Z\rangle$. Therefore, in Tassan-Got's model the system evolves towards greater asymmetry, while in Randrup's model the system evolves towards symmetry.

The variances and correlation coefficients from the two models are compared in Figure V.6. For about the first $60 \mathrm{MeV}$ of energy loss, the variances and correlation coefficient predicted by both models show th - same qualitative trend; they increase smoothly with increasing energy loss. As the Coulomb barrier is approached ( $75 \mathrm{MeV}$ of energy loss), the variances predicted by Randrup show a pronounced increase, while, after the first $50 \mathrm{MeV}$ of energy loss, the variances predicted by Tassan-Got remain more or less constant. The $\mathrm{Z}$ variance predicted by Tassan-Got is smaller overall than that predicted by Randrup's model, while the $\mathbf{N}$ variance crosses over and becomes higher than Randrup's variance between 24 and $60 \mathrm{MeV}$ of energy loss. The correlation coefficient predicted by Tassan-Got remains more or less constant at 0.7 after the first $50 \mathrm{MeV}$ of energy loss and is higher than Randrup's prediction up to $60 \mathrm{MeV}$ of energy loss.

The experimental $\langle\mathrm{Z}\rangle$ and $\langle\mathrm{N}\rangle$ and their ratio are compared to model predictions in Figure V.7. Two sets of values are shown for the experimental data; each one corresponding to a different assumption in the energy-loss scale correction for evaporation, as indicated in Chapters II and IV. The circles and squares represent the correction assuming equal and thermal division of the excitation energy, respectively. Tassan-Got's model shows a good agreement in $\langle\mathrm{Z}\rangle$ with the experimental data, while Randrup's model overestimates $\langle Z\rangle$. For the first $40 \mathrm{MeV}$ of energy loss, Tassan-Got's prediction of $\langle\mathrm{N}\rangle$ is also good, after that value of energy loss, it slightly overpredicts $<N>$, but follows the trend of the experimental data. Randrup's model predicts an increase of $\langle\mathrm{N}\rangle$ with increasing energy loss, even after evaporation corrections, a behavior opposite to the trend of the experimental data. There do not seem to be important differences in the ratio 


\section{Figure V.6}

Model predictions for $\sigma^{2} \mathrm{Z}, \sigma_{\mathrm{N}}^{2}$, and $\rho_{\mathrm{NZ}}$ corresponding to the primary distributions of the reaction ${ }^{37} \mathrm{Cl}$ on ${ }^{209} \mathrm{Bi}$ at $270 \mathrm{MeV}$ as a function of energy loss. The solid line represents the results from Randrup's model and the dashed line represents the results from Tassan-Got's. 


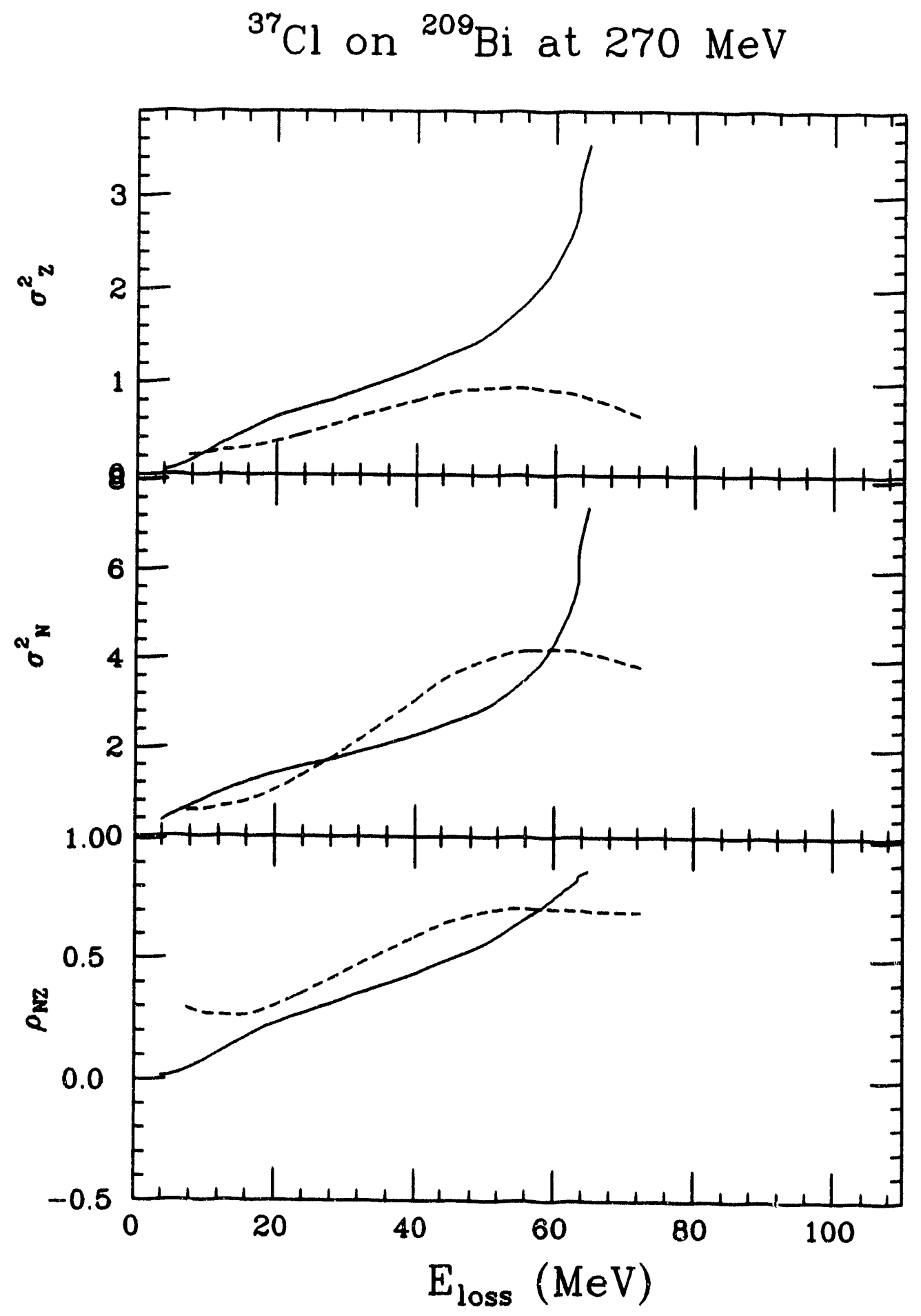


Figure V.7

Experimental results (circles and squares) and model predictions for $\langle\mathrm{Z}\rangle$, $\langle\mathrm{N}\rangle$, and $\langle\mathrm{N}\rangle \mid\langle\mathrm{Z}\rangle$ corresponding to the secondary distributions of the reaction ${ }^{37} \mathrm{Cl}$ on ${ }^{209} \mathrm{Bi}$ at $270 \mathrm{MeV}$ as a function of energy loss. The solid line represents the results from Randrup's model and the dashed line represents the results from Tassan-Got's. The circles and squares represent the results after correcting the energy loss scale assuming equal and thermal division of the excitation energy, respectively. The horizontal dotted lines represent the ratio $N / Z$ of the projectile (bottom) and compound system (top), respectively. 


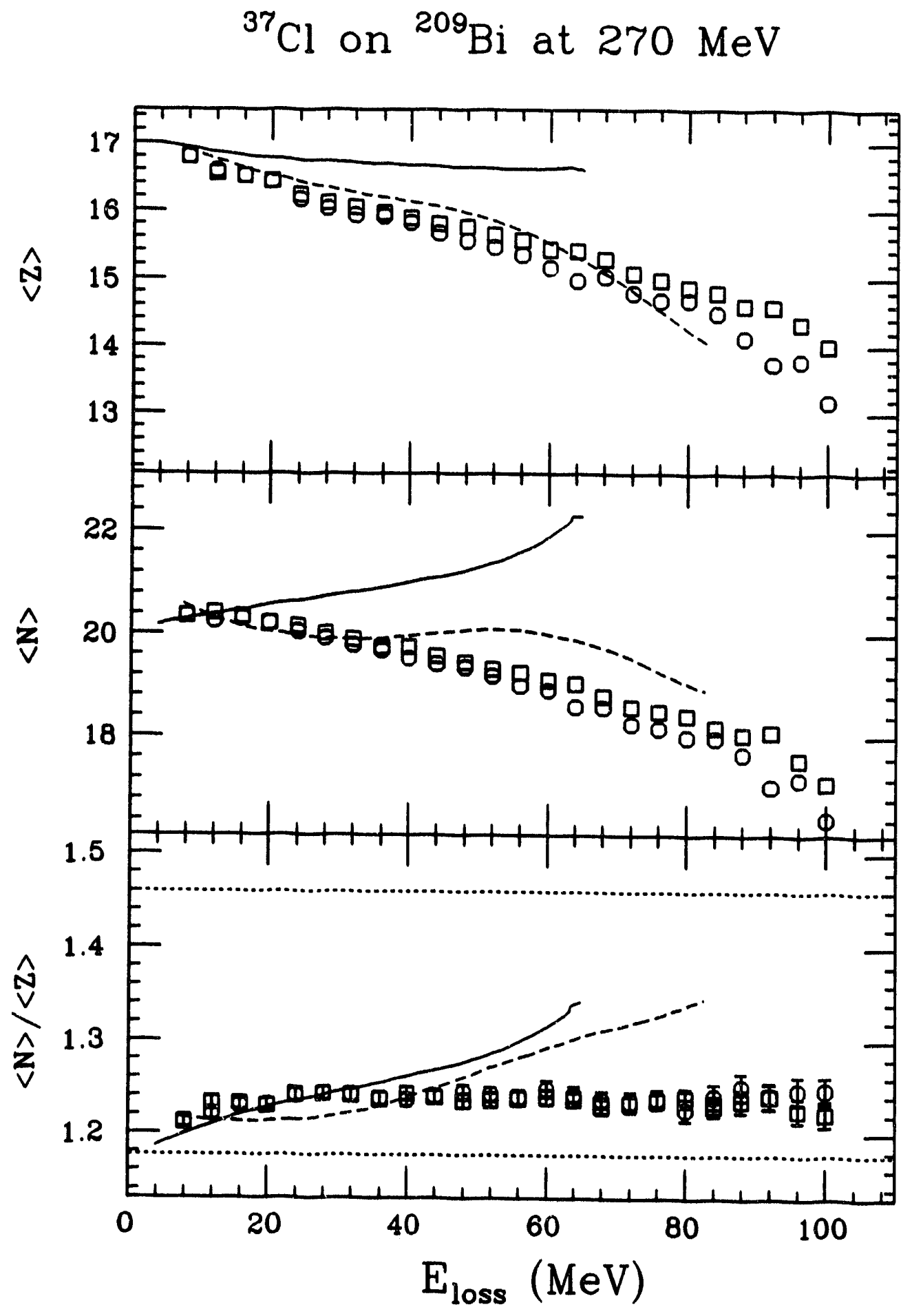


$<N>\mid<Z>$ between the models and experiment for the first $40 \mathrm{MeV}$ of energy loss. However, the experiment shows that this degree of freedom raises quickly and then remains more or less constant, while both models show a steady increase of the ratio with increasing energy loss.

The experimental variances and the correlation coefficient are compared to the models in Figure V.8. Randrup's model agrees very well with the experimental variances up to about $60 \mathrm{MeV}$ of energy loss. Tassan-Got's model reproduces very well the $\mathrm{Z}$ variance, but it overestimates the $\mathrm{N}$ variance after the first $25 \mathrm{MeV}$ of energy loss. The experimental correlation coefficient as a function of energy loss shows a sudden increase to a value of about 0.5 , then a slow linear growth towards a value of 1.0. The models do not reproduce this behavior very well; they show an overall smooth increase of the coefficient with increasing energy loss.

V.C.3 The system ${ }^{35} \mathrm{Cl}$ on ${ }^{209} \mathrm{Bi}$ at $528 \mathrm{MeV}$

The $\langle\mathrm{Z}\rangle,\langle\mathrm{N}\rangle$, and ratio $\langle\mathrm{N}\rangle \mid\langle\mathrm{Z}\rangle$ for the primary distributions are shown in Figure V.9. The discrepancies found in the predictions of $\langle\mathrm{Z}\rangle$ and $\langle\mathrm{N}\rangle$ for the previous case $\left({ }^{37} \mathrm{Cl}\right.$ on $\left.{ }^{209} \mathrm{Bi}\right)$ are qualitatively the same in this system. However, there is a very good agreement between the ratios $\langle\mathrm{N}\rangle \mid\langle\mathrm{Z}\rangle$ predicted by the two models. The variances and correlation coefficients are shown in Figure V.10. Both models follow qualitatively the same trend. Tassan-Got's variances are always smaller than Randrup's, and, as in the previous case, Randrup's variances increase rapidly as they approach the Coulomb barrier ( $298 \mathrm{MeV}$ of energy loss) while Tassan-Got's remain more or less constant. The correlation coefficients tend very slowly to 1.0 in both cases, and there is not an important difference between models up to about $200 \mathrm{MeV}$ of energy loss. After that energy loss value, Tassan-Got's 
Figure V.8

Experimental results (circles and squares) and model predictions for $\sigma^{2} \mathrm{z}$, $\sigma^{2}$, and PNZ corresponding to the secondary distributions of the reaction ${ }^{37} \mathrm{Cl}$ on ${ }^{209} \mathrm{Bi}$ at $270 \mathrm{MeV}$ as a function of energy loss. The solid line represents the results from Randrup's model and the dashed line represents the results from Tassan-Got's. The circles and squares represent the results after correcting the energy loss scale assuming equal and thermal division of the excitation energy, respectively. 


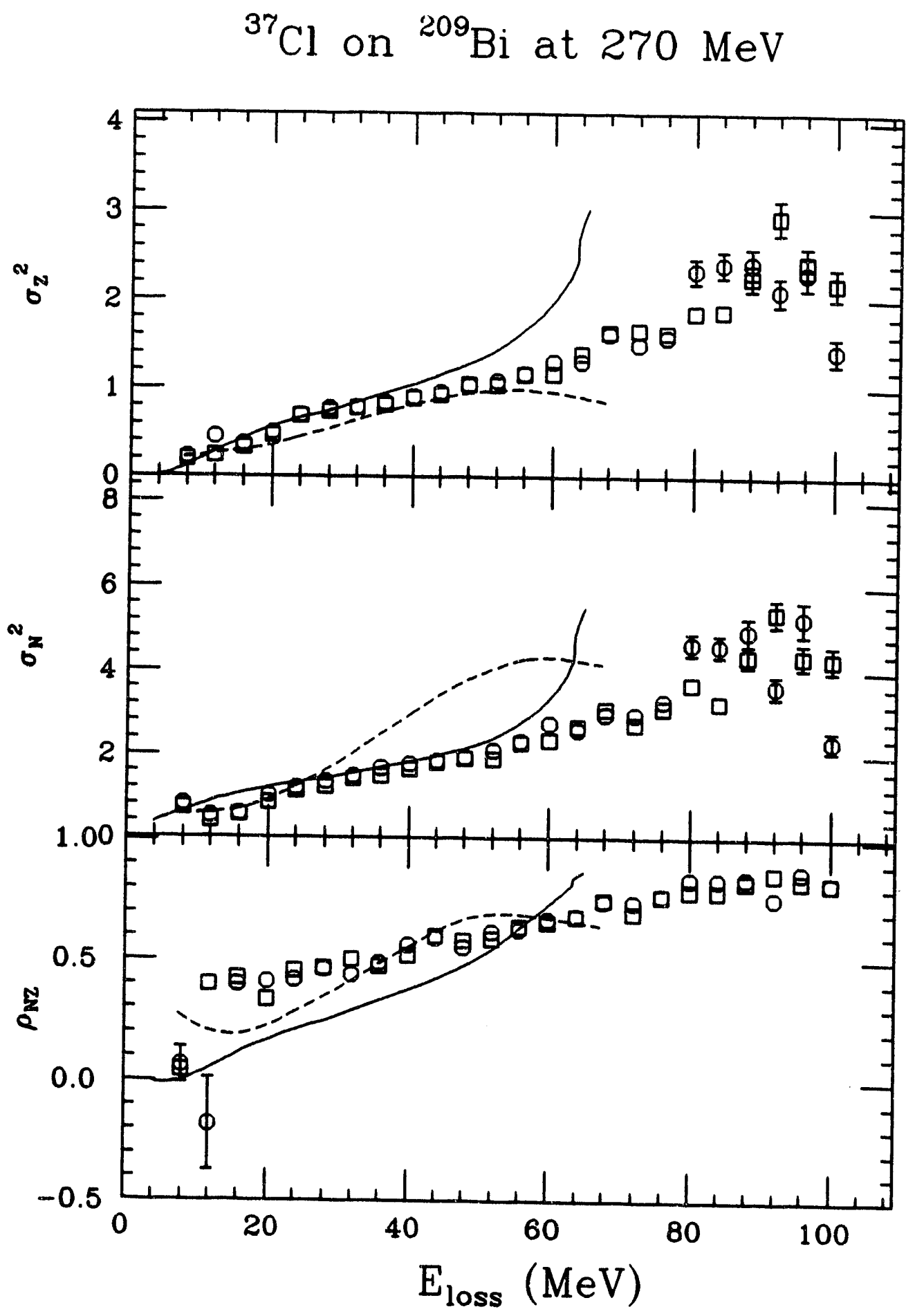




\section{Figure V.9}

Model predictions for $\langle\mathrm{Z}\rangle,\langle\mathrm{N}\rangle$, and $\langle\mathrm{N}\rangle \mid\langle\mathrm{Z}\rangle$ corresponding to the primary distributions of the reaction ${ }^{35} \mathrm{Cl}$ on ${ }^{209} \mathrm{Bi}$ at $528 \mathrm{MeV}$ as a function of energy loss. The solid line represents the results from Randrup's model and the dashed line represents the results from Tassan-Got's. The horizontal dotted lines represent the ratio $N / Z$ of the projectile (bottom) and compound system (top), respectively. 


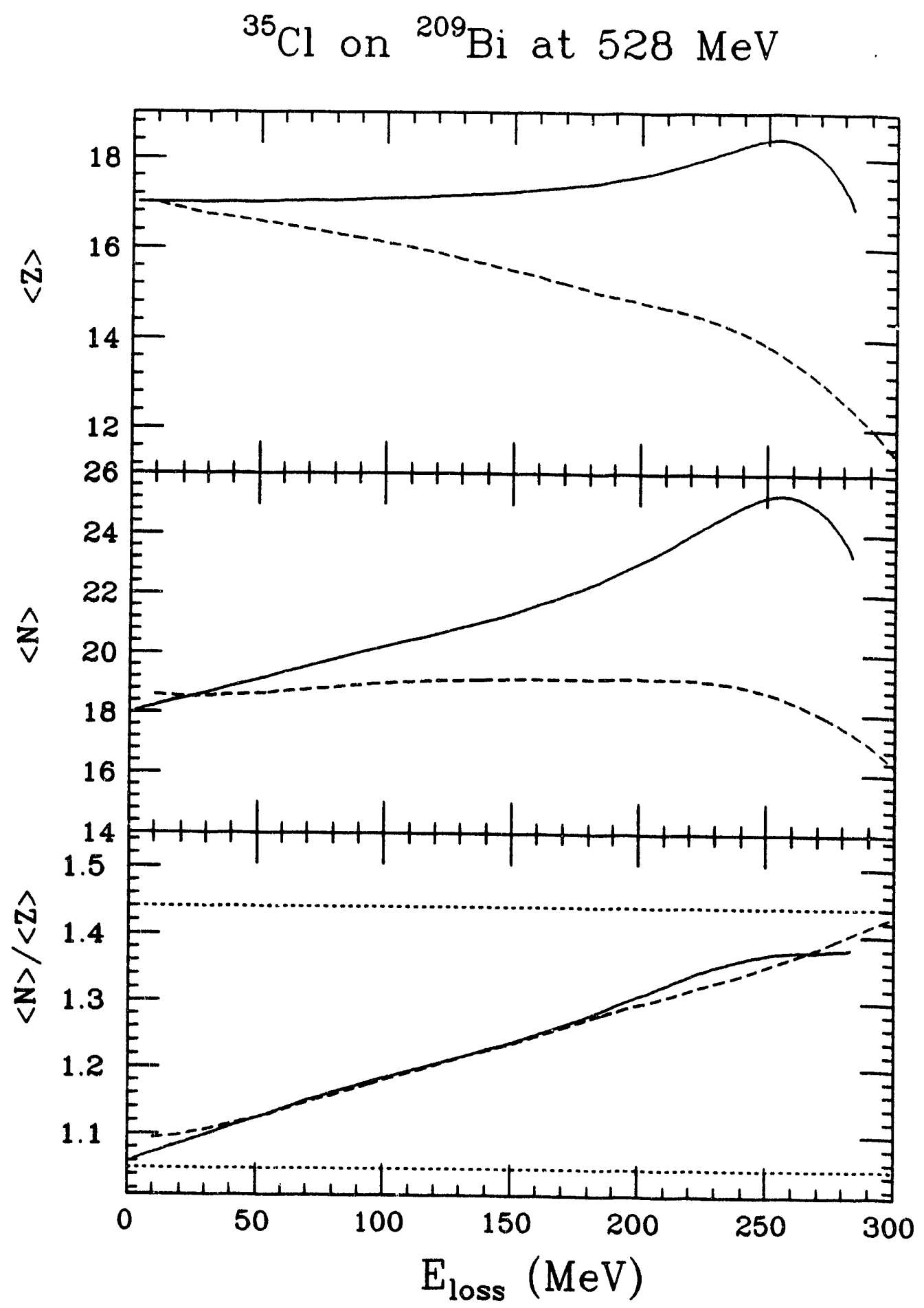


Figure V.10

Model predictions for $\sigma^{2} \mathrm{Z}, \sigma^{2} \mathrm{~N}$, and $\rho_{\mathrm{NZ}}$ corresponding to the primary

distributions of the reaction ${ }^{35} \mathrm{Cl}$ on ${ }^{209} \mathrm{Bi}$ at $528 \mathrm{MeV}$ as a function of energy

loss. The solid line represents the results from Randrup's model and

the dashed line represents the results from Tassan-Got's. 
${ }^{35} \mathrm{Cl}$ on ${ }^{209} \mathrm{Bi}$ at $528 \mathrm{MeV}$

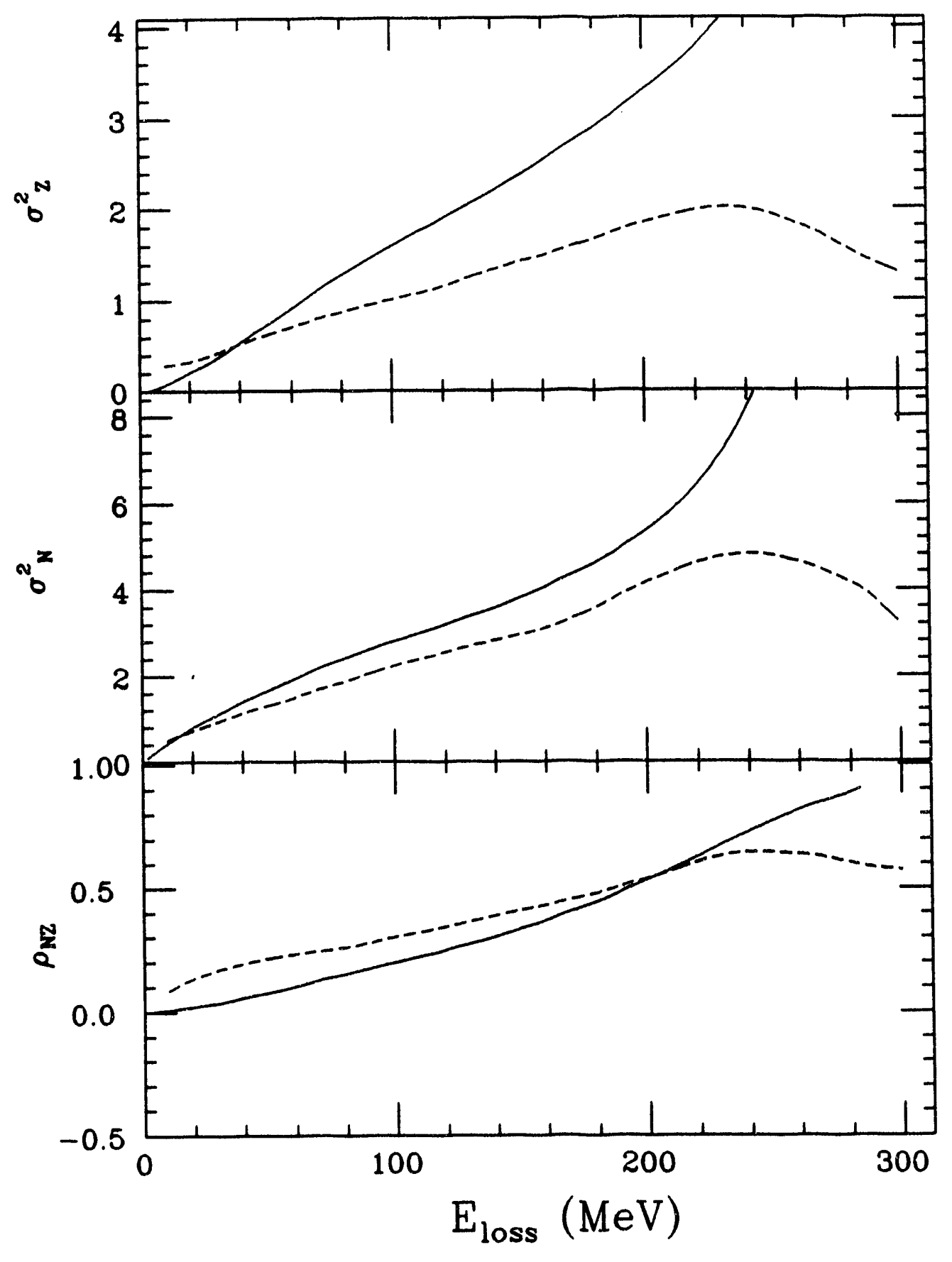


correlation coefficient remains more or less constant at about 0.5 while Randrup's keeps increasing towards 1.0 .

In Figure V.11 the experimental values for $\langle\mathrm{Z}\rangle,\langle\mathrm{N}\rangle$, and the ratio $<\mathrm{N}>\mid<\mathrm{Z}>$ are compared to the model predictions. There are two sets of experimental data shown, each corresponding to a different correction of the energy loss scale, as in the previous case. Tassan-Got's model gives a better overall agreement with the experimental $<Z>$ than does Randrup's. However, both models fail to describe the evolution of the experimental $\langle\mathrm{N}\rangle$ with energy loss. The ratio $\langle\mathrm{N}\rangle \mid\langle\mathrm{Z}\rangle$ is underestimated by both models. It is interesting to note that while the experimental $\langle\mathrm{N}>\mid<\mathrm{Z}\rangle$ increases towards the composite system value (1.44) for the first $100 \mathrm{MeV}$ of energy loss, both models predict a more or less constant value around 1.10. This is in contrast with the predictions for the system ${ }^{37} \mathrm{Cl}$ on ${ }^{209} \mathrm{Bi}$.

The comparison of model predictions to experimental variances and correlation coefficients can be found in Figure V.12. Unfortunately, due to the experimental problems described in Chapter II, the variances may have components that are not accounted for. These components should contribute mainly to the low energy loss part of the spectra, which corresponds to energies around the elastic peak where the spurious contributions are observed. However, it is possible to compare trends on the data with more confidence in the region of high energy loss.

The experimental variances increase up to about $100 \mathrm{MeV}$ of energy loss where they reach a maximum and start to decrease slowly, while both models predict a steady increase of the variances with energy loss. This is an interesting feature that is not observed in the other two systems. In the same energy region where the variances reach a maximum, there is a sudden change in the slope of the average values of $\mathrm{N}$ and $\mathrm{Z}$ as a function of energy loss. These findings seem to indicate that a different type of mechanism is starting to surface at higher energy losses. A breakup 
Figure V.11

Experimental results (circles and squares) and model predictions for $\langle\mathrm{Z}\rangle$, $\langle N\rangle$, and $\langle N\rangle \mid<Z>$ corresponding to the secondary distributions of the reaction ${ }^{35} \mathrm{Cl}$ on ${ }^{209} \mathrm{Bi}$ at $528 \mathrm{MeV}$ as a function of energy loss. The solid line represents the results from Randrup's model and the dashed line represents the results from Tassan-Got's. The circles and squares represent the results after correcting the energy loss scale assuming equal and thermal division of the excitation energy, respectively. The horizontal dotted lines represent the ratio $N / Z$ of the projectile (bottom) and compound system (top), respectively. 


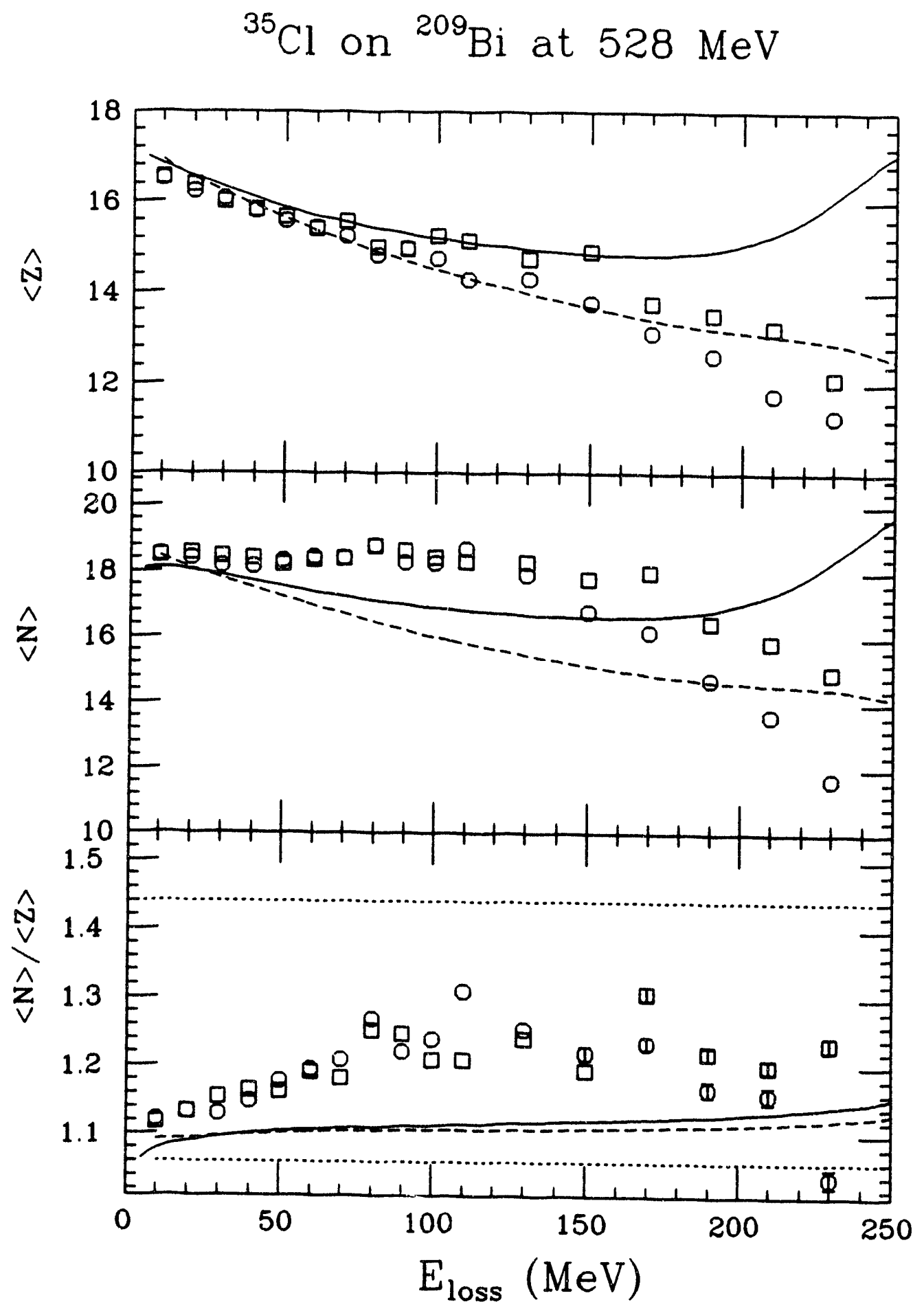


Figure V.12

Experimental results (circles and squares) and model predictions for $\sigma^{2} z$, $\sigma^{2} \mathrm{~N}$, and $\rho_{\mathrm{NZ}}$ corresponding to the secondary distributions of the reaction ${ }^{35} \mathrm{Cl}$ on ${ }^{209} \mathrm{Bi}$ at $528 \mathrm{MeV}$ as a function of energy loss. The solid line represents the results from Randrup's model and the dashed line represents the results from Tassan-Got's. The circles and squares represent the the results after correcting the energy loss scale assuming equal and thermal division of the excitation energy, respectively. 


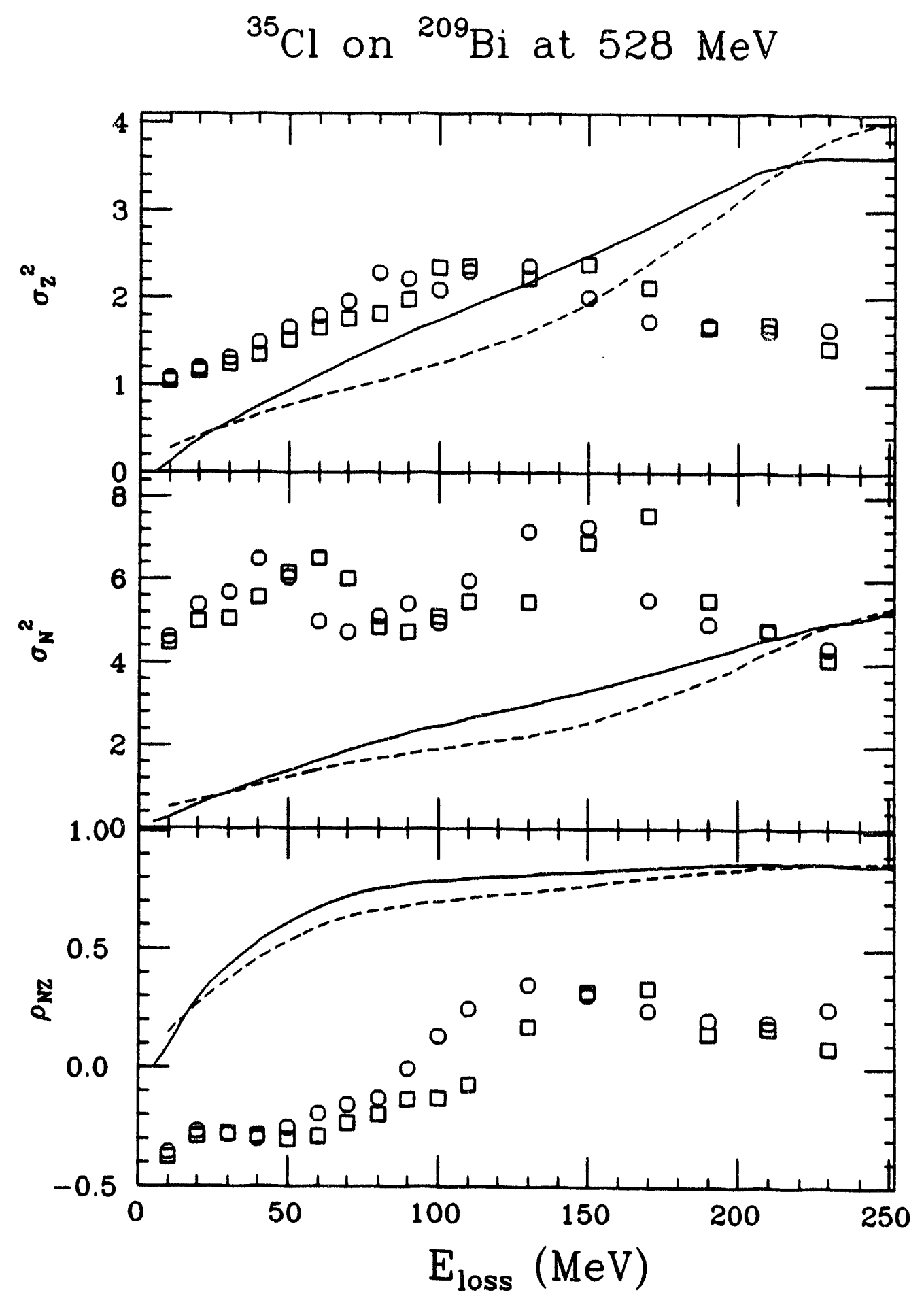


of the projectile-like fragment is a possible explanation for these observations; it would explain both the narrowing of the variances and the sudden negative drifts in $<\mathrm{N}>$ and $<\mathrm{Z}>$. The experimental $\rho$ is negative for the first $100 \mathrm{MeV}$ of energy loss, in disagreement with both models, which predict a sudden rise followed by a smooth increase towards 1.0. However, it is not conclusive that there is anticorrelation, since the negative value could be the effect of the mass resolution.

\section{V.D SYSTEMATICS}

Mass and charge distributions have been determined as a function of energy loss for a variety of systems. The methodology and assumptions employed in these determinations are not unique, and this should be taken into consideration when performing rigorous quantitative comparisons. However, general features and trends should be fairly independent of the particular method employed and can be readily compared. The charge and mass drifts are the result of driving forces acting on the dinuclear system. In principle, these forces are produced by mass and charge gradients between the reaction partners and, therefore, become evident in asymmetric systems. On the other hand, the variances are related to the total number of nucleon exchanges in statistical models, and reflect the nucleon mobility.

V.D.1 Mass and Charge Equilibration

It is instructive to look at the experimental averages for $\mathrm{Z}$ and $\mathrm{N}$ corresponding to different energy losses on the N-Z plane, as shown in Figure V.13 for the system ${ }^{37} \mathrm{Cl}$ on ${ }^{209} \mathrm{Bi}$ and in Figure V.14 for the system ${ }^{35} \mathrm{Cl}$ on ${ }^{209} \mathrm{Bi}$. A line corresponding to the ratio $\mathrm{N} / \mathrm{Z}$ of the composite system (dot-dash), and a $\beta$-stability 
Figure V.13

Evolution of $\langle\mathrm{N}\rangle$ and $\langle\mathrm{Z}\rangle$ in the $\mathrm{N}-\mathrm{Z}$ plane for the reaction ${ }^{37} \mathrm{Cl}$ on ${ }^{209} \mathrm{Bi}$ at $270 \mathrm{MeV}$. The circles represent the experimerital values, the solid and dashed lines represent Randrup and Tassan-Got's predictions, respectively. The lines corresponding to the primary distribution predictions are marked PR and TP, respectively. The dotted line corresponds to the valley of $\beta$-stability and the dotted-dashed line represents the ratio $N / Z$ of the compound system. 


\section{${ }^{37} \mathrm{Cl}$ on ${ }^{209} \mathrm{Bi}$ at $270 \mathrm{MeV}$}

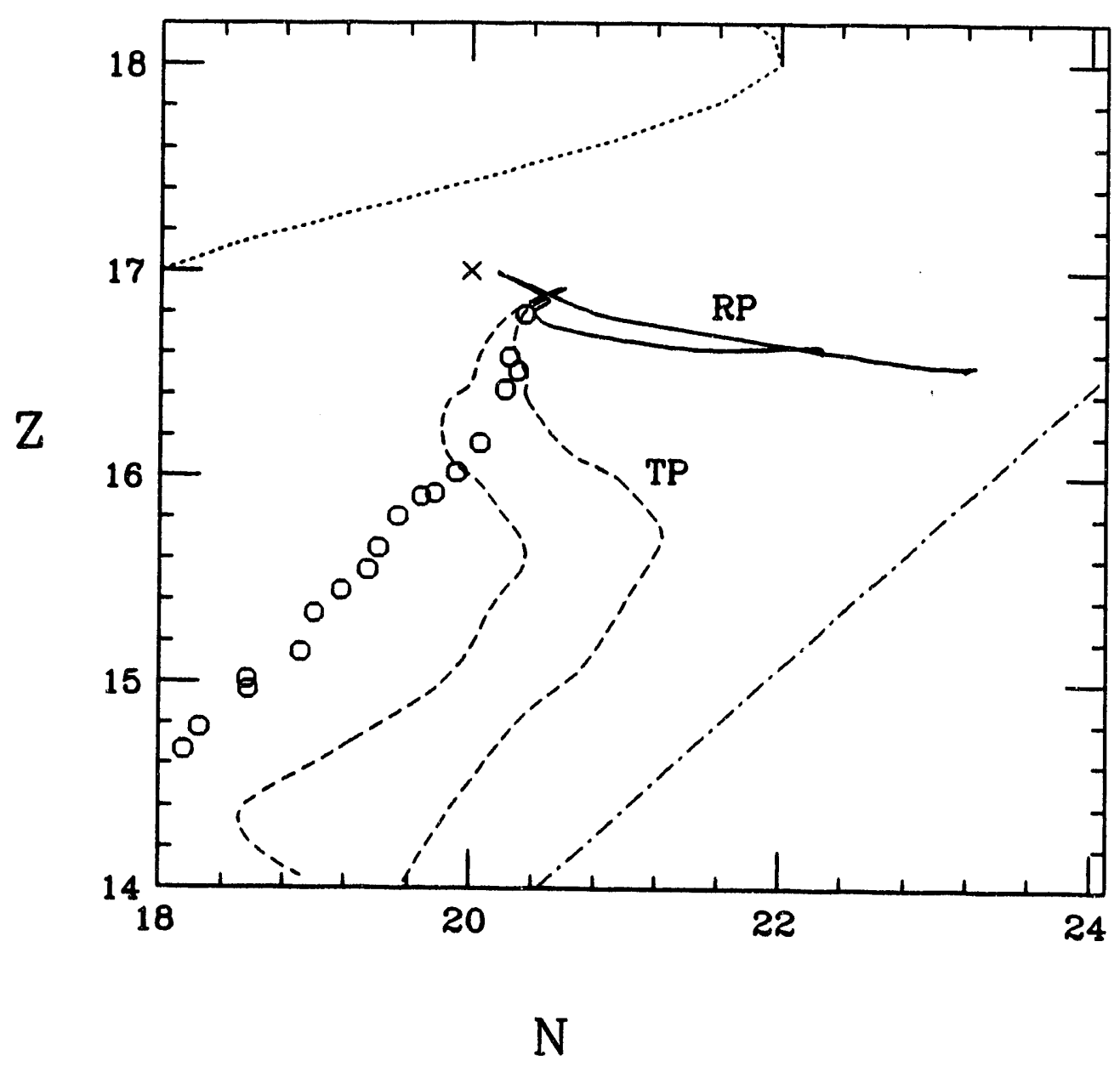


Figure V.14

Evolution of $\langle\mathrm{N}\rangle$ and $\langle\mathrm{Z}\rangle$ in the $\mathrm{N}-\mathrm{Z}$ plane for the reaction ${ }^{35} \mathrm{Cl}$ on ${ }^{209} \mathrm{Bi}$ at $528 \mathrm{MeV}$. The circles represent the experimental values, the solid and dashed lines represent Randrup and Tassan-Got's predictions, respectively. The lines corresponding to the primary distribution predictions are marked PR and TP, respectively. The dotted line corresponds to the valley of $\beta$-stability and the dotted-dashed line represents the ratio $N / Z$ of the compound system. 


\section{${ }^{35} \mathrm{Cl}$ on ${ }^{209} \mathrm{Bi}$ at $528 \mathrm{MeV}$}

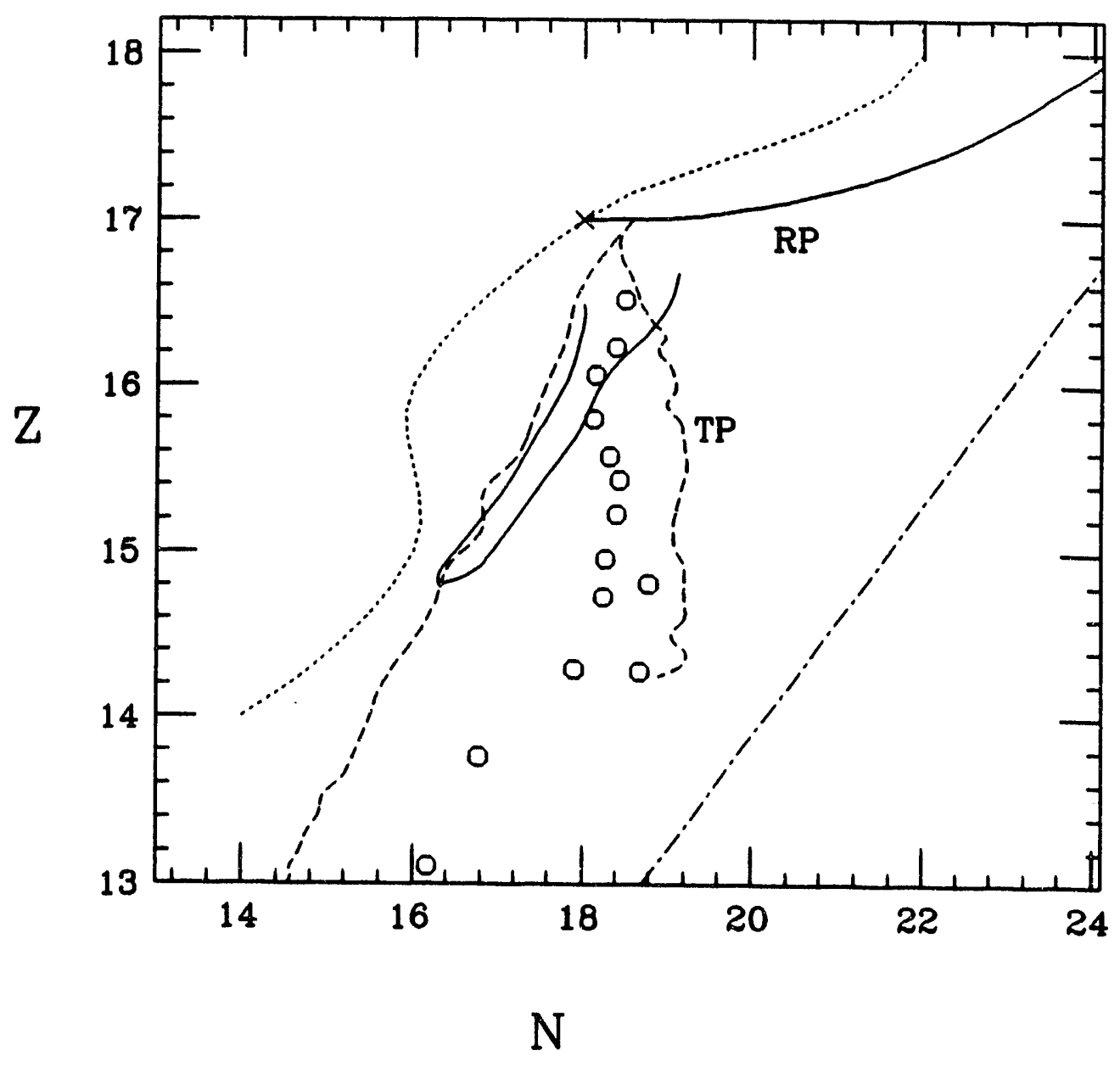


line (dot) are included in the figures to serve as guides. The $\beta$-stability line was obtained by plotting the most stable mass for each Z. Both systems show a strong negative charge drift with production of neutron-rich projectile-like fragments. The negative drift in $\langle Z>$ of the projectile-like fragments has been observed in many asymmetric systems in which the projectile has a lower $N / Z$ ratio than the target [BEN 88, BRE79, BRE 83b, HOO 82, PEN 90, PLA 88, PLA 90, SAP 85]. This is evidence of a net flow of protons from the projectile to the target. Likewise, the increase in the $N / Z$ ratio of the projectile-like fragments can be assigned to a net flow of neutrons from the target to the projectile. Observations made on the system ${ }^{136} \mathrm{Xe}$ on ${ }^{56} \mathrm{Fe}$, where the projectile has a higher ratio $\mathrm{N} / \mathrm{Z}$ than the target, showed that the $<\mathrm{Z}>$ of the projectile-like fragments increased while the $\langle\mathrm{N}\rangle$ decreased [SCH 81].

The effect of the $N / Z$ ratio on the charge and mass drifts was studied by de Souza et al. [SOU 88]. For a given target $\left({ }^{238} U\right)$ and for the same bombarding energy per nucleon $(E / A=8.5 \mathrm{MeV})$, the charge drift was found to be strongly correlated to the $N / Z$ of the projectile: the smaller the $N / Z$ of the projectile the larger the negative drift. However, no such rigorous correlation was found for the case of the neutron drift. It is interesting to compare the results of ${ }^{58} \mathrm{Ni}(\mathrm{N} / \mathrm{Z}=1.07)$ and ${ }^{64} \mathrm{Ni}(\mathrm{N} / \mathrm{Z}=1.29)$ on ${ }^{238} \mathrm{U}(\mathrm{N} / \mathrm{Z}=1.59)$, shown in Figure V.15.(a) and (b), to the results of the asymmetric systems studied here, ${ }^{35} \mathrm{Cl}(\mathrm{N} / \mathrm{Z}=1.06)$ and ${ }^{37} \mathrm{Cl}(\mathrm{N} / \mathrm{Z}=$ 1.18) on ${ }^{209} \mathrm{Bi}(\mathrm{N} / \mathrm{Z}=1.52)$, since they have similar $\mathrm{N} / \mathrm{Z}$. The products of ${ }^{37} \mathrm{Cl}$ and ${ }^{64} \mathrm{Ni}$ show a more or less linear and negative drift in $\langle\mathrm{Z}\rangle$ and $\langle\mathrm{N}\rangle$ from the initial values of energy loss. On the other hand, the products of ${ }^{35} \mathrm{Cl}$ and ${ }^{58} \mathrm{Ni}$ show an almost constant value for $<\mathrm{N}>$ for the first $100 \mathrm{MeV}$ of energy loss and a negative drift in $\langle Z\rangle$. There is a strong correlation between the yields of products and the $N / Z$ ratio. These observations seem independent on the mass asymmetry parameter, 
Figure V.15

Average nucleon drifts for the reactions ${ }^{40,48} \mathrm{Ca}$, and ${ }^{58,64} \mathrm{Ni}$ on ${ }^{238} \mathrm{U}$ at

$\mathrm{E} / \mathrm{A}=8.5 \mathrm{MeV}$ as a function of energy loss. (a) $\langle\mathrm{Z}\rangle-\langle\mathrm{Z}\rangle_{\text {projectile and (b) }}$ $\langle N>-\langle N>$ projectile. The lines represent Randrup's model predictions after corrections for evaporation. Reproduced from [SOU 88]. 

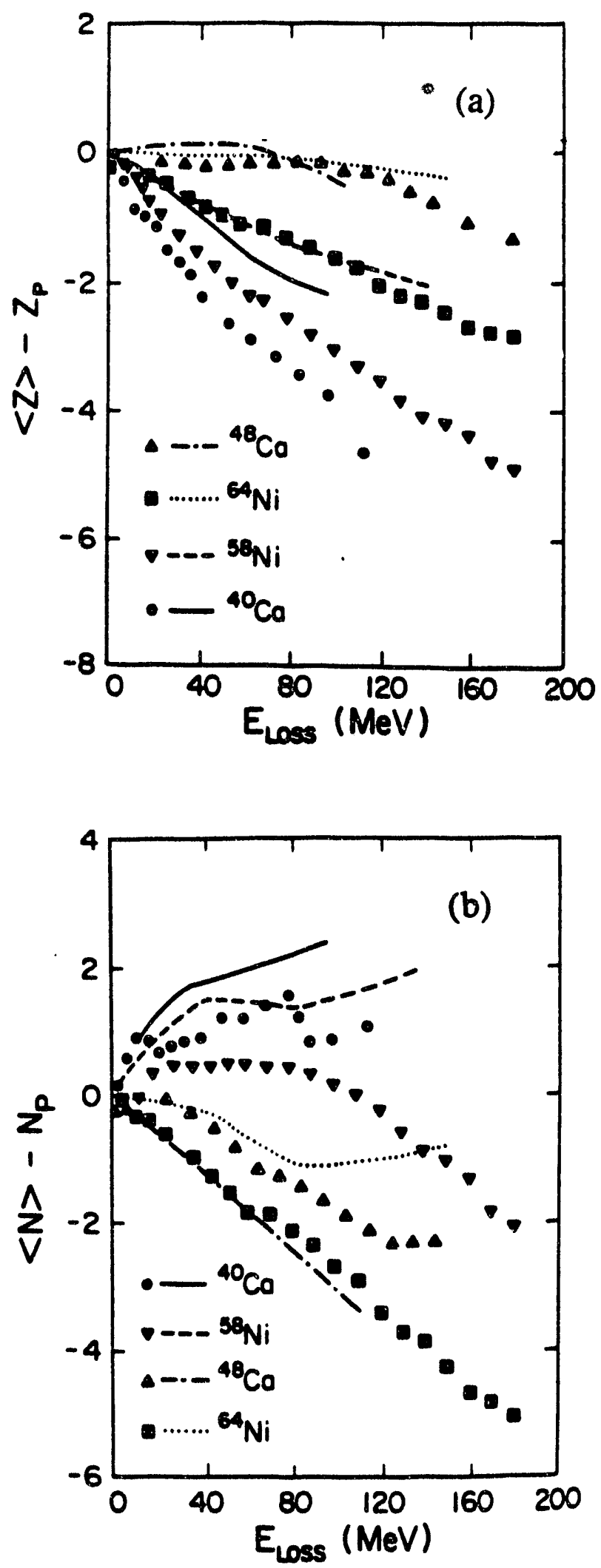
defined as the difference of projectile and target mass, divided by the total mass of the system.

The experimental evidence seems to indicate that charge equilibrates faster than mass, and this explains the evolution of asymmetric systems towards larger asymmetry. These observations are based on secondary distributions from which the characteristics of the primary distributions are inferred. It is generally assumed that the evaporation process occurs mainly via neutron emission and has a negligible effect on $\mathrm{Z}$. Therefore, it is implied that the $<Z>$ of the secondary distribution is very close to that of the primary. But, it can be argued that charged particle emission is an important evaporation process, especially for lighter systems. However, the production of neutron-rich projectile-like fragments, away from the $\beta$-stability line, seems to support the hypothesis on $\langle Z\rangle$. Since evaporation favors the formation of stable species, a neutron-rich secondary nucleus should originate via neutron emission from a primary one with an even higher $\mathrm{N} / \mathrm{Z}$ ratio.

As seen in Figures V.13 and 14, the primary $\langle\mathrm{Z}\rangle$ and $\langle\mathrm{N}\rangle$ predicted by Randrup's model show that mass tends to equilibrate faster than charge, which is opposite to the experimental evidence. On the other hand, the predictions of TassanGot agree, at least qualitatively, with the experimentally deduced trend for the primary $\langle\mathrm{Z}\rangle$ and $\langle\mathrm{N}\rangle$. The $\langle\mathrm{Z}\rangle$ and $\langle\mathrm{N}\rangle$ predicted by both models after evaporation corrections are also shown for comparison with the experimental secondary values. In both cases, Tassan-Got presents a better qualitative agreement. Randrup's model predictions have been compared to the experimental distributions for several asymmetric systems [LOC 85, PEN 90, PLA 88, PLA 90, WIL 89a]. The model seems to always predict higher values for $\langle\mathrm{Z}\rangle$ and $\langle N\rangle$ than the experimental ones. Figure V.16 shows the evolution in the $\mathrm{N}-\mathrm{Z}$ plane of the system ${ }^{74} \mathrm{Ge}$ on ${ }^{165} \mathrm{Ho}$ at $\mathrm{E} / \mathrm{A}=8.5 \mathrm{MeV}$; in this case, the " experimental" primary distribution (circles) is 
Figure V.16

Evolution of $\langle\mathrm{N}\rangle$ and $\langle\mathrm{Z}\rangle$ in the $\mathrm{N}-\mathrm{Z}$ plane for the reaction ${ }^{74} \mathrm{Ge}$ on ${ }^{165} \mathrm{Ho}$ at $\mathrm{E} / \mathrm{A}=8.5 \mathrm{MeV}$. The solid line is Randrup's prediction for the primary distributions, the squares are the measured data, and the circles are the reconstructed primary distributions, from [PLA 90]. 


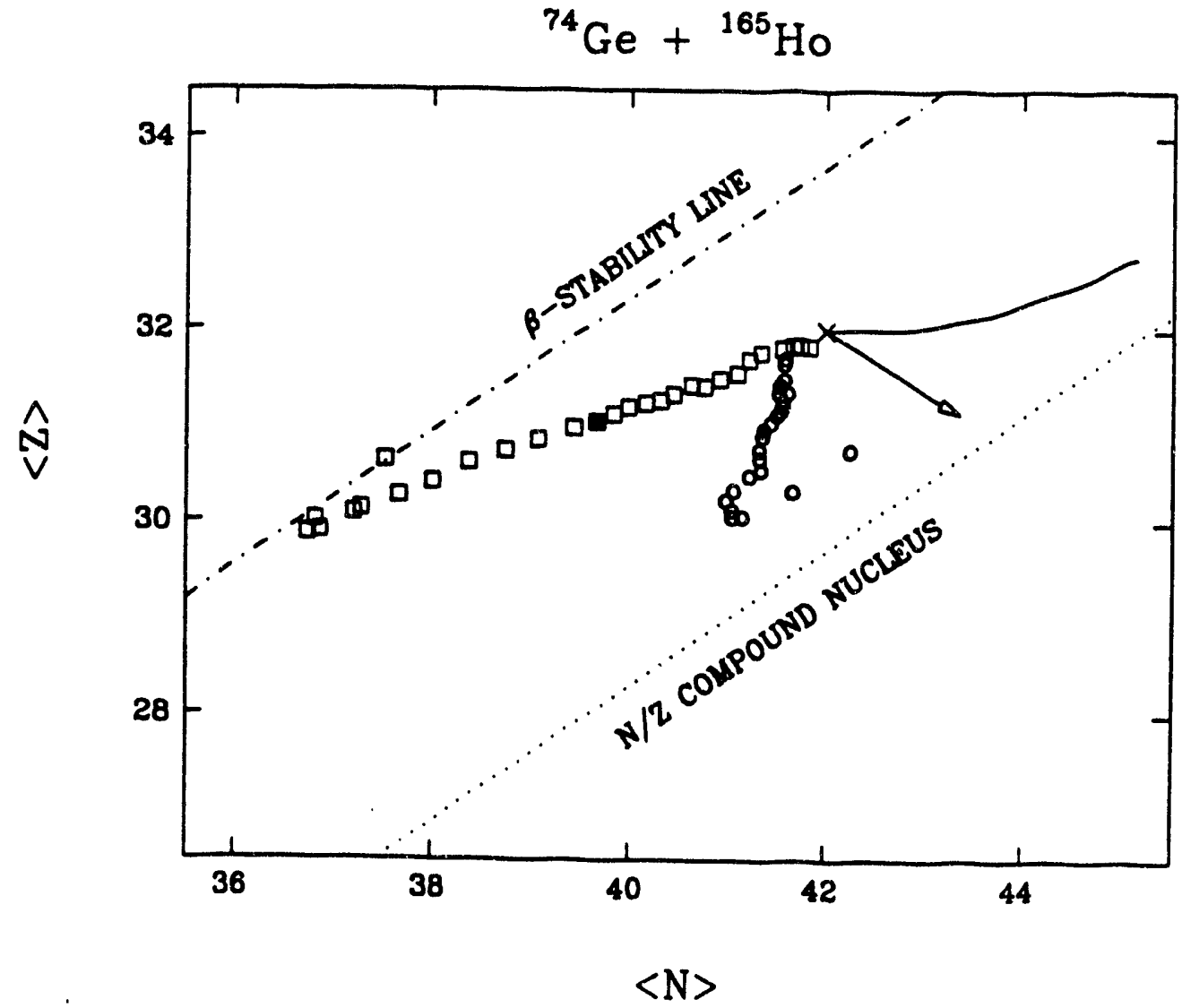


reconstructed from the measured secondary distributions (squares), using the coincident detection of the target-like recoil, and compared to Randrup's model (solid line).

Tassan-Got's model is recent and, hence, it has not been compared to as many systems as Randrup's. Tassan-Got performed comparisons to some of the published data and found a good agreement with the predicted centroids [BOR 90]. In the systems studied here, Tassan-Got 's predictions reproduce more or less the trends of the experimental centroids, but fail to account for some of the details. Calculations performed using the Tassan-Got code on the system ${ }^{58} \mathrm{Ni}$ on ${ }^{165} \mathrm{Ho}$ at $\mathrm{E} / \mathrm{A}=16 \mathrm{MeV}$ [PEN 90] showed that $\langle\mathrm{Z}\rangle$ and $\langle\mathrm{N}\rangle$ were significantly underpredicted by the code, as seen in Figure V.17. However, there is a good agreement in the ratio $<\mathrm{N}>|<\mathrm{Z}\rangle$.

\section{V.D.2 Variances and Correlation Coefficients}

The variances are related to the number of nucleon exchanges in the statistical models, hence, they represent the nucleonic mobility and should not be very sensitive to the driving forces. For different systems at $\mathrm{E} / \mathrm{A}=8.5 \mathrm{MeV}$ of bombarding energy, the $\mathrm{Z}$ and $\mathrm{N}$ variances measured as a function of energy loss were found to be in fairly good quantitative agreement with each other [PLA 90, SOU 88]. The variances

measured here for the system ${ }^{37} \mathrm{Cl}$ on ${ }^{209} \mathrm{Bi}$ at $7.3 \mathrm{MeV} / \mathrm{A}$ also show good agreement with those of the systems at $8.5 \mathrm{MeV} / \mathrm{A}$. Since the systems compared have very different potential gradients on the $\mathrm{N}-\mathrm{Z}$ plane, this finding supports the idea that the variances are mainly related to the nucleonic mobility which should not differ too much among different systems. In general, it is observed that the variance in $Z$ is smaller than the variance in $\mathrm{N}$, roughly by a factor of 2.0 . Randrup's model 


\section{Figure V.17}

Comparison of the $\langle\mathrm{Z}\rangle,\langle\mathrm{N}\rangle$, and $\langle\mathrm{N}\rangle \mid\langle\mathrm{Z}\rangle$ values of the reaction ${ }^{58} \mathrm{Ni}$ on ${ }^{165} \mathrm{Ho}$ at $\mathrm{E} / \mathrm{A}=16 \mathrm{MeV}$ to the predictions of Randrup's model (solid line) [PEN 90], and Tassan-Got's model (dashed line) as a function of energy loss. The horizontal dotted lines represent the ratio $N / Z$ of the projectile (bottom) and compound system (top), respectively. 


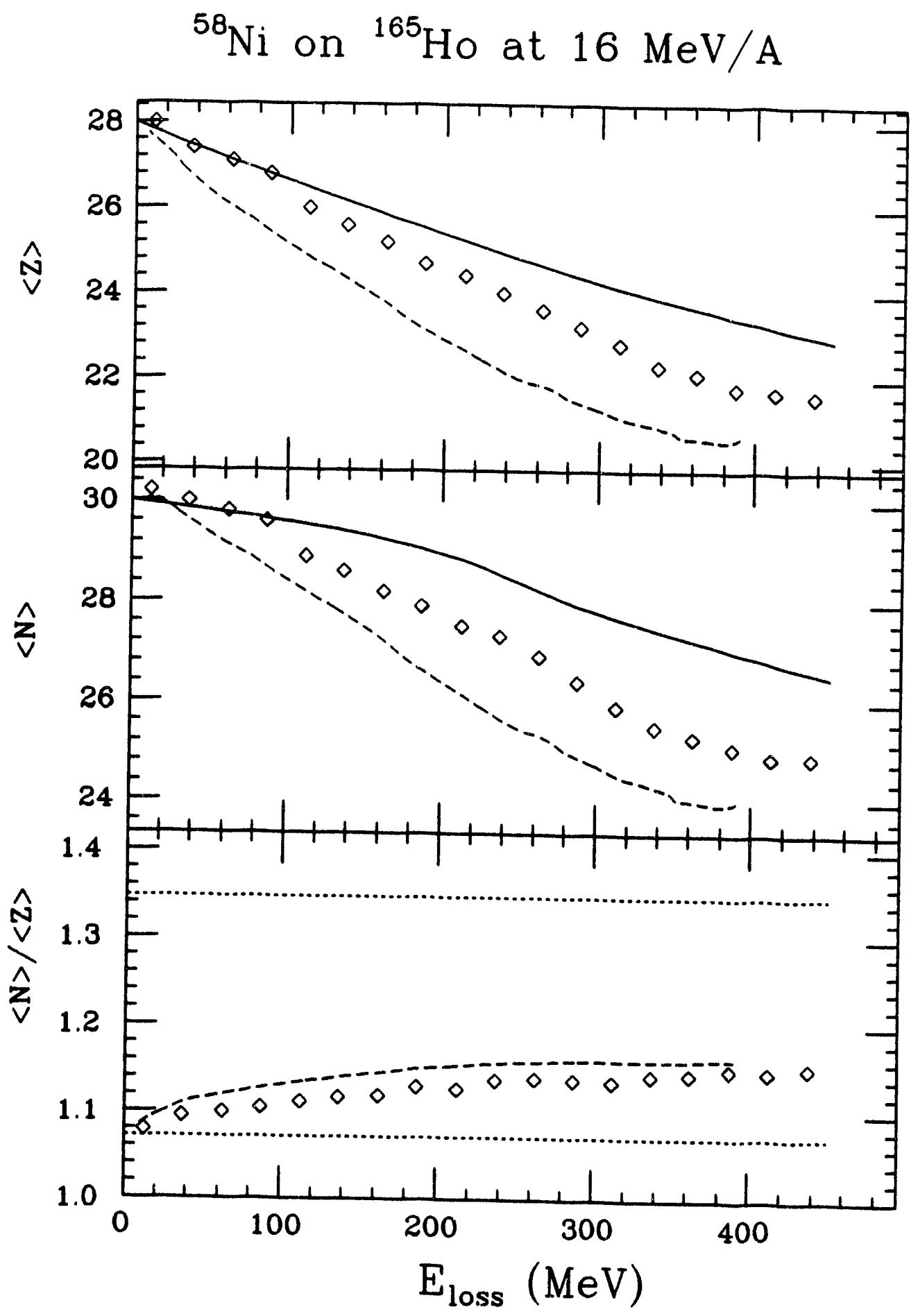


reproduced very well the experimental variances of the systems discussed in the previous section. It is also in good overall agreement with the variances observed here for the system ${ }^{37} \mathrm{Cl}$ on ${ }^{209} \mathrm{Bi}(\mathrm{E} / \mathrm{A}=7.3 \mathrm{MeV}$ ). Tassan-Got's model reproduces more or less the variances of the latter, but exhibits a different functional dependence from Randrup's, especially at high energy loss.

The correlation coefficient is a measure of the mutual dependence between neutron and proton transfers. Values of $\rho_{N Z}>0.0$ are associated with correlated exchange of neutrons and protons constrained to the valley of $\beta$-stability. A value of $\rho_{N Z}<0.0$ would imply that the charge exchange is anticorrelated, and a value of $\rho_{\mathrm{NZ}}$ $=0.0$ signifies that charge and mass exchange are independent of each other. The general trend in the evolution of the correlation coefficient as a function of energy loss is a sharp initial increase followed by a smooth grow towards 1.0 . This indicates that the charge and mass exchanges become more correlated with increasing energy loss. Some systems show negative correlation coefficients at low energy loss. However, it has been pointed out that, at low energy loss, this could be explained as an effect of reaction Q-values, and/or the small number of species present [BRE 83b, PLA 88, PLA 90]. 


\section{CHAPTER VI CONCLUSIONS}

The deep-inelastic reactions corresponding to the systems ${ }^{37} \mathrm{Cl}$ on ${ }^{40} \mathrm{Ca}$ and ${ }^{209} \mathrm{Bi}$ at $\mathrm{E} / \mathrm{A}=7.3 \mathrm{MeV}$, and ${ }^{35} \mathrm{Cl}$ on ${ }^{209} \mathrm{Bi}$ a: $\mathrm{E} / \mathrm{A}=15 \mathrm{MeV}$ have been studied. The projectile-like fragments were completely characterized in terms of mass, charge, and energy. Mass and charge distributions were determined for all three systems as a function of energy loss in the $\mathrm{N}-\mathrm{Z}$ plane. These distributions were characterized in terms of their centroids ( $\langle N\rangle$ and $\langle Z\rangle)$, variances $\left(\sigma^{2} N\right.$ and $\left.\sigma^{2} Z\right)$ and coefficients of correlation (PNZ). Two methods wide employed to determine these parameters: Gaussian fit and moment analysis. For the most part, no significant differences were found between the results of both methods, and, in the cases of disagreement, the meaning of the parameters is questionable.

For the almost symmetric system ${ }^{37} \mathrm{Cl}$ on ${ }^{40} \mathrm{Ca}$, the evolution of $\langle\mathrm{N}\rangle,\langle\mathrm{Z}\rangle$, and variances with energy loss seems consistent with a stochastic exchange of nucleons. The drift in the centroids can be explained by evaporative processes following the production of the primary fragments. The variances increase with energy loss as would be expected frcm an increasing number of nucleons exchanges. However, at high energy loss, the variances are much higher than those expected from a nucleon exchange mechanism. The behavior of the ratio $\langle N|\langle Z\rangle$ is indicative of charge equilibration, reaching the value of the composite system (1.08) at about $60 \mathrm{MeV}$ of energy loss. There is a strong correlation between $\mathrm{N}$ and $\mathrm{Z}$ which shows that the exchange is constrained by $Q$-value considerations to the valley of $\beta$-stability.

A very striking feature of the asymmetric systems studied here is the very low yield of products with $\mathrm{Z}$ higher than the projectile. As mentioned in Chapter $\mathrm{V}$, the strong negative drift in $\langle Z\rangle$, accompanied by the formation of neutron-rich nuclei, 
indicates a net flow of charge towards the target and of neutrons towards the projectile. It is important to note that such a trend is against the Coulomb potential, and an indication of the importance of the ratio $N / Z$ of projectile and target in determining the underlying driving forces. A qualitative comparison of the evolution of $\langle\mathrm{N}\rangle$ and $\langle\mathrm{Z}\rangle$ with energy loss for the projectiles ${ }^{37} \mathrm{Cl}(\mathrm{N} / \mathrm{Z}=1.18)$ and ${ }^{35} \mathrm{Cl}(\mathrm{N} / \mathrm{Z}$ $=1.06$ ) gives additional support to this point. Both cases show a decrease in $\langle Z\rangle$ from the very initial values of energy loss. However, the ${ }^{35} \mathrm{Cl}$ products maintain a constant $<\mathrm{N}>$ over a wide range of energy losses, while the $<\mathrm{N}>$ of the ${ }^{37} \mathrm{Cl}$ products decrease. These observations agree with those of the systems ${ }^{58} \mathrm{Ni}$ and ${ }^{64} \mathrm{Ni}$ on ${ }^{238} \mathrm{U}$ at $\mathrm{E} / \mathrm{A}=8.5 \mathrm{MeV}$ [PLA 88] which, when compared ${ }^{35} \mathrm{Cl}$ and ${ }^{37} \mathrm{Cl}$ on ${ }^{209} \mathrm{Bi}$, have similar ratios $\mathrm{N} / \mathrm{Z}$, but different asymmetry parameters. It would appear that the $N / Z$ ratios of the projectile and target play a major role in determining the product yields.

The evolution of the variances for the system ${ }^{37} \mathrm{Cl}$ on ${ }^{209} \mathrm{Bi}$ is in good agreement with other asymmetric systems, and with the predictions from a nucleonexchange mechanism. Despite the mass resolution problems, the variances of the system ${ }^{35} \mathrm{Cl}$ on ${ }^{209} \mathrm{Bi}$ seem to indicate the same trend at low energy losses. However, after the first $100 \mathrm{MeV}$ of energy loss, the variances show a sudden decrease, contrary to what would be expected from a pure nucleon exchange mechanism. It is postulated that a breakup mechanism of the projectile-like fragment could explain this focusing effect. The coefficient of correlation increases with energy loss for the system ${ }^{37} \mathrm{Cl}$ on ${ }^{209} \mathrm{Bi}$, as expected from a correlated nucleor exchange process. In the ${ }^{35} \mathrm{Cl}$ on ${ }^{209} \mathrm{Bi}$ system, it is difficult to interpret the negative value of this coefficient in the first $100 \mathrm{MeV}$ of energy loss as anticorrelation, since this could be an effect of the poor mass resolution. However, negative coefficients of 
correlation have been reported at very low energy losses for different systems [BRE 83, PLA 88, PLA 90], but anticorrelation was not conclusive.

Stochastic nucleon-exchange models have been relatively successful in reproducing some of the features of the deep-inelastic reactions. The good agreement generally found between the experimental and predicted variances supports the nucleon exchange mechanism for these reactions. However, the mass and charge drifts are not properly accounted for. In this type of mechanism, the variances are directly proportional to the sum of the (large) nucleon currents between the projectile and target, and the drifts are proportional to their difference [LOC 85]. As a consequence, the drifts are more sensitive to the details of the underlying potential. The two models used here reproduce the mass and charge drift of the almost symmetric system very well, but they both underestimate the variances at high energy loss. Randrup's model overpredicts $\langle\mathrm{N}\rangle$ and $\langle\mathrm{Z}\rangle$ for the asymmetric systems, while Tassan-Got's model gives a better qualitative agreement with the data, but still fails to account for the details. The variances of the asymmetric systems are in overall agreement with the predictions of both models.

It is interesting that two models that are very similar in their physical foundations predict such different trends for the mass and charge drift of asymmetric systems. According to Tassan-Got, the main difference between the two models is Randrup's use of the Lagrangian to derive the driving forces; the inclusion of kinetic terms in the potential (in particular rotational energy) that are not present in his description explains the discrepancy. However, calculations performed by $R$. de Souza (Indiana University) on the system ${ }^{35} \mathrm{Cl}$ on ${ }^{209} \mathrm{Bi}$ seem to indicate that angular momentum does not have a great effect on the potential gradient in the $N-Z$ plane. $D$. Pal et al. [PAL 90] concluded that the inclusion of trajectory fluctuations in their calculations resulted in a much better agreement with the experiment than the use of 
the mean trajectory method (Randrup's model). It has also been suggested that the consideration of non-Markovian effects (meaning that the microscopic degrees of freedom are not in equilibrium in the time frame of the macroscopic ones) can also give a better description of the experimental data [PAL 88]. Overall, this stresses the need for a more realistic and quantitative description of the driving forces acting on the dinuclear system.

It is apparent that, while there is a basic understanding of the deep-inlastic process, there is still a need for more detailed experiments to be able to reconstruct these reactions with a minimum of assumptions. Unfortunately, the attempt to measure light-charged particles in coincidence with projectile-like fragments for the system ${ }^{35} \mathrm{Cl}$ on ${ }^{209} \mathrm{Bi}$ gave inconclusive results, eliminating an interesting piece of information. In general, coincidence measurements of projectile-like and target-like fragments combined with the determination of evaporation products are necessary to provide new insights in these reactions. Recent experiments suggest that deepinelastic processes also occur at intermediate energies (of the order of the Fermi energy E/A $37 \mathrm{MeV}$ )[BOR 88, TAS 89, BOR 90]. Hopefully, this will provide a renewed interest in the study of the deep-inelastic mechanism. 


\section{APPENDIX A PARAMETERS OF THE DISTRIBUTIONS}

Table A.1 Parameters obtained using a moment analysis for the system ${ }^{37} \mathrm{Cl}+{ }^{40} \mathrm{Ca}$ at $270 \mathrm{MeV}$. The energy loss (Eloss) values have been corrected assuming equal division of the excitation energy.

\begin{tabular}{|c|c|c|c|c|c|}
\hline Eloss $(\mathrm{MeV})$ & $\langle Z\rangle$ & $\langle\mathrm{N}\rangle$ & $\sigma_{z}^{2}$ & $\sigma_{N}^{2}$ & $\rho$ \\
\hline 8 & $\begin{array}{c}16.94 \\
\pm .12\end{array}$ & $\begin{array}{r}19.53 \\
\pm .14\end{array}$ & $\begin{array}{r}.400 \\
\pm .010\end{array}$ & $\begin{array}{c}.705 \\
\pm .016\end{array}$ & $\begin{array}{r}-.490 \\
\pm .001\end{array}$ \\
\hline 12 & $\begin{array}{l}16.83 \\
\pm .16\end{array}$ & $\begin{array}{r}19.49 \\
\pm .18\end{array}$ & $\begin{array}{r}.586 \\
\pm .014\end{array}$ & $\begin{array}{l}1.085 \\
\pm .025\end{array}$ & $\begin{array}{r}-.204 \\
\pm .001\end{array}$ \\
\hline 16 & $\begin{array}{l}16.79 \\
\pm .21\end{array}$ & $\begin{array}{r}19.16 \\
\pm .24\end{array}$ & $\begin{array}{r}.770 \\
\pm .022\end{array}$ & $\begin{array}{l}1.321 \\
\pm .038\end{array}$ & $\begin{array}{r}.021 \\
\pm .001\end{array}$ \\
\hline 20 & $\begin{array}{l}16.75 \\
\pm .26\end{array}$ & $\begin{array}{c}18.94 \\
\pm .29\end{array}$ & $\begin{array}{r}1.012 \\
\pm .032\end{array}$ & $\begin{array}{l}1.499 \\
\pm .050\end{array}$ & $\begin{array}{r}.250 \\
\pm .001\end{array}$ \\
\hline 24 & $\begin{array}{l}16.70 \\
\pm .30\end{array}$ & $\begin{array}{r}18.79 \\
\pm .34\end{array}$ & $\begin{array}{r}1.178 \\
\pm .042\end{array}$ & $\begin{array}{l}1.820 \\
\pm .069\end{array}$ & $\begin{array}{r}.374 \\
\pm .001\end{array}$ \\
\hline 28 & $\begin{array}{l}16.65 \\
\pm .34\end{array}$ & $\begin{array}{r}18.65 \\
\pm .38\end{array}$ & $\begin{array}{r}1.394 \\
\pm .057\end{array}$ & $\begin{array}{l}2.375 \\
\pm .100\end{array}$ & $\begin{array}{r}.480 \\
\pm .002\end{array}$ \\
\hline 32 & $\begin{array}{l}16.57 \\
\pm .37\end{array}$ & $\begin{array}{c}18.43 \\
\pm .41\end{array}$ & $\begin{array}{r}1.786 \\
\pm .079\end{array}$ & $\begin{array}{l}3.067 \\
\pm .141\end{array}$ & $\begin{array}{r}.603 \\
\pm .003\end{array}$ \\
\hline 36 & $\begin{array}{l}16.45 \\
\pm .37\end{array}$ & $\begin{array}{l}18.25 \\
\pm .41\end{array}$ & $\begin{array}{r}2.196 \\
\pm .097\end{array}$ & $\begin{array}{l}3.550 \\
\pm .154\end{array}$ & $\begin{array}{r}.710 \\
\pm .004\end{array}$ \\
\hline 40 & $\begin{array}{l}16.40 \\
\pm .36\end{array}$ & $\begin{array}{l}18.11 \\
\pm .40\end{array}$ & $\begin{array}{r}2.578 \\
\pm .106\end{array}$ & $\begin{array}{l}4.003 \\
\pm .168\end{array}$ & $\begin{array}{r}.762 \\
\pm .005\end{array}$ \\
\hline 44 & $\begin{array}{l}16.35 \\
\pm .34\end{array}$ & $\begin{array}{c}18.02 \\
\pm .37\end{array}$ & $\begin{array}{r}3.095 \\
\pm .119\end{array}$ & $\begin{array}{l}4.657 \\
\pm .179\end{array}$ & $\begin{array}{r}.803 \\
\pm .005\end{array}$ \\
\hline 48 & $\begin{array}{l}16.22 \\
\pm .32\end{array}$ & $\begin{array}{r}17.80 \\
\pm .35\end{array}$ & $\begin{array}{l}3.850 \\
\pm .140\end{array}$ & $\begin{array}{l}5.793 \\
\pm .213\end{array}$ & $\begin{array}{r}.833 \\
\pm .006\end{array}$ \\
\hline 52 & $\begin{array}{l}16.13 \\
\pm .30\end{array}$ & $\begin{array}{c}17.66 \\
\pm .33\end{array}$ & $\begin{array}{l}4.667 \\
\pm .156\end{array}$ & $\begin{array}{l}6.714 \\
\pm .225\end{array}$ & $\begin{array}{r}.864 \\
\pm .006\end{array}$ \\
\hline 56 & $\begin{array}{l}16.02 \\
\pm .28\end{array}$ & $\begin{array}{l}17.52 \\
\pm .31\end{array}$ & $\begin{array}{l}5.627 \\
\pm .175\end{array}$ & $\begin{array}{l}7.934 \\
\pm .248\end{array}$ & $\begin{array}{r}.887 \\
\pm .007\end{array}$ \\
\hline 60 & $\begin{array}{l}15.88 \\
\pm .27\end{array}$ & $\begin{array}{l}17.34 \\
\pm .30\end{array}$ & $\begin{array}{l}6.512 \\
\pm .194\end{array}$ & $\begin{array}{l}8.911 \\
\pm .266\end{array}$ & $\begin{array}{r}.901 \\
\pm .007\end{array}$ \\
\hline 64 & $\begin{array}{l}15.81 \\
\pm .27\end{array}$ & $\begin{array}{r}17.24 \\
\pm .29\end{array}$ & $\begin{array}{r}7.536 \\
\pm .215\end{array}$ & $\begin{array}{c}10.446 \\
\pm .298\end{array}$ & $\begin{array}{r}919 \\
\pm .008\end{array}$ \\
\hline 68 & $\begin{array}{l}15.66 \\
\pm .26\end{array}$ & $\begin{array}{r}17.07 \\
\pm .28\end{array}$ & $\begin{array}{r}8.638 \\
\pm .232\end{array}$ & $\begin{array}{l}11.838 \\
\pm .322\end{array}$ & $\begin{array}{r}.932 \\
\pm .008\end{array}$ \\
\hline 72 & $\begin{array}{l}15.54 \\
\pm .26\end{array}$ & $\begin{array}{r}16.95 \\
\pm .28\end{array}$ & $\begin{array}{r}9.866 \\
\pm .262\end{array}$ & $\begin{array}{r}13.470 \\
\pm .361\end{array}$ & $\begin{array}{r}.939 \\
\pm .009\end{array}$ \\
\hline 76 & $\begin{array}{l}15.39 \\
\pm .26\end{array}$ & $\begin{array}{r}16.81 \\
\pm .29\end{array}$ & $\begin{array}{l}10.673 \\
\pm .283\end{array}$ & $\begin{array}{r}14.676 \\
\pm .396\end{array}$ & $\begin{array}{r}.945 \\
\pm .010\end{array}$ \\
\hline 80 & $\begin{array}{l}15.26 \\
\pm .27\end{array}$ & $\begin{array}{r}16.71 \\
\pm .30\end{array}$ & $\begin{array}{l}11.571 \\
\pm .316\end{array}$ & $\begin{array}{c}15.908 \\
\pm .440\end{array}$ & $\begin{array}{r}.951 \\
\pm .012\end{array}$ \\
\hline 84 & $\begin{array}{l}15.22 \\
\pm .29 \\
\end{array}$ & $\begin{array}{r}16.67 \\
\pm .32\end{array}$ & $\begin{array}{c}12.123 \\
\pm .348\end{array}$ & $\begin{array}{c}16.984 \\
\pm .495\end{array}$ & $\begin{array}{r}.953 \\
\pm .014\end{array}$ \\
\hline
\end{tabular}




\begin{tabular}{cccccc}
\hline 88 & 15.17 & 16.67 & 12.532 & 17.594 & .956 \\
& \pm .32 & \pm .35 & \pm .396 & \pm .564 & \pm .017 \\
\hline 92 & 15.26 & 16.77 & 12.915 & 18.340 & .957 \\
& \pm .36 & \pm .40 & \pm .454 & \pm .654 & \pm .022 \\
\hline 96 & 15.27 & 16.84 & 12.835 & 18.446 & .956 \\
& \pm .42 & \pm .46 & \pm .527 & \pm .772 & \pm .030 \\
\hline 100 & 15.37 & 17.04 & 11.919 & 17.557 & .955 \\
& \pm .50 & \pm .56 & \pm .572 & \pm .863 & \pm .039 \\
\hline
\end{tabular}


Table A.2 Parameters obtained using a Gaussian fit for the system ${ }^{37} \mathrm{Cl}+{ }^{40} \mathrm{Ca}$ at $270 \mathrm{MeV}$. The energy loss ( $E_{\text {loss}}$ ) values have been corrected assuming equal division of the excitation energy.

\begin{tabular}{|c|c|c|c|c|c|}
\hline $\mathrm{E}_{\text {loss }}(\mathrm{MeV})$ & $\langle\mathrm{Z}\rangle$ & $\langle\mathrm{N}\rangle$ & $\sigma_{z}^{2}$ & $\sigma_{N}^{2}$ & $\rho$ \\
\hline 8 & $\begin{array}{l}17.12 \\
\pm .05 \\
\end{array}$ & $\begin{array}{r}19.67 \\
\pm .08\end{array}$ & $\begin{array}{r}.237 \\
\pm .021\end{array}$ & $\begin{array}{r}.289 \\
\pm .026\end{array}$ & $\begin{array}{r}.073 \\
\pm .065\end{array}$ \\
\hline 12 & $\begin{array}{l}16.97 \\
\pm .05\end{array}$ & $\begin{array}{l}19.60 \\
\pm .08\end{array}$ & $\begin{array}{r}.345 \\
\pm .023 \\
\end{array}$ & $\begin{array}{r}.596 \\
\pm .036\end{array}$ & $\begin{array}{r}.152 \\
\pm .043\end{array}$ \\
\hline 16 & $\begin{array}{l}16.96 \\
\pm .05\end{array}$ & $\begin{array}{l}19.26 \\
\pm .08\end{array}$ & $\begin{array}{r}.617 \\
\pm .025\end{array}$ & $\begin{array}{r}.921 \\
\pm .033\end{array}$ & $\begin{array}{r}.375 \\
\pm .025 \text {. }\end{array}$ \\
\hline 20 & $\begin{array}{l}16.91 \\
\pm .05\end{array}$ & $\begin{array}{l}19.02 \\
\pm .08 \\
\end{array}$ & $\begin{array}{r}.919 \\
\pm .029 \\
\end{array}$ & $\begin{array}{r}1.142 \\
\pm .034\end{array}$ & $\begin{array}{r}.559 \\
\pm .016\end{array}$ \\
\hline 24 & $\begin{array}{l}16.84 \\
\pm .05\end{array}$ & $\begin{array}{l}18.89 \\
\pm .08\end{array}$ & $\begin{array}{r}1.104 \\
\pm .034 \\
\end{array}$ & $\begin{array}{l}1.388 \\
\pm .041\end{array}$ & $\begin{array}{r}.660 \\
\pm .014\end{array}$ \\
\hline 28 & $\begin{array}{l}16.79 \\
\pm .05\end{array}$ & $\begin{array}{l}18.71 \\
\pm .08\end{array}$ & $\begin{array}{l}1.310 \\
\pm .040\end{array}$ & $\begin{array}{l}1.859 \\
\pm .053\end{array}$ & $\begin{array}{r}.725 \\
\pm .011\end{array}$ \\
\hline 32 & $\begin{array}{l}16.69 \\
\pm .05\end{array}$ & $\begin{array}{l}18.51 \\
\pm .08\end{array}$ & $\begin{array}{l}1.713 \\
\pm .047\end{array}$ & $\begin{array}{l}2.404 \\
\pm .063\end{array}$ & $\begin{array}{r}.799 \\
\pm .008\end{array}$ \\
\hline 36 & $\begin{array}{l}16.57 \\
\pm .05 \\
\end{array}$ & $\begin{array}{c}18.26 \\
\pm .08 \\
\end{array}$ & $\begin{array}{r}2.142 \\
\pm .055 \\
\end{array}$ & $\begin{array}{l}3.079 \\
\pm .075\end{array}$ & $\begin{array}{r}.860 \\
\pm .006 \\
\end{array}$ \\
\hline 40 & $\begin{array}{l}16.47 \\
\pm .05 \\
\end{array}$ & $\begin{array}{c}18.14 \\
\pm .08 \\
\end{array}$ & $\begin{array}{r}2.635 \\
\pm .047 \\
\end{array}$ & $\begin{array}{l}3.630 \\
\pm .063\end{array}$ & $\begin{array}{r}.883 \\
\pm .004\end{array}$ \\
\hline 44 & $\begin{array}{l}16.42 \\
\pm .06\end{array}$ & $\begin{array}{l}18.00 \\
\pm .08\end{array}$ & $\begin{array}{r}3.296 \\
\pm .079\end{array}$ & $\begin{array}{l}4.460 \\
\pm .105\end{array}$ & $\begin{array}{r}.906 \\
\pm .004\end{array}$ \\
\hline 48 & $\begin{array}{l}16.31 \\
\pm .06\end{array}$ & $\begin{array}{l}17.82 \\
\pm .08\end{array}$ & $\begin{array}{r}3.812 \\
\pm .078\end{array}$ & $\begin{array}{l}5.250 \\
\pm .105\end{array}$ & $\begin{array}{r}.921 \\
\pm .003\end{array}$ \\
\hline 52 & $\begin{array}{l}16.22 \\
\pm .06 \\
\end{array}$ & $\begin{array}{r}17.69 \\
\pm .08\end{array}$ & $\begin{array}{r}4.737 \\
\pm .092 \\
\end{array}$ & $\begin{array}{l}6.401 \\
\pm .122 \\
\end{array}$ & $\begin{array}{r}.934 \\
\pm .002\end{array}$ \\
\hline 56 & $\begin{array}{l}16.12 \\
\pm .06\end{array}$ & $\begin{array}{r}17.56 \\
\pm .08 \\
\end{array}$ & $\begin{array}{l}5.776 \\
\pm .109 \\
\end{array}$ & $\begin{array}{r}7.842 \\
\pm .146\end{array}$ & $\begin{array}{r}.948 \\
\pm .002 \\
\end{array}$ \\
\hline 60 & $\begin{array}{l}15.94 \\
\pm .06 \\
\end{array}$ & $\begin{array}{r}17.35 \\
\pm .07 \\
\end{array}$ & $\begin{array}{r}6.801 \\
\pm .092 \\
\end{array}$ & $\begin{array}{l}9.102 \\
\pm .122\end{array}$ & $\begin{array}{r}.955 \\
\pm .001\end{array}$ \\
\hline 64 & $\begin{array}{l}15.84 \\
\pm .06\end{array}$ & $\begin{array}{r}17.23 \\
\pm .08 \\
\end{array}$ & $\begin{array}{r}8.231 \\
\pm .170 \\
\end{array}$ & $\begin{array}{l}10.959 \\
\pm .225\end{array}$ & $\begin{array}{r}.964 \\
\pm .001\end{array}$ \\
\hline 68 & $\begin{array}{l}15.65 \\
\pm .07 \\
\end{array}$ & $\begin{array}{r}17.02 \\
\pm .09 \\
\end{array}$ & $\begin{array}{r}9.849 \\
\pm .211 \\
\end{array}$ & $\begin{array}{r}13.087 \\
\pm .279 \\
\end{array}$ & $\begin{array}{r}.969 \\
\pm .001 \\
\end{array}$ \\
\hline 72 & $\begin{array}{l}15.48 \\
\pm .07 \\
\end{array}$ & $\begin{array}{l}16.83 \\
\pm .09\end{array}$ & $\begin{array}{r}11.955 \\
\pm .274 \\
\end{array}$ & $\begin{array}{l}15.921 \\
\pm .364\end{array}$ & $\begin{array}{r}.974 \\
\pm .001\end{array}$ \\
\hline 76 & $\begin{array}{l}15.25 \\
\pm .07 \\
\end{array}$ & $\begin{array}{r}16.60 \\
\pm .10 \\
\end{array}$ & $\begin{array}{r}13.875 \\
\pm .350 \\
\end{array}$ & $\begin{array}{r}18.819 \\
\pm .474 \\
\end{array}$ & $\begin{array}{r}.976 \\
\pm .001 \\
\end{array}$ \\
\hline 80 & $\begin{array}{l}14.98 \\
\pm .09 \\
\end{array}$ & $\begin{array}{l}16.29 \\
\pm .11\end{array}$ & $\begin{array}{l}16.607 \\
\pm .493\end{array}$ & $\begin{array}{r}22.320 \\
\pm .662\end{array}$ & $\begin{array}{r}.981 \\
\pm .001\end{array}$ \\
\hline 84 & $\begin{array}{l}14.83 \\
\pm .09\end{array}$ & $\begin{array}{l}16.12 \\
\pm .12\end{array}$ & $\begin{array}{l}18.366 \\
\pm .586\end{array}$ & $\begin{array}{r}25.187 \\
\pm .804\end{array}$ & $\begin{array}{r}.982 \\
\pm .001\end{array}$ \\
\hline 88 & $\begin{array}{l}14.66 \\
\pm .10 \\
\end{array}$ & $\begin{array}{c}15.94 \\
\pm .13 \\
\end{array}$ & $\begin{array}{c}20.409 \\
\pm .721\end{array}$ & $\begin{array}{r}27.848 \\
\pm .986\end{array}$ & $\begin{array}{r}.985 \\
\pm .001\end{array}$ \\
\hline 92 & $\begin{array}{l}14.71 \\
\pm .11\end{array}$ & $\begin{array}{l}15.98 \\
\pm .14\end{array}$ & $\begin{array}{l}21.889 \\
\pm .881\end{array}$ & $\begin{array}{l}30.254 \\
\pm 1.129\end{array}$ & $\begin{array}{r}.985 \\
\pm .001\end{array}$ \\
\hline
\end{tabular}




\begin{tabular}{cccccc}
\hline 96 & 14.78 & 16.08 & 21.385 & 29.989 & .986 \\
& \pm .10 & \pm .12 & \pm .664 & \pm .932 & \pm .001 \\
\hline 100 & 15.15 & 16.54 & 16.850 & 24.016 & .982 \\
& \pm .11 & \pm .13 & \pm .709 & \pm 1.011 & \pm .001 \\
\hline
\end{tabular}


Table A.3 Parameters obtained using a moment analysis for the system ${ }^{37} \mathrm{Cl}+{ }^{209} \mathrm{Bi}$ at $270 \mathrm{MeV}$. The energy loss (Eloss) values have been corrected assuming equal division of the excitation energy.

\begin{tabular}{|c|c|c|c|c|c|}
\hline$E_{\text {loss }}(\mathrm{MeV})$ & $\langle\mathrm{Z}\rangle$ & $\langle\mathrm{N}\rangle$ & $\sigma_{\mathrm{z}}{ }^{2}$ & $\sigma_{N}^{2}$ & $\rho$ \\
\hline 8 & $\begin{array}{l}16.69 \\
\pm .21\end{array}$ & $\begin{array}{c}20.22 \\
\pm .26\end{array}$ & $\begin{array}{r}.370 \\
\pm .015\end{array}$ & $\begin{array}{l}1.287 \\
\pm .038\end{array}$ & $\begin{array}{l}-.337 \\
\pm .001\end{array}$ \\
\hline 12 & $\begin{array}{l}16.41 \\
\pm .23 \\
\end{array}$ & $\begin{array}{r}20.16 \\
\pm .28 \\
\end{array}$ & $\begin{array}{r}.491 \\
+.018 \\
\end{array}$ & $\begin{array}{r}1.114 \\
\pm .042 \\
\end{array}$ & $\begin{array}{r}-.088 \\
\pm .001\end{array}$ \\
\hline 16 & $\begin{array}{l}16.37 \\
\pm .24 \\
\end{array}$ & $\begin{array}{r}20.13 \\
\pm .30 \\
\end{array}$ & $\begin{array}{r}.503 \\
\pm .019 \\
\end{array}$ & $\begin{array}{l}1.290 \\
\pm .058\end{array}$ & $\begin{array}{r}-.016 \\
\pm .001\end{array}$ \\
\hline 20 & $\begin{array}{l}16.28 \\
\pm .26 \\
\end{array}$ & $\begin{array}{l}20.08 \\
\pm .32 \\
\end{array}$ & $\begin{array}{r}.643 \\
\pm .025\end{array}$ & $\begin{array}{r}1.648 \\
\pm .065\end{array}$ & $\begin{array}{r}.142 \\
\pm .001\end{array}$ \\
\hline 24 & $\begin{array}{l}16.08 \\
\pm .26 \\
\end{array}$ & $\begin{array}{r}19.94 \\
\pm .32 \\
\end{array}$ & $\begin{array}{r}.813 \\
\pm .027\end{array}$ & $\begin{array}{l}1.793 \\
\pm .071 \\
\end{array}$ & $\begin{array}{r}.213 \\
\pm .001\end{array}$ \\
\hline 28 & $\begin{array}{l}15.94 \\
\pm .26 \\
\end{array}$ & $\begin{array}{r}19.80 \\
\pm .32 \\
\end{array}$ & $\begin{array}{r}.901 \\
\pm .030 \\
\end{array}$ & $\begin{array}{l}2.056 \\
\pm .081 \\
\end{array}$ & $\begin{array}{r}.236 \\
\pm .001 \\
\end{array}$ \\
\hline 32 & $\begin{array}{l}15.85 \\
\pm .27 \\
\end{array}$ & $\begin{array}{r}19.71 \\
\pm .33 \\
\end{array}$ & $\begin{array}{r}.919 \\
\pm .033 \\
\end{array}$ & $\begin{array}{r}2.135 \\
\pm .084 \\
\end{array}$ & $\begin{array}{r}.305 \\
\pm .001 \\
\end{array}$ \\
\hline 36 & $\begin{array}{l}15.80 \\
\pm .28 \\
\end{array}$ & $\begin{array}{r}19.62 \\
\pm .35 \\
\end{array}$ & $\begin{array}{r}.978 \\
\pm .037 \\
\end{array}$ & $\begin{array}{r}2.380 \\
\pm .104\end{array}$ & $\begin{array}{r}.312 \\
\pm .001 \\
\end{array}$ \\
\hline 40 & $\begin{array}{l}15.71 \\
\pm .30 \\
\end{array}$ & $\begin{array}{r}19.47 \\
\pm .37 \\
\end{array}$ & $\begin{array}{r}1.083 \\
\pm .044 \\
\end{array}$ & $\begin{array}{r}2.740 \\
\pm .142 \\
\end{array}$ & $\begin{array}{r}.363 \\
\pm .002 \\
\end{array}$ \\
\hline 44 & $\begin{array}{l}15.57 \\
\pm .31 \\
\end{array}$ & $\begin{array}{r}19.38 \\
\pm .39 \\
\end{array}$ & $\begin{array}{r}1.175 \\
\pm .050 \\
\end{array}$ & $\begin{array}{l}2.642 \\
\pm .136 \\
\end{array}$ & $\begin{array}{r}.430 \\
\pm .002 \\
\end{array}$ \\
\hline 48 & $\begin{array}{l}15.53 \\
\pm .33 \\
\end{array}$ & $\begin{array}{l}19.30 \\
\pm .42\end{array}$ & $\begin{array}{r}1.272 \\
\pm .057\end{array}$ & $\begin{array}{r}2.849 \\
\pm .143\end{array}$ & $\begin{array}{r}.483 \\
\pm .003\end{array}$ \\
\hline 52 & $\begin{array}{l}15.40 \\
\pm .35 \\
\end{array}$ & $\begin{array}{r}19.15 \\
\pm .44 \\
\end{array}$ & $\begin{array}{r}1.304 \\
\pm .063 \\
\end{array}$ & $\begin{array}{r}2.832 \\
\pm .152\end{array}$ & $\begin{array}{r}.510 \\
\pm .003\end{array}$ \\
\hline 56 & $\begin{array}{l}15.27 \\
\pm .37 \\
\end{array}$ & $\begin{array}{r}19.01 \\
\pm .46 \\
\end{array}$ & $\begin{array}{r}1.427 \\
\pm .071 \\
\end{array}$ & $\begin{array}{l}3.074 \\
\pm .165\end{array}$ & $\begin{array}{r}.558 \\
\pm .004\end{array}$ \\
\hline 60 & $\begin{array}{l}15.14 \\
\pm .41 \\
\end{array}$ & $\begin{array}{r}18.85 \\
\pm .51 \\
\end{array}$ & $\begin{array}{l}1.620 \\
\pm .091 \\
\end{array}$ & $\begin{array}{l}3.653 \\
\pm .211 \\
\end{array}$ & $\begin{array}{r}.578 \\
\pm .006\end{array}$ \\
\hline 64 & $\begin{array}{l}14.96 \\
\pm .43 \\
\end{array}$ & $\begin{array}{r}18.67 \\
\pm .54 \\
\end{array}$ & $\begin{array}{l}1.771 \\
\pm .109\end{array}$ & $\begin{array}{r}3.806 \\
\pm .251 \\
\end{array}$ & $\begin{array}{r}.653 \\
\pm .010 \\
\end{array}$ \\
\hline 68 & $\begin{array}{l}14.97 \\
\pm .46 \\
\end{array}$ & $\begin{array}{r}18.65 \\
\pm .58 \\
\end{array}$ & $\begin{array}{l}1.998 \\
\pm .127\end{array}$ & $\begin{array}{r}4.468 \\
\pm .324\end{array}$ & $\begin{array}{r}.706 \\
\pm .013\end{array}$ \\
\hline 72 & $\begin{array}{l}14.77 \\
\pm .48 \\
\end{array}$ & $\begin{array}{r}18.48 \\
\pm .60 \\
\end{array}$ & $\begin{array}{l}2.034 \\
\pm .138 \\
\end{array}$ & $\begin{array}{r}4.642 \\
\pm .339 \\
\end{array}$ & $\begin{array}{r}.707 \\
+.015 \\
\end{array}$ \\
\hline 76 & $\begin{array}{l}14.63 \\
\pm .53 \\
\end{array}$ & $\begin{array}{r}18.26 \\
\pm .66 \\
\end{array}$ & $\begin{array}{l}2.031 \\
\pm .156 \\
\end{array}$ & $\begin{array}{l}5.004 \\
\pm .418 \\
\end{array}$ & $\begin{array}{r}.722 \\
+.020 \\
\end{array}$ \\
\hline 80 & $\begin{array}{l}14.60 \\
\pm .56 \\
\end{array}$ & $\begin{array}{r}18.14 \\
\pm .70 \\
\end{array}$ & $\begin{array}{r}2.657 \\
\pm .204 \\
\end{array}$ & $\begin{array}{l}6.075 \\
\pm .482 \\
\end{array}$ & $\begin{array}{r}.787 \\
\pm .025 \\
\end{array}$ \\
\hline 84 & $\begin{array}{l}14.40 \\
\pm .61 \\
\end{array}$ & $\begin{array}{r}18.03 \\
\pm .76 \\
\end{array}$ & $\begin{array}{r}2.717 \\
\pm .227 \\
\end{array}$ & $\begin{array}{r}5.995 \\
\pm .565 \\
\end{array}$ & $\begin{array}{r}.787 \\
\pm .033 \\
\end{array}$ \\
\hline 88 & $\begin{array}{l}14.15 \\
\pm .69 \\
\end{array}$ & $\begin{array}{r}17.77 \\
\pm .87 \\
\end{array}$ & $\begin{array}{r}2.869 \\
+.278 \\
\end{array}$ & $\begin{array}{l}6.598 \\
\pm .720 \\
\end{array}$ & $\begin{array}{r}.799 \\
\pm .050\end{array}$ \\
\hline 92 & $\begin{array}{l}13.80 \\
\pm .74 \\
\end{array}$ & $\begin{array}{r}17.24 \\
\pm .93 \\
\end{array}$ & $\begin{array}{r}2.7112 \\
\pm .294 \\
\end{array}$ & $\begin{array}{r}5.818 \\
\pm .749 \\
\end{array}$ & $\begin{array}{r}.767 \\
\pm .057\end{array}$ \\
\hline
\end{tabular}




\begin{tabular}{cccccc}
\hline 96 & 13.93 & 17.46 & 3.260 & 7.357 & .852 \\
& \pm .82 & \pm 1.03 & \pm .386 & \pm .939 & \pm .080 \\
\hline 100 & 13.32 & 16.72 & 2.739 & 5.094 & .829 \\
& \pm .90 & \pm 1.13 & \pm .406 & \pm .880 & \pm .105 \\
\hline
\end{tabular}


Table A.4 Parameters obtained using a Gaussian fit for the system ${ }^{37} \mathrm{Cl}+{ }^{209} \mathrm{Bi}$ at $270 \mathrm{MeV}$. The energy loss (Eloss) values have been corrected assuming equal division of the excitation energy.

\begin{tabular}{|c|c|c|c|c|c|}
\hline $\mathrm{E}_{\text {loss }}(\mathrm{MeV})$ & $\langle Z\rangle$ & $\langle\mathrm{N}\rangle$ & $\sigma_{z}^{2}$ & $\sigma_{N}^{2}$ & $\rho$ \\
\hline 8 & $\begin{array}{l}16.79 \\
\pm .06\end{array}$ & $\begin{array}{c}20.35 \\
\pm .11\end{array}$ & $\begin{array}{r}.219 \\
\pm .021\end{array}$ & $\begin{array}{r}.809 \\
\pm .079\end{array}$ & $\begin{array}{r}.065 \\
\pm .073\end{array}$ \\
\hline 12 & $\begin{array}{l}16.54 \\
\pm .05\end{array}$ & $\begin{array}{r}20.25 \\
\pm .07\end{array}$ & $\begin{array}{r}.448 \\
\pm .080\end{array}$ & $\begin{array}{c}510 \\
\pm .158\end{array}$ & $\begin{array}{l}-.181 \\
\pm .191\end{array}$ \\
\hline 16 & $\begin{array}{l}16.51 \\
\pm .06\end{array}$ & $\begin{array}{c}20.30 \\
\pm .08\end{array}$ & $\begin{array}{r}.367 \\
\pm .022\end{array}$ & $\begin{array}{r}.580 \\
\pm .033\end{array}$ & $\begin{array}{r}.397 \\
\pm .036\end{array}$ \\
\hline 20 & $\begin{array}{l}16.42 \\
\pm .05\end{array}$ & $\begin{array}{r}20.22 \\
\pm .08\end{array}$ & $\begin{array}{c}.501 \\
\pm .017\end{array}$ & $\begin{array}{l}1.018 \\
\pm .030\end{array}$ & $\begin{array}{r}.410 \\
\pm .020\end{array}$ \\
\hline 24 & $\begin{array}{l}16.16 \\
\pm .06\end{array}$ & $\begin{array}{c}20.06 \\
\pm .09\end{array}$ & $\begin{array}{r}.697 \\
\pm .034\end{array}$ & $\begin{array}{l}1.197 \\
\pm .050\end{array}$ & $\begin{array}{r}.416 \\
\pm .028\end{array}$ \\
\hline 28 & $\begin{array}{l}16.02 \\
\pm .06\end{array}$ & $\begin{array}{r}19.91 \\
\pm .09\end{array}$ & $\begin{array}{r}.773 \\
\pm .039\end{array}$ & $\begin{array}{r}1.356 \\
\pm .059\end{array}$ & $\begin{array}{r}.462 \\
\pm .027\end{array}$ \\
\hline 32 & $\begin{array}{l}15.92 \\
\pm .06\end{array}$ & $\begin{array}{l}19.78 \\
\pm .09\end{array}$ & $\begin{array}{r}.783 \\
\pm .040\end{array}$ & $\begin{array}{l}1.488 \\
\pm .064\end{array}$ & $\begin{array}{r}.438 \\
\pm .028\end{array}$ \\
\hline 36 & $\begin{array}{l}15.90 \\
\pm .06\end{array}$ & $\begin{array}{c}19.68 \\
\pm .09\end{array}$ & $\begin{array}{r}.838 \\
\pm .040\end{array}$ & $\begin{array}{l}1.678 \\
\pm .070\end{array}$ & $\begin{array}{r}.490 \\
\pm .025\end{array}$ \\
\hline 40 & $\begin{array}{l}15.81 \\
\pm .06\end{array}$ & $\begin{array}{r}19.53 \\
\pm .09\end{array}$ & $\begin{array}{r}.903 \\
\pm .044\end{array}$ & $\begin{array}{l}1.774 \\
\pm .075\end{array}$ & $\begin{array}{r}.563 \\
\pm .024\end{array}$ \\
\hline 44 & $\begin{array}{l}15.65 \\
\pm .06 \\
\end{array}$ & $\begin{array}{l}19.41 \\
\pm .09 \\
\end{array}$ & $\begin{array}{r}.953 \\
\pm .048 \\
\end{array}$ & $\begin{array}{l}1.863 \\
\pm .081\end{array}$ & $\begin{array}{r}.594 \\
\pm .024\end{array}$ \\
\hline 48 & $\begin{array}{r}15.55 \\
\pm .06 \\
\end{array}$ & $\begin{array}{r}19.34 \\
\pm .09 \\
\end{array}$ & $\begin{array}{r}1.033 \\
\pm .049 \\
\end{array}$ & $\begin{array}{r}1.946 \\
\pm .080\end{array}$ & $\begin{array}{r}.554 \\
\pm .024\end{array}$ \\
\hline 52 & $\begin{array}{l}15.45 \\
\pm .06 \\
\end{array}$ & $\begin{array}{c}19.18 \\
\pm .10\end{array}$ & $\begin{array}{r}1.080 \\
\pm .054\end{array}$ & $\begin{array}{l}2.109 \\
\pm .093\end{array}$ & $\begin{array}{r}.618 \\
\pm .023\end{array}$ \\
\hline 56 & $\begin{array}{l}15.34 \\
\pm .06\end{array}$ & $\begin{array}{r}19.00 \\
\pm .10\end{array}$ & $\begin{array}{r}1.167 \\
\pm .058\end{array}$ & $\begin{array}{r}2.329 \\
\pm .102\end{array}$ & $\begin{array}{r}.627 \\
\pm .022\end{array}$ \\
\hline 60 & $\begin{array}{l}15.15 \\
\pm .07\end{array}$ & $\begin{array}{l}18.91 \\
\pm .10 \\
\end{array}$ & $\begin{array}{r}1.304 \\
\pm .067 \\
\end{array}$ & $\begin{array}{r}2.753 \\
\pm .120 \\
\end{array}$ & $\begin{array}{r}.670 \\
\pm .021 \\
\end{array}$ \\
\hline 64 & $\begin{array}{l}14.96 \\
\pm .07\end{array}$ & $\begin{array}{c}18.58 \\
\pm .10\end{array}$ & $\begin{array}{r}1.297 \\
\pm .068\end{array}$ & $\begin{array}{l}2.607 \\
\pm .123\end{array}$ & $\begin{array}{r}.686 \\
\pm .021\end{array}$ \\
\hline 68 & $\begin{array}{l}15.02 \\
\pm .07\end{array}$ & $\begin{array}{c}18.57 \\
\pm .11 \\
\end{array}$ & $\begin{array}{r}1.615 \\
\pm .085\end{array}$ & $\begin{array}{l}2.971 \\
\pm .141\end{array}$ & $\begin{array}{r}.746 \\
\pm .018\end{array}$ \\
\hline 72 & $\begin{array}{r}14.78 \\
\pm .070 \\
\end{array}$ & $\begin{array}{c}18.26 \\
\pm .11 \\
\end{array}$ & $\begin{array}{r}1.498 \\
\pm .085\end{array}$ & $\begin{array}{l}2.972 \\
\pm .155\end{array}$ & $\begin{array}{r}.743 \\
\pm .019\end{array}$ \\
\hline 76 & $\begin{array}{r}14.67 \\
\pm .073 \\
\end{array}$ & $\begin{array}{c}18.16 \\
\pm .11\end{array}$ & $\begin{array}{r}1.572 \\
\pm .099\end{array}$ & $\begin{array}{l}3.276 \\
\pm .183\end{array}$ & $\begin{array}{r}.771 \\
\pm .020\end{array}$ \\
\hline 80 & $\begin{array}{l}14.68 \\
\pm .09\end{array}$ & $\begin{array}{r}17.99 \\
\pm .14\end{array}$ & $\begin{array}{l}2.325 \\
\pm .140\end{array}$ & $\begin{array}{l}4.645 \\
\pm .261\end{array}$ & $\begin{array}{r}.838 \\
\pm .015\end{array}$ \\
\hline 84 & $\begin{array}{l}14.48 \\
\pm .09\end{array}$ & $\begin{array}{r}17.97 \\
\pm .15\end{array}$ & $\begin{array}{l}2.401 \\
\pm .149\end{array}$ & $\begin{array}{r}4.609 \\
\pm .263\end{array}$ & $\begin{array}{r}.836 \\
\pm .016\end{array}$ \\
\hline 88 & $\begin{array}{l}14.12 \\
\pm .09\end{array}$ & $\begin{array}{r}17.67 \\
\pm .16 \\
\end{array}$ & $\begin{array}{r}2.413 \\
\pm .169 \\
\end{array}$ & $\begin{array}{l}4.954 \\
\pm .327\end{array}$ & $\begin{array}{r}.843 \\
\pm .016\end{array}$ \\
\hline 92 & $\begin{array}{l}13.73 \\
\pm .09\end{array}$ & $\begin{array}{l}17.05 \\
\pm .14\end{array}$ & $\begin{array}{r}2.096 \\
\pm .161\end{array}$ & $\begin{array}{l}3.640 \\
\pm .255\end{array}$ & $\begin{array}{r}.762 \\
\pm .026\end{array}$ \\
\hline
\end{tabular}




\begin{tabular}{cccccc}
\hline 96 & 13.79 & 17.20 & 2.303 & 5.253 & .866 \\
& \pm .10 & \pm .17 & \pm .188 & \pm .399 & \pm .017 \\
\hline \multirow{2}{*}{100} & 13.17 & 16.42 & 1.425 & 2.343 & .823 \\
& \pm .09 & \pm .15 & \pm .151 & \pm .237 & \pm .028 \\
\hline
\end{tabular}


Table A.5 Parameters obtained using a moment analysis for the system ${ }^{37} \mathrm{Cl}+{ }^{209} \mathrm{Bi}$ at $270 \mathrm{MeV}$. The energy loss (Eloss) values have been corrected assuming thermal division of the excitation energy.

\begin{tabular}{|c|c|c|c|c|c|}
\hline Eloss (MeV) & $\langle\mathbf{Z}\rangle$ & $\langle N\rangle$ & $\sigma_{z^{2}}$ & $\sigma_{N}^{2}$ & $\rho$ \\
\hline 8 & $\begin{array}{l}16.73 \\
\pm .20\end{array}$ & $\begin{array}{r}20.22 \\
\pm .25\end{array}$ & $\begin{array}{r}.343 \\
\pm .014\end{array}$ & $\begin{array}{l}1.294 \\
\pm .048\end{array}$ & $\begin{array}{l}-.382 \\
\pm .001\end{array}$ \\
\hline 12 & $\begin{array}{l}16.44 \\
\pm .24\end{array}$ & $\begin{array}{r}20.14 \\
\pm .29\end{array}$ & $\begin{array}{r}.462 \\
\pm .017\end{array}$ & $\begin{array}{l}1.104 \\
\pm .040\end{array}$ & $\begin{array}{r}-.197 \\
\pm .001\end{array}$ \\
\hline 16 & $\begin{array}{l}16.37 \\
\pm .25\end{array}$ & $\begin{array}{c}20.17 \\
\pm .31\end{array}$ & $\begin{array}{r}.505 \\
\pm .019\end{array}$ & $\begin{array}{l}1.258 \\
\pm .052\end{array}$ & $\begin{array}{r}-.031 \\
\pm .001\end{array}$ \\
\hline 20 & $\begin{array}{l}16.33 \\
\pm .27\end{array}$ & $\begin{array}{r}20.09 \\
\pm .33\end{array}$ & $\begin{array}{r}.611 \\
\pm .024\end{array}$ & $\begin{array}{r}1.375 \\
\pm .059\end{array}$ & $\begin{array}{r}.035 \\
\pm .001\end{array}$ \\
\hline 24 & $\begin{array}{l}16.16 \\
\pm .27\end{array}$ & $\begin{array}{r}20.00 \\
\pm .34\end{array}$ & $\begin{array}{r}.801 \\
\pm .029\end{array}$ & $\begin{array}{l}1.695 \\
\pm .069\end{array}$ & $\begin{array}{r}.201 \\
\pm .001\end{array}$ \\
\hline 28 & $\begin{array}{l}16.04 \\
\pm .27\end{array}$ & $\begin{array}{r}19.89 \\
\pm .34\end{array}$ & $\begin{array}{r}.892 \\
\pm .032\end{array}$ & $\begin{array}{l}1.812 \\
\pm .074\end{array}$ & $\begin{array}{r}.241 \\
\pm .001\end{array}$ \\
\hline 32 & $\begin{array}{l}15.95 \\
\pm .28\end{array}$ & $\begin{array}{r}18.80 \\
\pm .34\end{array}$ & $\begin{array}{r}.919 \\
\pm .032\end{array}$ & $\begin{array}{l}2.033 \\
\pm .081\end{array}$ & $\begin{array}{r}.267 \\
\pm .001\end{array}$ \\
\hline 36 & $\begin{array}{l}15.86 \\
\pm .28\end{array}$ & $\begin{array}{c}19.70 \\
\pm .35 \\
\end{array}$ & $\begin{array}{r}.938 \\
\pm .036\end{array}$ & $\begin{array}{r}2.233 \\
\pm .093 \\
\end{array}$ & $\begin{array}{r}.288 \\
\pm .001 \\
\end{array}$ \\
\hline 40 & $\begin{array}{l}15.82 \\
\pm .30\end{array}$ & $\begin{array}{r}19.64 \\
\pm .37\end{array}$ & $\begin{array}{r}1.035 \\
\pm .040\end{array}$ & $\begin{array}{l}2.379 \\
\pm .105\end{array}$ & $\begin{array}{r}.372 \\
\pm .002\end{array}$ \\
\hline 44 & $\begin{array}{l}15.72 \\
\pm .31\end{array}$ & $\begin{array}{r}19.52 \\
\pm .39\end{array}$ & $\begin{array}{r}1.072 \\
\pm .045\end{array}$ & $\begin{array}{l}2.556 \\
\pm .120\end{array}$ & $\begin{array}{r}.419 \\
\pm .002\end{array}$ \\
\hline 48 & $\begin{array}{l}15.67 \\
\pm .33\end{array}$ & $\begin{array}{r}19.38 \\
\pm .40\end{array}$ & $\begin{array}{r}1.214 \\
\pm .052\end{array}$ & $\begin{array}{l}2.797 \\
\pm .150\end{array}$ & $\begin{array}{r}.395 \\
\pm .002\end{array}$ \\
\hline 32 & $\begin{array}{l}15.55 \\
\pm .34 \\
\end{array}$ & $\begin{array}{r}19.30 \\
\pm .43 \\
\end{array}$ & $\begin{array}{r}1.240 \\
\pm .057\end{array}$ & $\begin{array}{r}2.887 \\
\pm .168\end{array}$ & $\begin{array}{r}.431 \\
\pm .003\end{array}$ \\
\hline 56 & $\begin{array}{l}15.48 \\
\pm .36\end{array}$ & $\begin{array}{r}19.21 \\
\pm .45\end{array}$ & $\begin{array}{r}1.332 \\
\pm .064\end{array}$ & $\begin{array}{l}2.969 \\
\pm .156\end{array}$ & $\begin{array}{r}.546 \\
\pm .004\end{array}$ \\
\hline 60 & $\begin{array}{l}15.39 \\
\pm .38 \\
\end{array}$ & $\begin{array}{r}19.09 \\
\pm .47 \\
\end{array}$ & $\begin{array}{r}1.463 \\
\pm .073 \\
\end{array}$ & $\begin{array}{l}3.162 \\
\pm .185\end{array}$ & $\begin{array}{r}.521 \\
\pm .004\end{array}$ \\
\hline 64 & $\begin{array}{l}15.28 \\
\pm .40\end{array}$ & $\begin{array}{r}18.98 \\
\pm .50\end{array}$ & $\begin{array}{r}1.508 \\
\pm .082 \\
\end{array}$ & $\begin{array}{r}3.405 \\
\pm .203 \\
\end{array}$ & $\begin{array}{r}.574 \\
\pm .006 \\
\end{array}$ \\
\hline 68 & $\begin{array}{l}15.12 \\
\pm .43\end{array}$ & $\begin{array}{r}18.82 \\
\pm .54\end{array}$ & $\begin{array}{r}1.743 \\
\pm .099\end{array}$ & $\begin{array}{l}3.751 \\
\pm .233\end{array}$ & $\begin{array}{r}.663 \\
\pm .008\end{array}$ \\
\hline 72. & $\begin{array}{l}14.99 \\
\pm .47\end{array}$ & $\begin{array}{r}18.66 \\
\pm .59\end{array}$ & $\begin{array}{r}1.882 \\
\pm .122\end{array}$ & $\begin{array}{l}4.060 \\
\pm .291\end{array}$ & $\begin{array}{r}.659 \\
\pm .012\end{array}$ \\
\hline 76 & $\begin{array}{l}14.94 \\
\pm .48 \\
\end{array}$ & $\begin{array}{r}18.60 \\
\pm .59\end{array}$ & $\begin{array}{r}2.000 \\
\pm .132\end{array}$ & $\begin{array}{r}4.370 \\
\pm .322 \\
\end{array}$ & $\begin{array}{r}.726 \\
\pm .014 \\
\end{array}$ \\
\hline 80 & $\begin{array}{l}14.87 \\
\pm .51 \\
\end{array}$ & $\begin{array}{r}18.56 \\
\pm .64\end{array}$ & $\begin{array}{r}2.295 \\
\pm .159\end{array}$ & $\begin{array}{r}5.357 \\
\pm .322 \\
\end{array}$ & $\begin{array}{r}.750 \\
\pm .010 \\
\end{array}$ \\
\hline 84 & $\begin{array}{l}14.73 \\
\pm .55\end{array}$ & $\begin{array}{r}18.38 \\
\pm .69\end{array}$ & $\begin{array}{r}2.236 \\
\pm .172\end{array}$ & $\begin{array}{l}5.113 \\
\pm .470\end{array}$ & $\begin{array}{r}.769 \\
\pm .025\end{array}$ \\
\hline $8 \overline{88}$ & $\begin{array}{l}14.55 \\
\pm .58\end{array}$ & $\begin{array}{l}18.13 \\
\pm .72\end{array}$ & $\begin{array}{r}2.653 \\
\pm .209\end{array}$ & $\begin{array}{l}6.048 \\
\pm .497\end{array}$ & $\begin{array}{r}.770 \\
\pm .026\end{array}$ \\
\hline 92 & $\begin{array}{l}14.52 \\
\pm .63\end{array}$ & $\begin{array}{r}18.15 \\
\pm .78\end{array}$ & $\begin{array}{r}3.142 \\
\pm .262\end{array}$ & $\begin{array}{l}7.041 \\
\pm .655\end{array}$ & $\begin{array}{r}.807 \\
\pm .039\end{array}$ \\
\hline
\end{tabular}




\begin{tabular}{cccccc}
\hline 96 & 14.30 & 17.88 & 3.171 & 6.988 & .787 \\
& \pm .69 & \pm .87 & \pm .298 & \pm .770 & \pm .052 \\
\hline 100 & 13.89 & 17.36 & 2.715 & 6.000 & .800 \\
& \pm .77 & \pm .97 & \pm .296 & \pm .744 & \pm .059 \\
\hline
\end{tabular}


Table A.6 Parameters obtained using a Gaussian fit for the system ${ }^{37} \mathrm{Cl}+{ }^{209} \mathrm{Bi}$ at $270 \mathrm{MeV}$. The energy loss (Eloss) values have been corrected assuming thermal division of the excitation energy.

\begin{tabular}{|c|c|c|c|c|c|}
\hline $\mathrm{E}_{\text {loss}}(\mathrm{MeV})$ & $\langle Z\rangle$ & $\langle\mathrm{N}\rangle$ & $\sigma_{\mathrm{Z}}^{2}$ & $\sigma_{N}^{2}$ & $\rho$ \\
\hline 8 & $\begin{array}{l}16.79 \\
\pm .05\end{array}$ & $\begin{array}{r}20.35 \\
\pm .08\end{array}$ & $\begin{array}{r}193 \\
\pm .009\end{array}$ & $\begin{array}{c}.716 \\
\pm .031\end{array}$ & $\begin{array}{c}.041 \\
\pm .036\end{array}$ \\
\hline 12 & $\begin{array}{l}16.55 \\
\pm .05 \\
\end{array}$ & $\begin{array}{r}20.41 \\
\pm .08 \\
\end{array}$ & $\begin{array}{r}.233 \\
\pm .010 \\
\end{array}$ & $\begin{array}{r}.408 \\
\pm .018\end{array}$ & $\begin{array}{r}.397 \\
\pm .026\end{array}$ \\
\hline 16 & $\begin{array}{l}16.51 \\
\pm .05\end{array}$ & $\begin{array}{r}20.35 \\
\pm .08\end{array}$ & $\begin{array}{r}.331 \\
\pm .013\end{array}$ & $\begin{array}{r}.542 \\
\pm .019\end{array}$ & $\begin{array}{r}.425 \\
\pm .022\end{array}$ \\
\hline 20 & $\begin{array}{l}16.44 \\
\pm .06\end{array}$ & $\begin{array}{c}20.21 \\
\pm .09 \\
\end{array}$ & $\begin{array}{r}.469 \\
\pm .025 \\
\end{array}$ & $\begin{array}{r}.846 \\
\pm .041\end{array}$ & $\begin{array}{r}.335 \\
\pm .033 \\
\end{array}$ \\
\hline 24 & $\begin{array}{l}16.23 \\
\pm .06\end{array}$ & $\begin{array}{c}20.16 \\
\pm .09 \\
\end{array}$ & $\begin{array}{r}.687 \\
\pm .033 \\
\end{array}$ & $\begin{array}{r}1.119 \\
\pm .047\end{array}$ & $\begin{array}{r}.455 \\
\pm .027 \\
\end{array}$ \\
\hline 28 & $\begin{array}{l}16.11 \\
\pm .06\end{array}$ & $\begin{array}{l}20.02 \\
\pm .09\end{array}$ & $\begin{array}{r}.741 \\
\pm .035\end{array}$ & $\begin{array}{l}1.231 \\
\pm .050\end{array}$ & $\begin{array}{r}.467 \\
\pm .026\end{array}$ \\
\hline 32 & $\begin{array}{l}16.04 \\
\pm .05 \\
\end{array}$ & $\begin{array}{r}19.90 \\
\pm .08\end{array}$ & $\begin{array}{r}.781 \\
\pm .027\end{array}$ & $\begin{array}{r}1.430 \\
\pm .044\end{array}$ & $\begin{array}{r}.503 \\
\pm .019\end{array}$ \\
\hline 36 & $\begin{array}{l}16.96 \\
\pm .06\end{array}$ & $\begin{array}{r}19.75 \\
\pm .09 \\
\end{array}$ & $\begin{array}{r}.813 \\
\pm .042\end{array}$ & $\begin{array}{r}1.487 \\
\pm .066\end{array}$ & $\begin{array}{r}.474 \\
\pm .028\end{array}$ \\
\hline 40 & $\begin{array}{l}15.88 \\
\pm .06\end{array}$ & $\begin{array}{r}19.74 \\
\pm .09\end{array}$ & $\begin{array}{r}.894 \\
.041 \\
.041\end{array}$ & $\begin{array}{l}1.653 \\
\pm .067\end{array}$ & $\begin{array}{r}.520 \\
\pm .024\end{array}$ \\
\hline 44 & $\begin{array}{l}15.80 \\
\pm .06\end{array}$ & $\begin{array}{c}19.57 \\
\pm .09\end{array}$ & $\begin{array}{r}.924 \\
\pm .043\end{array}$ & $\begin{array}{r}1.822 \\
\pm .074\end{array}$ & $\begin{array}{r}.601 \\
\pm .022\end{array}$ \\
\hline 48 & $\begin{array}{l}15.75 \\
\pm .06\end{array}$ & $\begin{array}{l}19.46 \\
\pm .09\end{array}$ & $\begin{array}{r}1.043 \\
\pm .050\end{array}$ & $\begin{array}{r}1.914 \\
\pm .082\end{array}$ & $\begin{array}{r}.582 \\
\pm .023\end{array}$ \\
\hline 52 & $\begin{array}{l}15.63 \\
\pm .06\end{array}$ & $\begin{array}{l}19.31 \\
\pm .09\end{array}$ & $\begin{array}{r}1.038 \\
\pm .049\end{array}$ & $\begin{array}{l}1.902 \\
\pm .080\end{array}$ & $\begin{array}{r}.588 \\
\pm .023\end{array}$ \\
\hline 56 & $\begin{array}{l}15.55 \\
\pm .06 \\
\end{array}$ & $\begin{array}{r}19.25 \\
\pm .09 \\
\end{array}$ & $\begin{array}{r}1.156 \\
\pm .051 \\
\end{array}$ & $\begin{array}{r}2.292 \\
\pm .087 \\
\end{array}$ & $\begin{array}{r}.641 \\
\pm .019\end{array}$ \\
\hline 60 & $\begin{array}{l}15.42 \\
\pm .06 \\
\end{array}$ & $\begin{array}{r}19.01 \\
\pm .10 \\
\end{array}$ & $\begin{array}{r}1.164 \\
\pm .058\end{array}$ & $\begin{array}{r}2.361 \\
\pm .103\end{array}$ & $\begin{array}{r}.658 \\
\pm .02\end{array}$ \\
\hline 64 & $\begin{array}{l}15.39 \\
\pm .06 \\
\end{array}$ & $\begin{array}{l}19.04 \\
\pm .10\end{array}$ & $\begin{array}{l}1.390 \\
\pm .065\end{array}$ & $\begin{array}{l}2.690 \\
\pm .113\end{array}$ & $\begin{array}{r}.684 \\
\pm .019\end{array}$ \\
\hline 68 & $\begin{array}{l}15.28 \\
\pm .07 \\
\end{array}$ & $\begin{array}{c}18.79 \\
\pm .11 \\
\end{array}$ & $\begin{array}{r}1.632 \\
\pm .082 \\
\end{array}$ & $\begin{array}{l}3.082 \\
\pm .140\end{array}$ & $\begin{array}{r}.751 \\
\pm .017 \\
\end{array}$ \\
\hline 72 & $\begin{array}{l}15.07 \\
\pm .07 \\
\end{array}$ & $\begin{array}{c}18.58 \\
\pm .11 \\
\end{array}$ & $\begin{array}{r}1.656 \\
\pm .090\end{array}$ & $\begin{array}{r}2.740 \\
\pm .134\end{array}$ & $\begin{array}{r}.698 \\
\pm .021\end{array}$ \\
\hline 76 & $\begin{array}{l}14.96 \\
\pm .07 \\
\end{array}$ & $\begin{array}{c}18.50 \\
\pm .11 \\
\end{array}$ & $\begin{array}{r}1.626 \\
+.088 \\
\end{array}$ & $\begin{array}{l}.116 \\
\pm .153 \\
\end{array}$ & $\begin{array}{r}.769 \\
\pm .018 \\
\end{array}$ \\
\hline 80 & $\begin{array}{l}14.87 \\
\pm .08\end{array}$ & $\begin{array}{c}18.42 \\
\pm .12 \\
\end{array}$ & $\begin{array}{r}1.852 \\
\pm .105 \\
\end{array}$ & $\begin{array}{r}3.689 \\
\pm .196\end{array}$ & $\begin{array}{r}.792 \\
\pm .017\end{array}$ \\
\hline 84 & $\begin{array}{l}14.79 \\
\pm .08 \\
\end{array}$ & $\begin{array}{c}18.19 \\
\pm .12 \\
\end{array}$ & $\begin{array}{r}1.871 \\
\pm .112 \\
\end{array}$ & $\begin{array}{r}3.262 \\
\pm .179 \\
\end{array}$ & $\begin{array}{r}.788 \\
\pm .020 \\
\end{array}$ \\
\hline 88 & $\begin{array}{l}14.60 \\
\pm .08 \\
\end{array}$ & $\begin{array}{r}18.05 \\
\pm .13 \\
\end{array}$ & $\begin{array}{r}2.249 \\
\pm .142 \\
\end{array}$ & $\begin{array}{r}4.369 \\
\pm .258 \\
\end{array}$ & $\begin{array}{r}.829 \\
\pm .017\end{array}$ \\
\hline 92 & $\begin{array}{l}14.57 \\
\pm .10\end{array}$ & $\begin{array}{l}18.09 \\
\pm .16\end{array}$ & $\begin{array}{r}2.934 \\
\pm .187\end{array}$ & $\begin{array}{l}5.402 \\
\pm .321\end{array}$ & $\begin{array}{r}.863 \\
\pm .014\end{array}$ \\
\hline
\end{tabular}




\begin{tabular}{cccccc}
\hline 96 & 14.33 & 17.57 & 2.427 & 4.350 & .830 \\
& \pm .10 & \pm .14 & \pm .169 & \pm .290 & \pm .019 \\
\hline 100 & 14.07 & 17.11 & 2.186 & 4.297 & .824 \\
& \pm .10 & \pm .16 & \pm .176 & \pm .310 & \pm .021 \\
\hline
\end{tabular}


Table A.7 Parameters obtained using a moment analysis for the system ${ }^{35} \mathrm{Cl}+{ }^{209} \mathrm{Bi}$ at $528 \mathrm{MeV}$. The energy loss (Eloss) values have been corrected assuming equal division of the excitation energy.

\begin{tabular}{|c|c|c|c|c|c|}
\hline$E_{\text {loss }}(\mathrm{MeV})$ & $\langle\mathrm{Z}\rangle$ & $\langle\mathrm{N}\rangle$ & $\sigma_{\mathrm{z}}^{2}$ & $\sigma_{N}^{2}$ & $\rho$ \\
\hline 10 & $\begin{array}{l}16.49 \\
\pm .06\end{array}$ & $\begin{array}{r}18.40 \\
\pm .07\end{array}$ & $\begin{array}{r}.950 \\
\pm .007\end{array}$ & $\begin{array}{l}4.991 \\
\pm .040\end{array}$ & $\begin{array}{r}-.370 \\
\pm .001\end{array}$ \\
\hline 20 & $\begin{array}{l}16.20 \\
\pm .08\end{array}$ & $\begin{array}{r}18.36 \\
\pm .09\end{array}$ & $\begin{array}{r}1.102 \\
\pm .010\end{array}$ & $\begin{array}{l}5.525 \\
\pm .054\end{array}$ & $\begin{array}{r}-.297 \\
\pm .001\end{array}$ \\
\hline 30 & $\begin{array}{c}15.94 \\
\pm .10\end{array}$ & $\begin{array}{r}18.20 \\
\pm .11\end{array}$ & $\begin{array}{r}1.247 \\
\pm .014\end{array}$ & $\begin{array}{l}6.143 \\
\pm .073\end{array}$ & $\begin{array}{r}-.292 \\
\pm .001\end{array}$ \\
\hline 40 & $\begin{array}{l}15.73 \\
\pm .11\end{array}$ & $\begin{array}{r}18.09 \\
\pm .13\end{array}$ & $\begin{array}{r}1.440 \\
\pm .018\end{array}$ & $\begin{array}{l}6.750 \\
\pm .094\end{array}$ & $\begin{array}{r}-.309 \\
\pm .001\end{array}$ \\
\hline 50 & $\begin{array}{l}15.49 \\
\pm .13\end{array}$ & $\begin{array}{l}18.17 \\
\pm .15\end{array}$ & $\begin{array}{r}1.628 \\
+.024\end{array}$ & $\begin{array}{l}6.385 \\
\pm .106\end{array}$ & $\begin{array}{r}-.264 \\
\pm .001\end{array}$ \\
\hline 60 & $\begin{array}{l}15.32 \\
\pm .14\end{array}$ & $\begin{array}{r}18.33 \\
\pm .17\end{array}$ & $\begin{array}{r}1.737 \\
\pm .028\end{array}$ & $\begin{array}{l}5.386 \\
\pm .100\end{array}$ & $\begin{array}{r}-.228 \\
\pm .001\end{array}$ \\
\hline 70 & $\begin{array}{l}15.21 \\
\pm .15\end{array}$ & $\begin{array}{r}18.33 \\
\pm .19\end{array}$ & $\begin{array}{r}1.955 \\
\pm .034\end{array}$ & $\begin{array}{l}5.233 \\
\pm .108\end{array}$ & $\begin{array}{r}-.187 \\
\pm .001\end{array}$ \\
\hline 80 & $\begin{array}{l}15.19 \\
\pm .17\end{array}$ & $\begin{array}{r}18.27 \\
\pm .20\end{array}$ & $\begin{array}{r}2.236 \\
\pm .041\end{array}$ & $\begin{array}{l}5.551 \\
\pm .125\end{array}$ & $\begin{array}{r}-.158 \\
\pm .001\end{array}$ \\
\hline 90 & $\begin{array}{l}14.92 \\
\pm .19\end{array}$ & $\begin{array}{r}18.22 \\
\pm .23\end{array}$ & $\begin{array}{r}2.193 \\
\pm .048\end{array}$ & $\begin{array}{l}5.840 \\
\pm .148\end{array}$ & $\begin{array}{r}. .070 \\
\pm .001\end{array}$ \\
\hline 100 & $\begin{array}{l}14.62 \\
\pm .22\end{array}$ & $\begin{array}{r}18.19 \\
\pm .27\end{array}$ & $\begin{array}{r}2.057 \\
\pm .053\end{array}$ & $\begin{array}{r}5.505 \\
\pm .152\end{array}$ & $\begin{array}{r}.077 \\
\pm .001\end{array}$ \\
\hline 110 & $\begin{array}{l}14.50 \\
\pm .24 \\
\end{array}$ & $\begin{array}{r}18.09 \\
+.29\end{array}$ & $\begin{array}{r}2.171 \\
\pm .044\end{array}$ & $\begin{array}{l}6.134 \\
\pm .128\end{array}$ & $\begin{array}{r}.189 \\
\pm .001\end{array}$ \\
\hline 130 & $\begin{array}{c}14.14 \\
\pm .20 \\
\end{array}$ & $\begin{array}{r}17.62 \\
+.25 \\
\end{array}$ & $\begin{array}{r}2.210 \\
\pm .055\end{array}$ & $\begin{array}{l}7.260 \\
\pm .176\end{array}$ & $\begin{array}{r}.301 \\
\pm .001\end{array}$ \\
\hline 150 & $\begin{array}{l}13.62 \\
\pm .22\end{array}$ & $\begin{array}{r}16.69 \\
\pm .27\end{array}$ & $\begin{array}{r}1.944 \\
+.058\end{array}$ & $\begin{array}{r}7.856 \\
\pm .248\end{array}$ & $\begin{array}{r}.291 \\
\pm .002\end{array}$ \\
\hline 170 & $\begin{array}{l}13.16 \\
\pm .25 \\
\end{array}$ & $\begin{array}{l}15.83 \\
\pm .30\end{array}$ & $\begin{array}{r}1.829 \\
\pm .065\end{array}$ & $\begin{array}{r}7.051 \\
\pm .272 \\
\end{array}$ & $\begin{array}{r}.278 \\
\pm .003 \\
\end{array}$ \\
\hline 190 & $\begin{array}{l}12.56 \\
\pm .29 \\
\end{array}$ & $\begin{array}{r}14.64 \\
\pm .34 \\
\end{array}$ & $\begin{array}{r}1.655 \\
\pm .070 \\
\end{array}$ & $\begin{array}{r}5.979 \\
+.298 \\
\end{array}$ & $\begin{array}{r}.210 \\
\pm .003 \\
\end{array}$ \\
\hline 210 & $\begin{array}{l}11.89 \\
\pm .35\end{array}$ & $\begin{array}{r}13.33 \\
\pm .39\end{array}$ & $\begin{array}{r}1.486 \\
\pm .079\end{array}$ & $\begin{array}{r}5.170 \\
\pm .311\end{array}$ & $\begin{array}{r}.164 \\
\pm .003\end{array}$ \\
\hline 230 & $\begin{array}{l}11.12 \\
\pm .45\end{array}$ & $\begin{array}{r}11.78 \\
\pm .48\end{array}$ & $\begin{array}{r}1.566 \\
\pm .118 \\
\end{array}$ & $\begin{array}{l}4.814 \\
\pm .400\end{array}$ & $\begin{array}{r}.203 \\
\pm .006\end{array}$ \\
\hline
\end{tabular}


Table A.8 Parameters obtained using a Gaussian fit for the system ${ }^{35} \mathrm{Cl}+{ }^{209} \mathrm{Bi}$ at $528 \mathrm{MeV}$. The energy loss (Eloss) values have been corrected assuming equal division of the excitation energy.

\begin{tabular}{|c|c|c|c|c|c|}
\hline Eloss(MeV) & $\langle\mathrm{Z}\rangle$ & $\langle\mathrm{N}\rangle$ & $\sigma_{\mathrm{z}^{2}}$ & $\sigma_{\mathrm{N}}^{2}$ & $\rho$ \\
\hline 10 & $\begin{array}{l}16.52 \\
\pm .06\end{array}$ & $\begin{array}{c}18.51 \\
\pm .09\end{array}$ & $\begin{array}{r}1.080 \\
\pm .033\end{array}$ & $\begin{array}{l}4.602 \\
\pm .125\end{array}$ & $\begin{array}{r}-.356 \\
\pm .018\end{array}$ \\
\hline 20 & $\begin{array}{l}16.23 \\
\pm .05\end{array}$ & $\begin{array}{c}18.40 \\
\pm .08\end{array}$ & $\begin{array}{r}1.193 \\
\pm .019\end{array}$ & $\begin{array}{r}5.366 \\
\pm .074\end{array}$ & $\begin{array}{r}-.269 \\
\pm .010\end{array}$ \\
\hline 30 & $\begin{array}{l}16.07 \\
\pm .05\end{array}$ & $\begin{array}{c}18.16 \\
\pm .08\end{array}$ & $\begin{array}{r}1.310 \\
\pm .017\end{array}$ & $\begin{array}{l}5.672 \\
\pm .062\end{array}$ & $\begin{array}{r}-.283 \\
\pm .008\end{array}$ \\
\hline 40 & $\begin{array}{l}15.80 \\
\pm .05\end{array}$ & $\begin{array}{c}18.14 \\
\pm .08\end{array}$ & $\begin{array}{r}1.489 \\
+.021\end{array}$ & $\begin{array}{l}6.491 \\
\pm .073\end{array}$ & $\begin{array}{r}-.298 \\
\pm .009\end{array}$ \\
\hline 50 & $\begin{array}{l}15.57 \\
\pm .05 \\
\end{array}$ & $\begin{array}{c}18.33 \\
\pm .08\end{array}$ & $\begin{array}{r}1.656 \\
\pm .024\end{array}$ & $\begin{array}{r}6.051 \\
\pm .069 \\
\end{array}$ & $\begin{array}{r}-.251 \\
\pm .009\end{array}$ \\
\hline 60 & $\begin{array}{l}15.43 \\
\pm .05\end{array}$ & $\begin{array}{c}18.44 \\
\pm .08\end{array}$ & $\begin{array}{r}1.785 \\
+.025\end{array}$ & $\begin{array}{l}4.980 \\
\pm .060\end{array}$ & $\begin{array}{r}-.196 \\
\pm .009\end{array}$ \\
\hline 70 & $\begin{array}{l}15.23 \\
\pm .06 \\
\end{array}$ & $\begin{array}{l}18.41 \\
\pm .08\end{array}$ & $\begin{array}{r}1.949 \\
\pm .041 \\
\end{array}$ & $\begin{array}{r}4.740 \\
\pm .085\end{array}$ & $\begin{array}{r}-.156 \\
\pm .014\end{array}$ \\
\hline 80 & $\begin{array}{l}14.81 \\
\pm .05\end{array}$ & $\begin{array}{r}18.79 \\
\pm .07\end{array}$ & $\begin{array}{r}2.279 \\
\pm .017\end{array}$ & $\begin{array}{r}5.099 \\
\pm .029\end{array}$ & $\begin{array}{l}1.01 \\
.132 \\
\pm .005\end{array}$ \\
\hline 90 & $\begin{array}{l}14.96 \\
\pm .06\end{array}$ & $\begin{array}{r}18.27 \\
\pm .09\end{array}$ & $\begin{array}{r}2.206 \\
\pm .056 \\
\end{array}$ & $\begin{array}{l}5.405 \\
\pm .113\end{array}$ & $\begin{array}{r}-.005 \\
\pm .017\end{array}$ \\
\hline 100 & $\begin{array}{l}14.73 \\
\pm .06\end{array}$ & $\begin{array}{l}18.25 \\
\pm .08\end{array}$ & $\begin{array}{r}2.084 \\
\pm .040\end{array}$ & $\begin{array}{l}4.951 \\
\pm .088\end{array}$ & $\begin{array}{r}.133 \\
\pm .012\end{array}$ \\
\hline 110 & $\begin{array}{l}14.28 \\
\pm .06\end{array}$ & $\begin{array}{c}18.69 \\
\pm .09\end{array}$ & $\begin{array}{r}2.286 \\
\pm .058\end{array}$ & $\begin{array}{l}5.956 \\
\pm .145\end{array}$ & $\begin{array}{r}.249 \\
\pm .016\end{array}$ \\
\hline 130 & $\begin{array}{c}14.29 \\
\pm .06\end{array}$ & $\begin{array}{l}17.90 \\
\pm .10\end{array}$ & $\begin{array}{l}2.351 \\
\pm .067\end{array}$ & $\begin{array}{l}7.174 \\
\pm .214\end{array}$ & $\begin{array}{r}.352 \\
\pm .017\end{array}$ \\
\hline 150 & $\begin{array}{l}13.76 \\
\pm .06\end{array}$ & $\begin{array}{c}16.77 \\
\pm .11\end{array}$ & $\begin{array}{r}1.996 \\
\pm .062\end{array}$ & $\begin{array}{r}7.290 \\
\pm .212\end{array}$ & $\begin{array}{r}.307 \\
\pm .020\end{array}$ \\
\hline 170 & $\begin{array}{l}13.11 \\
\pm .06\end{array}$ & $\begin{array}{l}16.17 \\
\pm .10\end{array}$ & $\begin{array}{r}1.732 \\
\pm .053 \\
\end{array}$ & $\begin{array}{r}5.515 \\
\pm .159\end{array}$ & $\begin{array}{r}.242 \\
\pm .020\end{array}$ \\
\hline 190 & $\begin{array}{l}12.62 \\
\pm .07 \\
\end{array}$ & $\begin{array}{r}14.75 \\
\pm .10\end{array}$ & $\begin{array}{r}1.683 \\
\pm .061\end{array}$ & $\begin{array}{l}4.923 \\
\pm .161\end{array}$ & $\begin{array}{r}.204 \\
\pm .024\end{array}$ \\
\hline 210 & $\begin{array}{l}11.76 \\
\pm .07 \\
\end{array}$ & $\begin{array}{l}13.64 \\
\pm .11\end{array}$ & $\begin{array}{r}1.616 \\
\pm .078\end{array}$ & $\begin{array}{l}4.757 \\
\pm .195\end{array}$ & $\begin{array}{r}.195 \\
\pm .031\end{array}$ \\
\hline 230 & $\begin{array}{l}11.28 \\
\pm .08\end{array}$ & $\begin{array}{l}11.70 \\
\pm .12\end{array}$ & $\begin{array}{r}1.641 \\
\pm .090\end{array}$ & $\begin{array}{r}4.351 \\
\pm .199\end{array}$ & $\begin{array}{r}.250 \\
\pm .036\end{array}$ \\
\hline
\end{tabular}


Table A.9 Parameters obtained using a moment analysis for the system ${ }^{35} \mathrm{Cl}+{ }^{209} \mathrm{Bi}$ at $528 \mathrm{MeV}$. The energy loss (Eloss) values have been corrected assuming thermal division of the excitation energy.

\begin{tabular}{|c|c|c|c|c|c|}
\hline Eloss $(\mathrm{MeV})$ & $\langle\mathrm{Z}\rangle$ & $\langle\mathrm{N}\rangle$ & $\sigma_{z^{2}}^{2}$ & $\sigma_{N}^{2}$ & $\rho$ \\
\hline 10 & $\begin{array}{l}16.55 \\
\pm .07 \\
\end{array}$ & $\begin{array}{c}18.33 \\
\pm .07\end{array}$ & $\begin{array}{r}.923 \\
\pm .007 \\
\end{array}$ & $\begin{array}{l}4.894 \\
\pm .041\end{array}$ & $\begin{array}{r}-.392 \\
\pm .001\end{array}$ \\
\hline 20 & $\begin{array}{l}16.35 \\
\pm .08 \\
\end{array}$ & $\begin{array}{l}18.41 \\
\pm .09\end{array}$ & $\begin{array}{r}1.046 \\
\pm .010 \\
\end{array}$ & $\begin{array}{l}5.138 \\
+.051 \\
\end{array}$ & $\begin{array}{r}-.319 \\
\pm .001\end{array}$ \\
\hline 30 & $\begin{array}{l}16.13 \\
\pm .10 \\
\end{array}$ & $\begin{array}{r}18.32 \\
\pm .11 \\
\end{array}$ & $\begin{array}{r}1.169 \\
+.013 \\
\end{array}$ & $\begin{array}{l}5.537 \\
\pm .065 \\
\end{array}$ & $\begin{array}{r}-.285 \\
\pm .001 \\
\end{array}$ \\
\hline 40 & $\begin{array}{l}15.92 \\
\pm .11 \\
\end{array}$ & $\begin{array}{r}18.21 \\
\pm .13 \\
\end{array}$ & $\begin{array}{r}1.280 \\
+.016 \\
\end{array}$ & $\begin{array}{l}5.939 \\
\pm .081 \\
\end{array}$ & $\begin{array}{r}-.293 \\
\pm .001 \\
\end{array}$ \\
\hline 50 & $\begin{array}{l}15.74 \\
\pm .12 \\
\end{array}$ & $\begin{array}{r}18.13 \\
\pm .14 \\
\end{array}$ & $\begin{array}{r}1.449 \\
+.020 \\
\end{array}$ & $\begin{array}{l}6.412 \\
\pm .099\end{array}$ & $\begin{array}{r}-.307 \\
\pm .001\end{array}$ \\
\hline 60 & $\begin{array}{l}15.57 \\
\pm .14 \\
\end{array}$ & $\begin{array}{r}18.07 \\
\pm .16 \\
\end{array}$ & $\begin{array}{r}1.610 \\
+.025 \\
\end{array}$ & $\begin{array}{r}6.732 \\
\pm .117 \\
\end{array}$ & $\begin{array}{r}.292 \\
\pm .001 \\
\end{array}$ \\
\hline 70 & $\begin{array}{l}15.41 \\
\pm .15 \\
\end{array}$ & $\begin{array}{c}18.16 \\
\pm .18 \\
\end{array}$ & $\begin{array}{r}1.715 \\
\pm .029\end{array}$ & $\begin{array}{l}6.215 \\
\pm .122\end{array}$ & $\begin{array}{l}-.265 \\
\pm .001\end{array}$ \\
\hline 80 & $\begin{array}{l}15.31 \\
\pm .16 \\
\end{array}$ & $\begin{array}{r}18.26 \\
\pm .19 \\
\end{array}$ & $\begin{array}{r}1.797 \\
\pm .033 \\
\end{array}$ & $\begin{array}{l}5.423 \\
\pm .117 \\
\end{array}$ & $\begin{array}{r}. .230 \\
\pm .001\end{array}$ \\
\hline 90 & $\begin{array}{l}15.22 \\
\pm .17 \\
\end{array}$ & $\begin{array}{r}18.30 \\
\pm .21 \\
\end{array}$ & $\begin{array}{r}1.971 \\
\pm .039 \\
\end{array}$ & $\begin{array}{l}5.218 \\
\pm .121 \\
\end{array}$ & $\begin{array}{r}-.172 \\
\pm .001 \\
\end{array}$ \\
\hline 100 & $\begin{array}{l}15.23 \\
\pm .19 \\
\end{array}$ & $\begin{array}{r}18.30 \\
\pm .22 \\
\end{array}$ & $\begin{array}{l}2.278 \\
\pm .046 \\
\end{array}$ & $\begin{array}{l}5.423 \\
\pm .135 \\
\end{array}$ & $\begin{array}{r}-.158 \\
\pm .001\end{array}$ \\
\hline 110 & $\begin{array}{l}15.06 \\
\pm .20 \\
\end{array}$ & $\begin{array}{r}18.15 \\
\pm .25 \\
\end{array}$ & $\begin{array}{l}2.291 \\
\pm .036 \\
\end{array}$ & $\begin{array}{l}5.734 \\
\pm .109 \\
\end{array}$ & $\begin{array}{r}-.123 \\
\pm .001 \\
\end{array}$ \\
\hline 130 & $\begin{array}{l}14.63 \\
\pm .17 \\
\end{array}$ & $\begin{array}{r}18.08 \\
\pm .22 \\
\end{array}$ & $\begin{array}{r}2.154 \\
\pm .044 \\
\end{array}$ & $\begin{array}{r}5.930 \\
\pm .130 \\
\end{array}$ & $\begin{array}{r}.088 \\
\pm .001 \\
\end{array}$ \\
\hline 150 & $\begin{array}{l}14.34 \\
\pm .20 \\
\end{array}$ & $\begin{array}{r}17.90 \\
\pm .26 \\
\end{array}$ & $\begin{array}{r}2.287 \\
+.058 \\
\end{array}$ & $\begin{array}{r}7.103 \\
\pm .174 \\
\end{array}$ & $\begin{array}{r}.255 \\
\pm .001 \\
\end{array}$ \\
\hline 170 & $\begin{array}{l}13.96 \\
\pm .23 \\
\end{array}$ & $\begin{array}{r}17.26 \\
\pm .28 \\
\end{array}$ & $\begin{array}{r}2.056 \\
\pm .061 \\
\end{array}$ & $\begin{array}{l}7.513 \\
\pm .221 \\
\end{array}$ & $\begin{array}{r}.276 \\
+.002 \\
\end{array}$ \\
\hline 190 & $\begin{array}{l}13.51 \\
\pm .25 \\
\end{array}$ & $\begin{array}{r}16.36 \\
\pm .30 \\
\end{array}$ & $\begin{array}{r}1.766 \\
\pm .060 \\
\end{array}$ & $\begin{array}{r}7.153 \\
\pm .264 \\
\end{array}$ & $\begin{array}{r}.215 \\
\pm .002 \\
\end{array}$ \\
\hline 210 & $\begin{array}{l}13.05 \\
\pm .27 \\
\end{array}$ & $\begin{array}{c}15.50 \\
\pm .33\end{array}$ & $\begin{array}{r}1.697 \\
\pm .066\end{array}$ & $\begin{array}{l}5.637 \\
\pm .244\end{array}$ & $\begin{array}{r}.138 \\
\pm .002\end{array}$ \\
\hline 230 & $\begin{array}{l}12.36 \\
\pm .31\end{array}$ & $\begin{array}{r}14.39 \\
\pm .37\end{array}$ & $\begin{array}{l}1.300 \\
\pm .060\end{array}$ & $\begin{array}{l}4.674 \\
\pm .241 \\
\end{array}$ & $\begin{array}{r}.024 \\
\pm .002 \\
\end{array}$ \\
\hline
\end{tabular}


Table A.10 Parameters obtained using Gaussian Fit for the system ${ }^{35} \mathrm{Cl}+{ }^{209} \mathrm{Bi}$ at $528 \mathrm{MeV}$. The energy loss (Eloss) values have been corrected assuming thermal division of the excitation energy.

\begin{tabular}{|c|c|c|c|c|c|}
\hline $\mathrm{E}_{\text {loss }}(\mathrm{MeV})$ & $\langle\mathrm{Z}\rangle$ & $\langle\mathrm{N}\rangle$ & $\sigma_{\mathrm{Z}}^{2}$ & $\sigma_{N}^{2}$ & $\rho$ \\
\hline 10 & $\begin{array}{l}16.54 \\
\pm .06\end{array}$ & $\begin{array}{c}18.48 \\
\pm .10\end{array}$ & $\begin{array}{r}1.046 \\
\pm .034\end{array}$ & $\begin{array}{l}4.472 \\
\pm .133\end{array}$ & $\begin{array}{r}-.376 \\
\pm .019\end{array}$ \\
\hline 20 & $\begin{array}{l}16.38 \\
\pm .05\end{array}$ & $\begin{array}{r}18.56 \\
\pm .08\end{array}$ & $\begin{array}{r}1.156 \\
\pm .021 \\
\end{array}$ & $\begin{array}{l}4.991 \\
\pm .083\end{array}$ & $\begin{array}{r}-.290 \\
\pm .011\end{array}$ \\
\hline 30 & $\begin{array}{l}16.01 \\
\pm .05\end{array}$ & $\begin{array}{r}18.47 \\
\pm .08\end{array}$ & $\begin{array}{r}1.244 \\
\pm .018\end{array}$ & $\begin{array}{l}5.064 \\
\pm .064\end{array}$ & $\begin{array}{r}-.277 \\
\pm .009\end{array}$ \\
\hline 40 & $\begin{array}{l}15.83 \\
\pm .05\end{array}$ & $\begin{array}{r}18.42 \\
\pm .08\end{array}$ & $\begin{array}{r}1.344 \\
\pm .018\end{array}$ & $\begin{array}{l} \pm 5.567 \\
\pm .063\end{array}$ & $\begin{array}{r}-.285 \\
\pm .008\end{array}$ \\
\hline 50 & $\begin{array}{l}15.67 \\
\pm .05\end{array}$ & $\begin{array}{r}18.22 \\
\pm .08\end{array}$ & $\begin{array}{r}1.511 \\
\pm .021\end{array}$ & $\begin{array}{l}6.173 \\
\pm .070\end{array}$ & $\begin{array}{r}-.300 \\
\pm .009\end{array}$ \\
\hline 60 & $\begin{array}{l}15.40 \\
\pm .05\end{array}$ & $\begin{array}{r}18.35 \\
\pm .08 \\
\end{array}$ & $\begin{array}{r}1.653 \\
\pm .024 \\
\end{array}$ & $\begin{array}{r}6.505 \\
\pm .079\end{array}$ & $\begin{array}{r}-.287 \\
\pm .010\end{array}$ \\
\hline 70 & $\begin{array}{l}15.56 \\
\pm .05 \\
\end{array}$ & $\begin{array}{r}18.39 \\
\pm .08 \\
\end{array}$ & $\begin{array}{r}1.755 \\
\pm .027\end{array}$ & $\begin{array}{r}6.020 \\
\pm .074 \\
\end{array}$ & $\begin{array}{r}-.233 \\
\pm .010\end{array}$ \\
\hline 80 & $\begin{array}{r}14.99 \\
\pm .06 \\
\end{array}$ & $\begin{array}{r}18.78 \\
\pm .08 \\
\end{array}$ & $\begin{array}{r}1.812 \\
\pm .037\end{array}$ & $\begin{array}{r}4.840 \\
\pm .085 \\
\end{array}$ & $\begin{array}{r}-.197 \\
\pm .014\end{array}$ \\
\hline 90 & $\begin{array}{l}14.95 \\
\pm .05\end{array}$ & $\begin{array}{r}18.64 \\
\pm .08\end{array}$ & $\begin{array}{r}1.972 \\
\pm .030\end{array}$ & $\begin{array}{l}4.722 \\
\pm .063\end{array}$ & $\begin{array}{r}-.134 \\
\pm .010\end{array}$ \\
\hline 100 & $\begin{array}{l}15.24 \\
\pm .06 \\
\end{array}$ & $\begin{array}{r}18.42 \\
\pm .09 \\
\end{array}$ & $\begin{array}{l}2.331 \\
\pm .061\end{array}$ & $\begin{array}{l}5.101 \\
\pm .106\end{array}$ & $\begin{array}{r}-.132 \\
\pm .017\end{array}$ \\
\hline 110 & $\begin{array}{l}15.14 \\
\pm .06 \\
\end{array}$ & $\begin{array}{r}18.30 \\
\pm .08\end{array}$ & $\begin{array}{r}2.345 \\
\pm .039\end{array}$ & $\begin{array}{l}5.450 \\
\pm .071\end{array}$ & $\begin{array}{r}-.072 \\
\pm .011\end{array}$ \\
\hline 130 & $\begin{array}{l}14.74 \\
\pm .06 \\
\end{array}$ & $\begin{array}{c}18.29 \\
\pm .09\end{array}$ & $\begin{array}{r}2.219 \\
\pm .054\end{array}$ & $\begin{array}{l}5.452 \\
\pm .127\end{array}$ & $\begin{array}{r}.174 \\
\pm .016\end{array}$ \\
\hline 150 & $\begin{array}{l}14.89 \\
\pm .05\end{array}$ & $\begin{array}{r}17.78 \\
\pm .07\end{array}$ & $\begin{array}{l}2.378 \\
\pm .020\end{array}$ & $\begin{array}{l}6.921 \\
\pm .063\end{array}$ & $\begin{array}{r}.321 \\
\pm .005\end{array}$ \\
\hline 170 & $\begin{array}{l}13.76 \\
\pm .07\end{array}$ & $\begin{array}{r}17.98 \\
\pm .10\end{array}$ & $\begin{array}{l}2.112 \\
\pm .066\end{array}$ & $\begin{array}{l}7.570 \\
\pm .238\end{array}$ & $\begin{array}{r}.336 \\
\pm .019\end{array}$ \\
\hline 190 & $\begin{array}{l}13.51 \\
\pm .06 \\
\end{array}$ & $\begin{array}{c}16.48 \\
\pm .10\end{array}$ & $\begin{array}{r}1.657 \\
\pm .053\end{array}$ & $\begin{array}{l}5.489 \\
\pm .165\end{array}$ & $\begin{array}{r}.145 \\
\pm .022\end{array}$ \\
\hline 210 & $\begin{array}{l}13.21 \\
\pm .06 \\
\end{array}$ & $\begin{array}{c}15.87 \\
\pm .10\end{array}$ & $\begin{array}{r}1.685 \\
\pm .056\end{array}$ & $\begin{array}{l}4.783 \\
\pm .150\end{array}$ & $\begin{array}{r}.167 \\
\pm .023\end{array}$ \\
\hline 230 & $\begin{array}{l}12.11 \\
\pm .07\end{array}$ & $\begin{array}{r}14.94 \\
\pm .10\end{array}$ & $\begin{array}{r}1.420 \\
\pm .061\end{array}$ & $\begin{array}{l}4.095 \\
\pm .144\end{array}$ & $\begin{array}{r}.087 \\
\pm .027\end{array}$ \\
\hline
\end{tabular}




\section{REFERENCES}

AND 77 H.C. Andrews, and B.R. Hunt, Digital Image Restoration; PrenticeHall: New Jersey, 1977.

AWE 84 T.C. Awes, R.L. Ferguson, R. Novotny, F.E. Obenshain, F. Plasil, S. Pontoppidan, V. Rauch, G.R. Young, and H. Sann, Phys. Rev. Lett. 52, 251 (1984).

BAL 84 R. Balian, Heavy-Ion Collisions, edited by P. Bonche; Plenum: New York, 1984; p 1.

BEN 85 D.R. Benton, Ph.D. Thesis PP \# 86-030; University of Maryland, 1985.

BEN 88 D.R. Benton, H. Breuer, F. Khazaie, K. Kwiatkowski, V.E. Viola, S. Bradley, A.C. Mignerey, and A.P. Weston-Dawkes, Phys. Rev. C38, 1207 (1988).

BEV 69 P.R. Bevington, Data Reduction and Emor Analysis for the Physical Sciences; McGraw-Hill: New York, 1969.

BOR 88 B. Borderie, M. Montoya, M.F. Rivet, D. Jouan, C. Cabot, H. Fuchs, D. Gardes, H. Gauvin, D. Jacquet, and F. Monnet, Phys. Lett. B205, 26 (1988).

BOR 90 B. Borderie, M.F. Rivet, and L. Tassan-Got, Internal Report INPODRE-90-06; Orsay, France, 1990

BRE 79 H. Breuer, B.G. Glagola, V.E. Viola, K.L. Wolf, A.C. Mignerey, J.R. Birkelund, D. Hilscher, A.D. Hoover, J.R. Huizenga, W.U. Schröder, and W.W. Wilcke, Phys. Rev. Lett. 43, 191 (1979). 
BRE 83a H. Breuer, N.R. Yoder, A.C. Mignerey, V.E. Viola, K.

Kwiatkowski, and K.L. Wolf, Nucl. Imstr. and Meth. 204, 419 (1983).

BRE 83b H. Breuer, A.C. Mignerey, V.E. Viola, K.L. Wolf, J.R. Birkelund, D. Hilscher, J.R. Huizenga, W.U. Schröder, and W.W. Wilcke, Phys. Rev. C28, 1080 (1983).

BRE 89 H. Breuer et al., LISA Collaboration; Department of Physics and Astromomy, University of Maryland, 1989.

BRO 74 R.A. Broglia, C.H. Dasso, and A. Winther, Phys. Lett. 53B, 301 (1974).

BRO 76 R.A. Broglia, C.H. Dasso, and A. Winther, Phys. Lett. 61B, 113 (1976).

CIT 31 P.H. van Cittert, Z. Physik 69, 298 (1931).

CRA 46 H. Cramer, Mathematical Methods of Statistics; Princeton University: Princeton, 1946.

FRE 84 H. Freiesleben, and J.V. Katz, Phys. Rep. 106, 1 (1984).

FRI 81 G. Friedlander, J.W. Kennedy, E.S. Macias, and J.M. Miller, Nuclear and Radiochemistry; John Wiley: New York, 1981; Chp. 6.

GAV 80 A. Gavron, Phys. Rev. C21, 230 (1980).

GOB 80 A. Gobbi, and W. Nöremberg, Heavy Jon Collisions. Vol.2, edited by R. Bock; North-Holland: Amsterdam, 1980; Chp. 3.

HOF 76 H. Hofmann, and P.J. Siemens, Nucl. Phys. A257, 165 (1976).

HOF 77 H. Hofmann, and P.J. Siemens, Nucl. Phys. A275, 464 (1977).

HOO 82 A.D. Hoover, J.R. Birkelund, D. Hilscher, W.U. Schriuder, W.W. Wilcke, J.R. Huizenga, H. Breuer, A.C. Mignerey, V.E. Viola, K.L. Wolf, Phys. Rev. C25, 256 (1982). 
JAN 70 P.A. Jansson, R.H. Hunt, and E.K. Plyler, J. Opt. Soc. Am. 60, 596 (1970).

JAN 84 P.A. Jansson, Deconvolution: with Applications in Spectroscopy; Academic: Orlando, 1984.

KAU 61 R. Kaufmann, and R. Wolfgang, Phys. Rev. 121, 192 (1961).

KNO 79 G.F. Knoll, Radiation Detection and Measurement; John Wiley and Sons: New York, 1979; Chp. 10.

LEF 78 M. Lefort, and Ch. Ngo, Ann. Phys. 3, 5 (1978).

LEO 87 W.R. Leo, Techniques for Nuclear Particle Physics Experiments; Springer-Verlag: Berlin, 1987; Chp. 7.

LOC 85 D.K. Lock, R. Vandenbosch, and J. Randrup, Phys. Rev. C31, 1268 (1985).

MOU 78 J.B. Moulton, J.E. Stephenson, R.P. Schmitt, G. Wozniak, Nucl. Instr. and Meth. 157, 325 (1978).

NAK 58 S. Nakajima, Theor. Phys. 20, 948 (1958).

NOR 75 W. Nörembergm, Z. Physik A274, 241 (1975).

OAK 87 Computer Handbook of the Holifield Heavy-Ion Research Facility; Oak Ridge National Laboratory, Oak Ridge, Tennessee; 1987.

PAL 88 D. Pal, S. Chattopadhay, and K. Kar, J. Phys. G14, 1083 (1988).

PAL 90 D. Pal, and S. Chattopadhay, Phys. Rev. C41, 390 (1990).

PEN 90 V. Penumetcha, G.A. Petitt, T.C. Awes, J.R. Beene, R.L. Ferguson, F.E. Obenshain, F. Plasil, G.R. Young, and S.P. Sorensen, Phys. Rev. C42, 1489 (1990).

PLA 88 R. Planeta, S.H. Zhou, K. Kwiatkowski, W.G. Wilson, V.E. Viola, H. Breuer, D. Benton, F. Khazaie, R.J. McDonald, A.C. Mignerey, 
A. Weston-Dawkes, R.T. de Souza, and W.U. Schröder, Phys. Rev. C38, 195 (1988).

PLA 90 R. Planeta, K. Kwiatkowski, S.H. Zhou, V.E. Viola, H. Breuer, M.A. McMahan, W. Kehoe, and A.C. Mignerey, Phys. Rev. C41, 942 (1990).

RAN 78 J. Randrup, Nucl. Phys. A307, 319 (1978).

RAN 79 J. Randrup, Nucl. Phys. A327, 490 (1979).

RAN 82 J. Randrup, Nucl. Phys. A383 , 468 (1982).

SAP $85 \quad$ K. Sapotta, R. Bass, V. Hartmann, H. Noll, R.E. Renfordt, and K. Stelzer, Phys. Rev. C31, 1297 (1985).

SAV 64 A. Savitzky, and M.J.E. Golay, Anal. Chem. 36, 1627 (1964).

SCH 77 W.U. Schröder, and J.R. Huizenga, Ann. Rev. Nucl. Sci. 27, 465 (1977).

SCH 81 D. Schüll, W.C. Shen, H. Freiesleben, R. Bock, F.Busch, D. Bangert, W. Pfeffer, and F. Pühlhofer, Phys. Lett. B102, 116 (1981)

SCH 84 W.U. Schröder, and J.R. Huizenga, in Treatise on Heavy-Ion Science. Vol.2, edited by D.A. Bromley; Plenum: New York, 1984;Chp. 3.

SOH 85 H. Sohlbach, H. Freiesleben, P. Braun-Muzinger, W.F.W. Schneider, D. Schüll, B. Kohlmeyer, M. Marinescu, and F. Pühlhofer, Phys. Lett. B153, 386 (1985).

SOU $88 \quad$ R.T. de Souza, W.U. Schröder, J.R. Huizenga, R. Planeta, K. Kwiatkowski, V.E. Viola, and H. Breuer, Phys. Rev. C37, 1783 (1988). 
STE 72 J. Steinier, Y. Termonoia, and J. Deltour, Anal. Chem. 44, 1906 (1972).

TAS 88 L. Tassan-Got, Ph.D. Thesis INPO-T-89-02; Orsay, France, 1988.

TAS 89 L. Tassan-Got, and C. Stephan, Internal Report INPO-DRE-89-46, 1989.

TEH 87 K.M. Teh, D. Shapira, B.L. Burks, R.L. Varner, J.L. Blankenship, E.J. Ludwig, R.E. Fauber, and C.F. Maguire, Nucl. Instr. and Meth. A254, 600 (1987).

VAN 84 R. Vandenbosch, A. Lazzarini, D. Leach, D.K. Lock, A. Ray, and A. Seamster, Phys. Rev. Lett. 52, 1964 (1984).

WEI 80 H.A. Weindenmüller, in Progress in Particle and Nuclear Physics. Vol.3, edited by D. Wilkinson, Pergamon: Oxford, 1980; p 49.

WIL 52 D.H. Wilkinson, Rev. Sci. Instr. 23, 414 (1952).

WIL 76 P.D. Willson, and T.H. Edwards, Appl. Spectrosc. Rev. 12, 1 (1976).

WIL 80 W.W. Wilcke, J.R. Birkelund, H.J. Wollersheim, A.D. Hoover, J.R. Huizenga, W.U. Schröder, and L.E. Tubbs, Atomic Data and Nuclear Data Tables 25, 389 (1980).

WIL 89a J.L. Wile, S.S. Datta, W.U. Schröder, J.R. Huizenga, R.T. de Souza, and D. Pade, Phys. Rev. C40, 1700 (1989).

WIL 89b J. Wilczynski, J.D. Hinnefeld, E.E. Koldenhof, H.K.W. Leegte, R.H. Siemssen, H.W. Wilschut, and Y.X. Xie, Phys. Lett. B220, 497 (1989).

ZWA $60 \quad$ R. Zwanzig, J. Chem. Phys. 33, 1338 (1960). 

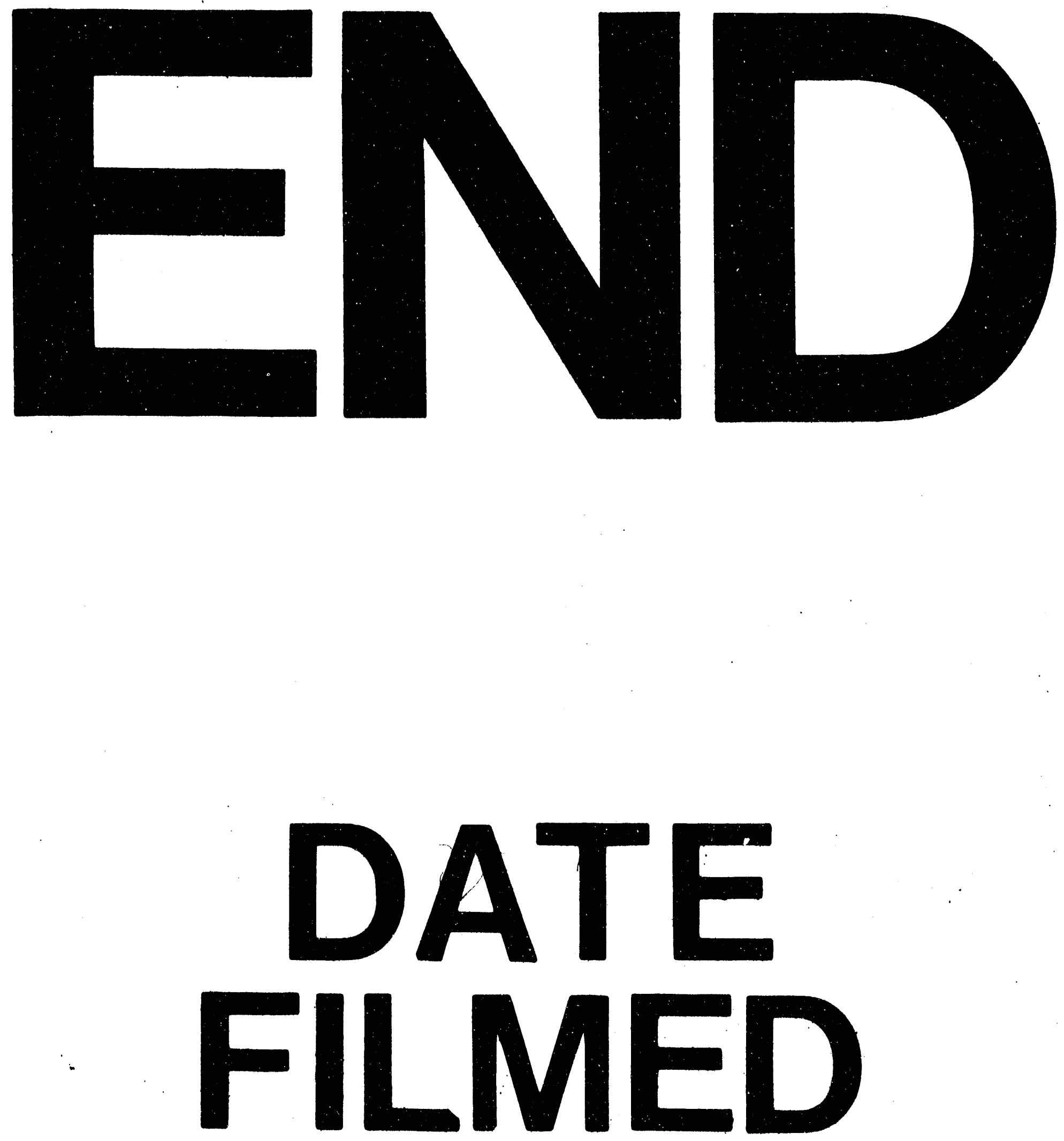

1

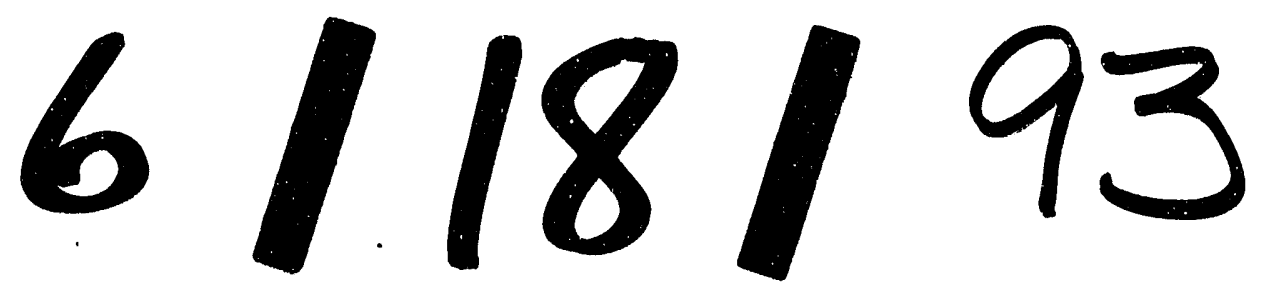


